$$
\begin{gathered}
\text { Universidade de São Paulo } \\
\text { Instituto de Química de São Carlos }
\end{gathered}
$$

André Gustavo de Araujo Fernandes

\title{
Quelato-Complexos de Rênio e Tecnécio com Potencial Aplicação Medicinal
}

São Carlos - SP 


\section{Quelato-Complexos de Rênio e Tecnécio com Potencial Aplicação Medicinal}

Tese apresentada ao Instituto de Química da Universidade de São Paulo para
obtenção do título de Doutor em Química.
Área de concentração: Química Analítica e Inorgânica.

Orientador:

Prof. Dr. Victor Marcelo Deflon

\begin{tabular}{|c|}
\hline Exemplar revisado \\
O exemplar original encontra-se em \\
acervo reservado na Biblioteca do IQSC-USP
\end{tabular}

São Carlos - SP 


\section{Dedicatória}

À Deus, por estar ao meu lado sempre.

Aos meus pais Juraci e Maria das Neves, pelo apoio incondicional e por todo amor recebido durante toda a minha vida.

As minhas amadas irmãs "Didéia", "Nãs" e "Cris" por sempre acreditarem que seria capaz de superar mais este desafio.

A minha única e amada vozinha Ana Maria, por ter me dado à alegria de conviver com ela, aos seus 96 aninhos, até este momento importante da minha vida.

Ao meu irmaozão, amigo e cunhado Roger, que durante todo tempo apoiou e torceu muito por mim.

Ao Adriano "Dri", meu outro cunhado, que sempre alegrou as nossas vidas durante todos esses anos.

Aos tesouros e paixões da minha vida, meus sobrinhos Heitor, Henrique e a "princesa do titio" Giovanna.

Aos meus tios amados "Dão", "Gordo" e Jaime (in memoriam) que sempre acreditaram que um dia este momento iria chegar. 


\section{Agradecimentos}

Ao Prof. Dr. Victor Marcelo Deflon os meus sinceros agradecimentos pela amizade, pelas oportunidades que tive, pela orientação e por não ter desistido de mim em 2003, quando tentávamos uma bolsa PIBIC, não remunerada, que foi negada sob a alegação de que eu era muito velho para desempenhar tal atividade. Certamente este momento não seria possível, se o Prof. Victor não tivesse entrado com o recurso que resultou no início da minha carreira científica dentro da química inorgânica.

Ao meu orientador, durante o período sanduíche em Berlin, Prof. Dr. Ulrich Abram pelos ensinamentos, pelo tratamento dispensado a minha pessoa e por me mostrar outro significado para palavra orientação, TAMBÉM muito importante para meu crescimento profissional. Agradeço por ter me concedido todo rênio e tecnécio que empreguei na execução deste trabalho.

Ao pesquisador e químico Dr. Fábio Luiz Navarro Marques e a Srt. Alyne Eloise Lafratta, ambos do Serviço de Medicina Nuclear da Faculdade de Medicina da USP. Todos os testes de marcação com o isótopo ${ }^{99 \mathrm{~m}} \mathrm{Tc}$ mostrados nesta tese foram feitos pela farmacêutica Alyne, sob a supervisão do Dr. Fábio. E a todos os demais membros da equipe que de alguma forma colaboraram com este trabalho.

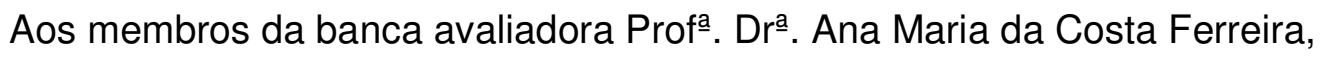
Profạ. Drª . Regina Célia Galvão Frem, Dr. Fábio Luiz Navarro Marques e Prof. Dr. Benedito dos Santos Lima Neto por suas indispensáveis contribuições para a melhoria deste trabalho.

Aos amigos que levarei por toda vida, pelos inúmeros momentos de prazer (de muito trabalho e claro... também de risadas), de troca de experiências (no laboratório ou fora dele) e apoio em várias situações adversas (algumas quase "exasperantes"): os brasileiros Murilo e Leandro, a colombiana 
"Moniquinha", e ao peruano Ivan, todos, cada um ao seu modo, são motivos de muito orgulho.

Ao Lenilson Coutinho, por todas as conversas, conselhos e apoio em momentos difíceis. Sujeito de convivência fácil e agradável, a quem hoje tenho o enorme prazer de chamar de AMIGO.

À querida Julieta, que dedicou a minha pessoa, ainda que durante um curto período de tempo, interrompido pelo meu retorno à Brasília, seus melhores sentimentos.

Ao atual Prof. Dr. Sailer Santos dos Santos, EXCELENTE AMIGO, que dividiu comigo vários momentos de alegria e tristezas em Berlim. Nos momentos ruins percebemos quem são os verdadeiros amigos.

Aos inesquecíveis amigos e amigas: as alemãs Drâ. Adelheid Hagenbach e Dr $r^{\text {a }}$. Elisabeth Oehlke, a indiana Samundeeswari Mariappan Balasekaran, ao irlandês Eamonn Barron, a espanhola Ara Núñez Montenegro e ao colombiano Juan Daniel Castillo que tornaram minha vida na Alemanha mais alegre com tanto carinho e conforto nos momentos em que mais precisei. Ser amigo destas pessoas foi a maior e melhor contribuição que recebi do período no exterior.

To my unforgettable friends: the Germans $D r^{\underline{a}}$. Adelheid Hagenbach and $D r^{\underline{a}}$. Elisabeth Oehlke, the Indian Ms. Samundeeswari Balasekaran Mariappan, the Irishman Mr. Eamonn Barron, the Spaniard Drª. Ara Núñez Montenegro and the Colombian Mr. Juan Daniel Castillo. They were the people who made my life happier in Germany, comforting and caring for me at the times when I most needed it. The friendship of these people was the greatest and most important contribution that I received during the period abroad. 
Für meine unvergessliche Freunde: Die Deutschen Dr. Adelheid Hagenbach und Dr.Elisabeth Oehlke, die Inderin Ms. Samundeeswari Balasekaran Mariappan, Der Ire Eamonn Barron, die Spanierin Dr. Ara Núñez Montenegro und der Kolumbianer Juan Daniel Castillo. Sie waren diejenigen, die mein Leben in Deutschland glücklicher gemacht haben. Sie waren für mich da in den Momenten, wo ich am meistens Unterstützung brauchte. Ihre Freundschaft war die großte und wichtigste Beitrag während meines Aufenthalts im Ausland.

Ao Prof. Dr. Alzir Azevedo Batista, da Universidade Federal de São Carlos UFSCar, pelo apoio recebido desde o mestrado o qual se estende até hoje. Agradeço também aos seus orientandos, que em sua maioria, sempre se dispuseram a me ajudar. Em especial: Marília, Edjane, Fábio, Lucas, João Paulo e Leonardo.

Ao Prof. Dr. Antônio Gilberto Ferreira, "Giba”, da Universidade Federal de São Carlos - UFSCar, pelas discussões relevantes e por sua contribuição significativa no que diz respeito ao estudo de $\mathrm{RMN}{ }^{1} \mathrm{H} \mathrm{e}{ }^{13} \mathrm{C}$, realizado à baixa temperatura. Estendo meus agradecimentos à toda equipe técnica do Laboratório de Ressonância Magnética Nuclear da UFSCar e em especial à técnica Luciana Vizotto por toda disponibilidade e ajuda.

Aos professores da Universidade de Brasília - UnB, Dr. Karl Eberhard Bessler, Dr. Sebastião de Souza Lemos e Drâ. Inês Sabioni Resk, pelas contribuições efetivas na minha formação, pois são exemplos de profissionalismo e de caráter.

Aos professores Dr. Ernesto Schulz Lang e Dr. Davi Fernando Back, da Universidade Federal de Santa Maria-RS, e a Prof ${ }^{2}$. Drª . Claudia Cristina Gatto, da Universidade de Brasília, pela amizade e celeridade nas medidas de coleta de dados para difração de raios $X$. 
Aos meus amigos, desde o ensino médio ou graduação, que tanto senti falta: Joarks, Fábio "senador", Guilherme Carvalho, Luana Alencar, Viviane de Paula, Juliana Mee, Juliana Alves, Noemi Neri e a Dr ${ }^{a}$ Vanda Maria de Oliveira pelo estímulo durante todos esses anos.

Aos amigos Edésio Coimbra e Débora Cristina, que desde 1998 estão sempre, de alguma forma, presentes na minha vida.

Ao amigo e criador de cães Rosivaldo Barbosa Maciel por todas as agradáveis conversas que tivemos em sua casa, onde fui sempre muito bem recebido.

Aos meus amigos de IMA (Instituto Mineiro de Agropecuária, autarquia onde trabalhei nos anos de 1998 e 1999): Deraldo e Francisco (técnicos em agropecuária), Ivanilda (secretária) e Dr. Ricardo e Dr. Altino (médicos veterinários).

Aos seguranças do IQSC-USP, por todas as noites em que eles foram ao laboratório para ter certeza de que tudo estava bem comigo durante as inúmeras reações noturnas "cheirosas" (síntese dos ditiocarbazatos) que fiz.

A todos os demais funcionários do Instituto de Química de São Carlos, em especial, às secretárias Veroneide, Gisley e Andreia e a Srª. Sílvia que tanto se prontificaram a ajudar em todos os momentos em que precisei.

A FAPESP e CAPES pelas bolsas concedidas. 


\section{Epígrafe}

...Eu poderia suportar, embora não sem dor, que tivessem morrido todos os meus amores... mas enlouqueceria se morressem todos os meus amigos!!!

\section{Vinícius de Moraes}




\section{Resumo em português}

Neste trabalho foram estudadas as formas de coordenação de piridinonas, ditiocarbazatos e N-(N",N"-dialquilaminotiocarbonil)-N"-(2-hidroxifenil)benzoamidinas aos centros metálicos Re (V) e Tc (V). Neste sentido, os complexos triclorobis(trifenilfosfina)oxorrênio(V), $\quad\left[\mathrm{ReOCl}_{3}\left(\mathrm{PPh}_{3}\right)_{2}\right]^{57}$, tribromobis(trifenilfosfina)oxorrênio(V), $\left[\mathrm{ReOBr}_{3}\left(\mathrm{PPh}_{3}\right)_{2}\right]^{57}$, e tetraclorooxorenato(V) de tetrabutilamônio, $\left(\mathrm{NBu}_{4}\right)\left[\mathrm{ReOCl}_{4}\right]^{58}$, foram sintetizados e utilizados como precursores. $\mathrm{O}$ precursor tetraclorooxotecnetato $(\mathrm{V})$ de tetrabutilamônio, $\left(\mathrm{NBu}_{4}\right)\left[\mathrm{TCOCl}_{4}\right]$, foi sintetizado e disponibilizado pelo grupo de Prof. Dr. Ulrich Abram, da Universidade Livre de Berlin, durante o período de trabalho realizado na Alemanha.

Foram utilizadas as seguintes técnicas para a caracterização dos complexos sintetizados: espectroscopia de absorção na região do infravermelho, análise elementar ( $\mathrm{C}, \mathrm{H}, \mathrm{N}$ e S), espectroscopia de ressonância magnética nuclear $\left({ }^{31} \mathrm{P},{ }^{1} \mathrm{H} \mathrm{e}\right.$ no caso de um dos complexos, também ${ }^{13} \mathrm{C}$ ), espectrometria de massas (MS-ESI) e determinação de estruturas cristalinas e moleculares, quando possível, por difração de raios $\mathrm{X}$ em monocristal. Por se tratar de um elemento radioativo, a avaliação do percentual de tecnécio em seus complexos foi determinada por meio da técnica de cintilação líquida.

Deste o início deste trabalho foram sintetizados e caracterizados por diversas técnicas 14 novos complexos de rênio e 1 de tecnécio, todos inéditos. Seis ditiocarbazatos, sendo 5 inéditos, também foram sintetizados e caracterizados. 


\section{Resumo em inglês}

This work evaluated the coordination mode of pyridinones, dithiocarbazates and $\mathrm{N}-(\mathrm{N} ", \mathrm{~N}$ "-Diethylaminothiocarbonyl)-N"-(2-hydroxyphenyl)benzamidine, to the metal centers $\operatorname{Re}(\mathrm{V})$ and $\mathrm{Tc}(\mathrm{V})$. For this purpose, the compounds trichlorobis(triphenylphosphine)oxorhenium(V), $\quad\left[\mathrm{ReOCl}_{3}\left(\mathrm{PPh}_{3}\right)_{2}\right]^{43}$, tribromobis(triphenylphosphine)oxorhenium(V), $\quad\left[\operatorname{ReOBr}_{3}\left(\mathrm{PPh}_{3}\right)_{2}\right]^{43}$, and tetra- $n$ butyl)ammonium tetrachlorooxorhenate $(\mathrm{V}),\left(\mathrm{NBu}_{4}\right)\left[\mathrm{ReOCl}_{4}\right]^{44}$, were synthesized and used as starting materials. The precursor tetra- $n$-butylammonium tetrachlorooxotechnetate $(\mathrm{V}),\left(\mathrm{NBu}_{4}\right)\left[\mathrm{TcOCl}_{4}\right]$ was synthesized and released by the Prof. Dr. Ulrich Abram's group, at the Freie Universität Berlin, during my research time in Germany.

The complexes were characterized by infrared absorption spectroscopy, elemental analyses (CHNS), mass spectrometry with electrospray ionization (MSESI), nuclear magnetic resonance spectroscopy $\left({ }^{31} \mathrm{P},{ }^{1} \mathrm{H}\right.$ and, in one case, also $\left.{ }^{13} \mathrm{C}\right)$ and had their crystalline and molecular structures, when possible, properties determined by X-ray diffraction on single crystals. Due to its radioactive element, the ${ }^{99} \mathrm{Tc}$ values were determined by standard liquid scintillation counting.

Since the beginning of this work were synthesized and characterized by various techniques 14 new rhenium and 1 technetium complexes, all of then unknown in the literature. All the complexes presented here were obtained in good or excellent yields. Six new dithiocarbazates were obtained and characterized, of which 5 are unknown. 


\section{Sumário}

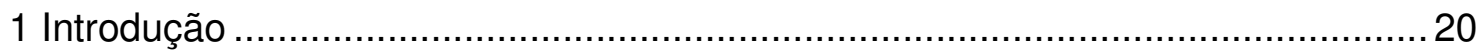

1.1 Rênio e Tecnécio ..............................................................................20

1.1.1 Complexos de Rênio e Tecnécio no Estado de Oxidação +V ....................21

1.1.2 Compostos de Rênio e Tecnécio e a Medicina Nuclear ............................22

1.2 Agentes Complexantes Utilizados ..........................................................29

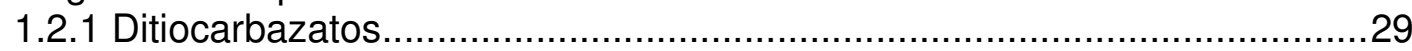

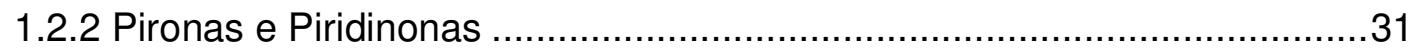

1.2.3 Dialquilamino(tiocarbonil)benzamidinas ...............................................3

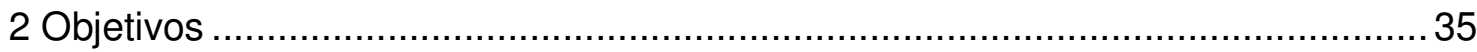

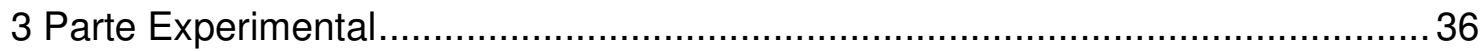

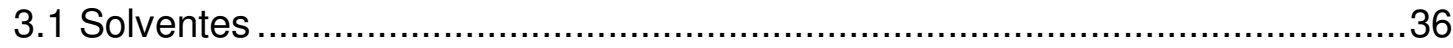

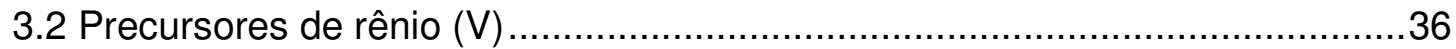

3.3 Instrumentação e Técnicas Experimentais .....................................................38

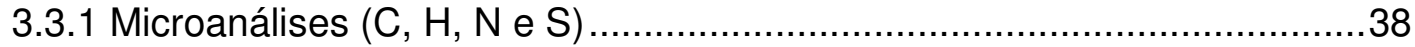

3.3.2 Espectrometria de Massas (MS - ESI) …………................................ 38

3.3.3 Espectroscopia de Absorção na Região do Infravermelho (IV) ..................38

3.3.4 Ressonância Magnética Nuclear (RMN) ………...................................39

3.3.5 Difração de raios X em monocristal...................................................40

3.3.6 Espectrometria de Cintilação Líquida .....................................................40

3.4 Sínteses ............................................................................................ 44

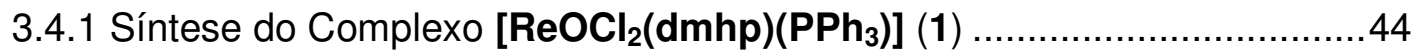

3.4.2 Síntese do Complexo [ReO(bdtc)(dmhp)] (2) .....................................45

3.4.3 Síntese do Complexo [ReO(bdtc)(mal)] (3) .......................................46

3.4.4 Síntese do Complexo $\left[\mathrm{ReOCl}(\mathbf{b d t c})\left(\mathrm{PPh}_{3}\right)\right]$ (4) ...............................4

3.4.5 Síntese do Complexo $\left[\operatorname{ReOBr}(\mathbf{b d t c})\left(\mathrm{PPh}_{3}\right)\right]$ (5) .................................48

3.4.6 Síntese do Complexo [ReOCl(bdtn)(PPh $)$ ] (6) ...................................49

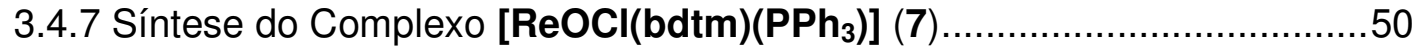

3.4.8 Síntese do Complexo [TcO(bdtc)Cl] (8) ..........................................5

3.4.9 Síntese do Complexo [ReO(bdtc)(Hbdtc)] (9) …...............................52

3.4.10 Síntese do Complexo [ReO(bdtn)(Hbdtn)] (10) ................................53

3.4.11 Síntese do Complexo [ReO(bdtm)(Hbdtm)] (11) ................................54

3.4.12 Síntese do Complexo [ReO(bdtc)(cisa)] (12) ....................................55

3.4.13 Síntese do Complexo [ReO(bdtc)(cism)] (13) ...................................56

3.4.14 Síntese do Complexo [ReO(deba)(dmhp)] (14) ...............................57

3.4.15 Síntese do Complexo [ReO(deba)(bmhp)] (15) …..............................

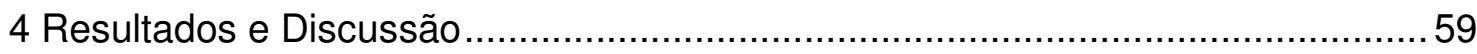

4.1 Complexos [ReO(dmhp) $\left.\mathbf{C l}_{2}\left(\mathrm{PPh}_{3}\right)\right]$ (1), [ReO(bdtc)(dmhp)] (2) e

[ReO(bdtc)(mal)] (3)

4.1.1 Espectroscopia de Absorção na Região do Infravermelho........................60

4.1.2 Espectroscopia de Ressonância Magnética Nuclear (RMN ${ }^{1} \mathrm{H} \mathrm{e}{ }^{31} \mathrm{P}$ ) para

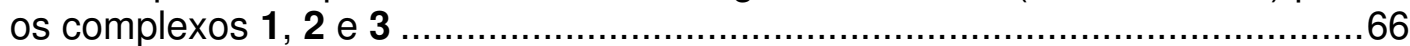

4.1.3 Difração de Raios X em Monocristal de 1, 2 e 3 ……..........................72

4.2 Complexos [ReO(bdtc)Cl( $\left.\left.\mathrm{PPh}_{3}\right)\right]$ (4), [ReO(bdtc) Br( $\left.\left.\mathrm{PPh}_{3}\right)\right]$ (5),

[ReO(bdtn)Cl(PPh $)]$ (6), [ReO(bdtm)Cl( $\left.\left.\mathrm{PPh}_{3}\right)\right]$ (7) e [TcO(bdtc)Cl] (8) ............79

4.2.1 Espectroscopia de Absorção na Região do Infravermelho..........................79 
4.2.2 Espectroscopia de Ressonância Magnética Nuclear (RMN ${ }^{1} \mathrm{H}$ e $\left.{ }^{31} \mathrm{P}\right)$ para os complexos 4, 5, 6, 7 e 8 88

4.2.3 Difração de Raios X em Monocristal dos Complexos 4, 5 e 8 .

4.2.4 Testes Realizados no Centro de Medicina Nuclear, da Universidade de São Paulo 104

4.2.4.2 Parâmetros Físico-Químicos de Avaliação do Complexo contendo o isótopo ${ }^{99 \mathrm{~m}} \mathrm{Tc}$ 107

4.3 Complexos [ReO(bdtc)(Hbdtc)] (9), [ReO(bdtn)(Hbdtn)] (10),

[ReO(bdtm)(Hbdtm)] (11)

4.3.1 Espectroscopia de Absorção na Região do Infravermelho

4.3.2 Espectroscopia de Ressonância Magnética Nuclear (RMN $\left.{ }^{1} \mathrm{H}\right)$ para os complexos 9,10 e 11

4.3.3 Difração de Raios X em Monocristal dos Complexos 9, 10 e 11 .............128

4.4 Complexos [ReO(bdtc)(cisa)] (12) e [ReO(bdtc)(cism)] (13) .....................134

4.4.1 Espectroscopia de Absorção na Região do Infravermelho......................135

4.4.2 Espectroscopia de Ressonância Magnética Nuclear $\left(\mathrm{RMN}{ }^{1} \mathrm{H} \mathrm{e}^{31} \mathrm{P}\right)$ para

os complexos 12 e 13

4.4.3 Difração de Raios X em Monocristal dos Complexos 12 e 13..................145

4.4.4 Cálculos Computacionais Envolvendo o Complexo 12 ..........................152

4.5 Complexos [ReO(deba)(dmhp)] (14) e [ReO(deba)(bmhp)] (15) ................155

4.5.1 Espectroscopia de Absorção na Região do Infravermelho.....................155

4.5.2 Espectroscopia de Ressonância Magnética Nuclear (RMN ${ }^{1} \mathrm{H} \mathrm{e}^{13} \mathrm{C}$ ) para os complexos 14 e 15 160

4.5.3 Difração de Raios X em Monocristal dos Complexos 14 e 15 170

4.5.4 Cálculos Computacionais Envolvendo os Complexos 14 e 15 178

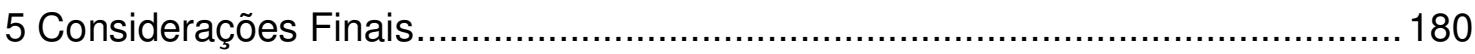

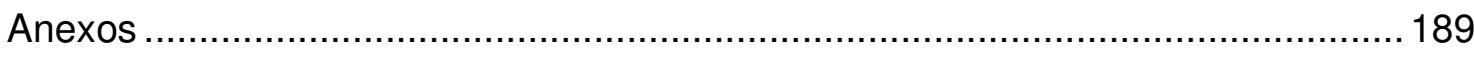




\section{Lista de figuras}

Figura 1 - Variação de energia dos orbitais frente à mudança de geometria do complexo. 22

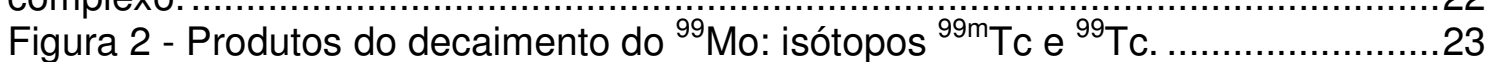

Figura 3 - Gerador de ${ }^{99 m}$ Tc disponível para uso em clínicas de medicina nuclear. .24

Figura 4 - Radiofármacos em uso nas clínicas de medicina nuclear.........................25

Figura 5 - Derivado do $\mathrm{MAG}_{3}$ com D-glicosamina coordenado ao centro de

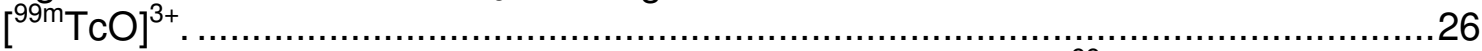

Figura 6 - Imagens obtidas por RMI (à esquerda) e SPECT - ${ }^{99 \mathrm{~m}} \mathrm{Tc}$-HMPAO]........27

Figura 7 - Representação do [ ${ }^{99 m}$ Tc-TRODAT] e da molécula cocaína.....................28

Figura 8 - Representação esquemática de ditiocarbazatos derivados da hidrazina...31

Figura 9 - Esquema para obtenção da piridinona Hdmhp a partir do maltol. .............32

Figura 10 - Representação esquemática do ligante $\mathrm{H}_{2}$ deba....................................34

Figura 11 - Equações para cálculo dos deslocamentos químicos de ${ }^{1} \mathrm{H}$ cujo sinal

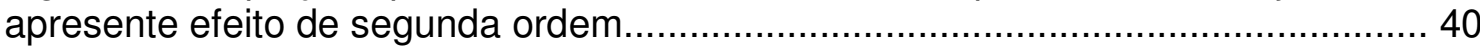

Figura 12 - Cintiladores 2,5-difeniloxazol (PPO) e 1,4-bis(5-fenil-oxazol-2-il)-benzeno

(POPOP).

Figura 13 - Interação de partículas $\beta$ com o solvente e subsequente emissão de radiação fluorescente.

Figura 14 - Esquema de funcionamento de um tubo fotomultiplicador......................43

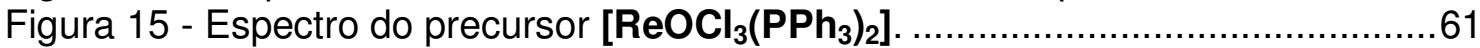

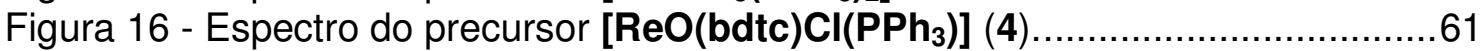

Figura 17 - Espectro do ligante Hdmhp. .........................................................62

Figura 18 - Espectro do agente complexante Hmal. ..........................................62

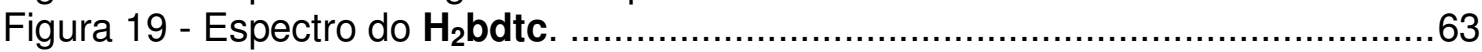

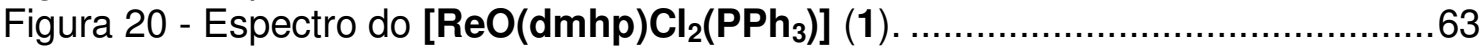

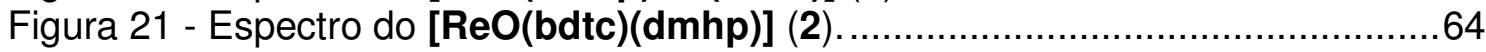

Figura 22 - Espectro do [ReO(bdtc)(mal)] (3) ...........................................64

Figura 23 - Forma ciclizada do $\mathbf{H}_{2}$ bdtc $(\mathbf{a})$ e forma aberta do bdtc $^{2-}$ (b) ................66

Figura 24 - Espectro de $\mathrm{RMN}{ }^{31} \mathrm{P}$ do precursor $\left[\mathrm{ReOCl}_{3}\left(\mathrm{PPh}_{3}\right)_{2}\right] \ldots \ldots \ldots \ldots \ldots \ldots \ldots \ldots . . .67$

Figura 25 - Espectro de $\mathrm{RMN}^{31} \mathrm{P}$ do $\left[\mathrm{ReO}(\mathrm{dmhp}) \mathrm{Cl}_{2}\left(\mathrm{PPh}_{3}\right)\right]$ (1) ......................67

Figura 26 - Espectro de $\mathrm{RMN}{ }^{1} \mathrm{H}$ de $\left[\mathrm{ReO}(\mathrm{dmhp}) \mathrm{Cl}_{2}\left(\mathrm{PPh}_{3}\right)\right]$ (1) ..........................68

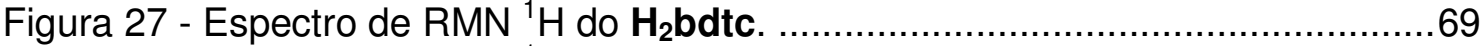

Figura 28 - Espectro de RMN ${ }^{1} \mathrm{H}$ de [ReO(bdtc)(dmhp)] (2) ...............................70

Figura 29 - Espectro de $\mathrm{RMN}{ }^{1} \mathrm{H}$ de $[\mathbf{R e O}(\mathbf{b d t c})(\mathrm{mal})](3) \ldots \ldots \ldots \ldots \ldots \ldots \ldots \ldots \ldots \ldots \ldots . . .71$

Figura 30 - Estrutura molecular do complexo 1 .................................................74

Figura 31 - Estrutura molecular do complexo 2 …….......................................

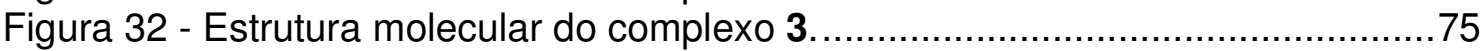

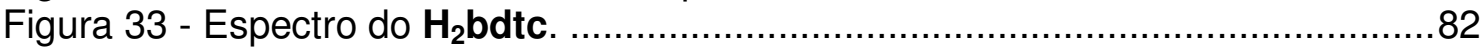

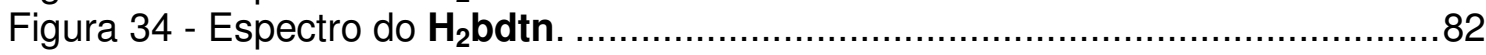

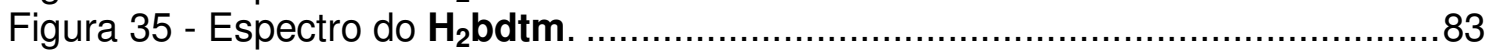

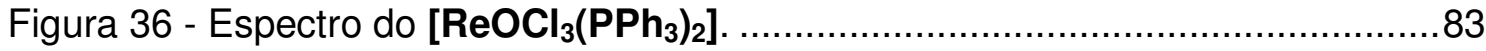

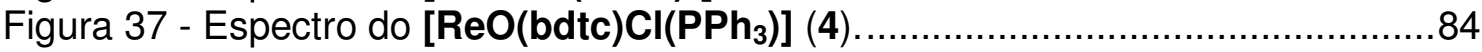

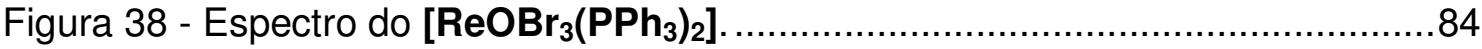

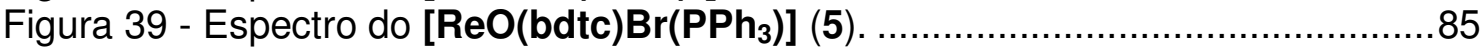

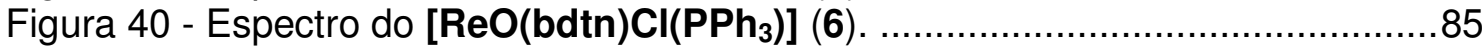

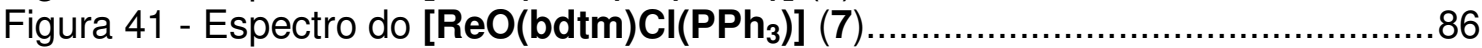

Figura 42 - Espectro do complexo de partida $\left(\mathrm{NBu}_{4}\right)\left[\mathrm{TCOCl}_{4}\right]$. ............................. 86 
Figura 43 - Espectro do [TcO(bdtc) Cl] (8).

Figura 44 - Proposta de deslocamento da nuvem eletrônica do nitrogênio em direção ao metal e consequente efeito indutivo que desblinda a metila. ..............................89

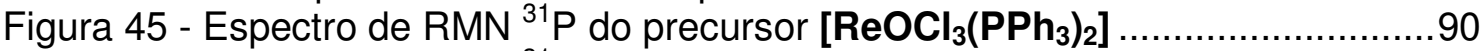

Figura 46 - Espectro de $\mathrm{RMN}{ }^{31} \mathrm{P}$ do precursor $\left[\mathrm{ReOBr}_{3}\left(\mathrm{PPh}_{3}\right)_{2}\right] \ldots \ldots \ldots \ldots \ldots \ldots \ldots \ldots . . . . . . . \ldots 0$

Figura 47 - Espectro de $\mathrm{RMN}{ }^{1} \mathrm{H}$ do $\mathrm{H}_{2}$ bdtc ......................................................

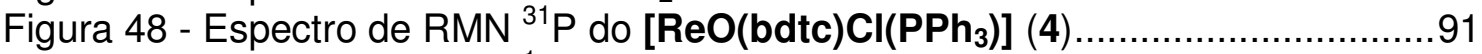

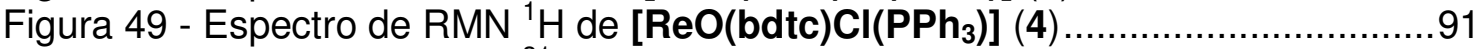

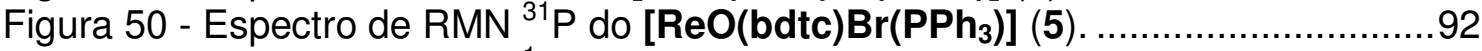

Figura 51 - Espectro de $\mathrm{RMN}{ }^{1} \mathrm{H}$ do $\left[\operatorname{ReO}(\mathbf{b d t c}) \mathrm{Br}\left(\mathrm{PPh}_{3}\right)\right]$ (5) ............................92

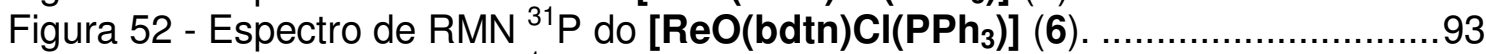

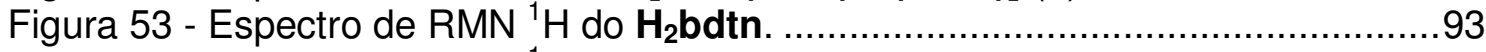

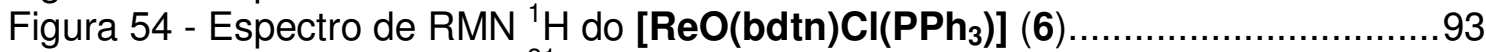

Figura 55 - Espectro de $\mathrm{RMN}^{31} \mathrm{P}$ do $\left[\mathrm{ReO}(\mathrm{bdtm}) \mathbf{C l}\left(\mathrm{PPh}_{3}\right)\right](7) \ldots \ldots \ldots \ldots \ldots \ldots \ldots \ldots . . . .94$

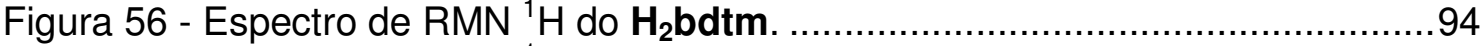

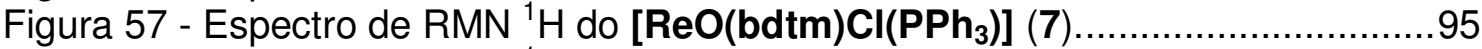

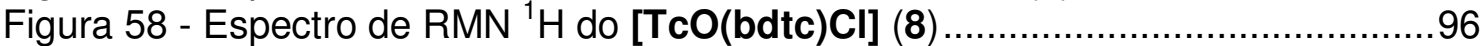

Figura 59 - Estrutura molecular do complexo 4 ..................................................99

Figura 60 - Representação da cela unitária do complexo 4 ..................................99

Figura 61 - Estrutura molecular do complexo 5 ...............................................100

Figura 62 - Estrutura molecular do complexo 8 …….....................................100

Figura 63 - Representação da cela unitária do complexo 8. .................................101

Figura 64 - Cromatograma obtido após a co-injeção do complexo padrão

$[\mathrm{ReO}(\mathrm{bdtc})(\mathrm{Hbdtc})]$ e Na[ $\left.{ }^{99 \mathrm{~m}} \mathrm{TcO}_{4}\right]$ com detecção em ultravioleta $(340 \mathrm{~nm})$............108

Figura 65 - Radiocromatograma da solução contendo $\left.\mathrm{Na}^{99 \mathrm{~m}} \mathrm{TcO}_{4}\right]$ e

$\left[{ }^{99 m} \mathrm{TcO}(\mathrm{bdtc}) \mathrm{Cl}\right]$, preparada de acordo com o método convencional.......................108

Figura 66 - Radiocromatograma da solução contendo $\left.\mathrm{Na}^{99 \mathrm{~m}} \mathrm{TcO}_{4}\right]$ e

[99m $\mathrm{TcO}(\mathrm{bdtc}) \mathrm{Cl}]$, preparada de acordo com o método convencional, aquecida à $55^{\circ} \mathrm{C}$

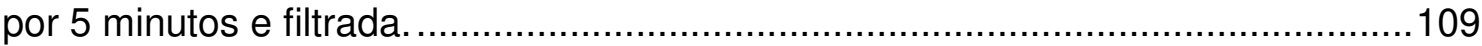

Figura 67 - Cromatografia em papel, cuba contendo acetona..............................110

Figura 68 - Cromatografia em papel, cuba contendo solução de $\mathrm{NaCl} 0,9 \%$.........111

Figura 69 - Cromatografia em papel, cuba contendo acetona..............................111

Figura 70 - Cromatografia em papel, cuba contendo solução de $\mathrm{NaCl} 0,9 \%$.........112

Figura 71 - Determinação do coeficiente de partição do complexo [ $\left.{ }^{99 m} \mathrm{TcO}(\mathrm{bdtc}) \mathrm{Cl}\right]$

Figura 72 - Gráfico de eletroforese do [ $\left.{ }^{9 m} \mathrm{TCO}_{4}\right]^{]}$obtido durante um período de 2 horas.

Figura 73 - Gráfico de eletroforese do [ [ $\left.{ }^{99 \mathrm{~T}} \mathrm{TCO}(\mathrm{bdtc}) \mathrm{Cl}\right]$ obtido durante um período de

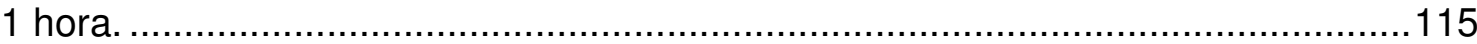

Figura 74 - Gráfico de eletroforese do [ $\left.{ }^{99 \mathrm{~m}} \mathrm{TcO}(\mathrm{bdtc}) \mathrm{Cl}\right]$ obtido durante um período de

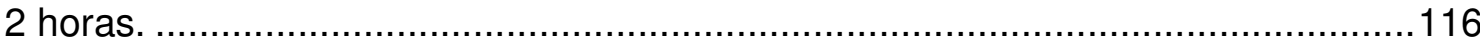

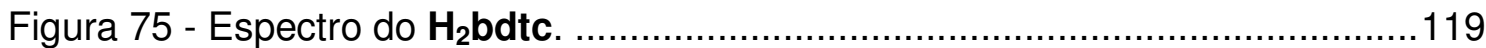

Figura 76 - Espectro do $\mathbf{H}_{2} \mathbf{b d t n}$............................................................119

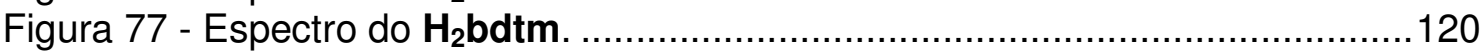

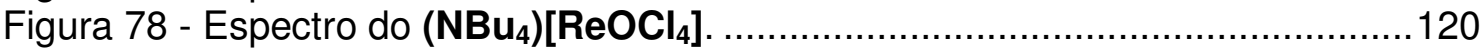

Figura 79 - Espectro do [ReO(bdtc)(Hbdtc)] (9). .........................................121

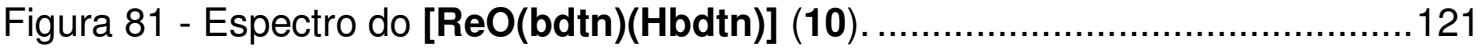

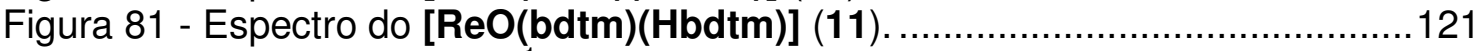

Figura 82 - Espectro de $\mathrm{RMN}{ }^{1} \mathrm{H}$ do $\mathbf{H}_{2}$ bdtc. .................................................123

Figura 83 - Espectro de RMN ${ }^{1} \mathrm{H}$ do [ReO(bdtc)(Hbdtc)] (9) ..............................124 


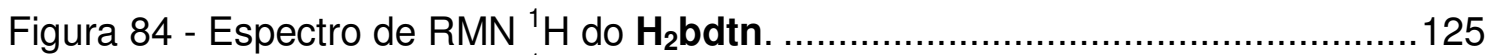

Figura 85 - Espectro de $\mathrm{RMN}{ }^{1} \mathrm{H}$ de [ReO(bdtn)(Hbdtn)] (10)..........................125

Figura 86 - Espectro de $\mathrm{RMN}{ }^{1} \mathrm{H}$ do $\mathrm{H}_{2}$ bdtm. .................................................126

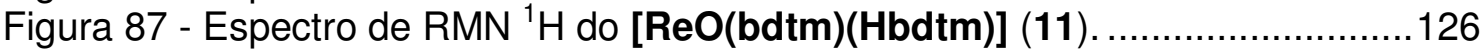

Figura 88 - Estrutura molecular do complexo 9...............................................130

Figura 89 - Cela unitária do complexo 9..........................................................130

Figura 90 - Estrutura molecular do complexo 10 ...........................................131

Figura 91 - Estrutura molecular do complexo 11 ...........................................131

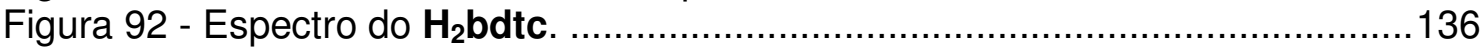

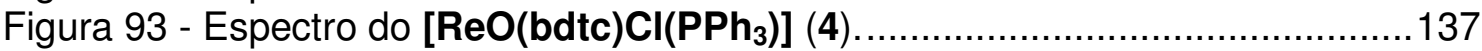

Figura 94 - Espectro do agente complexante Hcisa. .......................................137

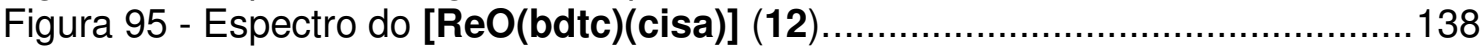

Figura 96 - Espectro do agente complexante Hcism......................................138

Figura 97 - Espectro do [ReO(bdtc)(cism)] (13). .............................................139

Figura 98 - Espectro de $\mathrm{RMN}^{31} \mathrm{P}$ do [ReO(bdtc)(cisa)] (12) ............................141

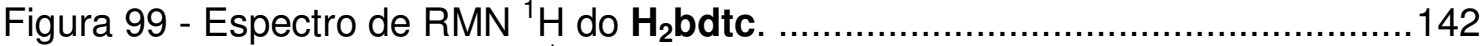

Figura 100 - Espectro de RMN ${ }^{1} \mathrm{H}$ do [ReO(bdtc)(cisa)] (12)............................142

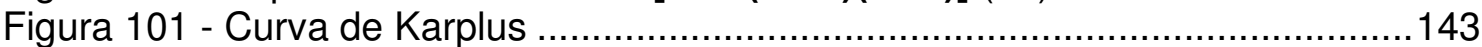

Figura 102 - Espectro de RMN ${ }^{1} \mathrm{H}$ do [ReO(bdtc)(cism)] (13). ...........................144

Figura 103 - Estrutura molecular do complexo 12 ….....................................147

Figura 104 - Ligações de hidrogênio intermoleculares observadas na rede cristalina

do complexo 12 ................................................................................ 147

Figura 105 - Estrutura molecular do complexo 13 .........................................148

Figura 106 - Ligações de hidrogênio intermoleculares e intramoleculares observadas

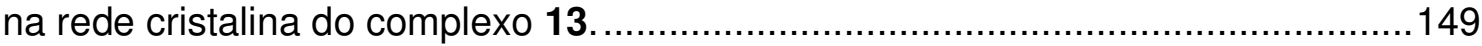

Figura 107 - Forma otimizada por cálculo DFT, baseada nas distâncias e ângulos determinados por Difração de Raios X em monocristal (12)..............................153

Figura 108 - Orbitais de fronteira HOMO e LUMO calculados para o complexo 12.

Figura 109 - Espectro do $\mathrm{H}_{2}$ deba.

153

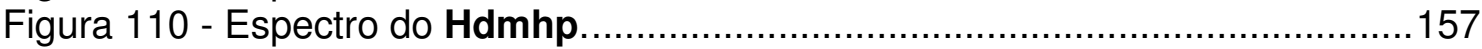

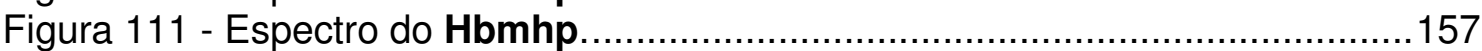

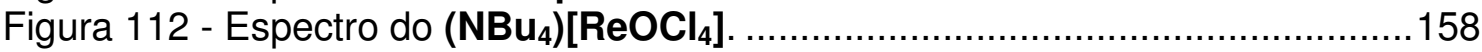

Figura 113 - Espectro do [ReO(deba)(dmhp)] (14) .......................................158

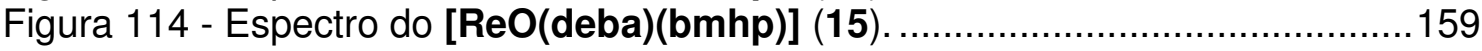

Figura 115 - Hipótese de formação dos isômeros A e C.....................................161

Figura 116 - Espectro de $\mathrm{RMN}^{\mathrm{P}} \mathrm{H}$ de $[\operatorname{ReO}($ deba)(dmhp)] (14) ..........................164

Figura 117 - Espectros de $R M N{ }^{13} \mathrm{C}$ de $[\operatorname{ReO}($ deba)(dmhp)] (14), com variação de

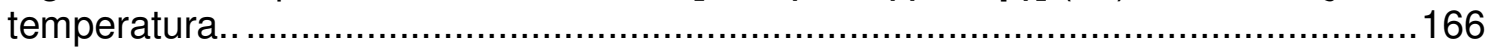

Figura 118 - Isomêros prováveis de [ReO(deba)(dmhp)] (14) em solução. ............166

Figura 119 - Espectro de $\mathrm{RMN}^{1} \mathrm{H}$ de [ReO(deba)(bmhp)] (15) .........................167

Figura 120 - Comparação entre as regiões aromáticas nos espectros de $\mathrm{RMN}{ }^{1} \mathrm{H}$ dos

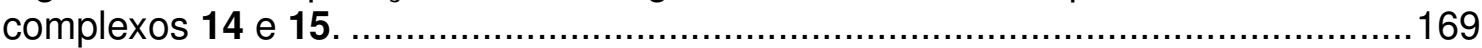

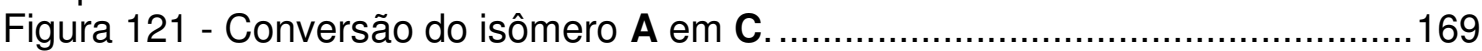

Figura 122 - Estrutura molecular do complexo 14 .........................................172

Figura 123 - Cela unitária do complexo 14 ……….....................................172

Figura 124 - Visão dos buracos existentes no retículo cristalino de 14.................173

Figura 125 - Estrutura molecular do complexo 15............................................173

Figura 126 - Cela unitária do composto 15..................................................174

Figura 127 - Visão do retículo cristalino de 15. ...............................................175 
Figura 128 - Formas otimizadas por cálculo DFT, baseadas nas distâncias e ângulos determinados por Difração de Raios X em monocristal (14 e 15). .........................179 


\section{Lista de tabelas}

Tabela 1 - Atividade tripanocida e antiproliferativa dos ditiocarbazatos $\mathbf{H}_{2}$ bdtc e $\mathrm{H}_{2}$ bdtn e seus complexos de $\mathrm{Pd}$, Pt e Re.........................................................30

Tabela 2 - Principais bandas $\left(\mathrm{cm}^{-1}\right)$ atribuídas aos modos vibracionais dos complexos 1, 2 e 3, seus precursores e ligantes............................................60 Tabela 3 - Dados de RMN ${ }^{1} \mathrm{H}(300 \mathrm{MHz}) \mathrm{e}^{31} \mathrm{P}(121,45 \mathrm{MHz})$ para $1 \ldots \ldots \ldots \ldots \ldots \ldots \ldots . . . . . . . . . . .68$

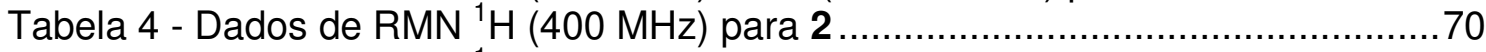

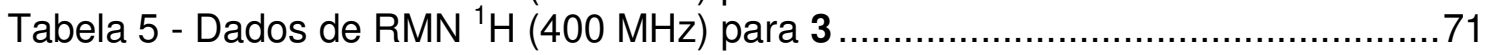
Tabela 6 - Dados cristalográficos de raios $\mathrm{X}$ e resultados dos refinamentos das estruturas dos complexos [ReO(dmhp) $\left.\mathrm{Cl}_{2}\left(\mathrm{PPh}_{3}\right)\right](\mathbf{1}),[\mathbf{R e O}(\mathrm{bdtc})(\mathrm{dmhp})](\mathbf{2})$

[ReO(bdtc)(mal)] (3)..................................................................... 76 Tabela 7 - Principais distâncias (pm) e ângulos $\left(^{\circ}\right)$ encontrados no complexo

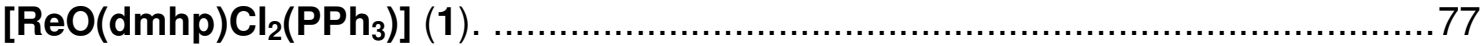
Tabela 8 - Principais distâncias (pm) e ângulos $\left(^{\circ}\right.$ ) encontrados nos complexos [ReO(bdtc)(dmhp)] (2) e [ReO(bdtc)(mal)] (3). 78

Tabela 9 - Principais bandas $\left(\mathrm{cm}^{-1}\right)$ atribuídas aos modos vibracionais dos complexos 4, 5, 6, 7 e 8, dos precursores $\left[\mathrm{ReOCl}_{3}\left(\mathrm{PPh}_{3}\right)_{2}\right],\left[\mathrm{ReOBr}_{3}\left(\mathrm{PPh}_{3}\right)_{2}\right]$ e $\left(\mathrm{NBu}_{4}\right)\left[\mathrm{TcOCl}_{4}\right]$ bem como dos agentes complexantes $\mathbf{H}_{2}$ bdtc, $\mathbf{H}_{2} \mathbf{b d t n}$ e $\mathbf{H}_{2} \mathbf{b d t m}$.

Tabela 10 - Dados de distância de ligação (pm) e RMN ${ }^{31} \mathrm{P}(161,70 \mathrm{MHz}$, em ppm) para 1, 4.

Tabela 11 - Dados de RMN ${ }^{1} \mathrm{H}(400 \mathrm{MHz}) \mathrm{e}^{31} \mathrm{P}(161,70 \mathrm{MHz})$ para 4 ..................91

Tabela 12 - Dados de RMN ${ }^{1} \mathrm{H}(200,1 \mathrm{MHz}) \mathrm{e}^{31} \mathrm{P}(81,0 \mathrm{MHz})$ para 5 ...................92

Tabela 13 - Dados de RMN ${ }^{1} \mathrm{H}(400 \mathrm{MHz}) \mathrm{e}^{31} \mathrm{P}(161,70 \mathrm{MHz})$ para 6 ...................93

Tabela 14 - Dados de RMN ${ }^{1} \mathrm{H}(400 \mathrm{MHz}) \mathrm{e}^{31} \mathrm{P}(161,70 \mathrm{MHz})$ para 7 ...................95

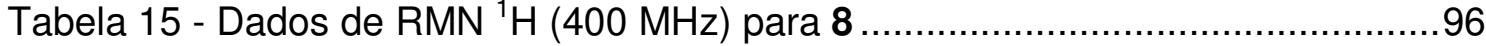

Tabela 16 - Dados cristalográficos de difração de raios $X$ e resultados dos refinamentos das estruturas dos complexos 4, 5 e 8. 102

Tabela 17 - As principais distâncias (pm) e ângulos $\left(^{\circ}\right)$ de ligação encontrados nos complexos 4 e 5 .

Tabela 18 - As principais distâncias $(\mathrm{pm})$ e ângulos $\left(^{\circ}\right)$ de ligação encontrados no complexo 8.

Tabela 19 - Coeficiente de partição do complexo [ $\left.{ }^{99 \mathrm{~m}} \mathrm{TcO}(\mathbf{b d t c}) \mathbf{C l}\right]$.

Tabela 20 - Principais bandas $\left(\mathrm{cm}^{-1}\right)$ atribuídas aos modos vibracionais dos complexos 9, 10 e 11 e seu precursor $\left(\mathrm{NBu}_{4}\right)\left[\mathrm{ReOCl}_{4}\right]$, bem como dos agentes complexantes $\mathbf{H}_{2}$ bdtc, $\mathbf{H}_{2}$ bdtn e $\mathbf{H}_{2}$ bdtm.

Tabela 21 - Dados de $R M N{ }^{1} \mathrm{H}(400 \mathrm{MHz})$ para 9.

Tabela 22 - Dados de RMN ${ }^{1} \mathrm{H}(400 \mathrm{MHz})$ para 10 125

Tabela 23 - Dados de RMN ${ }^{1} \mathrm{H}(400 \mathrm{MHz})$ para 11

Tabela 24 - Dados cristalográficos de difração de raios $X$ e resultados dos refinamentos das estruturas dos complexos 9,10 e 11.

Tabela 25 - As principais distâncias (pm) e ângulos $\left(^{\circ}\right.$ encontrados nos complexos

9,10 e 11

Tabela 26 - Principais bandas $\left(\mathrm{cm}^{-1}\right)$ atribuídas aos modos vibracionais dos complexos 12 e 13, precursor [ReO(bdtc)Cl( $\left.\mathrm{PPh}_{3}\right)$ ] (4) e agentes complexantes $\mathrm{H}_{2}$ bdtc, Hcisa e Hcism. 
Tabela 29 - Dados cristalográficos de difração de raios $X$ e resultados dos refinamentos das estruturas dos complexos 12 e 13.

Tabela 30 - Principais distâncias (pm) e ângulos $\left(^{\circ}\right)$ de ligação encontrados nos complexos 12 e 13. O segundo valor mostrado para o produto 12 refere-se aos comprimentos e ângulos de ligação determinados por meio da DFT.

Tabela 31 - Comparação entre os deslocamentos químicos obtidos experimentalmente e calculados (exp. / calc.)

Tabela 32 - Comparação entre os dados de IV obtidos experimentalmente e calculados para o complexo 12

Tabela 33 - Principais bandas $\left(\mathrm{cm}^{-1}\right)$ atribuídas aos modos vibracionais dos complexos 14 e 15 e dos agentes complexantes $\mathrm{H}_{2}$ deba, Hdmhp e Hbmhp........159

Tabela 34 - Dados de RMN ${ }^{1} \mathrm{H}(400 \mathrm{MHz})$ para 14.

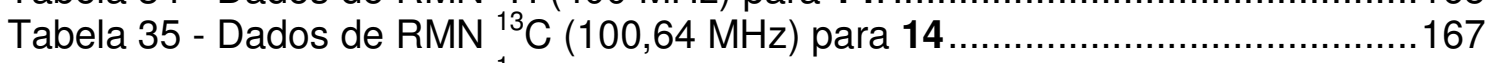

Tabela 36 - Dados de RMN ${ }^{1} \mathrm{H}(400 \mathrm{MHz})$ para 15

Tabela 37 - Dados cristalográficos de difração de raios $X$ e resultados dos refinamentos das estruturas dos complexos 14 e 15.

Tabela 38 - As principais distâncias (pm) e ângulos $\left(^{\circ}\right)$ encontrados nos complexos

14 e 15. 


\section{Lista de abreviaturas e símbolos}

\begin{tabular}{|c|c|}
\hline Hmal & 2-metil-3-hidroxi-4-pirona \\
\hline Hdmhp & 1,2-dimetil-3-hidroxi-4-piridinona \\
\hline $\mathrm{H}_{2}$ bdtc & 5-hidroxi-3-metil-5-fenil-pirazol-1-(S-benzilditiocarbazato) \\
\hline $\mathrm{H}_{2}$ bdtn & 5-hidroxi-3-metil-5-fenil-pirazol-1-( $p$-nitro-S-benzilditiocarbazato) \\
\hline $\mathrm{H}_{2} \mathrm{bdtm}$ & 5-hidroxi-3-metil-5-fenil-pirazol-1-(p-metoxi-S-benzilditiocarbazato) \\
\hline $\mathrm{H}_{2}$ deba & N-(N",N"-dietilaminotiocarbonil)-N'-(2-hidroxifenil)benzoamidina \\
\hline Hcism & Cloridrato de metil-(2R)-2-amino-3-sulfanilpropanato \\
\hline Hcisa & Cloridrato de cisteamina \\
\hline RMN & Ressonância magnética nuclear \\
\hline IV & Espectroscopia de absorção na região do infravermelho \\
\hline DRX & Difração de raios $X$ em monocristal \\
\hline MS-ESI & Espectrometria de massas com ionização eletrospray \\
\hline $\mathbf{P P h}_{3}$ & Trifenilfosfina \\
\hline d & Dupleto \\
\hline dd & Duplo dupleto \\
\hline ddd & Duplo duplo dupleto \\
\hline dl & Dupleto largo \\
\hline $\mathbf{t}$ & Tripleto \\
\hline $\mathbf{m}$ & Multipleto \\
\hline $\mathbf{s}$ & Simpleto \\
\hline $\mathbf{J}$ & Constante de acoplamento escalar \\
\hline TMS & Tetrametilsilano \\
\hline $\mathrm{CDCl}_{3}$ & Clorofórmio deuterado \\
\hline $\mathrm{CD}_{2} \mathrm{Cl}_{2}$ & Diclorometano deuterado \\
\hline $\mathrm{Ar}$ & Hidrogênios aromáticos \\
\hline$\Phi$ & Ângulo diedral \\
\hline $\mathrm{Et}_{3} \mathrm{~N}$ & Trietilamina \\
\hline$\left(\mathrm{NBu}_{4}\right)^{+}$ & Cátion tetrabutilamônio \\
\hline$E_{g}$ & $\begin{array}{c}\text { Representação bidimensional }(\mathrm{E}) \text {, os orbitais são simétricos com relação ao centro de } \\
\text { inversão }(\mathrm{g}) \text {. }\end{array}$ \\
\hline $\mathrm{T}_{2 \mathrm{~g}}$ & $\begin{array}{l}\text { Representação tridimensional }(\mathrm{T}) \text {, os orbitais são antissimétricos frente ao segundo } \\
\text { elemento de simetria em importância }(2) \text { e simétricos com relação ao centro de } \\
\text { inversão }(\mathrm{g}) \text {. }\end{array}$ \\
\hline$A_{1}$ & $\begin{array}{c}\text { O orbital é simétrico com relação ao eixo principal }(A) \text { e frente ao segundo elemento } \\
\text { de simetria em importância }\left(_{1}\right) .\end{array}$ \\
\hline $\mathbf{B}_{1}$ & $\begin{array}{c}\text { O orbital é antissimétrico com relação ao eixo principal }(B) \text {, e simétrico frente ao } \\
\left.\text { segundo elemento de simetria em importância }{ }_{1}\right) \text {. }\end{array}$ \\
\hline $\mathbf{E}$ & Representação bidimensional (E). \\
\hline $\mathbf{B}_{2}$ & $\begin{array}{c}\text { O orbital é antissimétrico tanto em relação ao eixo principal (B) quanto frente ao } \\
\text { segundo elemento de simetria em importância }(2) \text {. }\end{array}$ \\
\hline DFT & Teoria do Funcional de Densidade (Density Functional Theory) \\
\hline B3LYP & $\begin{array}{c}\text { Método envolvendo } 3 \text { parâmetros de Becke com funcional de correlação de Lee, } \\
\text { Yang e Parr }\end{array}$ \\
\hline LANL2DZ & Conjunto de base não relativística: Los Alamos National Laboratory 2 Double $\zeta$ \\
\hline CSGT & $\begin{array}{c}\text { Método Teórico para cálculo de deslocamento químico: Continuous Set of Gauge } \\
\text { Transformations }\end{array}$ \\
\hline GIAO & $\begin{array}{c}\text { Método Teórico para cálculo de deslocamento químico: Gauge Including Atomic } \\
\text { Orbital }\end{array}$ \\
\hline HF & Método Teórico ab initio: Hartree-Fock \\
\hline HOMO & Orbital molecular ocupado de mais alta energia \\
\hline LUMO & Orbital molecular desocupado de mais baixa energia \\
\hline
\end{tabular}




\section{Introdução}

\subsection{Rênio e Tecnécio}

O rênio, número atômico 75 , foi descoberto por W. Noddack, I. Tacke e O. Berg, no mineral gadolinita (um silicato básico constituído de berílio, ferro e lantanídeos), em 1925, sendo o último elemento químico de ocorrência natural identificado. ${ }^{1} \mathrm{O}$ nome deste raro elemento, cuja abundância na crosta terrestre fica em torno de 0,7 ppb, é derivado do rio Reno. ${ }^{2,3}$ A principal fonte de rênio consiste em resíduos de minerais de molibdênio, como a molibdenita $\mathrm{MoS}_{2}{ }^{3}$

O rênio é encontrado na natureza sob a forma de dois isótopos, ${ }^{185} \mathrm{Re}$ e ${ }^{187} \mathrm{Re}$, com abundância natural de 37,07 \% e 62,93 \%, respectivamente. ${ }^{4}$ Embora o principal constituinte nas fontes naturais de rênio seja o ${ }^{187} \mathrm{Re}$, ele é fracamente radioativo e $\beta$-emissor, com meia vida muito longa, de cerca de $5 \times 10^{10}$ anos. $^{5} \mathrm{~A}$ razão entre os isótopos ${ }^{187} \mathrm{Re} /{ }^{187}$ Os é utilizada na Geologia para determinar a idade dos minerais. ${ }^{6}$

Os pesquisadores Carlo Perrier e Emilio Segré, em 1937, descobriram o tecnécio, elemento químico de número atômico 43, por meio do bombardeamento de uma amostra de molibdênio com núcleos de deutérios. Este recém-descoberto elemento pôde ser isolado em quantidades maiores a partir da fissão de compostos de urânio. O nome "technetium", de origem grega, significa elemento artificial e foi dado pelo químico inorgânico austríaco Friedrich Adolf Paneth. A comprovação da existência de diferentes isótopos, e principalmente o metaestável, emissor $100 \%$ de radiação gama, ${ }^{99 \mathrm{~m}} \mathrm{Tc}$, foi feita por Glenn T. Seaborg e Emilio Segré. ${ }^{7}$

Compostos de coordenação de rênio e tecnécio são conhecidos em estados de oxidação que podem variar de $+\mathrm{l}$ a +VII. O estado de oxidação com maior número de complexos é $0+\mathrm{V}$. $^{3}$ Por se tratar do estado de oxidação dos complexos descritos neste trabalho, apenas compostos no estado de oxidação $+\mathrm{V}$ serão discutidos. 


\subsubsection{Complexos de Rênio e Tecnécio no Estado de Oxidação +V}

De longe, o maior número de estruturas caracterizadas de rênio e tecnécio contém esses metais no estado de oxidação $+\mathrm{V}$. Isto pode ser atribuído à alta estabilidade desses centros metálicos, quando ligado com os grupos oxo, nitrido e imido, em uma grande variedade de sistemas ligantes. ${ }^{8}$

$\mathrm{O}$ domínio de ligantes $\mathrm{O}^{2-}, \mathrm{N}^{3-}$ e $\mathrm{NR}^{2-}$ pode ser racionalizado uma vez que são excelentes doadores $\sigma$ e $\pi$ estabilizando, portanto, altos estados de oxidação.

Uma análise computacional da estrutura eletrônica de complexos de rênio com ligantes oxo e nitrido mostrou que as ligações multiplas $\mathrm{ReO}$ e $\mathrm{ReN}$ são fortemente covalentes. ${ }^{9}$

A forte influência trans destes ligantes geralmente fornece complexos pentacoordenados, com geometria pirâmidal de base quadrada, ou compostos hexacoordenados com forte distorção tetragonal.

Nos complexos de tecnécio, a presença de ligantes ocupando a sexta posição de coordenação, trans ao grupo oxo, está relacionada com a natureza dos substituintes situados em posição cis. Em particular, a presença no plano equatorial de "bases moles" bem como de ligantes $\pi$-receptores, como átomos de nitrogênio imínicos, induzem à formação de complexos com geometria pirâmidal quadrática devido à estabilização da carga do centro metálico, enquanto "bases duras", como átomos de oxigênio, levam a obtenção de produtos octaédricos. ${ }^{10}$

As distorções da geometria octaédrica nos complexos de oxorênio (V) e oxotecnécio $(\mathrm{V})$, configuração $d^{2}$, levam à quebra da degenerescência dos orbitais $t_{2 g}$ e $e_{g}$ (Figura 1). As contribuições $\sigma$ e $\pi$ para as ligações $\mathrm{ReO}$ são altamente polarizadas em direção ao átomo de oxigênio. As ligações com ligantes equatoriais possuem caráter principal de doação ligante $\rightarrow$ Re. Estas propriedades de ligação dão origem ao emparelhamento dos dois elétrons em um único orbital $b_{2}$, de mais baixa energia. Os complexos de rênio $(\mathrm{V})$ e tecnécio $(\mathrm{V})$ com ligantes oxo, nitrido e imido são, portanto, diamagnéticos ou dependendo da temperatura, fracamente paramagnéticos. $^{3}$ 
Figura 1 - Variação de energia dos orbitais frente à mudança de geometria do complexo. $L_{a}$ e $L_{e}$ representam, respectivamente, ligantes nos planos axiais $e$ equatoriais.

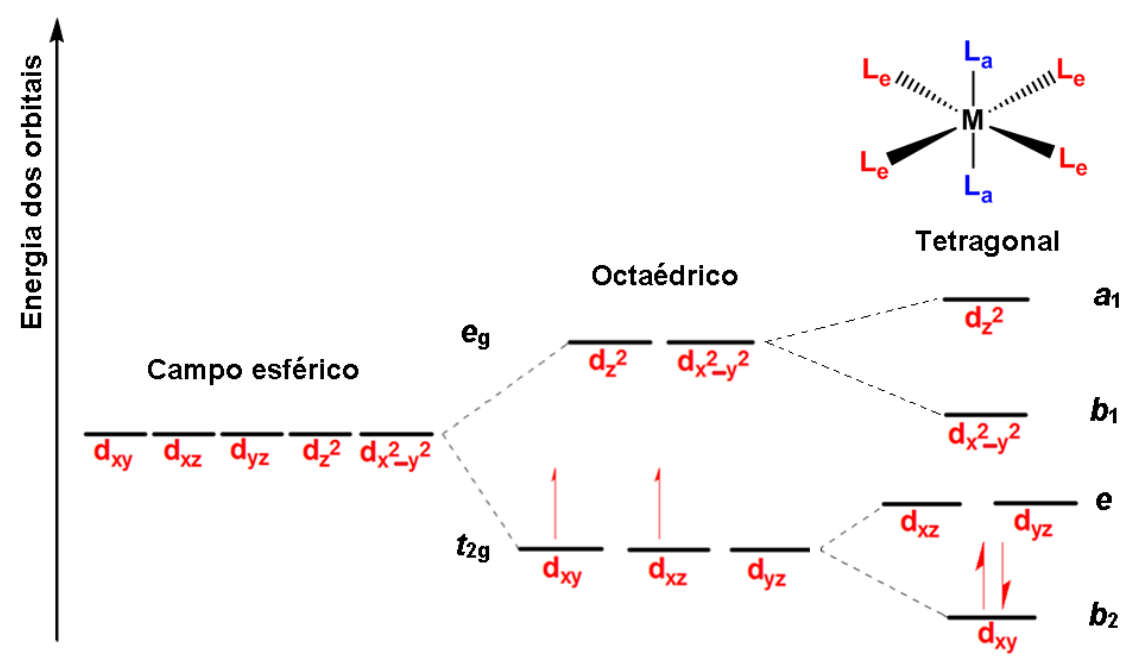

\subsubsection{Compostos de Rênio e Tecnécio e a Medicina Nuclear}

O desenvolvimento de radiofármacos com habilidade para captar receptores específicos, incluindo sistemas de transporte em membranas, tem despertado maior interesse devido ao seu potencial para monitorar funções bioquímicas e fisiológicas in vivo. ${ }^{11}$

Nos últimos anos, a química de coordenação do rênio e do tecnécio tem sido estudada em razão do uso potencial como radiofármacos de seus radionuclídeos. Em virtude de suas propriedades físicas ideais (energia de sua radiação gama, $E \gamma=$ $140 \mathrm{~K}$ e $\mathrm{V}$ e tempo de meia vida, $\left.\mathrm{t}_{1 / 2}=6,02 \mathrm{~h}\right)^{12}$, os radiofármacos contendo o isótopo metaestável do tecnécio ${ }^{99 \mathrm{~m}} \mathrm{Tc}$ são os mais utilizados nos diagnósticos por imagem. Um outro fator importante, que torna prático e conveniente o uso dos compostos deste metal em análises de rotina nas clínicas médicas, está relacionado com a disponibilidade comercial de sistemas geradores deste isótopo a partir do decaimento do ${ }^{99} \mathrm{Mo}$, conforme pode ser visto na figura $2 .{ }^{13}$ 
Figura 2 - Produtos do decaimento do ${ }^{99} \mathrm{Mo}$ : isótopos ${ }^{99 \mathrm{~m}} \mathrm{Tc}$ e ${ }^{99} \mathrm{Tc}$.

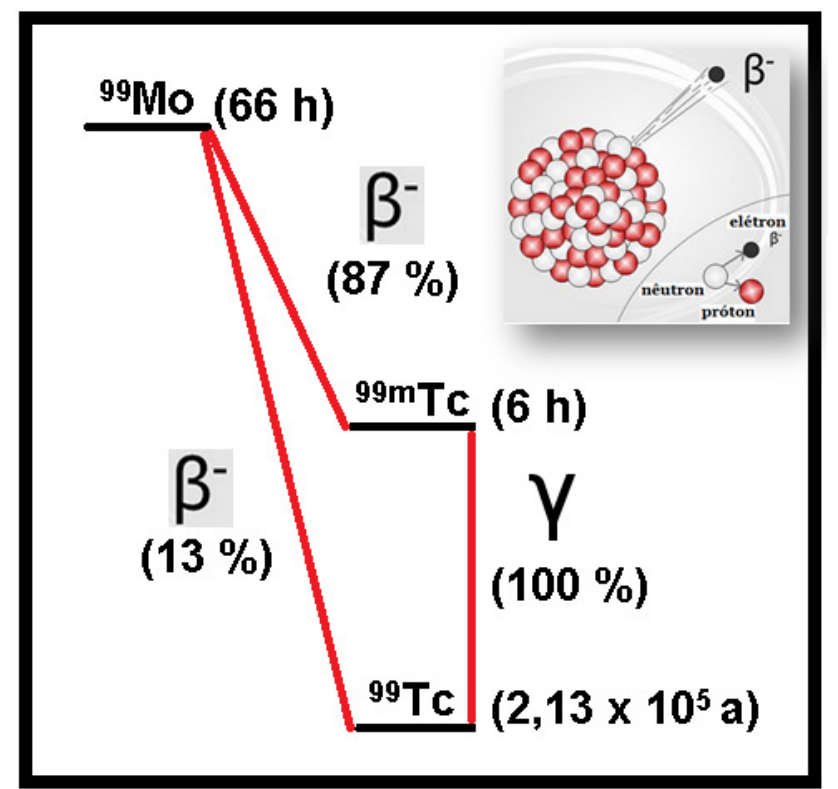

Fonte: MARQUES, F. L. N.; Radiol. Bras., v. 34, p. 233, $2001 .^{14}$

Desde que o ${ }^{99 m} \mathrm{Tc}$ foi reconhecido como radionuclídeo de extrema importância para os diagnósticos por imagem de várias patologias, houve um crescente interesse no desenvolvimento de tecnologias radioquímicas que permitissem a obtenção deste isótopo. Entretanto, o primeiro gerador de ${ }^{99 \mathrm{~m}} \mathrm{Tc}$ só foi desenvolvido em 1950, na Brookhaven National Laboratory (BNL). Inicialmente, as pesquisas destinavam-se à produção de geradores de ${ }^{132} \mid$ quando o ${ }^{99 \mathrm{~m}} \mathrm{Tc}$ foi detectado como uma impureza. Esta evolução tecnológica permitiu, em 1961, pela primeira vez, que o ânion $\left[{ }^{99 \mathrm{~m}} \mathrm{TcO}_{4}\right]^{-}$fosse injetado em humanos. ${ }^{10}$ As semelhanças químicas existentes entre os elementos ${ }^{132} \mathrm{Te} /{ }^{132}$ I permitiram a concepção do par análogo ${ }^{99} \mathrm{Mo} /{ }^{99 \mathrm{~m}} \mathrm{Tc} .{ }^{7}$

$\mathrm{Na}$ figura 3, pode ser visualizado o esquema que descreve um gerador de ${ }^{99 \mathrm{~m}} \mathrm{Tc}$ produzido e disponibilizado comercialmente pelo Instituto de Pesquisas Energéticas e Nucleares, IPEN, sob o gerenciamento da Comissão Nacional de Energia Nuclear, CNEN. 
Figura 3 - Gerador de ${ }^{99 m}$ Tc disponível para uso em clínicas de medicina nuclear.
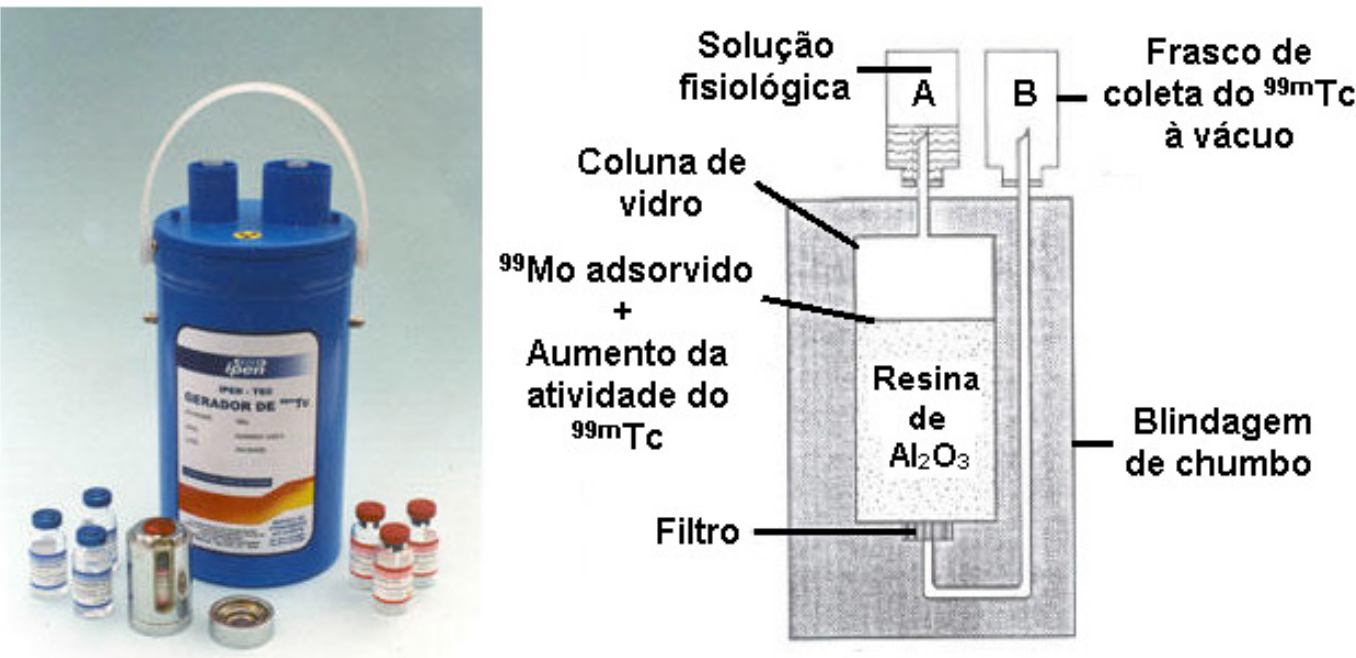

Fonte: <http://www.fcf.usp.br/Ensino/Graduacao/Disciplinas/LinkAula/My-Files/radiofarmacia.htm>. ${ }^{15}$ Acesso em: 02 mar. 2012.

Dois isótopos de rênio, ${ }^{186} \mathrm{Re}$ (energia máxima, $\mathrm{E}_{\max }=1,1 \mathrm{MeV}, \mathrm{t}_{1 / 2}=89,25$ h) e o ${ }^{188} \mathrm{Re}\left(E_{\max }=2,1 \mathrm{MeV}, \mathrm{t}_{1 / 2}=17 \mathrm{~h}\right)$, foram recentemente introduzidos como emissores de radiação $\beta$ no desenvolvimento de pesquisas relacionadas à medicina nuclear, já que possuem energia adequada à terapia de doenças malignas e degenerativas. ${ }^{16,17}$ Especificamente, a disponibilidade de um gerador $d e^{188} \mathrm{~W} /{ }^{188} \mathrm{Re}$ torna $\mathrm{O}$ isótopo ${ }^{188} \mathrm{Re}$ um importante aliado no desenvolvimento de novos radiofármacos para utilização em radioterapia. ${ }^{18}$

Torna-se desafiadora, portanto, a elucidação das estruturas moleculares dos complexos contendo ${ }^{99 m} \mathrm{Tc}$ ou ${ }^{186 / 188} \mathrm{Re}$ cujas sínteses são realizadas partindo-se de soluções com concentrações baixíssimas desses isótopos, em escala nanomolar. Para sanar a problemática de se trabalhar com concentrações tão diluídas, tem-se utilizado a comparação entre as propriedades químicas e físicas dos complexos obtidos somente em escala microscópica com aquelas dos compostos preparados em escala macroscópica (sintetizados a partir do isótopo de tecnécio com meia vida longa, ${ }^{99} \mathrm{Tc}$ ou isótopo não radioativo e estável do rênio, ${ }^{185} \mathrm{Re}$ ). Além disso, rênio e tecnécio pertencem ao mesmo grupo da tabela periódica e, deste modo, apresentam propriedades químicas semelhantes, o que faz dos complexos de ${ }^{185} \mathrm{Re}$ uma alternativa não radioativa e de custo mais baixo no desenvolvimento de futuros radiofármacos. ${ }^{19}$ 
As rotas de síntese dos radiofármacos de rênio são similares às feitas com ${ }^{99 \mathrm{~m}} \mathrm{Tc}$ e podem ser classificadas como as seguintes: (i) síntese de complexos com propriedades biológicas desejadas, que são principalmente controladas pela carga, tamanho e lipofilicidade da molécula; (ii) desenvolvimento de complexos de rênio, similares em formato e polaridade às moléculas orgânicas receptoras; (iii) a marcação direta de peptídeos ou de proteínas, utilizando suas funções doadoras intrínsecas; (iv) a rotulação de moléculas bioativas pela conjugação com um complexo de rênio altamente estável. ${ }^{20}$

Dentre os principais compostos atualmente utilizados em clínicas de medicina nuclear, destacam-se: [ $\left.{ }^{99 \mathrm{~m}} \mathrm{Tc}-\mathrm{MIBI}^{+},{ }^{\left.{ }^{99 \mathrm{~m}} \mathrm{Tc}-\mathrm{MAG}_{3}\right]}{ }^{-},\left[{ }^{99 \mathrm{~m}} \mathrm{Tc}-\mathrm{ECD}\right],{ }^{99 \mathrm{~m}} \mathrm{Tc}-\mathrm{HMPAO}\right]$ e [ ${ }^{99 m}$ Tc-TRODAT]. Suas estruturas podem ser visualizadas na figura 4.

Figura 4 - Radiofármacos em uso nas clínicas de medicina nuclear.
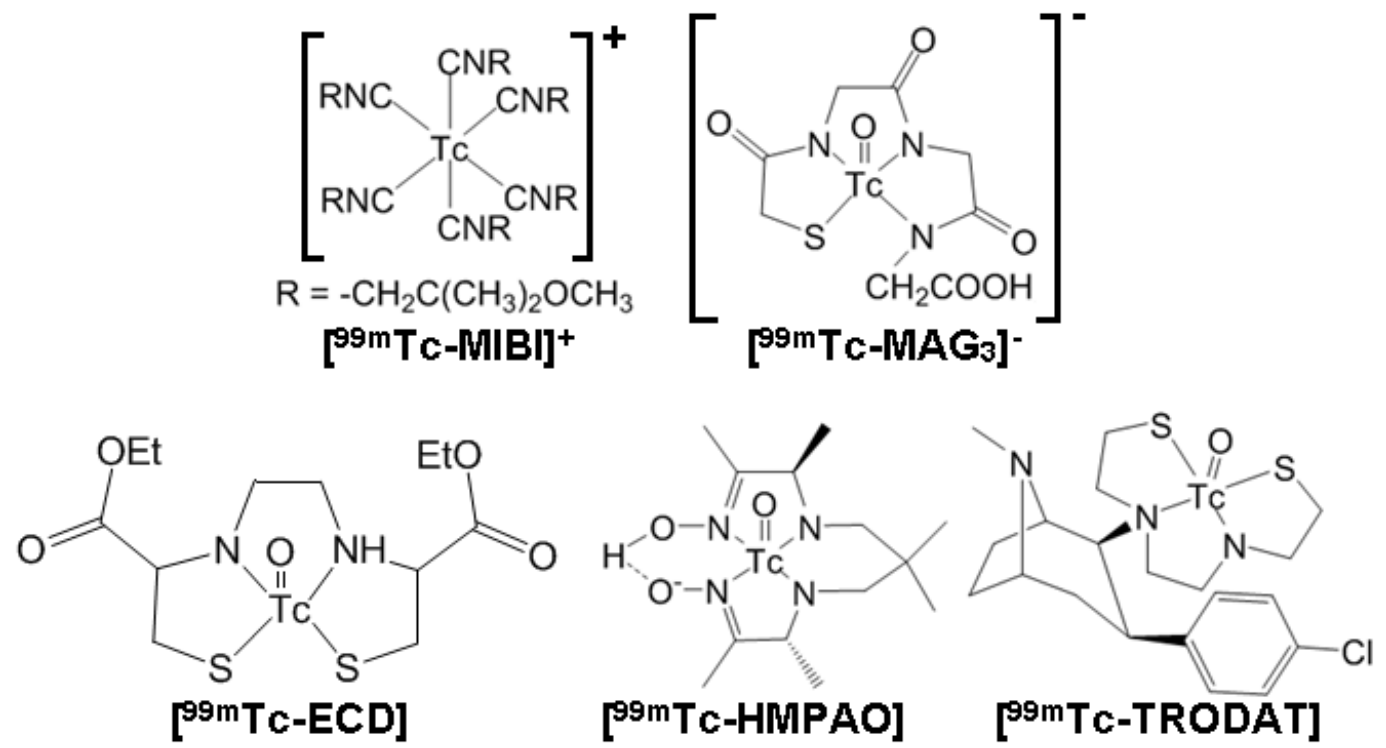

O complexo catiônico de $\left.\mathrm{Tc}(\mathrm{l}),{ }^{99 \mathrm{~m}} \mathrm{Tc}-\mathrm{MIBI}\right]^{+}$, comercializado sob o nome de Cardiolite, foi o primeiro e continua sendo um composto de referência em análises de perfusão no miocárdio. ${ }^{21}$ Tem sido o radiofármaco utilizado no Instituto do Coração do Hospital das Clínicas, em São Paulo (InCor-HC) em cintilografias de perfusão miocárdica há mais de duas décadas, contribuindo de modo expressivo na conduta junto ao paciente potencialmente ou sabidamente portador de doença arterial coronariana. ${ }^{22}$ 
Estudos a respeito do mecanismo de captação deste radiofármaco, nos quais foram utilizadas células do miocárdio e de carcinomas, demonstram que propriedades como lipofilicidade e carga positiva atuam de forma determinante para o acúmulo e retenção do radiotraçador. A carga positiva deste composto favorece a interação eletrostática com potenciais de carga negativas existente nas membranas citosólicase mitocondriais do miocárdio, assim como nas células de carcinoma. Já a passagem do complexo através da bicamada lipídica é favorecida pela lipofilicidade. ${ }^{23}$

O método de estudo renal, no qual isótopos radioativos estão envolvidos, é o único capaz de fornecer subsídios a respeito tanto do funcionamento, quanto da estrutura deste órgão. Assim, o ânion $\left.{ }^{99 \mathrm{~m}} \mathrm{Tc}-\mathrm{MAG}_{3}\right]^{-} \quad\left(\mathrm{MAG}_{3}\right.$, mercaptoacetiltriglicina), introduzido por Fritzberg et al. em 1986, é amplamente administrado por via intravenosa e utilizado no diagnóstico e nas avaliações para transplantes de rins, de doenças nefro-urológicas, como hipertensão renovascular e hidronefrose, bem como em exames de cistografia indireta. ${ }^{24}$

$\mathrm{Na}$ literatura encontram-se descritos diversos trabalhos onde derivados do $\mathrm{MAG}_{3}$ são utilizados como pré-ligantes para o $\left[{ }^{99 \mathrm{~m}} \mathrm{TcO}\right]^{3+}$. Uma nova biodistribuição do radiofármaco dentro do organismo é gerada pela alteração de grupos periféricos do $\mathrm{MAG}_{3}$ por substituintes como carboidratos (Figura 5), proteínas, anticorpos, além de outros, possibilitando o estudo e o diagnóstico de enfermidades, neste caso em particular, do câncer. ${ }^{25}$

Figura 5 - Derivado do $\mathrm{MAG}_{3}$ com D-glicosamina coordenado ao centro de $\left[{ }^{99 \mathrm{~m}} \mathrm{TcO}\right]^{3+}$.

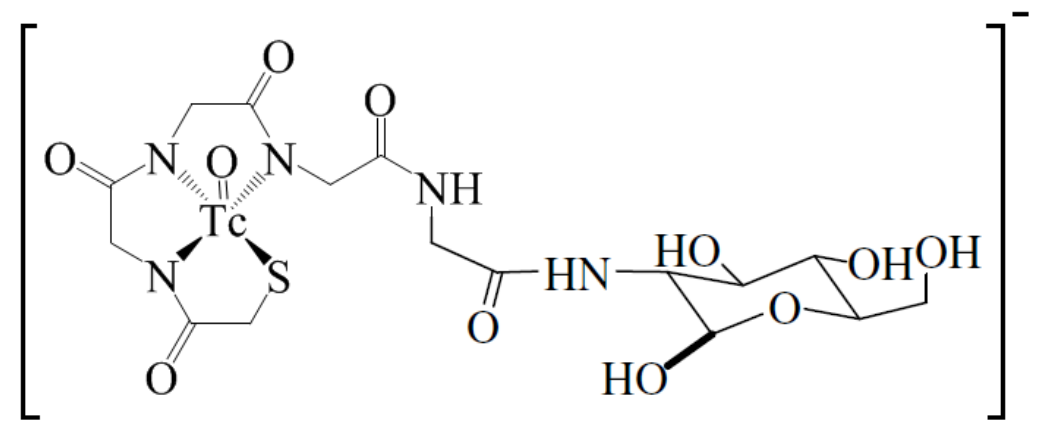

Utilizados com frequência em clínicas de medicina nuclear, o [ $\left.{ }^{99 \mathrm{~m}} \mathrm{Tc}-\mathrm{HMPAO}\right]$ e o [ ${ }^{99 m}$ Tc-ECD] foram os dois primeiros complexos neutros de $\mathrm{Tc}(\mathrm{V})$ conhecidos. $\mathrm{O}$ primeiro possui o agente complexante hexametilpropilenaminaoxima (HMPAO) e o 
segundo o etileno dicisteinadietilester (ECD). Seus ligantes HMPAO e ECD apresentam, respectivamente, modo de coordenação ao centro metálico $N, N, N, N$ - e $S, N, N, S$ - doador (Figura 4). Ambos são capazes de atravessar a barreira hematoencefálica, o que possibilita o uso dos mesmos como agentes para perfusão cerebral. ${ }^{26}$ No Brasil, o [ ${ }^{99 m}$ Tc-ECD] é o mais utilizado, sendo inclusive produzido pelo IPEN, em São Paulo. ${ }^{27}$

Imagens obtidas com o uso de radiofármacos são frequentemente utilizadas para avaliação diagnóstica precisa de diversas patologias cerebrais. A utilização da técnica de SPECT (Single-Photon Emission Computed Tomography), associada ao complexo [ ${ }^{99 m}$ Tc-HMPAO], permite o diagnóstico da doença de Alzheimer a partir da distinção de pequenas alterações do fluxo sanguíneo em regiões específicas do cérebro. ${ }^{28}$ Estudos indicam que as imagens obtidas pela técnica de SPECT são mais eficazes para revelar isquemias cerebrais - reduções localizadas de fluxo sanguíneo neste órgão - do que aquelas produzidas por MRI (Magnetic Resonance Imaging) (Figura 6), conforme é destacado pelas setas amarelas. ${ }^{29}$

Figura 6 - Imagens obtidas por RMI (à esquerda) e SPECT - [ ${ }^{99 m}$ Tc-HMPAO] (à direita). São mostrados cortes dos gânglios basais de um paciente que apresenta infarto na artéria cerebral média direita.

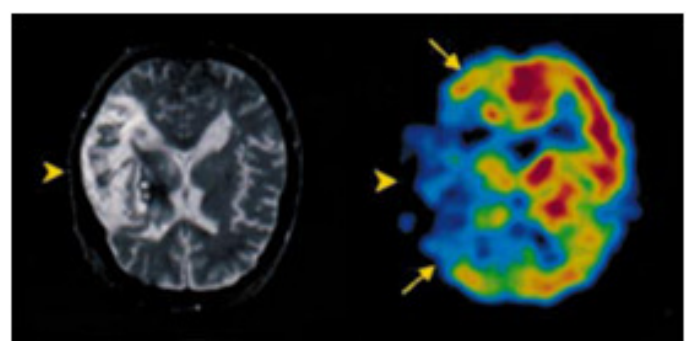

Fonte: CATAFAU, A. M.; The Journal of Nuclear Medicine, v. 42, p. 259-271, 2000. ${ }^{29}$

Outros pesquisadores relatam que o uso da técnica SPECT, associada ao desenvolvimento de ligantes com alta afinidade por sistemas transportadores de dopamina (DAT), poderiam ser uma opção para a detecção da doença de Parkinson, permitindo uma estimativa sobre a perda de células causada pela doença em fase precoce ou mesmo adiantada. Este avanço possibilitou a classificação dos indivíduos com síndromes parkinsonianas clinicamente pouco esclarecidas (CUPS Clinically Unclear Parkinsonian Syndromes) em formas degenerativas e nãodegenerativa de parkinsonismo. ${ }^{30}$ 
Pacientes com CUPS são frequentemente avaliados por neurologistas e especialistas em distúrbios do movimento e representam um desafio para diagnóstico médico. As técnicas de neuroimagem oferecem dados importantes no diagnóstico dessa síndrome, bem como na avaliação dos pacientes com déficit dopaminérgico. $O$ desenvolvimento do [ ${ }^{99 m}$ Tc-TRODAT], complexo de carga neutra de $\mathrm{Tc}(\mathrm{V})$ inspirado na cocaína (Figura 7) e com alta seletividade para sítios dopaminérgicos, tornou-se uma alternativa útil e de custo mais baixo nos estudos envolvendo imagens do cérebro. ${ }^{30}$

Figura 7 - Representação do [ ${ }^{99 m}$ Tc-TRODAT] e da molécula cocaína.

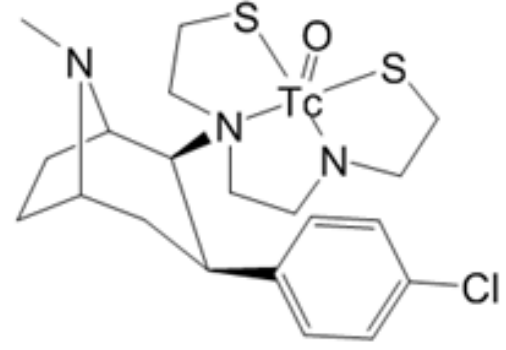

[99mTc-TRODAT]

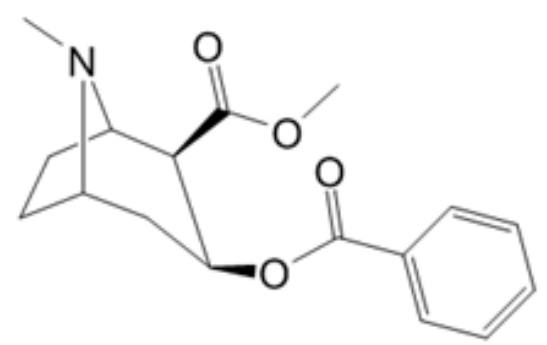

Molécula de Cocaína

A busca por novos e melhores radiofármacos para avaliações de perfusão cerebral tem sido alvo de pesquisas em diversos países. De modo geral, estes agentes formadores de imagens devem possuir certas características para que possam atravessar a barreira hematoencefálica. Eles precisam ser estáveis in vitro e in vivo, possuir carga neutra, ter caráter lipofílico (expresso por meio do coeficiente de partição, Log P) na faixa de 1 até 2,5 e massa molar inferior a $600 \mathrm{~g} / \mathrm{mol}^{31}$

Apesar de ser exemplo bem sucedido, o [ ${ }^{99 m}$ Tc-TRODAT] ainda esbarra em problemas econômicos e burocráticos quanto ao seu uso. Somente em Taiwan as clínicas médicas têm liberação para utilizá-lo. ${ }^{32}$

No Brasil, o primeiro estudo envolvendo [99m Tc-TRODAT] e SPECT foi realizado no Departamento de Imagem do Hospital Israelita Albert Einstein, em São Paulo, em colaboração com o Instituto de Pesquisa em Energia Nuclear de Taiwan e demonstrou a eficiência da técnica diagnóstica associada e ao medicamento na distinção precisa entre pacientes com ou sem a doença de Parkinson. ${ }^{33}$ 
$\mathrm{Na}$ Medicina Nuclear, a eficácia dos compostos de tecnécio como radiofármacos tem sido motivadora para a pesquisa de novos complexos. O aprimoramento destes radiofármacos depende do esforço dos profissionais de diversas áreas do conhecimento, como Química, Física, Biologia e Medicina, para desenvolver novos complexos radioterápicos capazes de transportar, com alta especificidade, doses de radiação aos tumores.

\subsection{Agentes Complexantes Utilizados}

\subsubsection{Ditiocarbazatos}

A classe de ligantes dos ditiocarbazatos (Figura 8) tem sido amplamente estudada nos últimos anos, principalmente em função de suas propriedades biológicas, tais como: antitumorais, bactericidas, fungicidas, inseticidas além da capacidade de se ligar ou clivar o DNA, entre outras. . $^{34,35,36,37}$

De acordo com um estudo publicado pela Organização Mundial da Saúde (OMS), 18 milhões de pessoas estão infectadas pelo protozoário chamado Trypanosoma cruzi ( $T$. cruzi), agente etiológico da doença de Chagas, responsável por 50.000 mortes anualmente. ${ }^{38}$

Estudos envolvendo os agentes complexantes 5-hidroxi-3-metil-5-fenil-pirazol1-(S-benzilditiocarbazato) $\quad\left(\mathbf{H}_{2} \mathbf{b d t c}\right) \quad$ e $\quad 0$ 5-hidroxi-3-metil-5-fenil-pirazol-1-(S-pnitrobenzilditiocarbazato) ( $\mathbf{H}_{2} \mathbf{b d t n}$ ) e seus respectivos complexos de paládio, platina e rênio, revelaram propriedades biológicas ainda não atribuídas a esta classe de ligantes e seus complexos: atuam como agentes tripanocida e antiproliferativo para doença de Chagas. ${ }^{38,39}$ Neste trabalho foram realizados ensaios in vitro contra as formas epimastigota (presentes na fase extracelular) e amastigota (presentes na fase intracelular) do $T$. cruzi. Conforme pode ser verificado na tabela 1 , os complexos de Re contendo o ânion bdtc ${ }^{2-}$ coordenado apresentam maior atividade tripanocida que os compostos de $\mathrm{Pd}$ ou $\mathrm{Pt}$ com este mesmo ligante. As surpreendentes atividades antiproliferativas (contra a forma epimastigota) e tripanocida (contra a forma amastigota) apresentadas pelos ditiocarbazatos e seus complexos levaram ao depósito de um pedido de patente de invenção. ${ }^{39}$ 
grupo metil ligado ao enxofre que não está ligado ao metal. Na maioria dos casos, formando bases de Schiff com substituintes tais como, 2-hidroxi-acetofenona, 2hidroxi-acetaldeído ou derivados do 2-acetonaftaleno. ${ }^{43,44}$

Deste modo, os $\mathrm{S}$-benzil-ditiocarbazatos e seus derivados S-p-nitro- e S-pmetoxo-benzil-ditiocarbazatos, foram priorizados neste trabalho para formação de bases de Schiff com benzoilacetilacetona.

Devido às diversas propriedades biológicas conferidas aos ditiocarbazatos e a capacidade de formar complexos estáveis com diversos metais de transição, a síntese e a caracterização de complexos de oxorênio(V) e oxotecnécio(V) com esta classe de ligantes se justifica, constituindo-se como uma das motivações para o desenvolvimento deste trabalho.

Figura 8 - Representação esquemática de ditiocarbazatos derivados da hidrazina (a) e ditiocarbazatos estruturalmente modificados através de reações com aldeídos ou cetonas (bases de Schiff) (b).

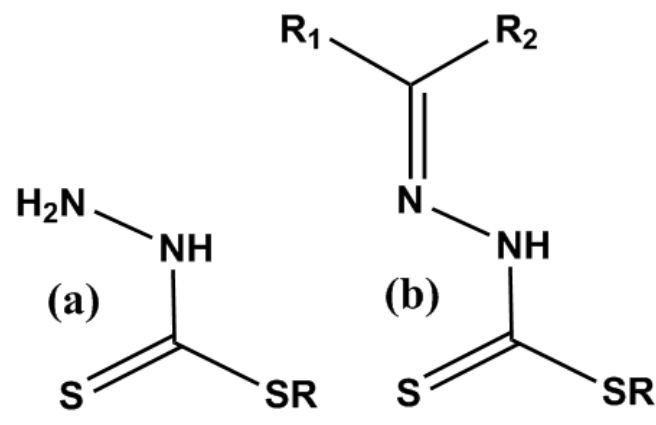

$R, R_{1}$ e $R_{2}=H$, alquil ou aril

\subsubsection{Pironas e Piridinonas}

Duas classes de ligantes O,O-bidentados têm sido estudadas extensivamente, segundo a literatura: as pironas, na qual o maltol, 2-metil-3-hidroxi4-pirona (Hmal), está incluído, e as piridinonas. Piridinonas como a 1,2-dimetil-3hidroxi-4-piridinona (Hdmhp) podem ser facilmente sintetizadas a partir do maltol, conforme pode ser observado na figura $9 .{ }^{45}$ 
Figura 9 - Esquema para obtenção da piridinona Hdmhp a partir do maltol.

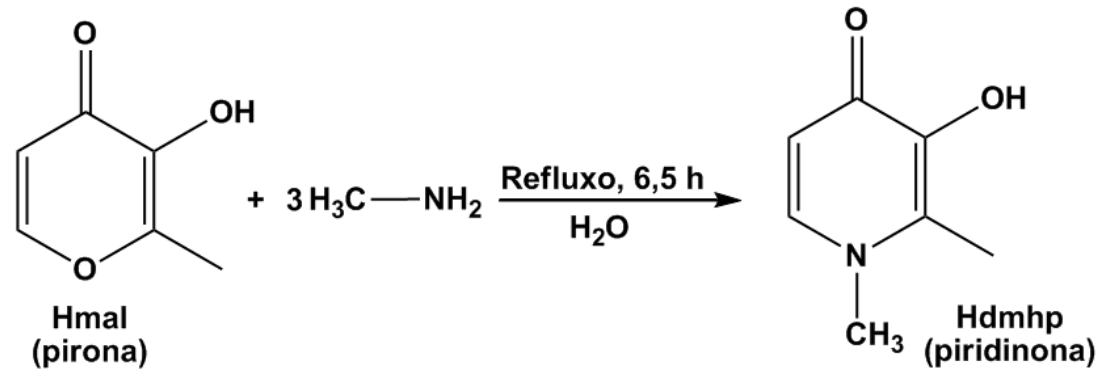

Por mais de duas décadas as hidroxi-piridinonas e hidroxi-pironas tem sido descritas como ligantes bidentados heterocíclicos adequados para coordenação com íons metálicos "duros", tais como $\mathrm{Fe}^{3+}$. Níveis elevados de íons férricos não coordenados estão associados a diversas doenças como $\beta$-talassemia maior, cânceres, Parkinson, Alzheimer entre outras. ${ }^{46}$ Um grande desenvolvimento no estudo de agentes quelantes para íons de ferro ocorreu a partir da divulgação, em 1982, do Hdmhp, que é o princípio ativo do medicamento conhecido como Ferriprox $^{\circledR}$, que está em uso clínico, desde 1999 , no combate $\beta$-talassemia maior. ${ }^{46}$

Outras pesquisas comprovam que o Hdmhp também é capaz de inibir a replicação de diversos vírus, entre eles o da imunodeficiência humana tipo 1 (HIV-1) e o da herpes (HSV-1 e 2). ${ }^{47,48}$ Sua atividade antirretroviral contra o HIV-1 apresenta um valor de concentração capaz de inibir $50 \%$ da replicação viral, $I_{50}$, na faixa entre 50 a $100 \mu \mathrm{M}^{49}$

Diversas piridinonas são adequadas para impedir o crescimento de vários fungos e bactérias tais como, Escherichia coli, Listeria inocua, Staphylococcus aureus, Pseudomonas aeruginosa, Candida albicans e Mycobacterium avium. ${ }^{50,51} \mathrm{~A}$ troca dos grupos ligados ao nitrogênio por alquilaminas ou alquilamidas, em ligantes similares ao Hdmhp, propiciaram o desenvolvimento de agentes antimicrobianos eficazes no tratamento de vários casos de infecções. Um bom exemplo é o derivado que possui um grupo etila ligado ao nitrogênio, que apresenta pecertuais de inibicão de crescimento de 100 e $89 \%$, no que se refere às bactérias E. Coli e L. Inocua. Mesmo em concentrações bastante diluídas, 5 e $25 \mathrm{mmol} / \mathrm{L}$, este composto é capaz de inibir, respectivamente, o crescimento das bactérias E. Coli e L. Inocua. ${ }^{52}$

Combinações com propriedades biologicamente significantes (solubilidade em água, estabilidade hidrolítica e lipofilicidade) foram verificadas no complexo 
tris(maltolato)alumínio(III), no estudo da neurotoxicidade do alumínio; para o complexo tris(1-(p-metoxifenil)-2-metil-3-oxi-4-piridinonato)galio(III), nos estudos de imagens do coração e no complexo tris(maltolato)galio(III), como agente oralmente ativo no combate a vários tipos de cânceres. ${ }^{53,54}$

Radioisótopos de ${ }^{67} \mathrm{Ga}$ são utilizados no diagnóstico de algumas doenças ósseas. Sua biodistribuição e, consequentemente, seu órgão de atuação está diretamente relacionada ao ligante-carreador desse centro emissor de radiação.

Um agente de formação de imagens deve apresentar uma alta concentração nos sítios de atividade osteogênica. Estas são propriedades esperadas para um bom detector de metástase óssea por exemplo. Estudos têm mostrado um aumento da captação de emissores de radiação por meio da complexação de Ga com ligantes da classe das piridinonas. ${ }^{55}$

Pironas e piridinonas, em geral, são agentes complexantes que exibem baixa toxicidade, além outras propriedades biológicas desejáveis, revelando a importância do seu uso no desenvolvimento de complexos com propósito medicinal.

\subsubsection{Dialquilamino(tiocarbonil)benzamidinas}

O ligante N-(N",N"'-dietilaminotiocarbonil)-N'-(2-hidroxifenil)benzoamidina $\left(\mathbf{H}_{2} \mathbf{d e b a}\right)$ se enquadra em uma nova classe de ligantes tridentados, ainda muito pouco explorada na literatura, as dialquilamino(tiocarbonil)benzamidinas (Figura 10). ${ }^{56} \mathrm{Em}$ função das propriedades conhecidas e atribuídas às piridinonas, foi de grande interesse unir essas duas classes de ligantes para a formação de novos complexos mistos visando a aplicação dos complexos seja na área da medicina nuclear ou da alopatia. 
Figura 10 - Representação esquemática do ligante $\mathbf{H}_{2}$ deba.

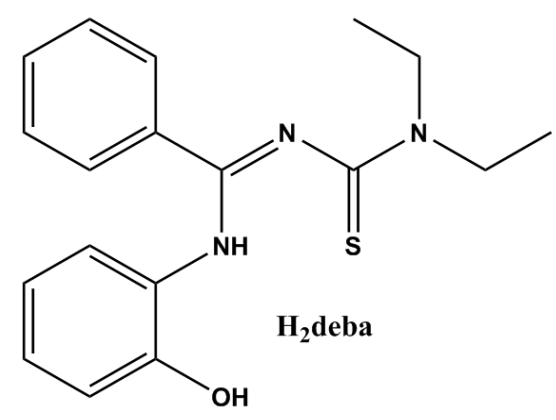

O desenvolvimento de potenciais candidatos a radiofármacos de rênio contendo esta classe de ligantes é interessante, no sentido em que o grupo etil na função dietilaminotiocarbonil do ligante, pode ser substituído, mantendo intacta a esfera de coordenação dos complexos, possibilitando que se façam, em princípio, ajustes finos de propriedades específicas e importantes, como, por exemplo, lipofilicidade e hidrofilicidade. 


\section{Objetivos}

Os objetivos deste trabalho consistem em:

- Sintetizar ligantes de relevância biológica, da classe dos ditiocarbazatos e piridinonas;

- Obter complexos com ligantes mistos que possibilitem à troca de grupos periféricos viabilizando uma melhor adequação a aplicação biológica desejada;

- Preparar compostos mistos que sejam potencialmente menos imunogênico ao organismo devido à coordenação de derivados de aminoácidos;

- Utilizar os ligantes sintetizados em reações de preparação de quelatocomplexos de oxorênio, partindo de precursores preparados no laboratório;

- $\quad$ Caracterizar os complexos preparados pelos métodos: espectroscopia vibracional na região do infravermelho, $R M N{ }^{1} \mathrm{H}$ e ${ }^{31} \mathrm{P}$, microanálises $(\mathrm{C}, \mathrm{H}, \mathrm{N}$ e S) e espectrometria de massa (MS-ESI);

- Quando possível, obter monocristais dos complexos formados e realizar determinação da estrutura cristalina e molecular pelo método de difração de raios $\mathrm{X}$;

- $\quad$ Submeter os compostos sintetizados e completamente caracterizados a ensaios biológicos contra diversas doenças;

- Utilizar os complexos de rênio obtidos como modelos para obtenção de complexos análogos de tecnécio, visando o desenvolvimento de radiofármacos, através de estudos futuros. 


\section{Parte Experimental}

\subsection{Solventes}

Os solventes utilizados, diclorometano, clorofórmio, metanol e $n$-hexano, foram adquiridos da Synth, Merck, Vetec e Reagen, e usados nos trabalhos de síntese, sem purificação prévia.

O preparo das soluções para análises por RMN envolveu, em alguns casos, o borbulhamento dos solventes utilizados durante cinco minutos, com argônio (99,9998 \% de pureza) para expurgar o oxigênio que porventura pudesse estar dissolvido e causar a oxidação da trifenilfosfina gerando produtos de oxidação indesejados.

\subsection{Precursores de rênio (V)}

O precursor $\left[\mathrm{ReOCl}_{3}\left(\mathrm{PPh}_{3}\right)_{2}\right]$ foi obtido de acordo com a síntese desenvolvida por N. P. Johnson e colaboradores, conforme o esquema abaixo: ${ }^{57}$

$$
\begin{gathered}
2 \mathrm{Re}(\mathrm{s})+5 \mathrm{H}_{2} \mathrm{O}_{2}(\mathrm{I}) \rightarrow 2 \mathrm{HReO}_{4}(\mathrm{aq})+2 \mathrm{H}_{2}(\mathrm{~g})+2 \mathrm{H}_{2} \mathrm{O}(\mathrm{I}) \\
\mathrm{HReO}_{4}+3 \mathrm{HCl}+3 \mathrm{PPh}_{3} \rightarrow\left[\mathrm{ReOCl}_{3}\left(\mathrm{PPh}_{3}\right)_{2}\right]+\mathrm{OPPh}_{3}+2 \mathrm{H}_{2} \mathrm{O}
\end{gathered}
$$

O espectro no infravermelho do $\left[\mathrm{ReOCl}_{3}\left(\mathrm{PPh}_{3}\right)_{2}\right]$ apresenta a banda $v(\mathrm{Re}=\mathrm{O})$ em $969 \mathrm{~cm}^{-1}$. O composto funde entre 211 e $214 \stackrel{\circ}{\circ} \mathrm{C}$.

A síntese consistiu, inicialmente, na reação de rênio metálico com excesso de peróxido de hidrogênio 30 \%. A solução formada de ácido perrênico, $\mathrm{HReO}_{4}$, foi então neutralizada com $\mathrm{KOH}$, com a precipitação do perrenato de potássio, $\mathrm{K}[\mathrm{ReO} 4]$. A mistura formada foi submetida à agitação prévia durante vinte minutos e, posteriormente, foi filtrada sob pressão reduzida para coleta do sólido, que foi seco sob corrente de ar.

O sal $\mathrm{K}\left[\mathrm{ReO}_{4}\right]$ foi adicionado a uma solução de $\mathrm{HCl}$ (37 \%), em excesso, sob agitação. Em seguida, essa mistura foi adicionada a uma suspensão de trifenilfosfina $\left(\mathrm{PPh}_{3}\right)$, em excesso (cinco equivalentes), em ácido acético glacial, previamente preparada. A suspensão final foi mantida sob agitação por 30 minutos. Após esse 
período, esta foi filtrada sob pressão reduzida e o sólido coletado foi lavado com ácido acético e éter etílico e, posteriormente, seco sob corrente de ar.

O precursor $\left(\mathrm{NBu}_{4}\right)\left[\mathrm{ReOCl}_{4}\right]$ foi preparado conforme a síntese desenvolvida por Alberto R. e colaboradores. ${ }^{58}$ Sua síntese consistiu em adicionar, sob agitação por 1 hora, uma solução de iodeto de tetrabutilamônio, $\mathrm{NBu}_{4} \mathrm{l}$, em metanol, à uma solução do perrenato de potássio, $\mathrm{K}\left[\mathrm{ReO}_{4}\right]$, dissolvido no mesmo solvente, para formar o perrenato de tetrabutilamônio $\left(\mathrm{NBu}_{4}\right)\left[\mathrm{ReO}_{4}\right]$, na forma de um precipitado branco, formado após a redução de 50 \% do volume da solução inicial, que foi então filtrado e seco à pressão reduzida. Posteriormente, o $\left(\mathrm{NBu}_{4}\right)\left[\mathrm{ReO}_{4}\right]$ foi dissolvido em metanol, em um balão volumétrico de duas bocas.

$\mathrm{Na}$ etapa seguinte, referente à reação de cloração (Cuidado! Trabalhou-se na capela a fim de evitar o contato com gás HCl!), foi adicionado ácido clorídrico concentrado, gota a gota, através de um funil de adição, sobre o dobro da quantidade de matéria de ácido sulfúrico concentrado, disposto em um balão de duas bocas, a fim de promover a liberação de $\mathrm{HCl}$ gasoso, que foi então borbulhado sobre a solução metanólica de $\left(\mathrm{NBu}_{4}\right)\left[\mathrm{ReO}_{4}\right]$. Deve-se tomar o cuidado de colocar um dispositivo de segurança (frasco de lavagem vazio, por exemplo) entre o balão contendo ácido sulfúrico concentrado e o balão contendo a solução de $\left(\mathrm{NBu}_{4}\right)\left[\mathrm{ReO}_{4}\right]$, com o intuito de prevenir acidentes, no caso de haver inversão de pressão entre ambos, durante a adição.

Após poucos segundos de borbulhamento, já se percebeu a mudança de coloração, de incolor para amarelo e, logo em seguida, para alaranjado intenso, indicando a formação de $\left(\mathrm{NBu}_{4}\right)\left[\mathrm{ReOCl}_{4}\right]$. Ao término do borbulhamento e da total saturação do metanol com $\mathrm{HCl}$, a solução alaranjada foi agitada por mais duas horas. Após o término da agitação, o volume foi reduzido à metade em fluxo de gás inerte, (argônio).

Após a redução de volume, a solução foi mantida resfriada à $-10{ }^{\circ} \mathrm{C}$ para cristalização do produto. Os cristais foram então coletados por filtração e mantidos em atmosfera livre de umidade, uma vez que o composto é sensível à hidrólise ao ar.

O complexo $\left(\mathrm{NBu}_{4}\right)\left[\mathrm{ReOCl}_{4}\right]$ foi obtido com $70 \%$ de rendimento e seu espectro de IV apresenta estiramentos em 2962 e $2875 \mathrm{~cm}^{-1}$ referentes à banda $v\left(\mathrm{CH}, \mathrm{NBu}_{4}\right)$ e em $1002 \mathrm{~cm}^{-1}$, referente à banda $v(\mathrm{Re}=\mathrm{O})$. 


\subsection{Instrumentação e Técnicas Experimentais}

\subsubsection{Microanálises (C, $\mathrm{H}, \mathrm{N}$ e S)}

As determinações dos teores de carbono, hidrogênio, nitrogênio e enxofre dos compostos sintetizados foram feitas na Central Analítica do Instituto de Química de São Carlos, Universidade de São Paulo, ou no Instituto de Química e Bioquímica da Freie Universität Berlin, ambos utilizando o mesmo tipo de equipamento: CHNS modelo EA 1108 da FISONS.

\subsubsection{Espectrometria de Massas (MS - ESI)}

Os espectros de massa dos complexos sintetizados foram obtidos utilizando 0 método de ionização eletrospray (MS-ESI), em um espectrômetro Agilent 6210 ESITOF. Todos os resultados são mostrados na forma de $\mathrm{m} / \mathrm{z}$.

\subsubsection{Espectroscopia de Absorção na Região do Infravermelho (IV)}

Foram utilizados dois espectrofotômetros para obtenção dos espectros de absorção na região do infravermelho mostrados neste trabalho, entre eles:

$\checkmark$ FTIR Shimadzu na região de 4000 a $400 \mathrm{~cm}^{-1}$, alocado no próprio grupo de pesquisa;

$\checkmark$ BOMEM MICHELSON FT BM 102, na região compreendida entre 4000 e 400 $\mathrm{cm}^{-1}$, na Freie Universität Berlin.

Para todas as análises foi utilizada a técnica de pastilhas com amostras em $\mathrm{KBr}$, na proporção 1:150 mg (amostra / KBr). 


\subsubsection{Ressonância Magnética Nuclear (RMN)}

Os espectros de RMN dos complexos 1 e 10 foram obtidos em um espectrômetro Varian Mercury plus 300 (campo de 7,05 T e freqüências de: 300 $\mathrm{MHz}$ para ${ }^{1} \mathrm{H}$ e $121,45 \mathrm{MHz}$ para ${ }^{31} \mathrm{P}$ ), no Instituto de Química da Universidade de Brasília - UnB.

Em Berlim, os espectros de $\mathrm{RMN}{ }^{1} \mathrm{H}$ e ${ }^{31} \mathrm{P}$ foram obtidos em um espectrômetro multinuclear JEOL, operando respectivamente em frequências de 399,95 e 161,70 MHz, para ${ }^{1} \mathrm{H}$ e ${ }^{31} \mathrm{P}$, respectivamente.

Espectros foram obtidos adicionalmente no equipamento Bruker, modelo Avance III, frequência de 399,95 MHz para ${ }^{1} \mathrm{H}$ e campo de 9,4 T, do Departamento de Química da Universidade Federal de São Carlos (UFSCar).

A utilização desta técnica foi fundamental para comprovar, em solução, a estrutura dos novos complexos e dos pré-ligantes sintetizados.

Os espectros de $\mathrm{RMN}{ }^{1} \mathrm{H}$ foram referenciados internamente ao tretrametilsilano, TMS, $\operatorname{com} \delta=0$. Para a obtenção dos espectros de ${ }^{31} \mathrm{P}$, foi utilizado ácido fosfórico, $\mathrm{H}_{3} \mathrm{PO}_{4} 85 \%$ e $\delta=0$, como referência externa. Foram utilizados diclorometano $\left(\mathrm{CD}_{2} \mathrm{Cl}_{2}\right)$ ou clorofórmio $\left(\mathrm{CDCl}_{3}\right)$ como solventes deuterados, para o preparo das amostras.

Nos espectros de RMN ${ }^{1} \mathrm{H}$ dos ditiocarbazatos livres e de alguns complexos foram observados efeitos de segunda ordem, de forma que, o deslocamento químico de cada hidrogênio deixa de ser o ponto médio entre os dois picos, constituindo no "centro de gravidade" dos mesmos. Nestes casos, valores confiáveis de deslocamento químico podem ser obtidos utilizando-se as equações descritas da figura 11. 
Figura 11 - Equações para cálculo dos deslocamentos químicos de ${ }^{1} \mathrm{H}$ cujo sinal apresente efeito de segunda ordem. Neste exemplo é mostrada a parte do espectro do $\mathbf{H}_{2}$ bdtc que corresponde a um de seus grupos metilenos.

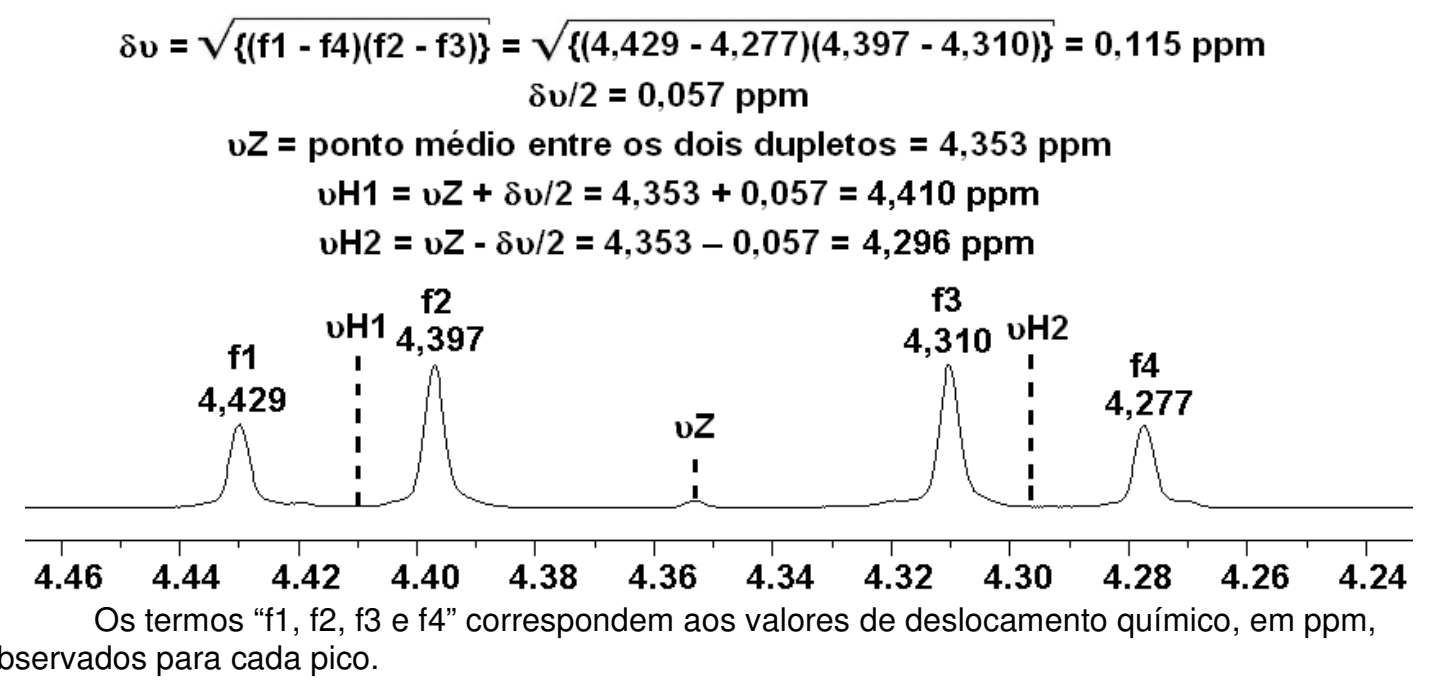

\subsubsection{Difração de raios $X$ em monocristal}

As medições dos monocristais foram feitas em três difratômetros diferentes:

$\checkmark$ BRUKER KAPPA APEX II, nas medidas efetuadas no Departamento de Química da Universidade Federal de Santa Maria (UFSM);

$\checkmark$ BRUKER SMART APEX II, para as medidas efetuadas no Instituto de Química da Universidade de Brasília (UnB);

$\checkmark$ STOE IPDS 2T, nas coletas dos dados feitas no Instituto de Química e Bioquímica da Freie Universität Berlin. Em todos os casos foi utilizada a radiação $\mathrm{K}_{\alpha}$ do molibdênio $(71,073$ pm) e monocromador de grafite.

\subsubsection{Espectrometria de Cintilação Líquida}

Emissores fracos de radiação $\beta$, como $0{ }^{99} \mathrm{Tc}$, podem ser detectados $\mathrm{e}$ quantificados através de um espectrômetro de cintilação líquida, sendo esta a técnica mais adequada para este fim. Os princípios desta técnica são baseados na interação da radiação nuclear, com uma substância em solução, o cintilador. O composto a ser analisado deve ser inicialmente solubilizado em uma solução cintilante chamada normalmente de "coquetel de cintilação". O coquetel é constituído de um solvente, um cintilador primário e um cintilador secundário. 
Cintiladores primários são corantes fluorescentes como, por exemplo, 2,5difeniloxazol (PPO) e 1,4-bis(5-fenil-oxazol-2-il)-benzeno (POPOP), (Figura 12). Devido à sua estrutura aromática, estes corantes têm a capacidade de absorver a radiação e emití-la em um determinado comprimento de onda. Cintiladores primários são adicionados ao solvente para formar soluções com concentrações entre $10^{-2} \mathrm{a}$ $10^{-3} \mathrm{~mol}^{-\mathrm{L}^{-1}}$.

Figura 12 - Cintiladores 2,5-difeniloxazol (PPO) e 1,4-bis(5-fenil-oxazol-2-il)-benzeno (POPOP).

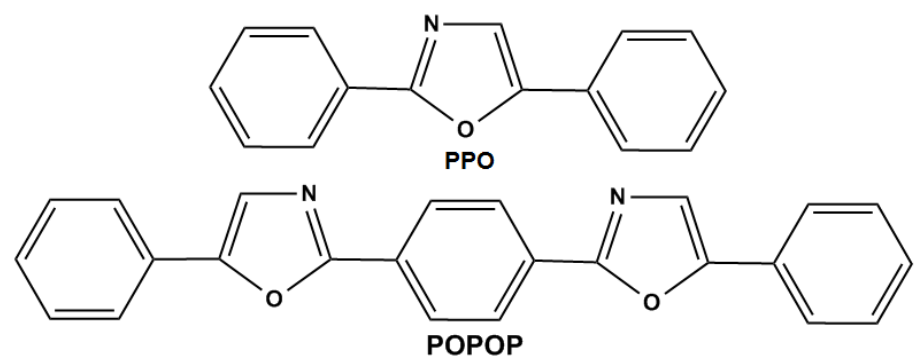

Fonte: ABRAM, U.; Radiochemistry practical course for chemists, Freie Universität Berlin, Institute of Chemistry and Biochemistry, p. 49, 2009. ${ }^{59}$

Os cintiladores secundários atuam no sentido de alterar o comprimento de onda da luz emitida por cintiladores primários (entre $340 \mathrm{~nm}$ e $480 \mathrm{~nm}$ ) para comprimentos de onda ligeiramente mais longos (entre $400 \mathrm{~nm}$ e $500 \mathrm{~nm}$ ) para que coincida com a faixa de maior sensibilidade do fotocátodo do equipamento (Figura 13). Um exemplo é o 1,4-bis(5-fenil-oxazol-2-il)-benzeno (POPOP, emissão entre 400 e $550 \mathrm{~nm})^{59}$

Figura 13 - Interação de partículas $\beta$ com o solvente e subsequente emissão de radiação fluorescente. Círculos vazios representam moléculas de solvente no estado de mais baixa energia. Círculos preenchidos indicam moléculas de solvente no estado excitado.

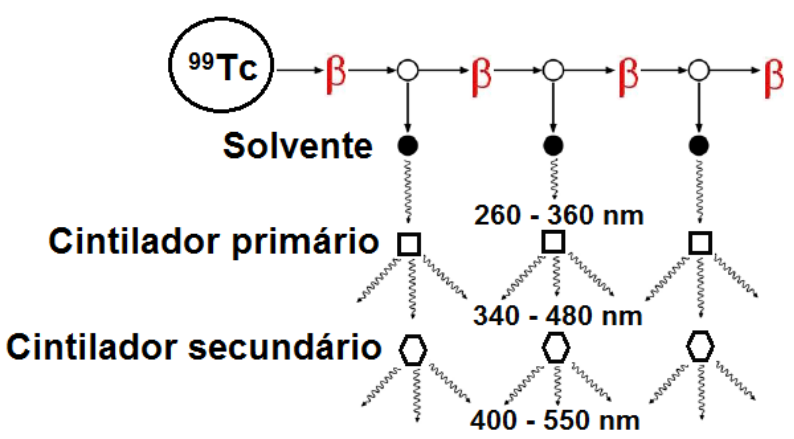

Fonte: ABRAM, U.; Radiochemistry practical course for chemists, Freie Universität Berlin, Institute of Chemistry and Biochemistry, p. 49, 2009. ${ }^{59}$ 
Os mecanismos de absorção de energia e emissão de luz em um sistema de cintilação líquida são extremamente complexos. A descrição a seguir é uma simplificação e resume as etapas da interação entre uma partícula carregada e o solvente do coquetel de cintilação e a subsequente emissão de radiação fluorescente que ocorre no processo:

1. Colisão de uma $\beta$-partícula com uma molécula de solvente;

2. Transferência de energia entre as moléculas de solvente, fosforescência;

3. Absorção de radiação fosforescente pelo cintilador primário;

4. Absorção da radiação fluorescente pelo cintilador secundário.

A quantidade de luz emitida pelo cintilador é extremamente pequena. Por esta razão, detectores altamente sensíveis são necessários para o registo da luz emitida. O dispositivo de deteç̧ão é um tubo fotomultiplicador (Figura 14), que converte o sinal de energia luminosa em um sinal mais facilmente mensurável. A parte superior do tubo (fotocátodo) é revestida com um material sensível à luz. Quando sua superfície é atingida por um pulso fluorescente proveniente do cintilador, vários elétrons são lançados e acelerados com a ajuda de um campo elétrico de aproximadamente 1000 a $2000 \mathrm{~V}$ na direção do primeiro dinodo positivo (cada um dos vários eletrodos de um fotomultiplicador). Dispositivos internos garantem que todos os elétrons liberados alcançem este dinodo. Cada elétron recebido pelo dinodo faz com que de 3 a 5 outros elétrons (secundários), localizados neste dinodo, sejam liberados. Este processo é repetido quando esses elétrons recém lançados encontram o dinodo seguinte. Um efeito cascata de cerca de 10 a 14 vezes, ocorre para cada elétron que colide com o primeiro dinodo e cerca de $10^{6}$ elétrons atingem o décimo segundo dinodo. ${ }^{59}$ 
Figura 14 - Esquema de funcionamento de um tubo fotomultiplicador.

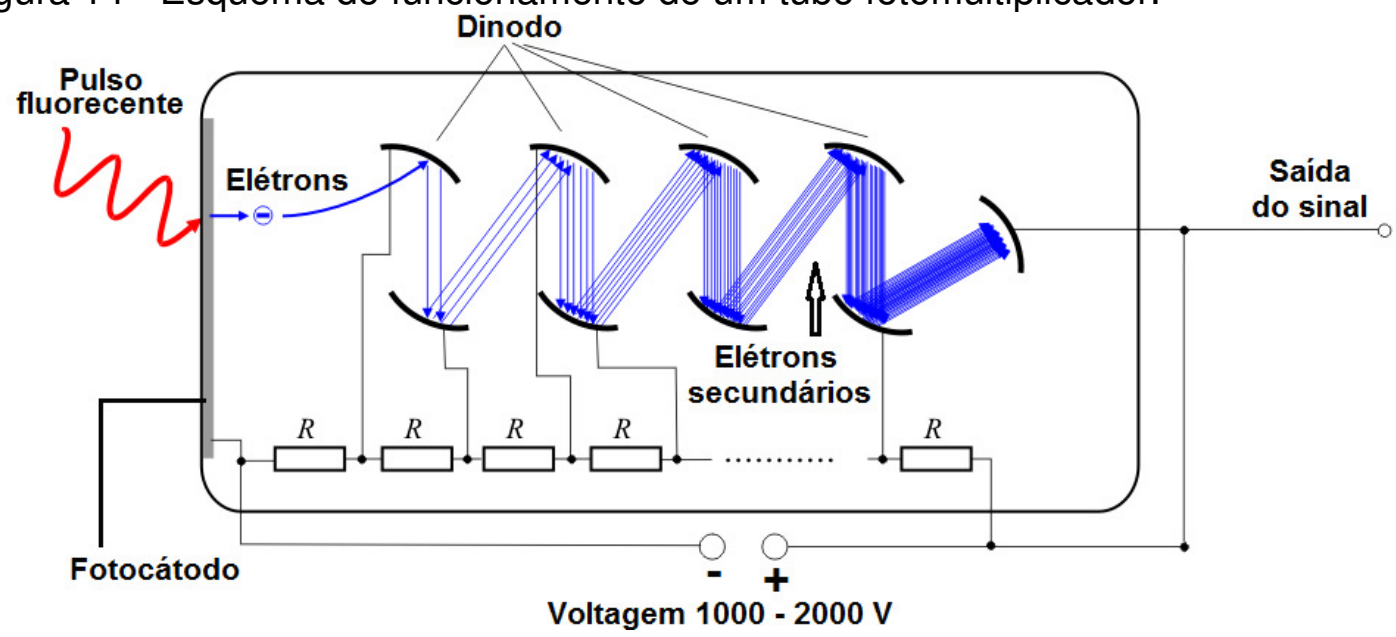

Fonte: sítio de internet <http://sv.wikipedia.org/wiki/Fil:Photomultiplier_schema_de.png>. Acesso em: 02 mar. 2012. ${ }^{60}$

Um impulso elétrico é gerado e analisado por um discriminador, que pode ser ajustado para medir impulsos de um determinado tamanho. Este ajuste de tamanho dos impulsos permite a formação dos limites superiores e inferiores, que originam a janela de detecção do dispositivo. O discriminador transmite apenas sinais que possuem níveis de impulsos específicos (aqueles conhecidos por serem proporcionais à energia de partículas $\beta$ ), que passaram pelos parâmetros prédefinidos pela janela de detecção. O discriminador é subdividido em 1000 canais e conectado a um contador de impulsos elétricos e a altura do impulso é diretamente ou logaritmicamente proporcional ao número de fótons absorvidos, o que permite analisar o percentual de tecnécio contido na amostra. ${ }^{59}$

A utilização desta técnica foi essencial para determinar o percentual de tecnécio no complexo 8 , uma vez que a análise elementar fica inviabilizada, devido ao caráter radioativo do composto.

A análise foi feita no Instituto de Química e Bioquímica da Freie Universität Berlin, utilizando equipamento da marca BECKMAN, modelo LS6500.

Precauções contra radiação. As manipulações de isótopos radioativos foram feitas em um laboratório de acordo com normas internacionais de proteção e manipulação de materiais radioativos e somente após aprovação (avaliação escrita, oral e prática) em curso de capacitação para este tipo de trabalho. 


\subsection{Sínteses}

\subsubsection{Síntese do Complexo $\left[\mathrm{ReOCl}_{2}(\mathrm{dmhp})\left(\mathrm{PPh}_{3}\right)\right](1)$}

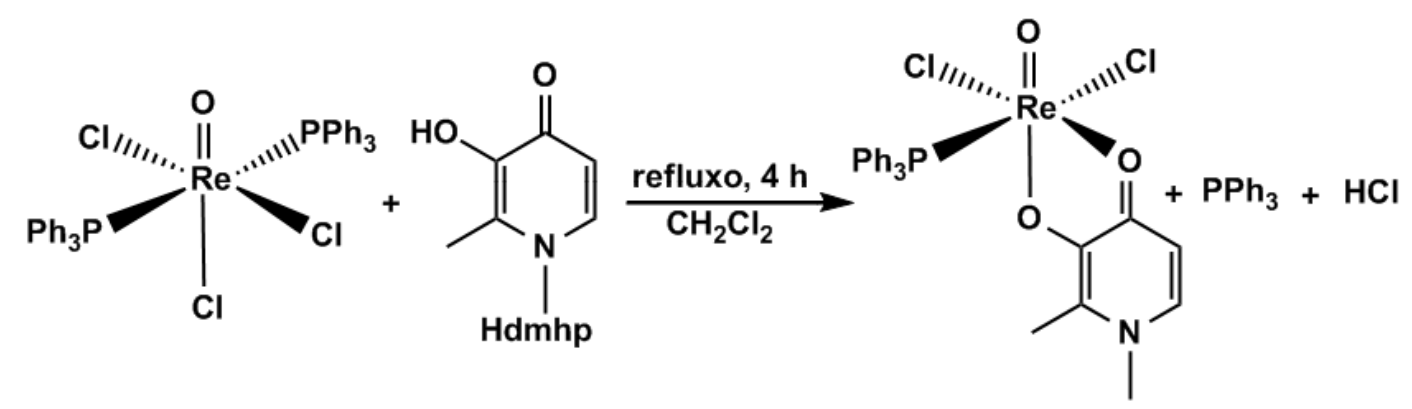

Esquema de Preparação do Complexo 1.

Foram adicionados $166,6 \mathrm{mg}(0,20 \mathrm{mmol})$ do precursor $\left[\mathrm{ReOCl}_{3}\left(\mathrm{PPh}_{3}\right)_{2}\right]$ à 20 $\mathrm{mL}$ de diclorometano. Em seguida, adicionou-se à suspensão $27,8 \mathrm{mg}(0,20 \mathrm{mmol})$ de Hdmhp. A mistura reacional foi submetida a refluxo por $4 \mathrm{~h}$, a $45^{\circ} \mathrm{C}$.

Foram obtidos cristais verdes adequados para difração de raios $\mathrm{X}$ pela adição de $20 \mathrm{~mL}$ de clorofórmio ao volume de diclorometano inicial, com posterior evaporação lenta da solução, que apresentam a composição $\left[R e O C_{2}(\mathrm{dmhp})\left(\mathrm{PPh}_{3}\right)\right] \cdot 0,5 \mathrm{CHCl}_{3} \cdot 0,25 \mathrm{CH}_{2} \mathrm{Cl}_{2}$. No entanto, os dados de microanálises estão de acordo com uma fórmula sem os solventes, demonstrando contínua a saída dos mesmos da rede cristalina. Isso se justifica devido à elevada volatilidade do clorofórmio e do diclorometano.

Foram obtidos $102,3 \mathrm{mg}(0,15 \mathrm{mmol})$, o que confere um rendimento de $76 \%$, em relação à quantidade de matéria do precursor de rênio.

O produto foi devidamente caracterizado por ponto de fusão, espectroscopia de absorção na região do infravermelho, $R M N{ }^{31} \mathrm{P}$ e ${ }^{1} \mathrm{H}$, microanálises $(\mathrm{C}, \mathrm{H}$ e N) e difração de raios $X$ em monocristal.

Os dados de caracterização são apresentados no capítulo "Resultados e Discussão".

$\mathrm{C}_{25} \mathrm{H}_{23} \mathrm{Cl}_{2} \mathrm{NO}_{3} \mathrm{PRe}\left(673,54 \mathrm{~g} \mathrm{~mol}^{-1}\right)$.

Encontrado (\%): $\quad \mathrm{C}=44,53 ; \mathrm{H}=3,28 ; \mathrm{N}=2,03$

Calculado (\%): $\quad \mathrm{C}=44,58 ; \mathrm{H}=3,44 ; \mathrm{N}=2,08$ 


\subsubsection{Síntese do Complexo [ReO(bdtc)(dmhp)] (2)}

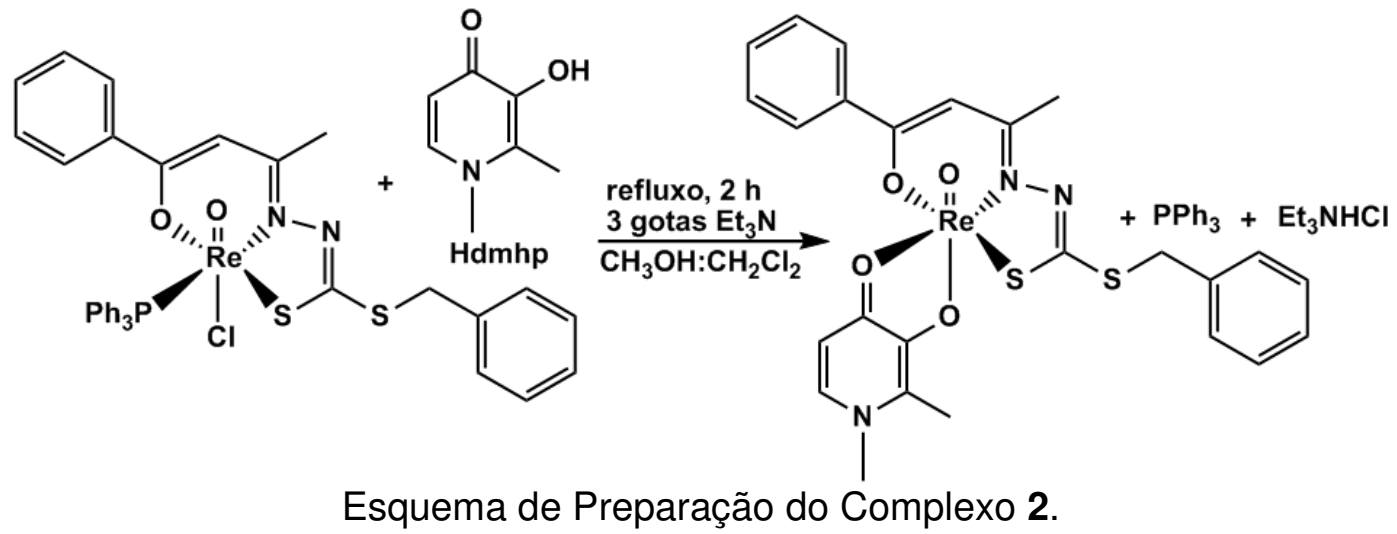

Foram adicionados $84,0 \mathrm{mg}(0,10 \mathrm{mmol})$ do complexo [ReO(bdtc) $\left.\mathrm{Cl}\left(\mathrm{PPh}_{3}\right)\right]$ (4), cuja síntese será descrita adiante, à uma solução de diclorometano e metanol (15 $\mathrm{mL}$ de cada). Em seguida, adicionou-se 13,9 $\mathrm{mg}(0,10 \mathrm{mmol})$ do agente complexante Hdmhp e 3 gotas de trietilamina $\left(\mathrm{Et}_{3} \mathrm{~N}\right)$. A mistura reacional foi deixada sob refluxo por 2 horas, à $90^{\circ} \mathrm{C}$. Após o resfriamento, a solução foi acondicionada à -15 ํ. Cristais vermelhos, adequados para difração de raios $\mathrm{X}$ em monocristal, foram coletados por filtração, após cerca de sete dias.

Cristais vermelhos, totalizando uma massa de 55,8 $\mathrm{mg}(0,08 \mathrm{mmol})$ foram coletados sob filtração, o que corresponde a um rendimento de $82 \%$, em relação à quantidade empregada do complexo de partida de rênio.

O produto foi devidamente caracterizado por espectroscopia de absorção na região do infravermelho, $R M N{ }^{1} \mathrm{H}$, microanálises $(\mathrm{C}, \mathrm{H}, \mathrm{N}$ e $\mathrm{S})$, espectrometria de massas MS-ESI (m/z) e difração de raios $X$ em monocristal.

A caracterização completa é mostrada no capítulo "Resultados e Discussão".

$\mathrm{C}_{25} \mathrm{H}_{24} \mathrm{~N}_{3} \mathrm{O}_{4} \mathrm{ReS}_{2}\left(680,81 \mathrm{~g} \mathrm{~mol}^{-1}\right)$.

Encontrado (\%): $\quad \mathrm{C}=44,08 ; \mathrm{H}=3,37 ; \mathrm{N}=6,06 ; \mathrm{S}=10,05$

Calculado (\%): $\mathrm{C}=44,10 ; \mathrm{H}=3,55 ; \mathrm{N}=6,17 ; \mathrm{S}=9,42$

MS-ESI (m/z): $682\left([\mathrm{M}+\mathrm{H}]^{+}\right) ; 704\left([\mathrm{M}+\mathrm{Na}]^{+}\right) ; 720\left([\mathrm{M}+\mathrm{K}]^{+}\right)$ 


\subsubsection{Síntese do Complexo [ReO(bdtc)(mal)] (3)}

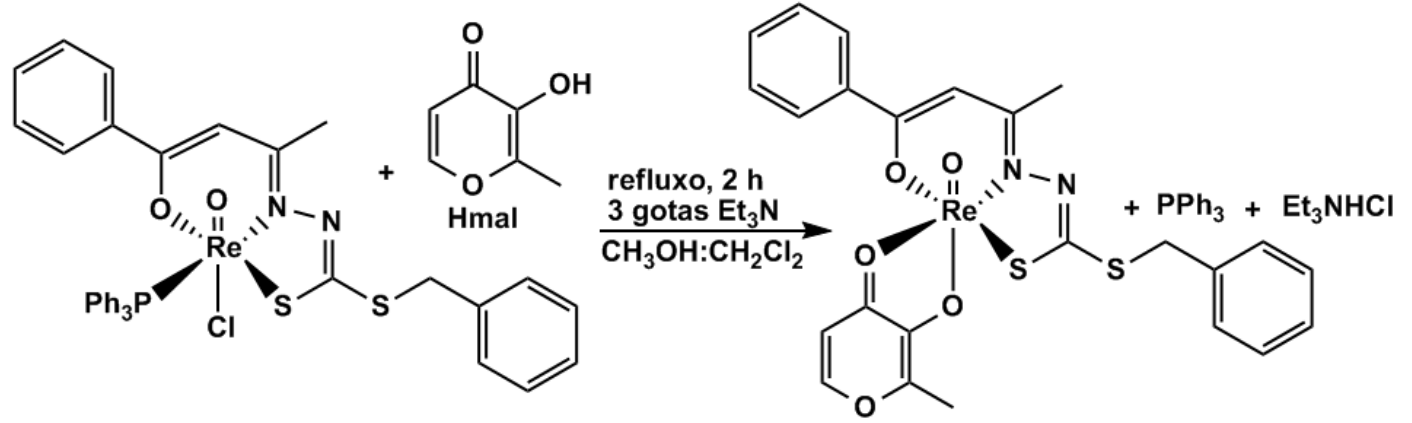

Esquema de Preparação do Complexo 3.

Foram adicionados $84,0 \mathrm{mg}(0,10 \mathrm{mmol})$ do complexo [ReO(bdtc)Cl(PPh $)$ ] (4) à uma solução de diclorometano e metanol (15 $\mathrm{mL}$ de cada). Em seguida, adicionou-se $12,5 \mathrm{mg}(0,10 \mathrm{mmol})$ do agente complexante Hmal e 3 gotas de trietilamina $\left(\mathrm{Et}_{3} \mathrm{~N}\right)$. A mistura reacional foi deixada sob refluxo por 2 horas, à $90{ }^{\circ} \mathrm{C}$. Após o resfriamento, a solução foi acondicionada à $-15^{\circ} \mathrm{C}$. Cristais vermelhos, adequados para difração de raios $X$ em monocristal, foram coletados por filtração, após cerca de sete dias.

Uma massa de $51,4 \mathrm{mg}(0,07 \mathrm{mmol})$ foi coletada sob filtração, o que confere um rendimento de $77 \%$, em relação à quantidade empregada do precursor metálico utilizado.

O produto foi caracterizado por espectroscopia de absorção na região do infravermelho, $\mathrm{RMN}{ }^{1} \mathrm{H}$, microanálises $(\mathrm{C}, \mathrm{H}, \mathrm{N}$ e $\mathrm{S})$, espectrometria de massas MS-ESI (m/z) e difração de raios X em monocristal.

Demais dados de caracterização podem ser visualizados no capítulo "Resultados e Discussão".

$\mathrm{C}_{24} \mathrm{H}_{21} \mathrm{~N}_{2} \mathrm{O}_{5} \mathrm{ReS}_{2}\left(667,77 \mathrm{~g} \mathrm{~mol}^{-1}\right)$.

Encontrado (\%): $\quad \mathrm{C}=43,14 ; \mathrm{H}=2,90 ; \mathrm{N}=4,06 ; \mathrm{S}=10,30$

Calculado (\%): $\quad \mathrm{C}=43,17 ; \mathrm{H}=3,17 ; \mathrm{N}=4,20 ; \mathrm{S}=9,60$

MS-ESI (m/z): $669\left([\mathrm{M}+\mathrm{H}]^{+}\right) ; 691\left([\mathrm{M}+\mathrm{Na}]^{+}\right) ; 707\left([\mathrm{M}+\mathrm{K}]^{+}\right)$ 


\subsubsection{Síntese do Complexo [ReOCl(bdtc) $\left.\left(\mathrm{PPh}_{3}\right)\right](4)$}

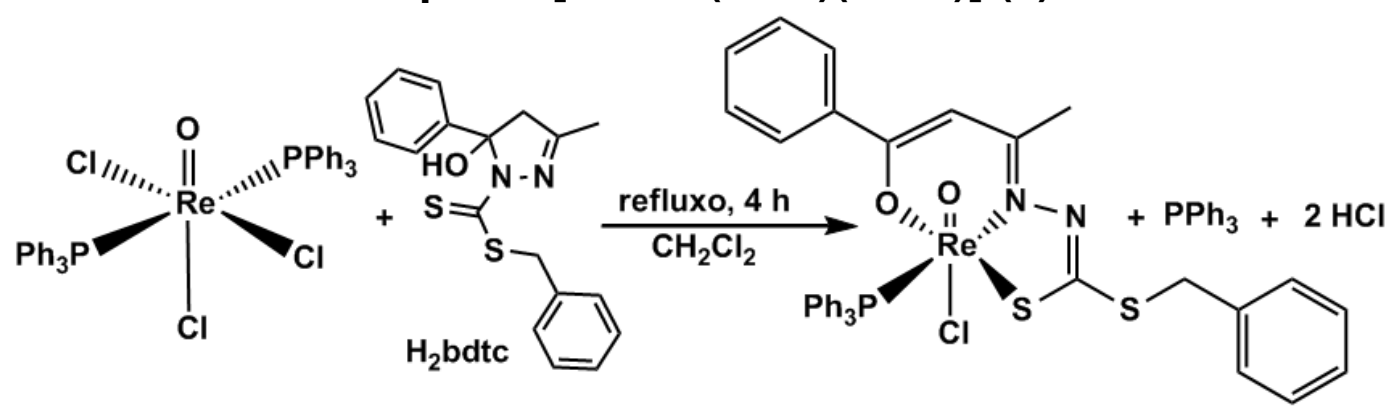

Esquema de Preparação do Complexo 4.

Foram adicionados $166,6 \mathrm{mg}(0,20 \mathrm{mmol})$ do precursor $\left[\mathrm{ReOCl}_{3}\left(\mathrm{PPh}_{3}\right)_{2}\right]$ à $20 \mathrm{~mL}$ de diclorometano. Em seguida, adicionou-se à suspensão $68,5 \mathrm{mg}(0,20$ mmol) de $\mathbf{H}_{2}$ bdtc. Essa mistura foi submetida a refluxo por $4 \mathrm{~h}$, a $50{ }^{\circ} \mathrm{C}$, tornando-se uma solução roxa após 30 min de aquecimento.

Com o resfriamento da solução, foram adicionados $7 \mathrm{~mL}$ de $n$-hexano, tendo a mesma sido mantida a $-15 \stackrel{\circ}{\circ}$ por uma semana, com a formação de cristais apropriados para difração de raios $\mathrm{X}$ em monocristal.

Os cristais roxos foram coletados por filtração sob pressão reduzida. Foram obtidos $154,6 \mathrm{mg}(0,18 \mathrm{mmol})$, o que confere um rendimento de $92 \%$, em relação à quantidade de matéria inicial do precursor de rênio.

A caracterização do produto foi feita por espectroscopia de absorção na região do infravermelho, $R M N{ }^{1} \mathrm{H}$ e ${ }^{31} \mathrm{P}$, microanálises $(\mathrm{C}, \mathrm{H}, \mathrm{N}$ e S), espectrometria de massas MS-ESI (m/z) e análise estrutural por difração de raios $X$ em monocristal.

Dados adicionais referentes à caracterização do composto podem ser encontrados no capítulo "Resultados e Discussão".

$\mathrm{C}_{36} \mathrm{H}_{31} \mathrm{ClN}_{2} \mathrm{O}_{2} \mathrm{PReS}_{2}\left(840,41 \mathrm{~g} \mathrm{~mol}^{-1}\right)$.

Encontrado (\%): $\quad \mathrm{C}=51,23 ; \mathrm{H}=3,65 ; \mathrm{N}=3,21 \mathrm{~S}=7,58$

Calculado (\%): $\quad \mathrm{C}=51,45 ; \mathrm{H}=3,72 ; \mathrm{N}=3,33 \mathrm{~S}=7,63$

MS-ESI (m/z): $805\left([\mathrm{M}-\mathrm{Cl}]^{+}\right)$. 


\subsubsection{Síntese do Complexo $\left[\mathrm{ReOBr}(\mathrm{bdtc})\left(\mathrm{PPh}_{3}\right)\right](5)$}

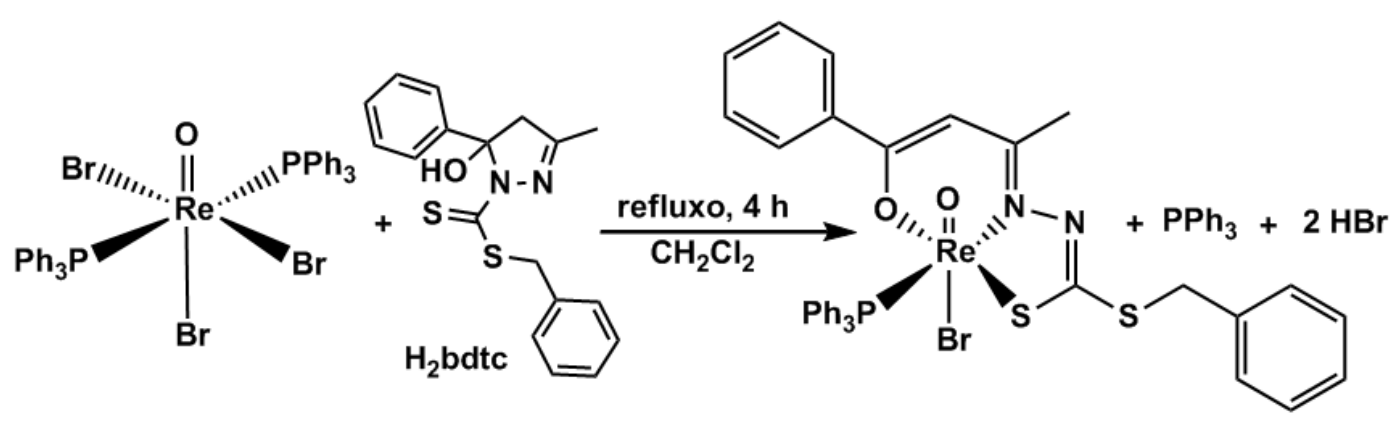

Esquema de Preparação do Complexo 5.

Foram adicionados $193,3 \mathrm{mg}(0,20 \mathrm{mmol})$ do precursor $\left[\mathrm{ReOBr}_{3}\left(\mathrm{PPh}_{3}\right)_{2}\right]$ à $20 \mathrm{~mL}$ de diclorometano. Em seguida, adicionou-se à suspensão $68,5 \mathrm{mg}(0,20$ $\mathrm{mmol}$ ) de $\mathbf{H}_{2}$ bdtc. A mesma metodologia de síntese e cristalização adotada para o complexo 4 foi utilizada na síntese e obtenção deste complexo.

De modo similar ao complexo 2 , tendo a solução sido mantida a $-15{ }^{\circ} \mathrm{C}$ durante uma semana, houve a formação de cristais apropriados para difração de raios $\mathrm{X}$ em monocristal.

Os cristais roxos foram coletados por filtração sob pressão reduzida. Foram obtidos $154,0 \mathrm{mg}(0,17 \mathrm{mmol})$, o que confere um rendimento de $87 \%$, em relação à quantidade de matéria inicial do precursor de rênio.

A caracterização do produto foi feita por espectroscopia de absorção na região do infravermelho, $\mathrm{RMN}{ }^{1} \mathrm{H}$ e ${ }^{31} \mathrm{P}$, microanálises $(\mathrm{C}, \mathrm{H}, \mathrm{N}$ e S), espectrometria de massas $M S-E S I ~(m / z)$ e análise estrutural por difração de raios $X$ em monocristal.

Dados adicionais referentes à caracterização do composto podem ser encontrados no capítulo "Resultados e Discussão".

$\mathrm{C}_{36} \mathrm{H}_{31} \mathrm{BrN}_{2} \mathrm{O}_{2} \mathrm{PReS}_{2}\left(884,86 \mathrm{~g} \mathrm{~mol}^{-1}\right)$.

Encontrado (\%): $\quad \mathrm{C}=48,81 ; \mathrm{H}=3,47 ; \mathrm{N}=3,12 \mathrm{~S}=7,12$

Calculado (\%): $\quad \mathrm{C}=48,86 ; \mathrm{H}=3,53 ; \mathrm{N}=3,17 \mathrm{~S}=7,25$

MS-ESI (m/z): $805\left([\mathrm{M}-\mathrm{Br}]^{+}\right)$. 


\subsubsection{Síntese do Complexo $\left[\mathrm{ReOCl}(\mathrm{bdtn})\left(\mathrm{PPh}_{3}\right)\right]$ (6)}

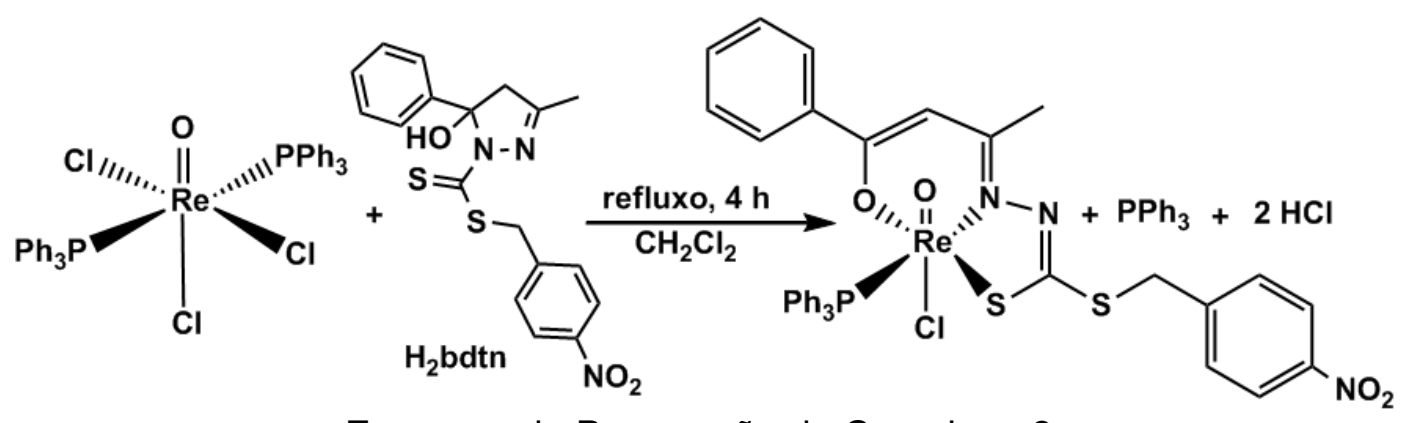

Esquema de Preparação do Complexo 6.

Foram adicionados $166,6 \mathrm{mg}(0,20 \mathrm{mmol})$ do precursor $\left[\mathrm{ReOCl}_{3}\left(\mathrm{PPh}_{3}\right)_{2}\right]$ à $20 \mathrm{~mL}$ de diclorometano. Em seguida, adicionou-se à suspensão $77,5 \mathrm{mg}(0,20$ mmol) de $\mathbf{H}_{2}$ bdtn. Essa mistura foi submetida a refluxo por $4 \mathrm{~h}$ a $50{ }^{\circ} \mathrm{C}$, tornando-se uma solução roxa após 30 minutos de aquecimento.

Com o resfriamento da solução, foram adicionados $10 \mathrm{ml}$ de $n$-hexano, tendo a mesma sido mantida a $-15 \stackrel{\circ}{\circ}$, por sete dias, com o intuito da formação de monocristais, o que não aconteceu. Foram feitas várias tentativas de cristalização, no entanto, não foi possível obter monocristais apropriados para difração de raios $\mathrm{X}$.

Um produto microcristalino foi coletado por filtração sob pressão reduzida. Foram obtidos $164,7 \mathrm{mg}(0,18 \mathrm{mmol})$, o que confere um rendimento de $93 \%$, em relação à quantidade de matéria inicial do precursor de rênio.

A caracterização do produto foi feita por espectroscopia de absorção na região do infravermelho, $R M N{ }^{1} \mathrm{H}$ e ${ }^{31} \mathrm{P}$ e microanálises $(C, H, N$ e $S)$ e espectrometria de massas MS-ESI ( $\mathrm{m} / \mathrm{z}$ ).

Dados adicionais referentes à caracterização do composto podem ser encontrados no capítulo "Resultados e Discussão".

$\mathrm{C}_{36} \mathrm{H}_{30} \mathrm{ClN}_{3} \mathrm{O}_{4} \mathrm{PReS}_{2}\left(885,40 \mathrm{~g} \mathrm{~mol}^{-1}\right)$.

Encontrado (\%): $\quad \mathrm{C}=48,76 ; \mathrm{H}=3,21 ; \mathrm{N}=4,62 ; \mathrm{S}=7,29$

Calculado (\%): $\quad \mathrm{C}=48,83 ; \mathrm{H}=3,42 ; \mathrm{N}=4,75 ; \mathrm{S}=7,24$

MS-ESI (m/z): $850\left([\mathrm{M}-\mathrm{Cl}]^{+}\right)$. 


\subsubsection{Síntese do Complexo $\left[\mathrm{ReOCl}(\mathrm{bdtm})\left(\mathrm{PPh}_{3}\right)\right](7)$}

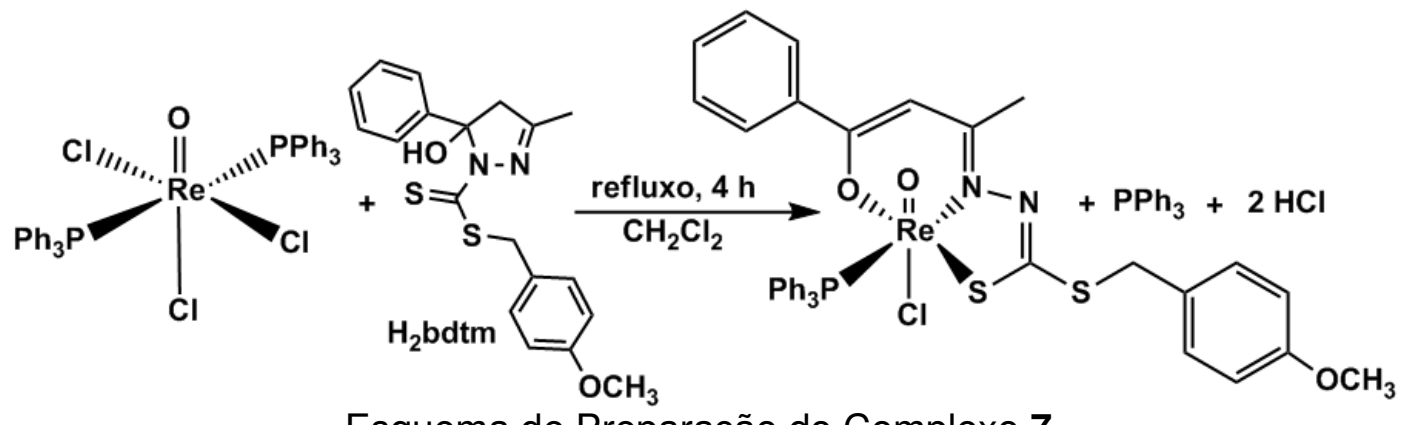

Esquema de Preparação do Complexo 7.

Foram adicionados $166,6 \mathrm{mg}(0,20 \mathrm{mmol})$ do precursor $\left[\mathrm{ReOCl}_{3}\left(\mathrm{PPh}_{3}\right)_{2}\right]$ à $20 \mathrm{~mL}$ de diclorometano. Em seguida, adicionou-se à suspensão $74,5 \mathrm{mg}(0,20$ $\mathrm{mmol}$ ) de $\mathbf{H}_{2} \mathbf{b d t m}$. O preparo deste composto seguiu a mesma metodologia de síntese e obtenção utilizada para o complexo 4.

Com o resfriamento da solução, foram adicionados $5 \mathrm{ml}$ de $n$-hexano, tendo a mesma sido mantida a $-15 \stackrel{\circ}{\circ}$, durante uma semana, com o intuito de favorecer a formação de monocristais, o que não aconteceu, mesmo após várias tentativas de cristalização do produto.

Um produto microcristalino foi coletado por filtração sob pressão reduzida. Foram obtidos $158,4 \mathrm{mg}(0,18 \mathrm{mmol})$, o que confere um rendimento de $91 \%$, em relação à quantidade de matéria inicial do precursor de rênio.

A caracterização do produto foi feita por espectroscopia de absorção na região do infravermelho, $R M N{ }^{1} \mathrm{H}$ e ${ }^{31} \mathrm{P}$ e microanálises (C, $\mathrm{H}, \mathrm{N}$ e $\left.\mathrm{S}\right)$ e espectrometria de massas MS-ESI (m/z).

Dados adicionais referentes à caracterização do composto podem ser encontrados no capítulo "Resultados e Discussão".

$\mathrm{C}_{37} \mathrm{H}_{33} \mathrm{ClN}_{2} \mathrm{O}_{3} \mathrm{PReS}_{2}\left(870,43 \mathrm{~g} \mathrm{~mol}^{-1}\right)$.

Encontrado (\%): $\quad \mathrm{C}=50,72 ; \mathrm{H}=3,39 ; \mathrm{N}=3,21 ; \mathrm{S}=7,34$

Calculado (\%): $\quad \mathrm{C}=51,05 ; \mathrm{H}=3,82 ; \mathrm{N}=3,22 ; \mathrm{S}=7,37$

MS-ESI (m/z): $835\left([\mathrm{M}-\mathrm{Cl}]^{+}\right)$. 


\subsubsection{Síntese do Complexo [TcO(bdtc)Cl] (8)}

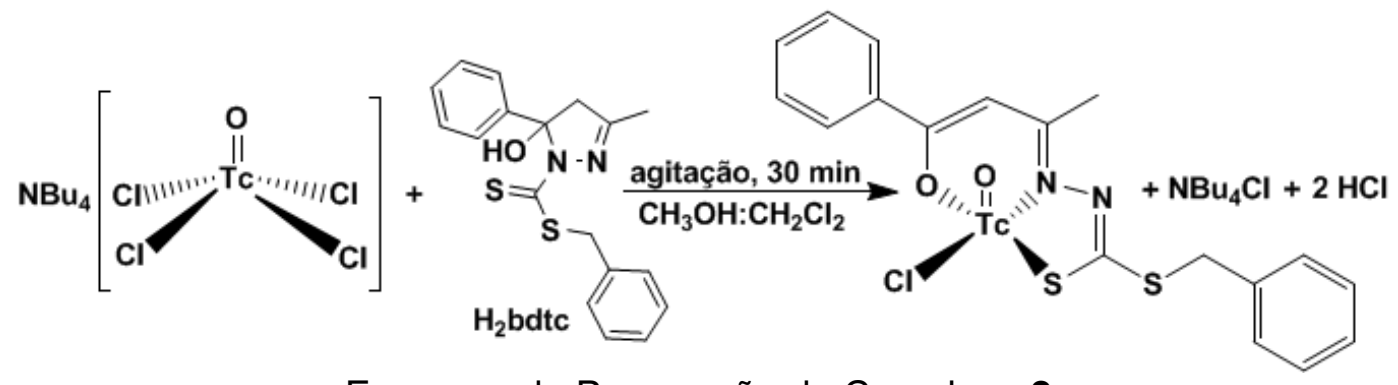

Esquema de Preparação do Complexo 8.

Foram adicionados $34,2 \mathrm{mg}(0,10 \mathrm{mmol})$ do ligante $\mathbf{H}_{2}$ bdtc à $10 \mathrm{ml}$ de diclorometano. Em seguida, adicionou-se à esta solução 49,8 $\mathrm{mg}(0,10 \mathrm{mmol})$ do complexo de partida $\left(\mathrm{NBu}_{4}\right)\left[\mathrm{TcOCl}_{4}\right]$. Verificou-se que a reação ocorreu de forma muito rápida. A solução inicialmente amarela tornou-se vermelha escura instantaneamente. Para assegurar que a reação se completasse, a solução foi deixada sob agitação por 30 minutos. Posteriormente, foram adicionados $5 \mathrm{ml}$ de $n$-hexano, tendo a mesma sido mantida a $-15 \stackrel{\circ}{ } \mathrm{C}$, durante uma semana, com o intuito de favorecer a formação de monocristais. Cristais apropriados para difração de raios $X$ puderam ser coletados por filtração sob pressão reduzida após este período. Os cristais foram secos sob fluxo contínuo de ar. Uma massa de 34,8 $\mathrm{mg}(0,07 \mathrm{mmol})$ foi obtida, o que confere um rendimento de $71 \%$, em relação à quantidade utilizada do complexo de partida de tecnécio.

A caracterização do produto foi feita por espectroscopia de absorção na região do infravermelho, detecção do percentual de tecnécio por cintilação líquida, $\mathrm{RMN}{ }^{1} \mathrm{H}$ e difração de raios $\mathrm{X}$ em monocristal.

A caracterização do complexo obtido é mostrada em detalhes no capítulo "Resultados e Discussão".

$\mathrm{C}_{18} \mathrm{H}_{16} \mathrm{CIN}_{2} \mathrm{O}_{2} \mathrm{~S}_{2} \mathrm{Tc}\left(489,91 \mathrm{~g} \mathrm{~mol}^{-1}\right)$.

$\%$ de Tc (detectado / calculado): $(19,5$ / 20,0) 


\subsubsection{Síntese do Complexo [ReO(bdtc)(Hbdtc)] (9)}

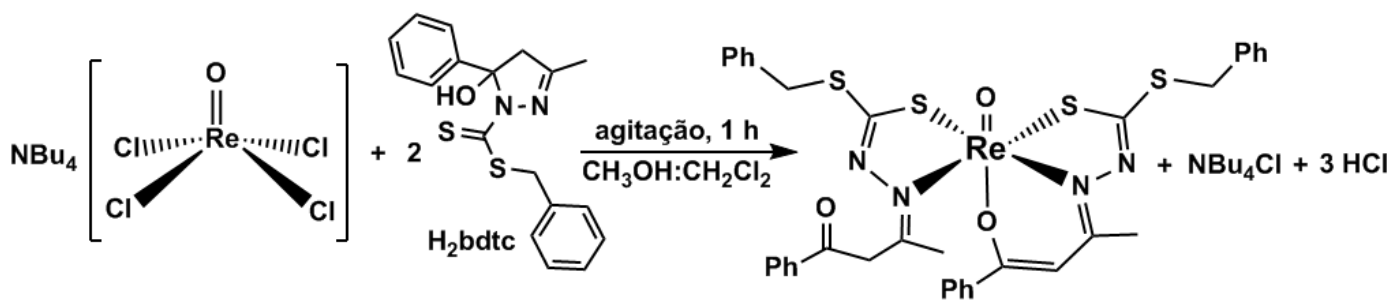

Esquema de Preparação do Complexo 9.

Foram adicionados $68,5 \mathrm{mg}(0,20 \mathrm{mmol})$ do ligante $\mathbf{H}_{\mathbf{2}}$ bdtc à uma mistura de $10 \mathrm{~mL}$ de diclorometano e $5 \mathrm{~mL}$ de metanol. Em seguida, adicionou-se à solução $58,6 \mathrm{mg}(0,10 \mathrm{mmol})$ do complexo de partida $\left(\mathrm{NBu}_{4}\right)\left[\mathrm{ReOCl}_{4}\right]$. Verificou-se, por meio de uma rápida mudança na coloração da solução, de amarelo claro para vermelho, que a reação ocorreu de forma muito rápida, a mistura reacional foi deixada sob agitação por $1 \mathrm{~h}$, para assegurar que a reação se completasse.

Com a lenta evaporação da solução, após um período de dois dias, cristais vermelhos, adequados para difração de raios $\mathrm{X}$ em monocristal foram obtidos $\mathrm{e}$ puderam ser separados por filtração a vácuo. Uma massa de 82,2 mg (0,09 mmol) foi coletada, correspondendo a um rendimento de $93 \%$, em relação à quantidade utilizada do precursor de rênio.

O produto foi caracterizado por espectroscopia de absorção na região do infravermelho, $\mathrm{RMN}^{1} \mathrm{H}$, microanálises $(\mathrm{C}, \mathrm{H}, \mathrm{N}$ e $\mathrm{S})$, espectrometria de massas MS$\operatorname{ESI}(\mathrm{m} / \mathrm{z})$ e determinação da estrutura cristalina por difração de raios $X$ em monocristal. A caracterização completa é mostrada no capítulo "Resultados e Discussão".

$\mathrm{C}_{36} \mathrm{H}_{33} \mathrm{~N}_{4} \mathrm{O}_{3} \mathrm{ReS}_{4}\left(884,10 \mathrm{~g} \mathrm{~mol}^{-1}\right)$.

Encontrado (\%): $\mathrm{C}=48,79 ; \mathrm{H}=3,45 ; \mathrm{N}=6,26 ; \mathrm{S}=14,42$

Calculado (\%): $\quad \mathrm{C}=48,90 ; \mathrm{H}=3,76 ; \mathrm{N}=6,34 ; \mathrm{S}=14,51$

MS-ESI $(\mathrm{m} / \mathrm{z}): 885\left([\mathrm{M}+\mathrm{H}]^{+}\right)$. 


\subsubsection{Síntese do Complexo [ReO(bdtn)(Hbdtn)] (10)}

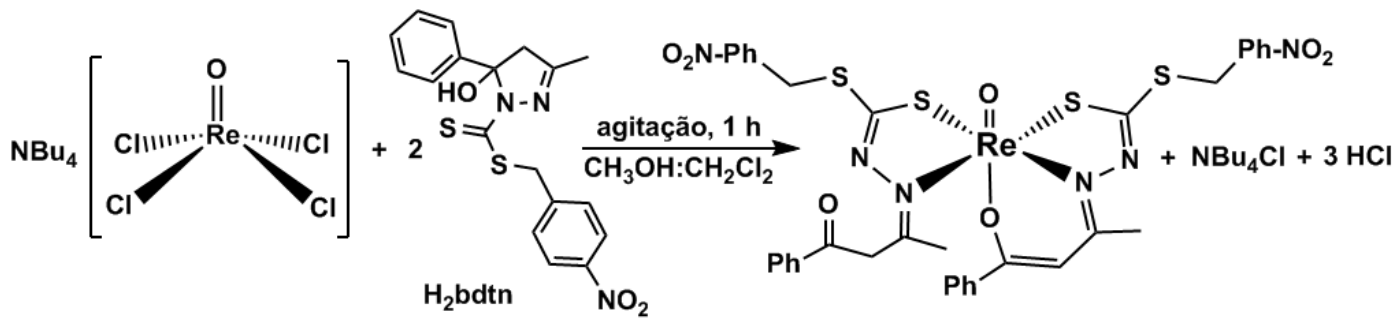

Esquema de Preparação do Complexo 10.

Foram adicionados $77,5 \mathrm{mg}(0,20 \mathrm{mmol})$ do ligante $\mathbf{H}_{\mathbf{2}} \mathbf{b d t n}$ à uma mistura de $10 \mathrm{~mL}$ de diclorometano e $5 \mathrm{~mL}$ de metanol. Em seguida, adicionou-se à solução $58,6 \mathrm{mg}(0,10 \mathrm{mmol})$ do complexo de partida $\left(\mathrm{NBu}_{4}\right)\left[\mathrm{ReOCl}_{4}\right]$. Para a síntese, obtenção e cristalização deste complexo foi utilizada a mesma metodologia adotada para o composto 9 .

Uma massa de $88,6 \mathrm{mg}$ de cristais vermelhos $(0,09 \mathrm{mmol})$ foi coletada por filtração sob pressão reduzida, o que corresponde a um rendimento de $91 \%$, em relação à quantidade do precursor de rênio utilizada.

O produto foi caracterizado por espectroscopia de absorção na região do infravermelho, $\mathrm{RMN}{ }^{1} \mathrm{H}$, microanálises ( $\mathrm{C}, \mathrm{H}, \mathrm{N}$ e $\mathrm{S}$ ), espectrometria de massas MS-ESI (m/z) e determinação da estrutura cristalina por difração de raios $X$ em monocristal. Dados adicionais do composto podem ser encontrados no capítulo "Resultados e Discussão".

$\mathrm{C}_{36} \mathrm{H}_{31} \mathrm{~N}_{6} \mathrm{O}_{7} \mathrm{ReS}_{4}\left(974,13 \mathrm{~g} \mathrm{~mol}^{-1}\right)$.

Encontrado (\%): $\mathrm{C}=44,37 ; \mathrm{H}=3,18 ; \mathrm{N}=8,60 ; \mathrm{S}=13,08$

Calculado (\%): $\quad \mathrm{C}=44,39 ; \mathrm{H}=3,21 ; \mathrm{N}=8,63 ; \mathrm{S}=13,17$

MS-ESI $(\mathrm{m} / \mathrm{z}): 975\left([\mathrm{M}+\mathrm{H}]^{+}\right) ; 997\left([\mathrm{M}+\mathrm{Na}]^{+}\right) ; 1013\left([\mathrm{M}+\mathrm{K}]^{+}\right)$. 


\subsubsection{Síntese do Complexo [ReO(bdtm)(Hbdtm)] (11)}

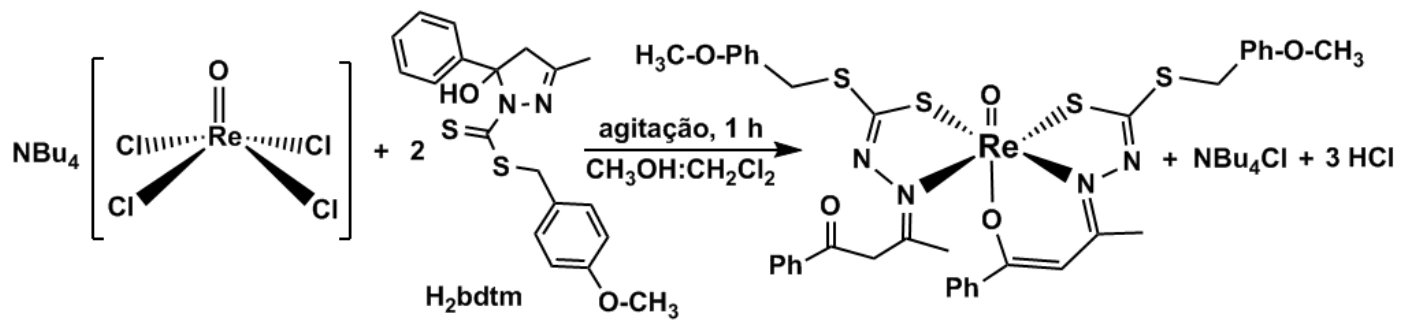

Esquema de Preparação do Complexo 11.

Foram adicionados $74,5 \mathrm{mg}(0,20 \mathrm{mmol})$ do ligante $\mathbf{H}_{2} \mathbf{b d t m}$ à uma mistura de $10 \mathrm{~mL}$ de diclorometano e $5 \mathrm{~mL}$ de metanol. Em seguida, adicionou-se à solução $58,6 \mathrm{mg}(0,10 \mathrm{mmol})$ do complexo de partida $\left(\mathrm{NBu}_{4}\right)\left[\mathrm{ReOCl}_{4}\right]$. Este complexo tratase de um análogo do composto $\mathbf{9}$, portanto, a metodologia deste último foi adotada na síntese, obtenção e cristalização desta substância.

Com a lenta evaporação da solução, cristais vermelhos, adequados para difração de raios $X$ em monocristal foram obtidos e puderam ser separados por filtração a vácuo. Uma massa de 91,6 mg (0,09 mmol) foi coletada, correspondendo a um rendimento de $97 \%$, em relação à quantidade utilizada do precursor de rênio.

O produto foi caracterizado por espectroscopia de absorção na região do infravermelho, $\mathrm{RMN}{ }^{1} \mathrm{H}$, microanálises ( $\mathrm{C}, \mathrm{H}, \mathrm{N}$ e $\mathrm{S}$ ), espectrometria de massas MS-ESI (m/z) e determinação da estrutura cristalina por difração de raios $X$ em monocristal. A caracterização completa é mostrada no capítulo "Resultados e Discussão".

$\mathrm{C}_{38} \mathrm{H}_{37} \mathrm{~N}_{4} \mathrm{O}_{5} \mathrm{ReS}_{4}\left(944,19 \mathrm{~g} \mathrm{~mol}^{-1}\right)$.

Encontrado (\%): $\quad \mathrm{C}=47,94 ; \mathrm{H}=3,55 ; \mathrm{N}=5,85 ; \mathrm{S}=13,57$

Calculado (\%): $\quad \mathrm{C}=48,34 ; \mathrm{H}=3,95 ; \mathrm{N}=5,93 ; \mathrm{S}=13,58$

MS-ESI $(\mathrm{m} / \mathrm{z}): 945\left([\mathrm{M}+\mathrm{H}]^{+}\right) ; 967\left([\mathrm{M}+\mathrm{Na}]^{+}\right) ; 983\left([\mathrm{M}+\mathrm{K}]^{+}\right)$. 


\subsubsection{Síntese do Complexo [ReO(bdtc)(cisa)] (12)}

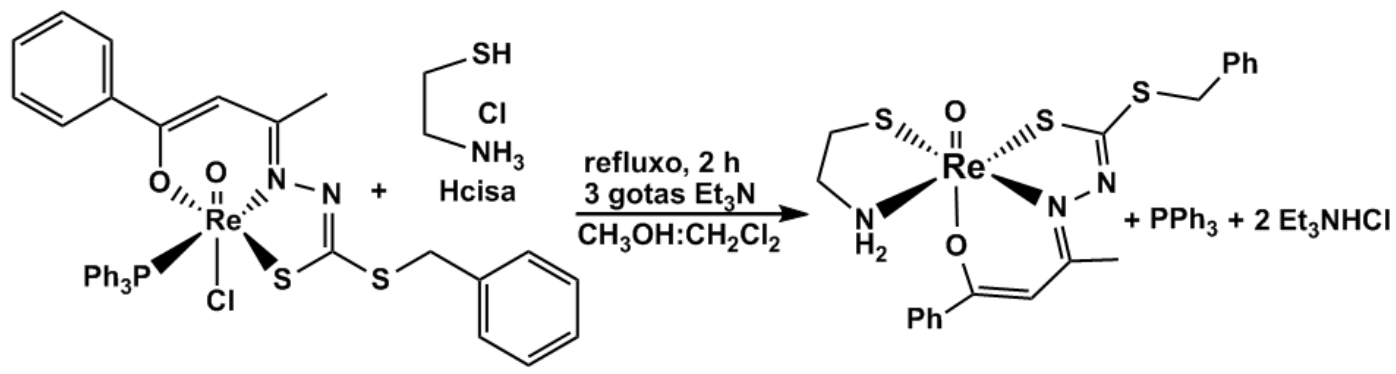

Esquema de Preparação do Complexo 12.

Foram adicionados $84,0 \mathrm{mg}(0,10 \mathrm{mmol})$ do complexo $\left[\mathrm{ReO}(\mathrm{bdtc}) \mathrm{Cl}\left(\mathrm{PPh}_{3}\right)\right]$ à uma solução de diclorometano e metanol (10 $\mathrm{mL}$ de cada). Em seguida, adicionou-se $11,4 \mathrm{mg}(0,10 \mathrm{mmol})$ do agente complexante Hcisa, seguido de 3 gotas de $\mathrm{Et}_{3} \mathrm{~N}$.

Após o resfriamento, a solução foi acondicionada à $-15^{\circ} \mathrm{C}$, por uma semana. Um precipitado microcristalino foi obtido $(58 \mathrm{mg})$ e recristalizado em uma mistura de diclorometano e metanol (15 $\mathrm{ml}$ de diclorometano e $5 \mathrm{~mL}$ de metanol). Após três dias, com a evaporação lenta da solução, 43,3 $\mathrm{mg}(0,07 \mathrm{mmol})$ de cristais vermelhos, apropriados para difração de raios $X$ em monocristal, foram coletados por filtração sob pressão reduzida. O rendimento de 70 \%, em relação à quantidade inicial do complexo de partida de rênio.

A caracterização do produto foi feita por espectroscopia de absorção na região do infravermelho, $R M N{ }^{1} \mathrm{H}$, microanálises $(\mathrm{C}, \mathrm{H}, \mathrm{N}$ e $\mathrm{S})$, espectrometria de massas MS-ESI (m/z) e difração de raios X em monocristal.

Demais dados relativos à caracterização desta substância estão disponíveis no capítulo "Resultados e Discussão".

$\mathrm{C}_{20} \mathrm{H}_{22} \mathrm{~N}_{3} \mathrm{O}_{2} \mathrm{ReS}_{3}\left(618,81 \mathrm{~g} \mathrm{~mol}^{-1}\right)$.

Encontrado (\%): $\quad \mathrm{C}=38,73 ; \mathrm{H}=3,18 ; \mathrm{N}=6,70 ; \mathrm{S}=15,02$

Calculado (\%): $\quad \mathrm{C}=38,82 ; \mathrm{H}=3,58 ; \mathrm{N}=6,79 ; \mathrm{S}=15,55$

MS-ESI (m/z): $620\left([M+H]^{+}\right)$. 


\subsubsection{Síntese do Complexo [ReO(bdtc)(cism)] (13)}

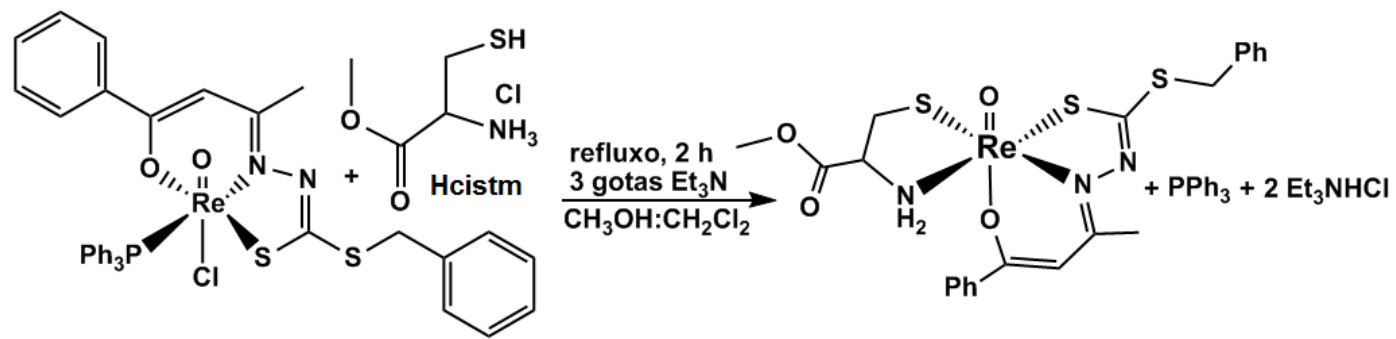

Esquema de Preparação do Complexo 13.

Foram adicionados $84,0 \mathrm{mg}(0,10 \mathrm{mmol})$ do $\left[\mathrm{ReO}(\mathrm{bdtc}) \mathrm{Cl}\left(\mathrm{PPh}_{3}\right)\right]$ à $20 \mathrm{~mL}$ de diclorometano. Em seguida, adicionou-se à solução 17,2 mg (0,10 mmol) de Hcism, seguido de 3 gotas de $\mathrm{Et}_{3} \mathrm{~N}$. Essa mistura foi submetida a refluxo por $2 \mathrm{~h}$, à $90{ }^{\circ} \mathrm{C}$.

Durante o resfriamento da solução, cristais vermelhos apropriados para difração de raios $X$ em monocristal foram formados, ainda no balão de reação.

Os cristais, $50,1 \mathrm{mg}(0,07 \mathrm{mmol})$, foram coletados por filtração sob pressão reduzida. O rendimento de $74 \%$, em relação à quantidade inicial do precursor de rênio.

A caracterização do produto foi feita por espectroscopia de absorção na região do infravermelho, $R M N{ }^{1} \mathrm{H}$, microanálises $(\mathrm{C}, \mathrm{H}, \mathrm{N}$ e $\mathrm{S})$, espectrometria de massas MS-ESI (m/z) e difração de raios X em monocristal.

Demais dados relativos à caracterização desta substância estão apresentados no capítulo "Resultados e Discussão".

$\mathrm{C}_{22} \mathrm{H}_{24} \mathrm{~N}_{3} \mathrm{O}_{4} \mathrm{ReS}_{3}\left(676,85 \mathrm{~g} \mathrm{~mol}^{-1}\right)$.

Encontrado (\%): $\mathrm{C}=39,05 ; \mathrm{H}=2,56 ; \mathrm{N}=5,91 ; \mathrm{S}=14,26$

Calculado (\%): $\quad \mathrm{C}=39,04 ; \mathrm{H}=3,57 ; \mathrm{N}=6,21 ; \mathrm{S}=14,21$

MS-ESI $(\mathrm{m} / \mathrm{z}): 678\left([\mathrm{M}+\mathrm{H}]^{+}\right)$. 


\subsubsection{Síntese do Complexo [ReO(deba)(dmhp)] (14)}

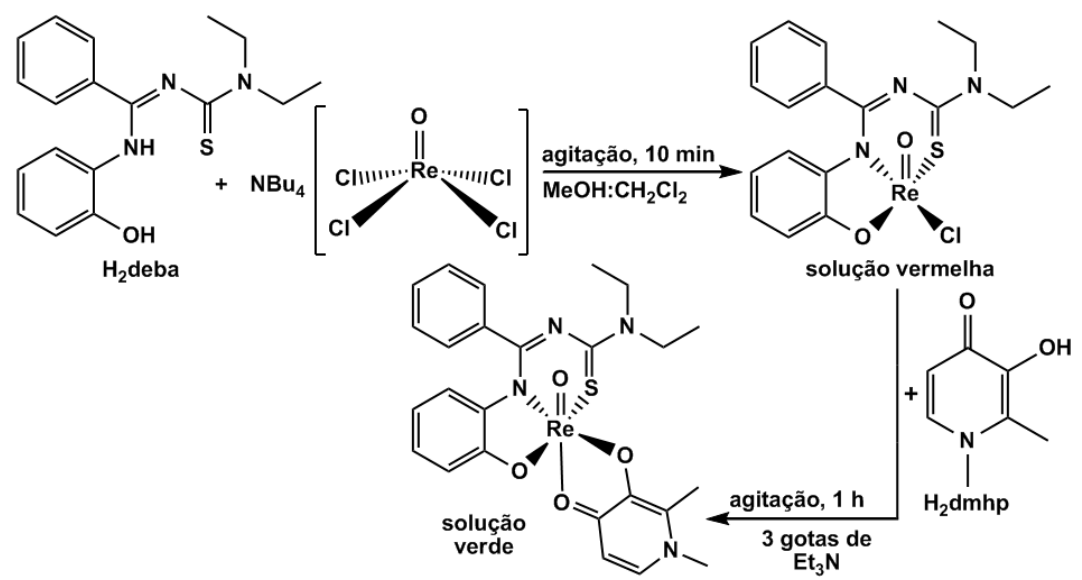

Esquema de Preparação do Complexo 14.

Foram adicionados $65,5 \mathrm{mg}(0,20 \mathrm{mmol})$ de $\mathbf{H}_{2}$ deba à $20 \mathrm{ml}$ de uma solução de metanol e diclorometano (10 $\mathrm{mL}$ de cada). Em seguida, adicionou-se à solução $117,2 \mathrm{mg}(0,20 \mathrm{mmol})$ de $\left(\mathrm{NBu}_{4}\right)\left[\mathrm{ReOCl}_{4}\right]$. Na etapa seguinte, $27,8 \mathrm{mg}(0,20 \mathrm{mmol})$ de Hdmhp e 3 gotas de $\mathrm{Et}_{3} \mathrm{~N}$ foram adicionados. A cor da solução mudou, instantaneamente, de vermelho para verde. Com intuito de assegurar que a reação se completasse, a mesma foi deixada sob agitação por uma hora.

Com a evaporação lenta da solução, cristais verdes-escuros adequados para difração de raios $\mathrm{X}$ em monocristal foram obtidos, possibilitando sua separação por meio de filtração a pressão reduzida.

Foram obtidos $110,5 \mathrm{mg}(0,16 \mathrm{mmol})$ do produto, o que confere um rendimento de $78 \%$, em relação à quantidade inicial do precursor de rênio.

A caracterização do complexo foi feita por espectroscopia de absorção na região do infravermelho, $R M N{ }^{1} \mathrm{H}$, análise elementar e espectrometria de massas MS-ESI (m/z). A caracterização do produto é apresentada no capítulo "Resultados e Discussão".

$\mathrm{C}_{25} \mathrm{H}_{27} \mathrm{~N}_{4} \mathrm{O}_{4} \operatorname{ReS}\left(665,78 \mathrm{~g} \mathrm{~mol}^{-1}\right)$.

Encontrado (\%): $\quad \mathrm{C}=43,07 ; \mathrm{H}=4,87 ; \mathrm{N}=8,05 ; \mathrm{S}=5,67$

Calculado (\%): $\quad \mathrm{C}=45,10 ; \mathrm{H}=4,09 ; \mathrm{N}=8,42 ; \mathrm{S}=4,82$

MS-ESI (m/z): $667\left([\mathrm{M}+\mathrm{H}]^{+}\right) ; 689\left([\mathrm{M}+\mathrm{Na}]^{+}\right) ; 705\left([\mathrm{M}+\mathrm{K}]^{+}\right)$. 


\subsubsection{Síntese do Complexo [ReO(deba)(bmhp)] (15)}

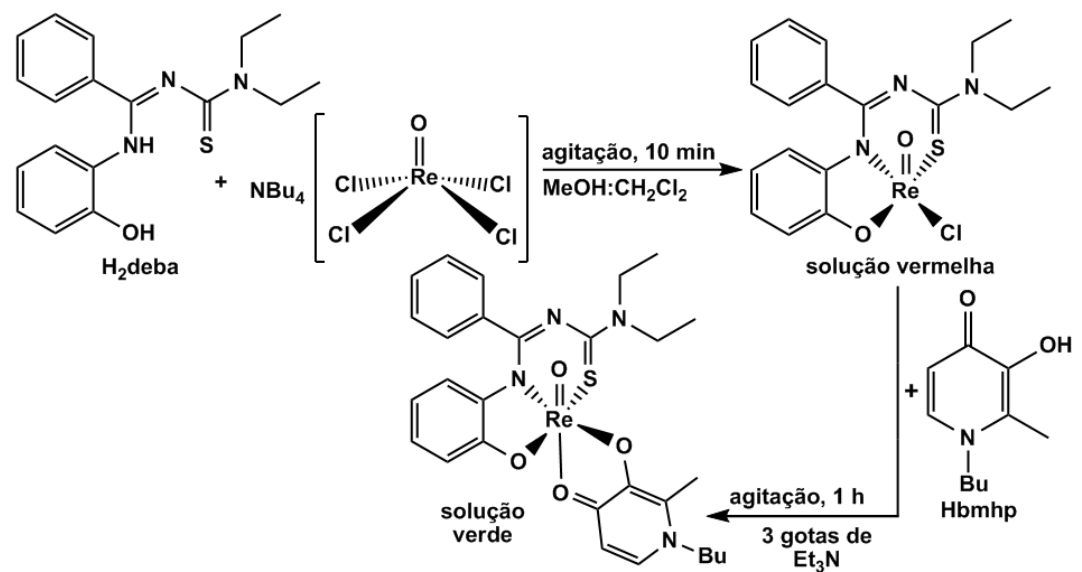

Esquema de Preparação do Complexo 15.

Foram adicionados $65,5 \mathrm{mg}(0,20 \mathrm{mmol})$ de $\mathbf{H}_{2}$ deba à $20 \mathrm{ml}$ de uma solução de $\mathrm{MeOH}: \mathrm{CH}_{2} \mathrm{Cl}_{2}$ (5 mL:5 mL). Em seguida, adicionou-se à solução 117,2 mg (0,20 $\mathrm{mmol})$ de $\left(\mathrm{NBu}_{4}\right)\left[\mathrm{ReOCl}_{4}\right]$. Na etapa seguinte, $36,2 \mathrm{mg}(0,20 \mathrm{mmol})$ de Hbmhp e 3 gotas de $\mathrm{Et}_{3} \mathrm{~N}$ foram adicionados. A cor da solução mudou, instantaneamente, de vermelho para verde. A reação foi deixada sob agitação por uma hora.

Cristais verdes-escuros apropriados para difração de raios $\mathrm{X}$ em monocristal foram obtidos por meio da evaporação lenta da solução, possibilitando sua separação por meio de filtração à pressão reduzida.

Foram obtidos $99,1 \mathrm{mg}(0,14 \mathrm{mmol})$ do produto, o que confere um rendimento de $70 \%$, em relação à quantidade inicial do precursor de rênio.

A caracterização do complexo foi feita por espectroscopia de absorção na região do infravermelho, $R M N{ }^{1} \mathrm{H}$, análise elementar e espectrometria de massas MS-ESI (m/z). A caracterização do produto é apresentada no capítulo "Resultados e Discussão".

$\mathrm{C}_{28} \mathrm{H}_{33} \mathrm{~N}_{4} \mathrm{O}_{4} \operatorname{ReS}\left(707,86 \mathrm{~g} \mathrm{~mol}^{-1}\right)$.

Encontrado (\%): $\quad \mathrm{C}=47,07 ; \mathrm{H}=5,22 ; \mathrm{N}=7,93 ; \mathrm{S}=5,36$

Calculado (\%): $\quad \mathrm{C}=47,51 ; \mathrm{H}=4,70 ; \mathrm{N}=7,91 ; \mathrm{S}=4,53$

MS-ESI (m/z): $709\left([\mathrm{M}+\mathrm{H}]^{+}\right) ; 731\left([\mathrm{M}+\mathrm{Na}]^{+}\right)$. 


\section{Resultados e Discussão}

\subsection{Complexos [ReO(dmhp) $\left.\mathrm{Cl}_{2}\left(\mathrm{PPh}_{3}\right)\right]$ (1), [ReO(bdtc)(dmhp)] (2) e [ReO(bdtc)(mal)] (3)}

A síntese do complexo [ReO(dmhp) $\left.\mathrm{Cl}_{2}\left(\mathrm{PPh}_{3}\right)\right]$ (1) partiu de quantidades equimolares de $\left[\mathrm{ReOCl}_{3}\left(\mathrm{PPh}_{3}\right)_{2}\right]$ e Hdmhp.

O composto [ReO(bdtc)(mal)] (3) foi sintetizado através de duas metodologias distintas. Inicialmente sua síntese consistiu em uma reação entre o complexo $\left[\mathrm{ReO}(\mathrm{mal})_{2} \mathrm{Cl}\right.$, já descrito na literatura, e um equivalente do ditiocarbazato $\mathbf{H}_{2}$ bdtc. ${ }^{61}$ No entanto, esta metodologia de síntese não forneceu um rendimento satisfatório, mas cerca de $47 \%$. Provavelmente, o baixo rendimento deve estar associado à quebra, pouco favorável, de duas ligações que fazem parte de um anel quelato de cinco membros, existente entre cada ânion maltolato e o centro metálico de rênio. Posteriormente, utilizando-se como precursor metálico o complexo [ReO(bdtc) $\left.\mathbf{C l}\left(\mathrm{PPh}_{3}\right)\right]$ (4), cuja caracterização completa pode ser vista no tópico 4.2 desta tese, ocorre a formação e não a quebra deste mesmo quelato, com a saída de uma trifenilfosfina e de um íon cloreto, contribuindo termodinamicamente para a estabilidade e obtenção de um maior rendimento $(77 \%)$ do produto desejado. Esta contribuição termodinâmica está relacionada com o aumento da entropia do sistema, uma vez que a coordenação de um íon maltolato ocorre somente com a liberação para a solução (meio) de dois equivalentes de outros ligantes (uma $\mathrm{PPh}_{3}$ e um $\mathrm{Cl}^{-}$). Os espectros de IV obtidos para 3 são idênticos com relação aos seus números de onda e intensidades das bandas apresentadas, e confirmaram a obtenção da mesma substância, tanto com a primeira, quanto com segunda metodologia adotada. Deste modo, o composto 4 foi adotado como precursor também para a obtenção do [ReO(bdtc)(dmhp)] (2) e suas sínteses consistiram em reações com quantidades equimolares dos ligantes Hdmhp ou Hmal e o precursor metálico, seguido da adição de 3 gotas de $\mathrm{Et}_{3} \mathrm{~N}$ e refluxo por 2 horas.

As estruturas dos complexos foram propostas com base nos dados de microanálises $(\mathrm{C}, \mathrm{H}, \mathrm{N}$ e S), nos dados espectroscópicos obtidos através das técnicas de IV, RMN ${ }^{1} \mathrm{H}$ e ${ }^{31} \mathrm{P}, \mathrm{MS}$-ESI e, posteriormente, confirmadas a partir dos dados de difração de raios $\mathrm{X}$ em monocristal. 


\subsubsection{Espectroscopia de Absorção na Região do Infravermelho}

A espectroscopia de absorção na região do infravermelho ofereceu informações que confirmaram a coordenação dos ligantes aos centros metálicos em todos os compostos obtidos (Tabela 2). Trata-se de uma técnica rápida e eficiente para detectar a presença de grupos funcionais nos compostos preparados.

Tabela 2 - Principais bandas $\left(\mathrm{cm}^{-1}\right)$ atribuídas aos modos vibracionais dos complexos 1, 2 e 3, seus precursores e ligantes.

\begin{tabular}{|c|c|c|c|c|c|c|}
\hline \multirow{2}{*}{$\begin{array}{c}\text { Complexos, Precursores } \\
\text { e Ligantes }\end{array}$} & \multicolumn{6}{|c|}{ Modos Vibracionais } \\
\hline & $v(\mathrm{O}-\mathrm{H})$ & $v(C=0)$ & $v(C=N)$ & $v(P-C)$ & $\beta\left(\mathrm{C}_{6} \mathrm{H}_{5}\right)_{\mathrm{PPh} 3}$ & $v(\mathbf{R e}=0)$ \\
\hline 1 & $-\cdots$ & 1615 & $-\cdots$ & 1098 & 694 & 973 \\
\hline 2 & $-\cdots---$ & 1612 & 1535 & ----- & ----- & 957 \\
\hline 3 & ----- & 1608 & 1581 & ----- & ----- & 964 \\
\hline$\left[\mathrm{ReO}(\mathrm{bdtc}) \mathrm{Cl}\left(\mathrm{PPh}_{3}\right)\right]$ & $\begin{array}{ll}--- \\
---\end{array}$ & ---- & 1585 & 1095 & 694 & 957 \\
\hline$\left[\mathrm{ReOCl}_{3}\left(\mathrm{PPh}_{3}\right)_{2}\right]$ & $\begin{array}{ll}--- \\
-\cdots\end{array}$ & ---- & --- & 1093 & 693 & 970 \\
\hline Hdmhp & 3148 & 1632 & ----- & ----- & $-\cdots$ & $-\overline{----}$ \\
\hline Hmal & 3261 & 1654 & ----- & ----- & ----- & ----- \\
\hline $\mathrm{H}_{2}$ bdtc & 3359 & ---- & 1629 & ----- & ----- & ----- \\
\hline
\end{tabular}

Nos espectros de IV dos compostos 1, 2 e 3 (Figuras 20, 21 e 22, respectivamente), as bandas referentes ao estiramento assimétrico $v(R e=0)$ se encontram em 973, 957 e $964 \mathrm{~cm}^{-1}$, respectivamente. ${ }^{61}$ Dentre os três produtos obtidos, apenas 3 apresenta uma variação significativa, ou seja, maior do que a resolução do equipamento de IV de $\pm 4 \mathrm{~cm}^{-1}$, no valor referente ao $v(\mathrm{Re}=\mathrm{O})$, quando comparados aos seus respectivos precursores $\left[\mathrm{ReOCl}_{3}\left(\mathrm{PPh}_{3}\right)_{2}\right]$ ou [ReO(bdtc) $\left.\mathrm{Cl}\left(\mathrm{PPh}_{3}\right)\right]$ (Figuras 15 e 16, respectivamente).

Entretanto, pode-se afirmar que nos complexos 1 e 2, houve coordenação do monoânion piridinonato, dmhp ${ }^{1-}$, por meio do surgimento, em seus respectivos espectros de bandas em 1615 e $1612 \mathrm{~cm}^{-1}$ que não existiam nos seus precursores e que são referentes ao estiramento assimétrico $v(\mathrm{C}=\mathrm{O})$ do ligante $\mathbf{d m h}^{1-}$ coordenado. De modo semelhante, a coordenação do ânion maltolato, mal ${ }^{1-}$, no produto 3, foi confirmada pela observação de uma banda em $1608 \mathrm{~cm}^{-1}$ que corresponde ao modo vibracional $v(\mathrm{C}=\mathrm{O}) .{ }^{47}$ Essa diminuição do número de onda das bandas originalmente em 1632 e $1654 \mathrm{~cm}^{-1}$, atribuídas ao $v(\mathrm{C}=\mathrm{O})$ no $\mathrm{Hdmhp}$ e Hmal, para valores entre 1608 e $1615 \mathrm{~cm}^{-1}$ nos complexos obtidos pode ser racionalizada através da redução da força relativa da ligação, (frequência de 
vibração: ligações duplas > ligações simples) devido à redução da densidade eletrônica entre e carbono e o oxigênio da carbonila, em função da nova ligação formada com o centro metálico, reduzindo o caráter de dupla ligação $\mathrm{C}=\mathrm{O}$.

Figura 15 - Espectro do precursor $\left[\mathrm{ReOCl}_{3}\left(\mathrm{PPh}_{3}\right)_{2}\right]$.

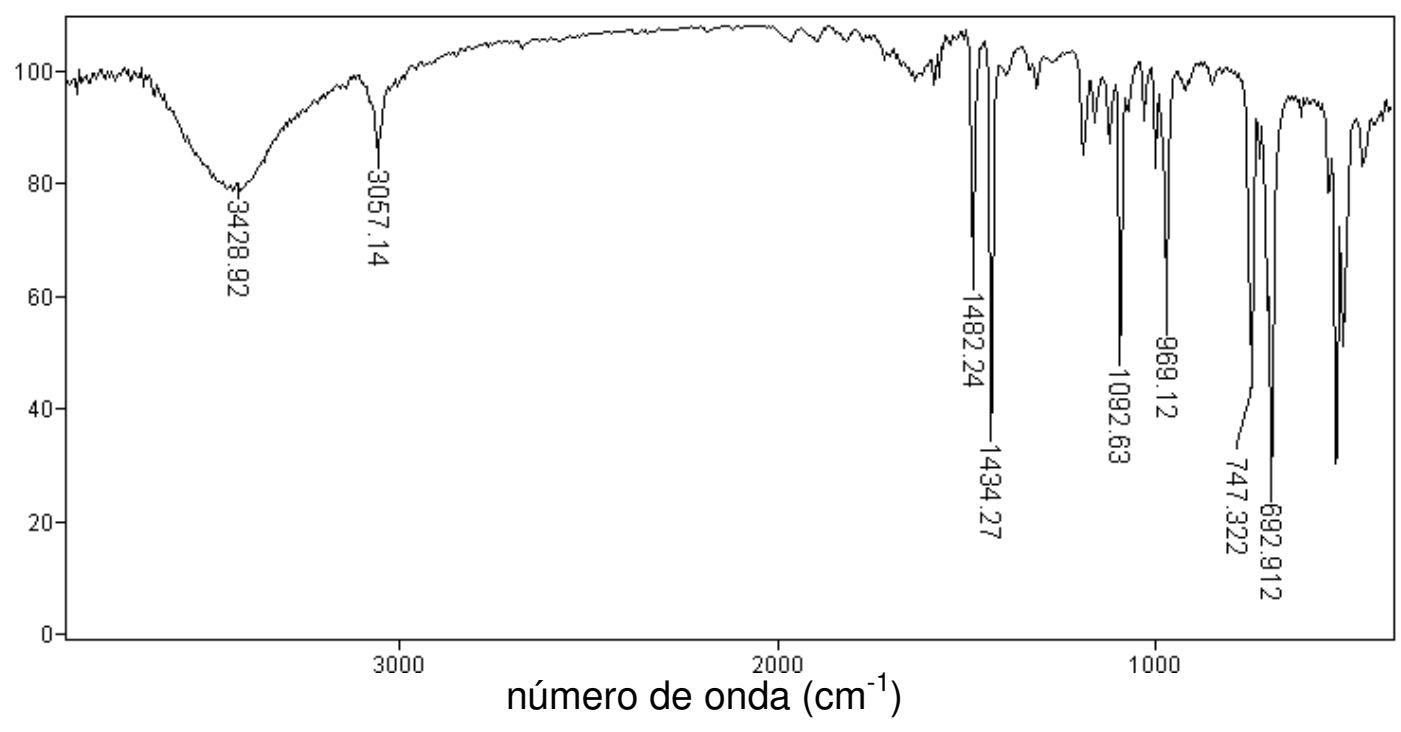

Figura 16 - Espectro do precursor [ReO(bdtc) $\left.\mathbf{C l}\left(\mathrm{PPh}_{3}\right)\right]$ (4).

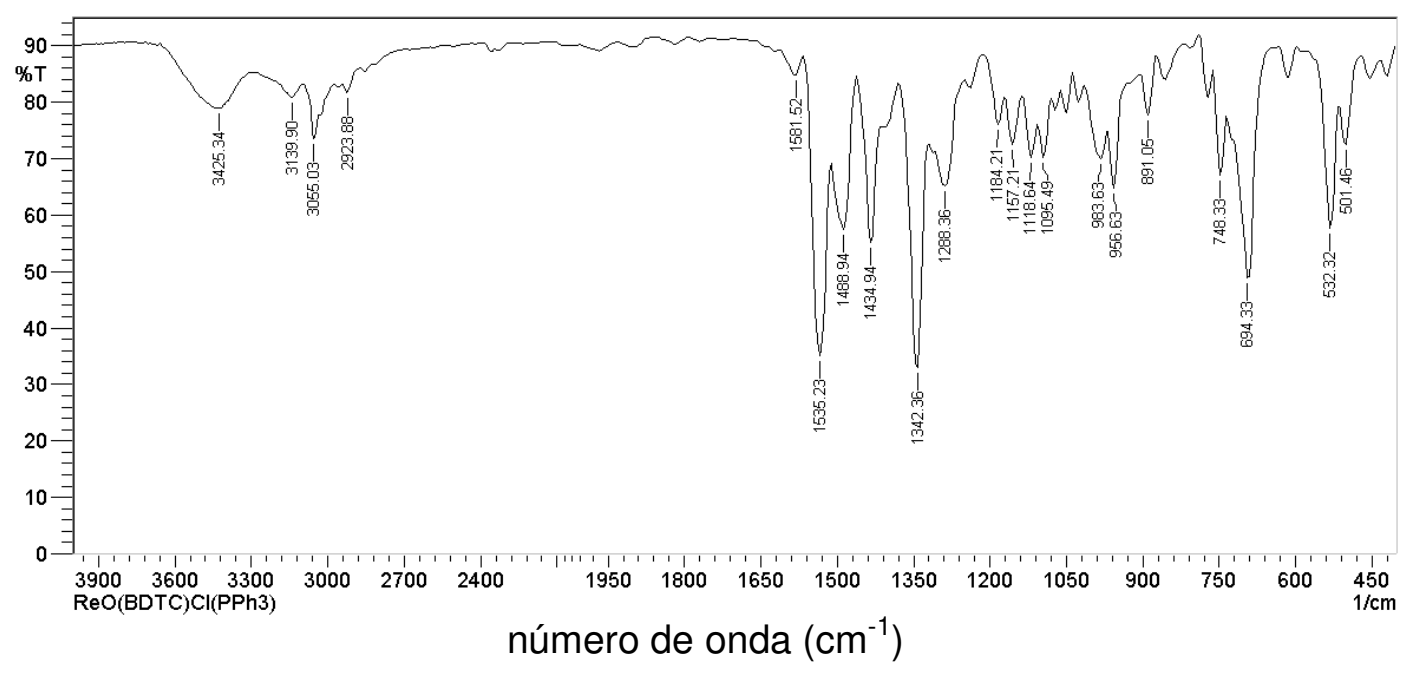


Figura 17 - Espectro do ligante Hdmhp.

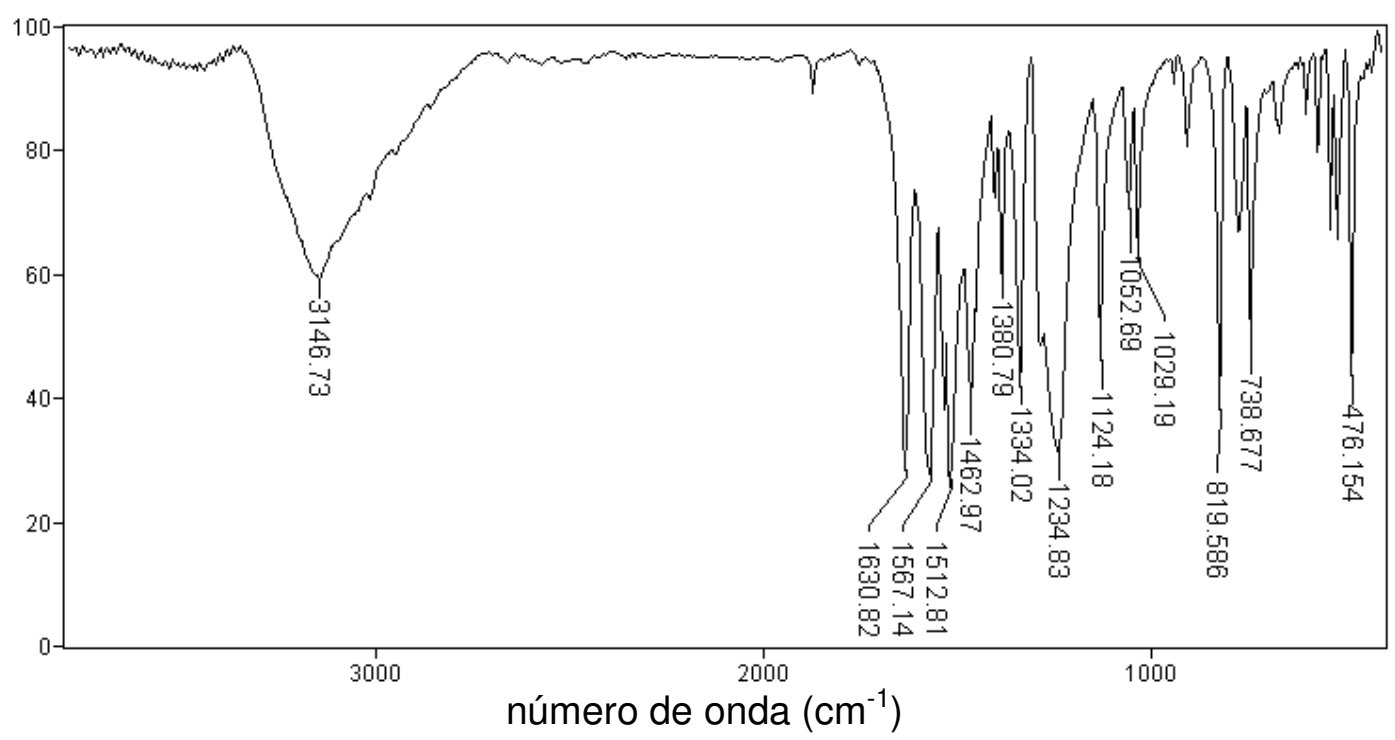

Figura 18 - Espectro do agente complexante Hmal.

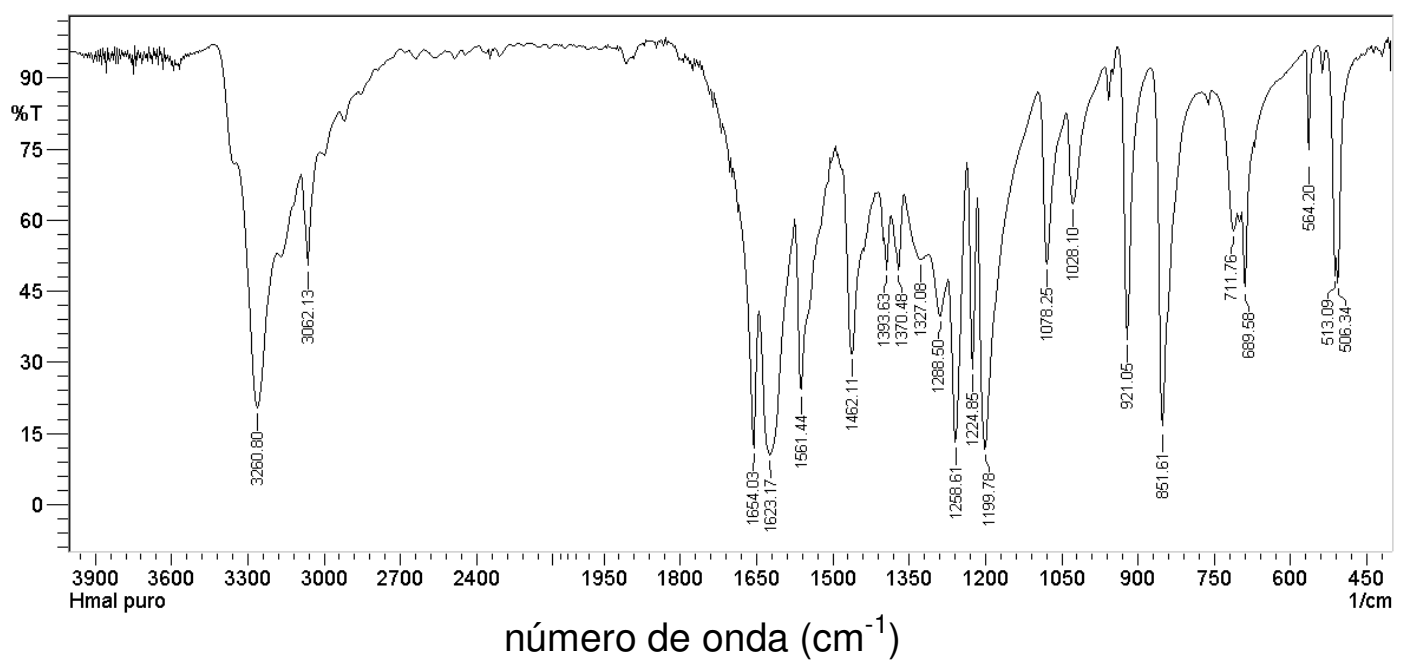


Figura 19 - Espectro do $\mathbf{H}_{2}$ bdtc.

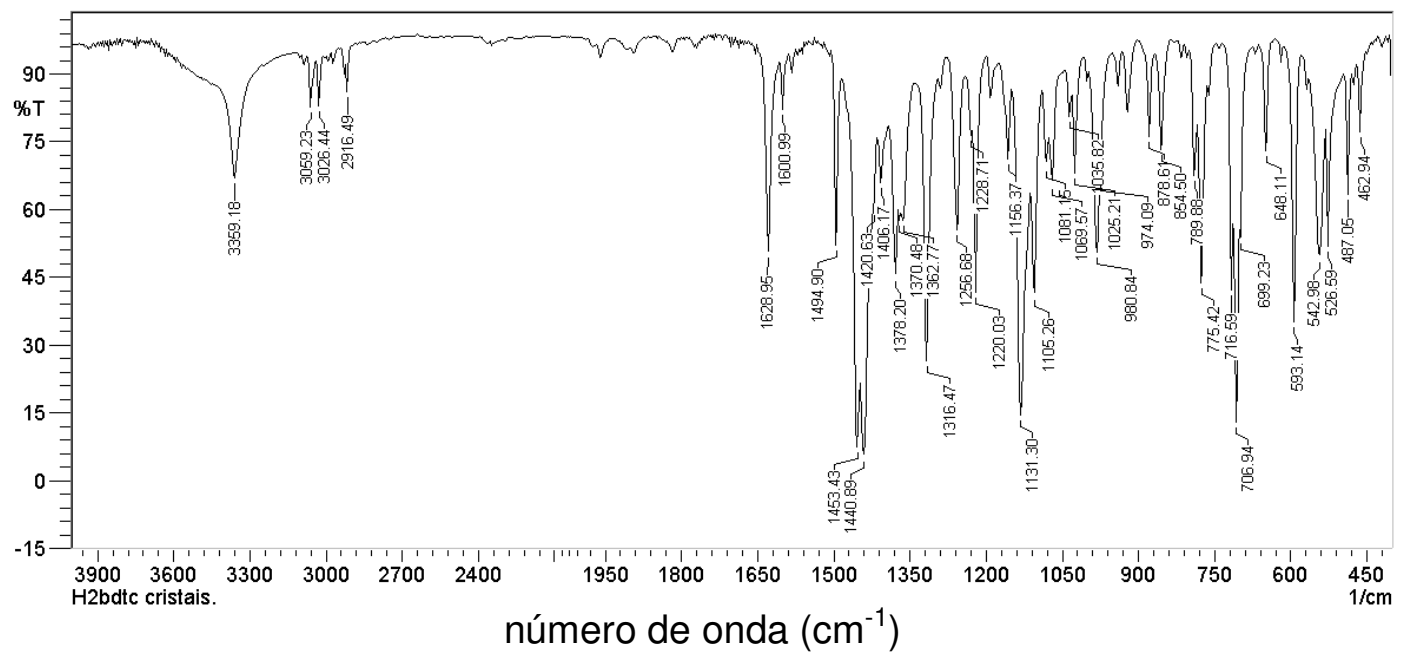

Figura 20 - Espectro do [ReO(dmhp) $\left.\mathrm{Cl}_{2}\left(\mathrm{PPh}_{3}\right)\right]$ (1).

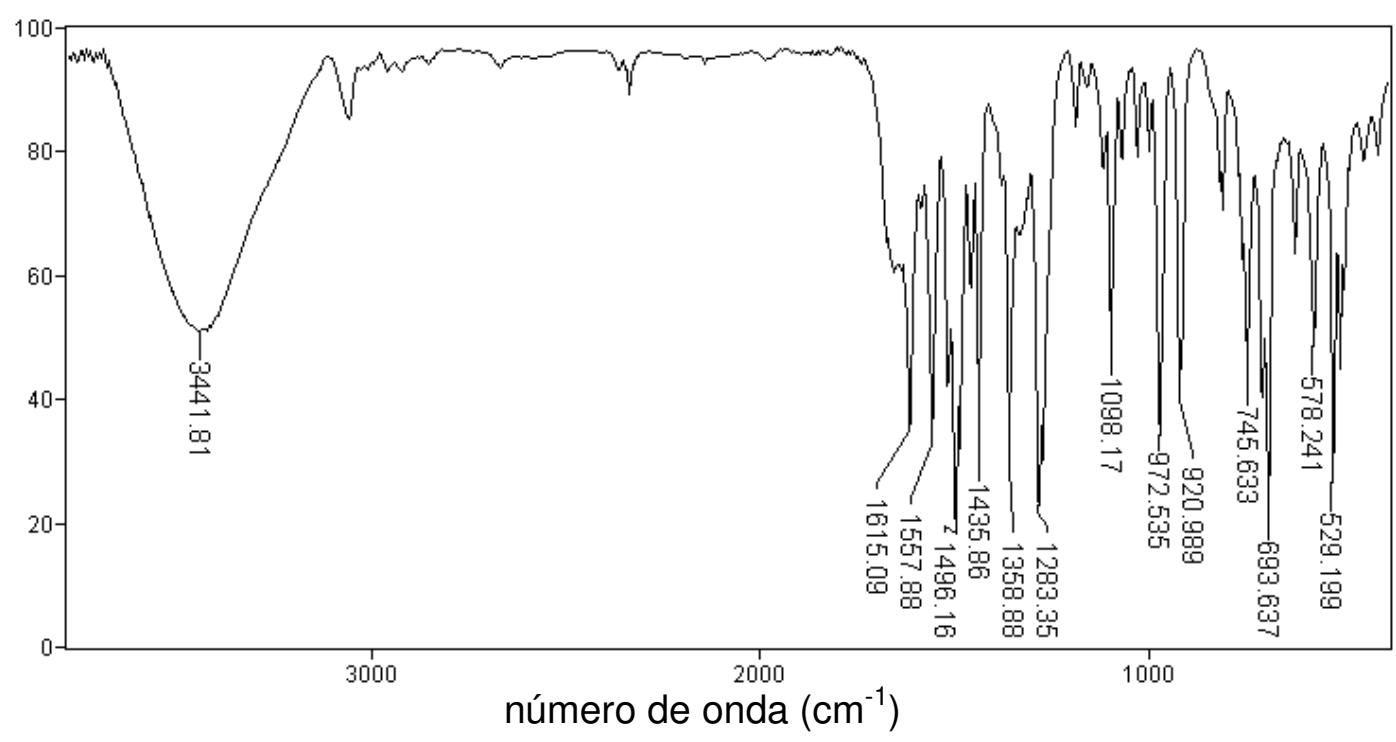


Figura 21 - Espectro do [ReO(bdtc)(dmhp)] (2).

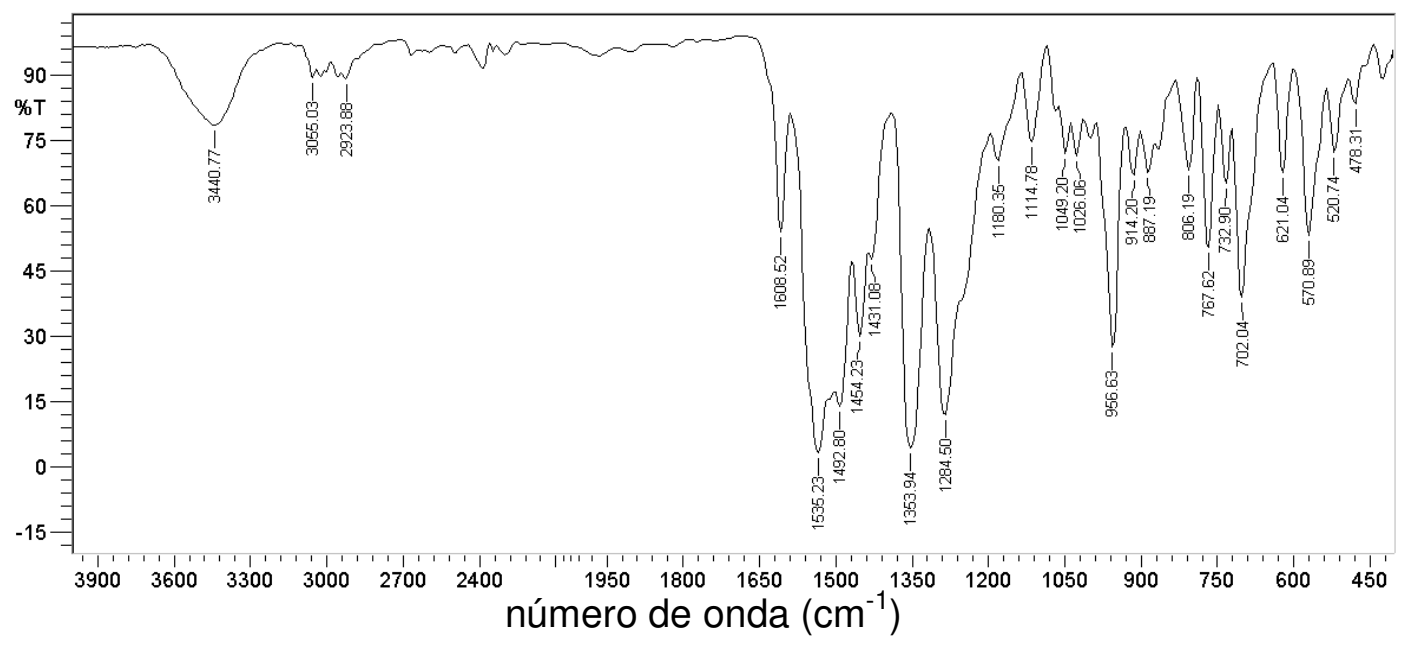

Figura 22 - Espectro do [ReO(bdtc)(mal)] (3).

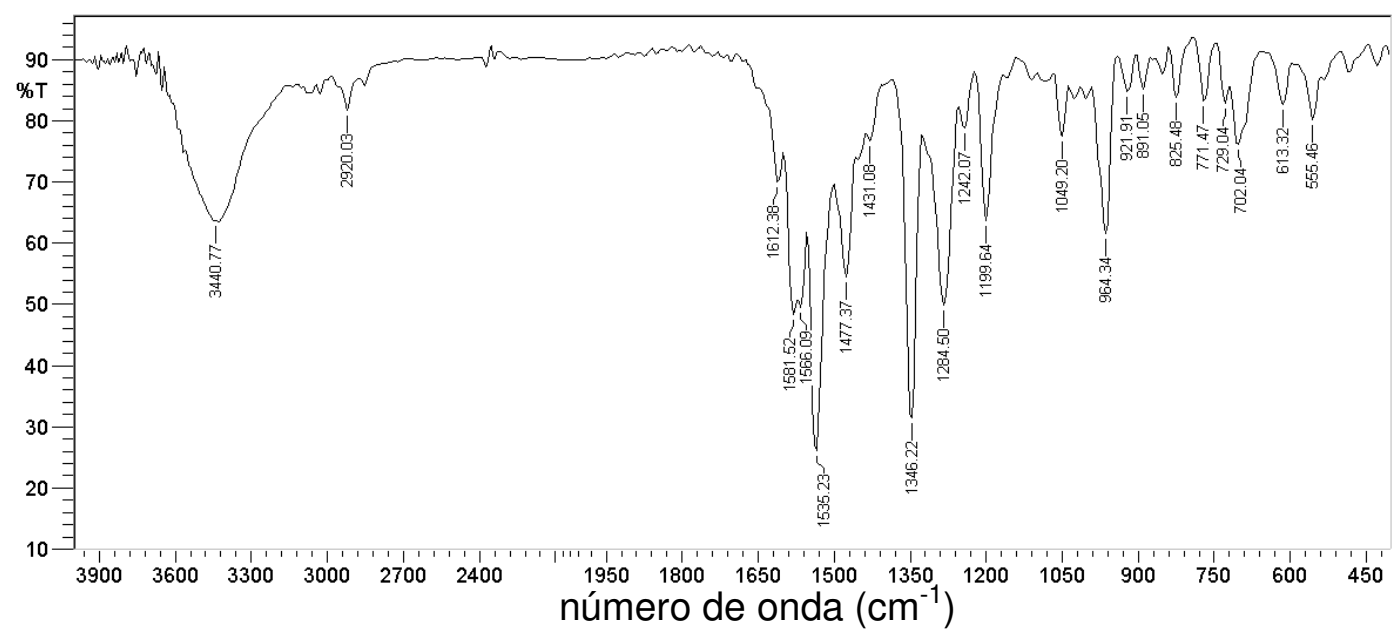


A coordenação dos ligantes $\mathbf{d m h p}^{1-}$ e mal $^{1-}$ de forma bidentada e monoaniônica aos centros metálicos por meio dos átomos de oxigênio provenientes dos grupos funcionais carbonila e hidroxila foi confirmada nos espectros dos três compostos pelo desaparecimento das bandas em 3147 e $3261 \mathrm{~cm}^{-1}$ referentes ao modo vibracional $v(\mathrm{O}-\mathrm{H})$ dos ligantes Hdmhp e Hmal (Figuras 17 e 18, respectivamente), evidenciando a desprotonação de suas hidroxilas e, como citado anteriormente, também pela redução do caráter de dupla ligação $\mathrm{C}=\mathrm{O}$ destes ligantes.

A presença de trifenilfosfina $\left(\mathbf{P P h}_{3}\right)$ foi confirmada no espectro de $\mathbf{1}$ (Figura 20) pela permanência de bandas referentes ao estiramento $v(P-C)$ em1098 $\mathrm{cm}^{-1} \mathrm{e}$ deformação no plano do anel fenila $\beta\left(\mathbf{C}_{6} \mathbf{H}_{5}\right)_{\mathrm{PPh} 3}$, em $694 \mathrm{~cm}^{-1}$, com relação ao espectro do seu precursor [ReOCl $\left.3\left(\mathrm{PPh}_{3}\right)_{2}\right]$, (Figura 15). ${ }^{61,62}$

A saída de $\mathrm{PPh}_{3}$ dos complexos 2 e 3 pode ser constatada nos seus espectros por meio da ausência de seus modos vibracionais característicos (Figuras 21 e 22, respectivamente), confirmando a eficácia da metodologia de síntese adotada.

A coordenação de forma $O, N, S$-doadora do ditiocarbazato bdtc $^{2-}$ ao metal pode ser inferida uma vez que o modo vibracional $v(\mathrm{O}-\mathrm{H})$ (presente no ditiocarbazato livre, figura 19) não aparece nos espectros dos complexos 2 e 3 , indicando a saída do hidrogênio e a ligação do oxigênio ao centro metálico, o que foi, posteriormente, confirmada através dos dados de difração de raios $X$ em monocristal. Outro fator que corrobora com este modo de coordenação é a redução da frequência atribuída ao $v(C=N)$, no ligante livre em $1629 \mathrm{~cm}^{-1}$, para 1535 e 1581 $\mathrm{cm}^{-1}$ nos complexos 2 e $\mathbf{3}$, respectivamente. Esta redução se justifica devido a alguns fatores. Primeiramente, o caráter de dupla ligação que existia entre os átomos de carbono e nitrogênio no ligante livre, foi reduzido para algo intermediário entre uma ligação simples e dupla. Por outro lado, observa-se uma mudança na estrutura do ligante livre cíclico (onde o anel de cinco membros possui menor deslocalização de elétrons $\pi$, aumentando o caráter de dupla ligação entre os átomos de carbono e nitrogênio), para a forma aberta adotada pelo ditiocarbazato no complexo obtido, onde se observa uma maior deslocalização densidade eletrônica $\pi$, devido à formação de um sistema conjugado de duplas ligações por quase todo o 
ligante bdtc $^{2-}$ (Figura 23), justificando sua visualização em regiões de menor número de onda.

Figura 23 - Forma ciclizada do $\mathbf{H}_{2}$ bdtc (a): sistema rígido e com pouca deslocalização $\pi$. Forma aberta do bdtc $^{2-}(\mathbf{b})$ : sistema com duplas ligações deslocalizadas (pontilhadas) ao longo do ligante complexado. Os demais ligantes foram omitidos para maior clareza do sistema n deslocalizado em (b).

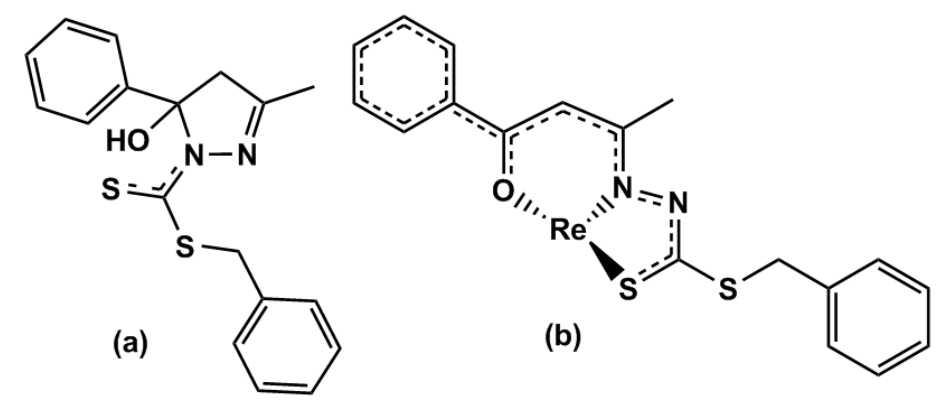

\subsubsection{Espectroscopia de Ressonância Magnética Nuclear (RMN ${ }^{1} \mathrm{H} \mathrm{e}$ $\left.{ }^{31} \mathrm{P}\right)$ para os complexos 1,2 e 3}

Os isótopos diamagnéticos com spin nuclear diferente de zero são suscetíveis ao fenômeno da ressonância magnética nuclear (os núcleos de certos átomos giram em torno de um eixo, como magnetos, e quando são submetidos a determinados campos eletromagnéticos podem absorver energia, entrando em ressonância). O isótopo natural do fósforo ${ }^{31} \mathrm{P}$ possui spin nuclear igual a $1 / 2$ e $100 \%$ de abundância. Por estes motivos, este núcleo mostra-se bastante sensível à técnica de RMN, o que permite analisar amostras com baixa solubilidade, como a destes complexos.

$\mathrm{O}$ espectro de $\mathrm{RMN}{ }^{31} \mathrm{P}$ do complexo de partida $\left[\mathrm{ReOCl}_{3}\left(\mathrm{PPh}_{3}\right)_{2}\right]$ exibe um simpleto em -18,5 ppm (Figura 24), referente ao deslocamento químico observado para os dois átomos de fósforo, magneticamente equivalentes, das trifenilfosfinas em posição trans entre si. O espectro deste mesmo núcleo, obtido para o complexo 1, exibe um sinal em -22,1 ppm (Figura 25), referente ao deslocamento químico atribuído ao átomo de fósforo da trifenilfosfina na posição trans ao ligante cloro. ${ }^{62}$ Esta diferença entre os deslocamentos químicos do precursor e do produto obtido revela que 0 átomo de fósforo da trifenilfosfina no composto 1 está ainda mais blindado do que aqueles presentes no precursor metálico. Este efeito de blindagem se justifica devido ao ligante cloro ser um bom doador de densidade eletrônica $\pi$, o 
que contribui de forma efetiva para o aumento da blindagem do átomo de fósforo pertencente à trifenilfosfina coordenada no complexo obtido.

Figura 24 - Espectro de $\mathrm{RMN}{ }^{31} \mathrm{P}$ do precursor $\left[\mathrm{ReOCl}_{3}\left(\mathrm{PPh}_{3}\right)_{2}\right](121,47 \mathrm{MHz}$, $\mathrm{CH}_{2} \mathrm{Cl}_{2}$ ).

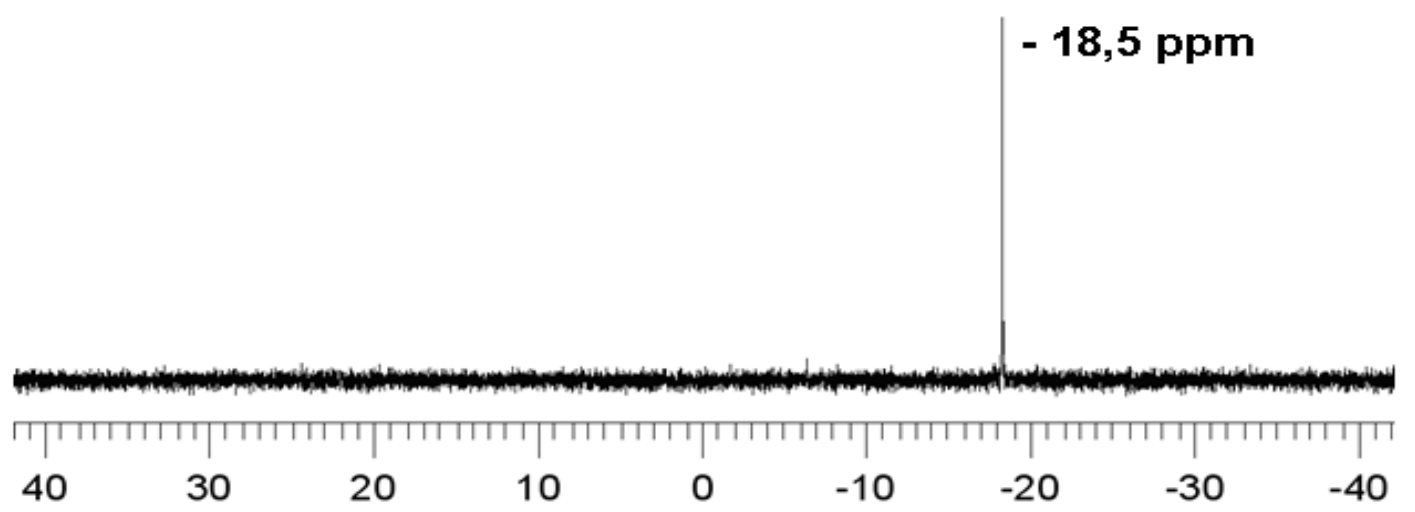

Figura 25 - Espectro de $R M N{ }^{31} \mathrm{P}$ do $\left[\mathbf{R e O}(\mathbf{d m h p}) \mathrm{Cl}_{2}\left(\mathrm{PPh}_{3}\right)\right]$ (1) $(121,47 \mathrm{MHz}$, $\mathrm{CD}_{2} \mathrm{Cl}_{2}$ ).

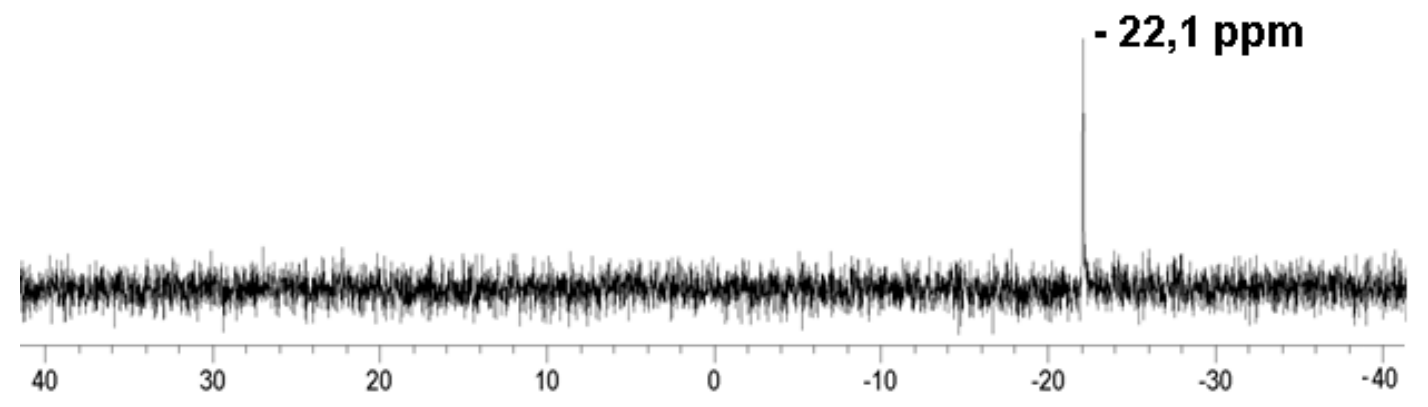


Figura 26 - Espectro de RMN ${ }^{1} \mathrm{H}$ de $\left[\mathrm{ReO}(\mathrm{dmhp}) \mathrm{Cl}_{2}\left(\mathrm{PPh}_{3}\right)\right]$ (1) $\left(300 \mathrm{MHz}, \mathrm{CD}_{2} \mathrm{Cl}_{2}\right)$.

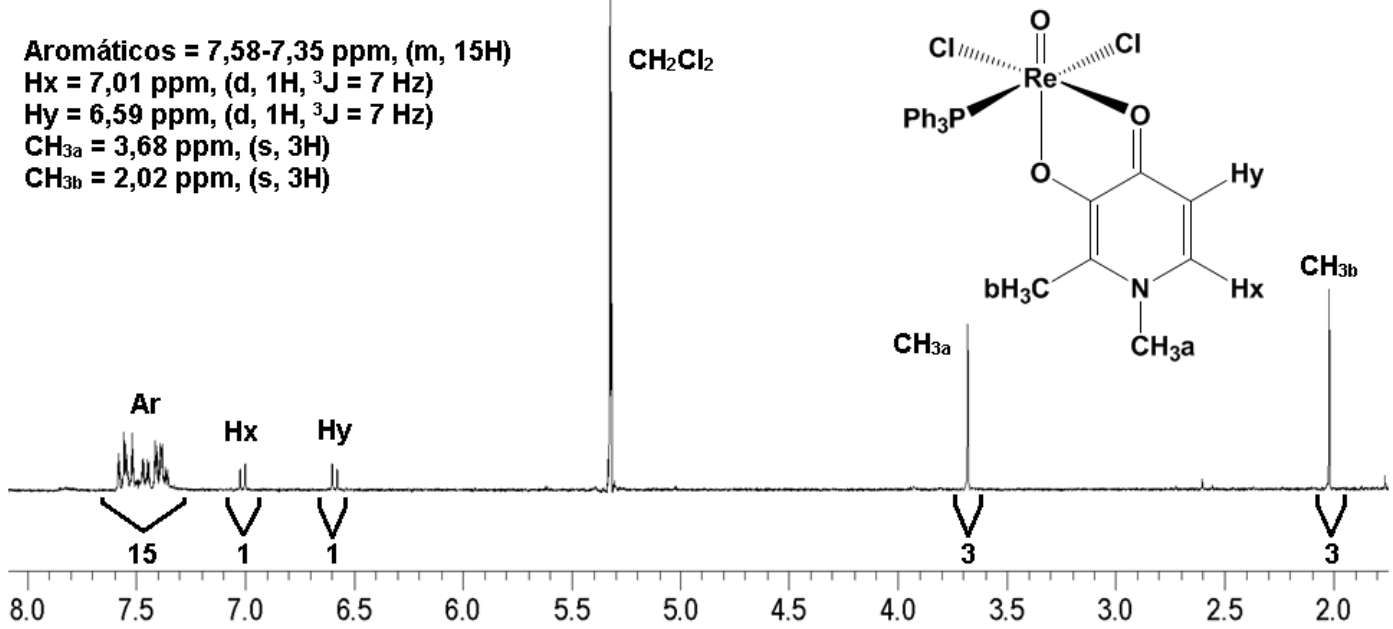

Tabela 3 - Dados de RMN ${ }^{1} \mathrm{H}(300 \mathrm{MHz})$ e ${ }^{31} \mathrm{P}(121,45 \mathrm{MHz})$ para 1 obtidos em $\mathrm{CD}_{2} \mathrm{Cl}_{2}$.

\begin{tabular}{|ccccc|}
\hline Complexo & $\mathrm{CH}_{3}$ & $\mathbf{C H}$ & Aromáticos & ${ }^{31} \mathbf{P}$ \\
\hline \multirow{1}{1}{} & $3,68\left(\mathrm{~s}, \mathrm{CH}_{3 \mathrm{a}}\right)$ & $7,01\left(\mathrm{~d}, \mathrm{CH}_{\mathrm{x}}\right)$ & $7,58-7,35(\mathrm{~m})$ & $-22,1(\mathrm{~s})$ \\
\hline
\end{tabular}

Os complexos 2 e 3 possuem em suas esferas de coordenação ligantes pertencentes a duas classes distintas, piridinona e ditiocarbazato no primeiro e pirona e ditiocarbazato no segundo.

O $\mathbf{H}_{2}$ bdtc manteve em solução a mesma estrutura cíclica, formada por um anel pirazolínico de cinco membros, determinada no estado sólido por difração de raios $\mathrm{X}$ em monocristal. ${ }^{63}$ Este fato foi comprovado pela presença no seu espectro de $\mathrm{RMN}{ }^{1} \mathrm{H}$ de dois sinais referentes aos grupos metilenos que apareceram desdobrados sob a forma de duplos dupletos (dd). Poderia ocorrer que este ligante apresentasse, em solução, algumas formas tautoméricas que favorecessem a coordenação bivalente e tridentada, observada em todos os compostos deste trabalho onde este agente complexante foi utilizado. No entanto, nenhum sinal correspondente aos seus possíveis tautômeros foi observado em seu espectro de RMN ${ }^{1} \mathrm{H}$ (Figura 27), ocorrendo somente a observação dos sinais correspondentes à sua forma cíclica. Por esta razão, acredita-se que somente através da reação com o metal ocorra a quebra do anel pirazolínico. A coordenação tridentada e dianiônica do bdtc $^{2-}$ teve como consequência um rearranjo de seus hidrogênios, o que deu origem 
a um grupo $\mathrm{CH}$, cujo sinal de hidrogênio foi facilmente identificado nos espectros de todos os produtos.

Um indício de doação de densidade eletrônica do ditiocarbazato para os átomos de rênio nos compostos 2 e 3 pode ser avaliado pela observação dos simpletos referentes às metilas deste ligante em regiões de campo mais baixo (efeito de desblindagem eletrônica) nos seus respectivos espectros de $\mathrm{RMN}^{1} \mathrm{H}$ (Figuras 28 e 29, respectivamente), com variações em torno de 0,5 ppm, quando comparados ao deslocamento químico deste mesmo grupo no $\mathbf{H}_{2}$ bdtc não complexado.

Os deslocamentos químicos dos hidrogênios nos ligantes bdtc ${ }^{2-}, \mathbf{d m h p}^{-1} \mathrm{e}$ mal $^{-1}$ coordenados, nos compostos 2 e 3, foram prontamente identificados e podem ser visualizados nas tabelas 4 e 5 , respectivamente.

Figura 27 - Espectro de $\mathrm{RMN}{ }^{1} \mathrm{H}$ do $\mathbf{H}_{\mathbf{2}}$ bdtc (400 $\mathrm{MHz}, \mathrm{CDCl}_{3}$ ).

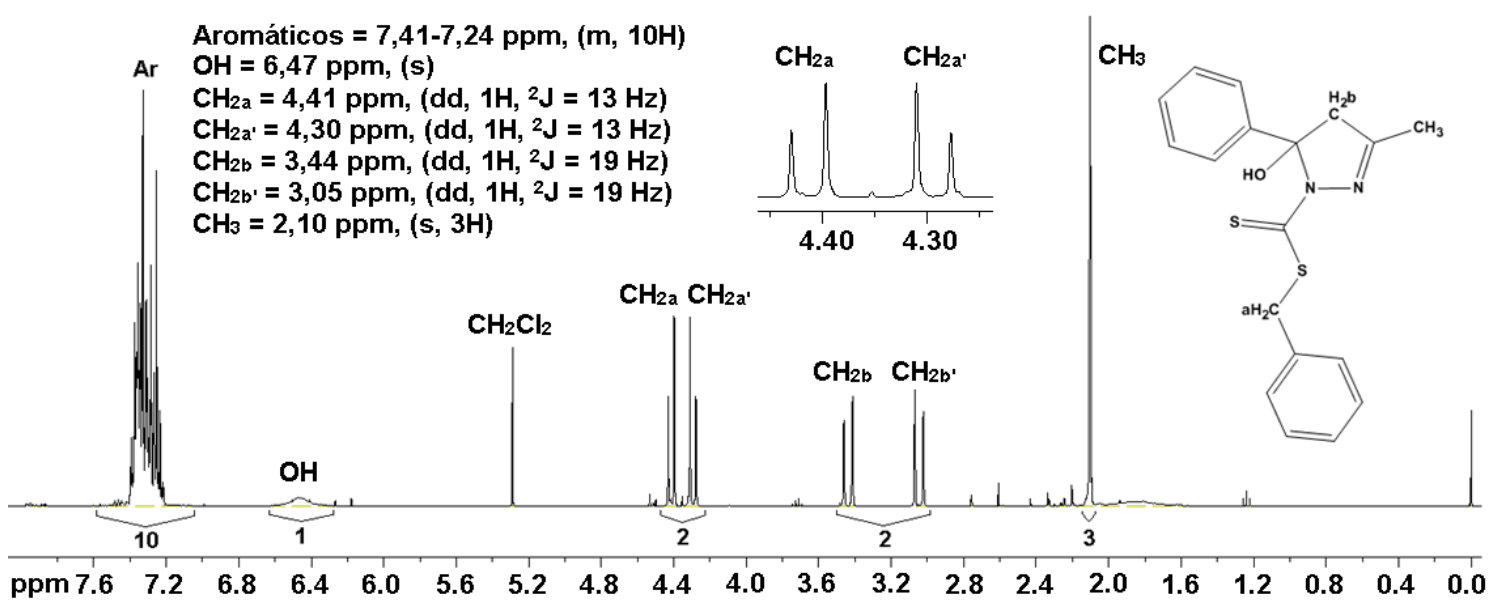


Figura 28 - Espectro de $\mathrm{RMN}^{1} \mathrm{H}$ de $\left[\operatorname{ReO}\left(\right.\right.$ bdtc)(dmhp)] (2) $\left(400 \mathrm{MHz}, \mathrm{CDCl}_{3}\right)$.

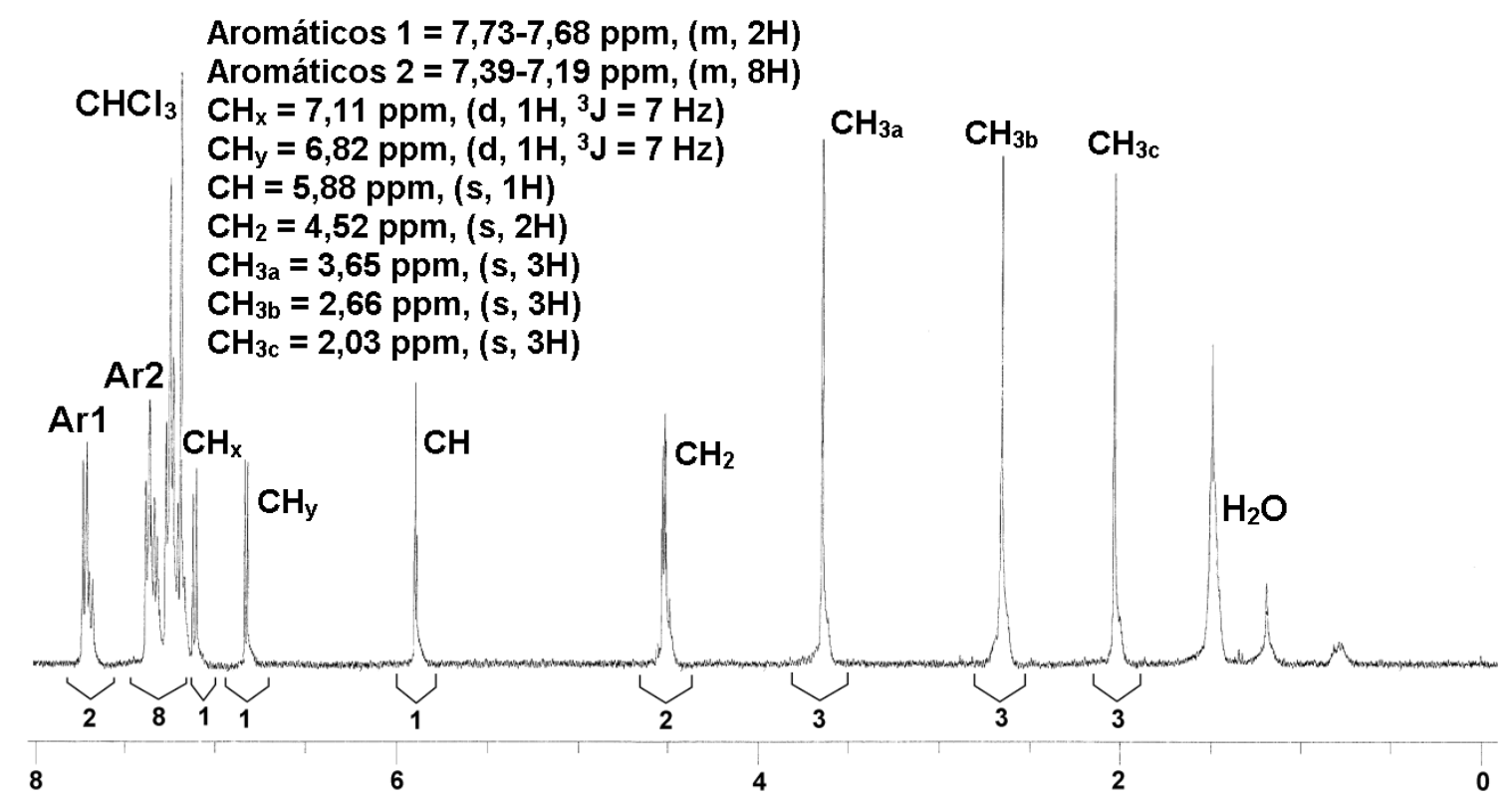

Tabela 4 - Dados de $\mathrm{RMN}{ }^{1} \mathrm{H}(400 \mathrm{MHz})$ para 2 obtidos em $\mathrm{CDCl}_{3}$.

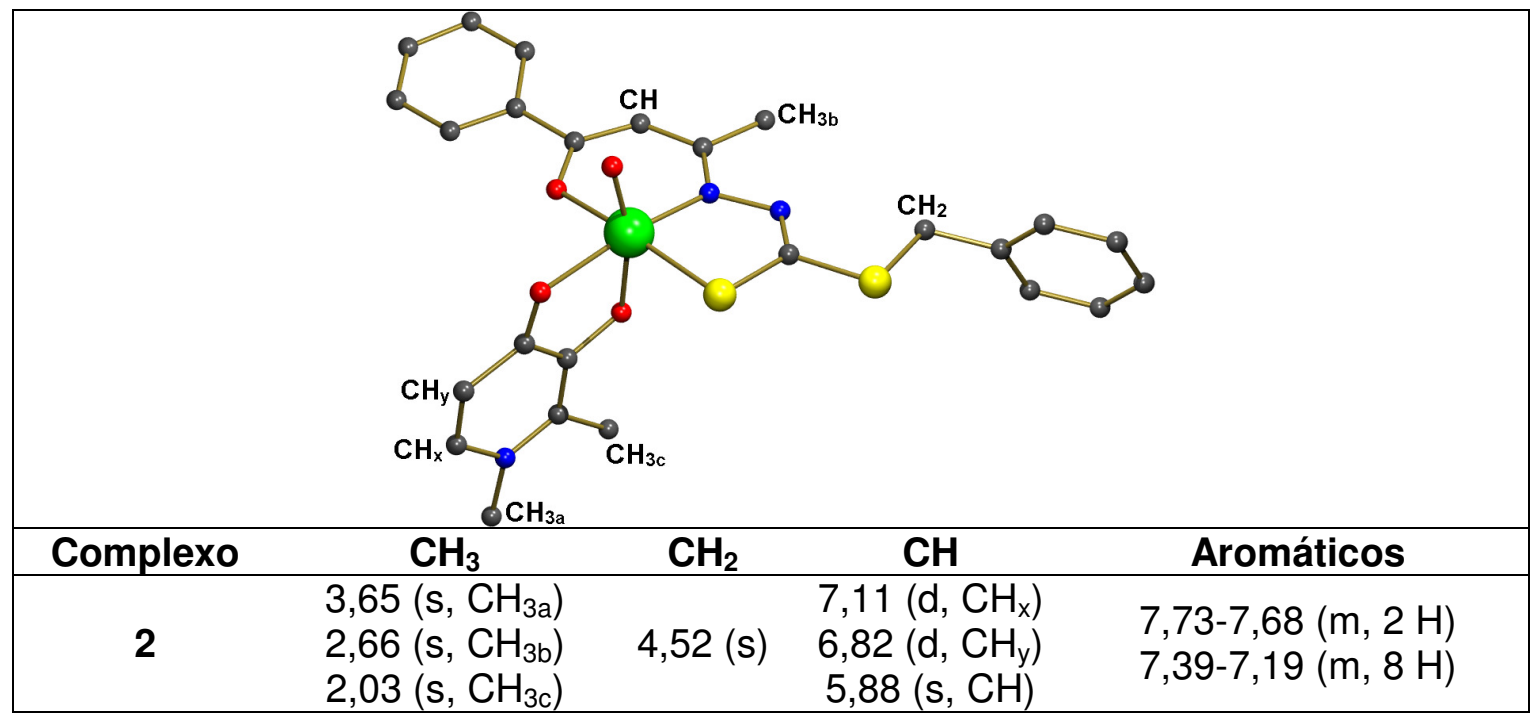


Figura 29 - Espectro de $\mathrm{RMN}^{1} \mathrm{H}$ de [ReO(bdtc)(mal)] (3) $\left(400 \mathrm{MHz}, \mathrm{CDCl}_{3}\right)$.

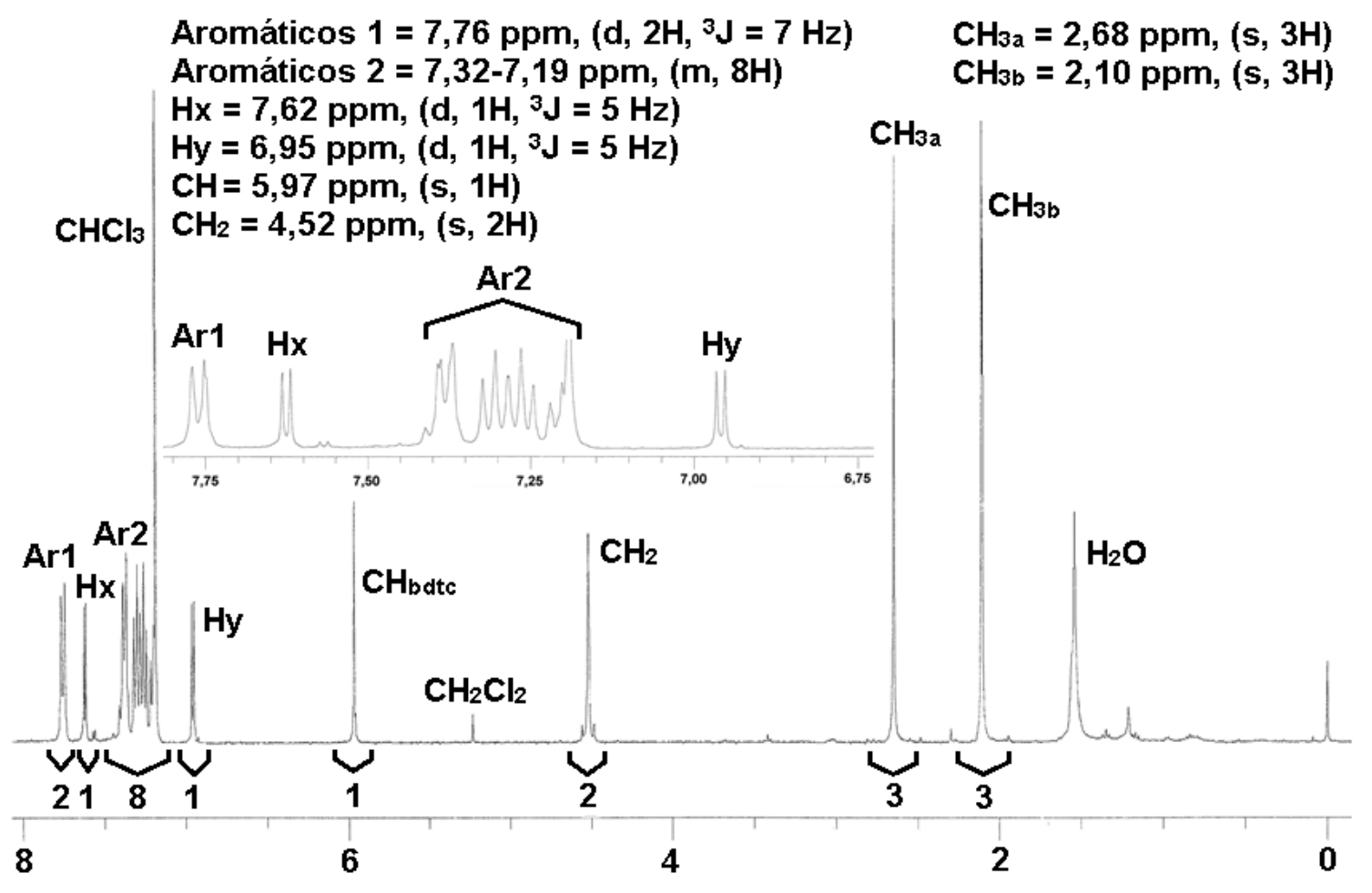

Tabela 5 - Dados de $\mathrm{RMN}{ }^{1} \mathrm{H}(400 \mathrm{MHz})$ para 3 obtidos em $\mathrm{CDCl}_{3}$.

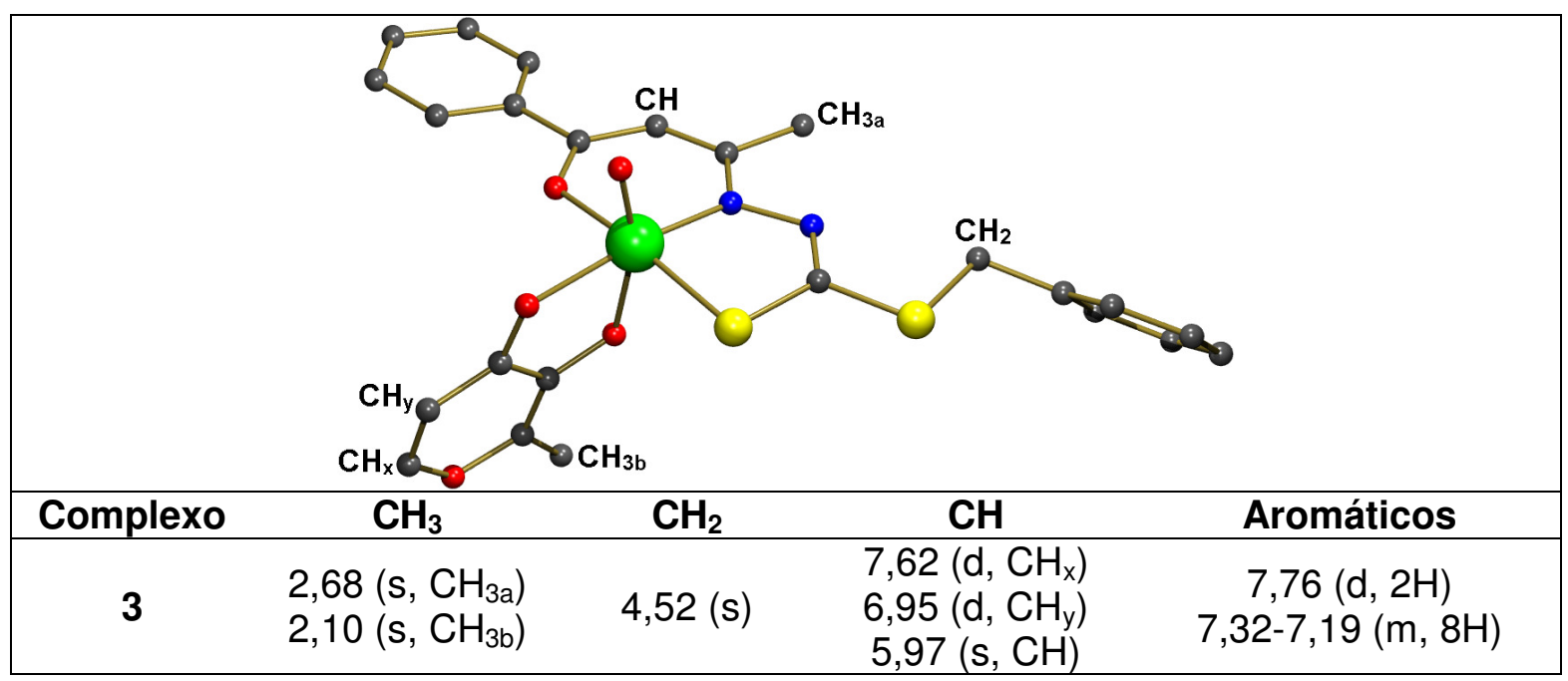




\subsubsection{Difração de Raios X em Monocristal de 1, 2 e 3}

\section{Determinação das Estruturas Cristalinas e Moleculares}

Foram obtidos monocristais adequados para determinação estrutural por difração de raios $X$ dos complexos 1, 2 e 3, conforme consta na descrição das sínteses. O complexo 1, cristalizou-se sob a forma de placas losangulares verdes escuras, enquanto 2 e $\mathbf{3}$ como prismas vermelhos retangulares.

As constantes de cela dos complexos $\mathbf{1}, \mathbf{2}$ e $\mathbf{3}$ foram calculadas, respectivamente, a partir de 33544, 37664 e 22882 reflexões, coletadas com uma ampla variação do ângulo $2 \theta$, em todos os casos.

Todos os complexos cristalizaram-se no sistema cristalino monoclínico. $\mathrm{O}$ composto 1 pertence ao grupo espacial $\mathrm{P} 2_{1}$, o que indica que sua cela é primitiva $(P)$, possui eixo de ordem 2 , de rotação + translação na direção de $b(21)$. Os complexos 2 e 3 cristalizaram no mesmo grupo espacial, $P 2_{1} / c$, sendo que possuem cela primitiva $(\mathrm{P})$, eixo de ordem 2 , de rotação + translação na direção de $b(21)$, centro de inversão, plano de reflexão + translação horizontal na direção de $c$.

A solução das estruturas se deu por métodos diretos. ${ }^{64}$

Com exceção dos átomos de hidrogênio, que foram calculados a partir de posições idealizadas, todos os demais foram refinados com deslocamento térmico anisotrópico. ${ }^{65}$ Foram aplicadas na solução das estruturas dos complexos 1,2 e 3 as correções de absorção multi-scan ${ }^{66}$, em 1, e Delabs $^{67}$, em 2 e 3. As demais informações referentes à determinação das estruturas, além dos ângulos e distâncias de ligações selecionadas são apresentadas nas tabelas 6, 7 e 8. 


\section{Discussão das Estruturas Cristalinas e Moleculares}

Os átomos de rênio $(\mathrm{V})$, nos complexos $\mathbf{1}, 2$ e $\mathbf{3}$, encontram-se hexacoordenados apresentando uma geometria de coordenação octaédrica distorcida (Figuras 30, 31 e 32, respectivamente). Em 1, a esfera de coordenação é ocupada pelo ligante oxo, dois átomos de oxigênio doadores provenientes do ligante $\mathrm{dmhp}^{1-}$, um átomo de fósforo da trifenilfosfina e dois ligantes cloro. De modo semelhante, em 2 e 3 a esfera de coordenação de cada complexo é também ocupada pelo ligante oxo e dois átomos de oxigênio doadores oriundos dos ânions $\mathbf{d m h p}^{1-}$ em 2 e mal ${ }^{1-}$, em 3. As demais posições nos compostos 2 e 3 são ocupadas por átomos $\mathrm{O}, \mathrm{N}, \mathrm{S}$-doadores procedentes do $\mathrm{bdtc}^{2-}$.

Os comprimentos de ligação entre o ligante oxo e o átomo de rênio(V) central, estão entre 166,3(4) e 170,3(1) pm e apresentam-se compatíveis com a ligação dupla $\mathrm{Re}=0 .{ }^{61,62,68}$

As ligações Re-O em posição axial, trans ao grupo oxo, são notadamente mais curtas que aquelas que ocupam posição equatorial, trans a um dos haletos. Este fenômeno, de aumento de densidade eletrônica na ligação $\mathrm{Re}-\mathrm{O}$ trans ao ligante oxo, tem sido observado em complexos de rênio $(\mathrm{V})$ onde o átomo de oxigênio ocupante da posição trans é oriundo de um ligante quelante ou de um fenolato ou alcoolato. ${ }^{8,69}$

Os comprimentos das ligações $\mathrm{Re}-\mathrm{Cl}$ e Re-P encontram-se adequados para as respectivas ligações (Tabela 7). ${ }^{61,62}$

O modo de coordenação quelante, bidentado e monoaniônico, dos ligantes mal $^{1-}$ e dmhp ${ }^{1-}$, assim como a capacidade de formar dois anéis quelatos (um com seis e outro com cinco membros), como consequência da coordenação de forma tridentada e bivalente do bdtc $^{2-}$ contribuem para a estabilidade dos produtos neutros formados. 
Figura 30 - Estrutura molecular do complexo 1. Por motivo de maior clareza, os átomos de hidrogênio foram omitidos.

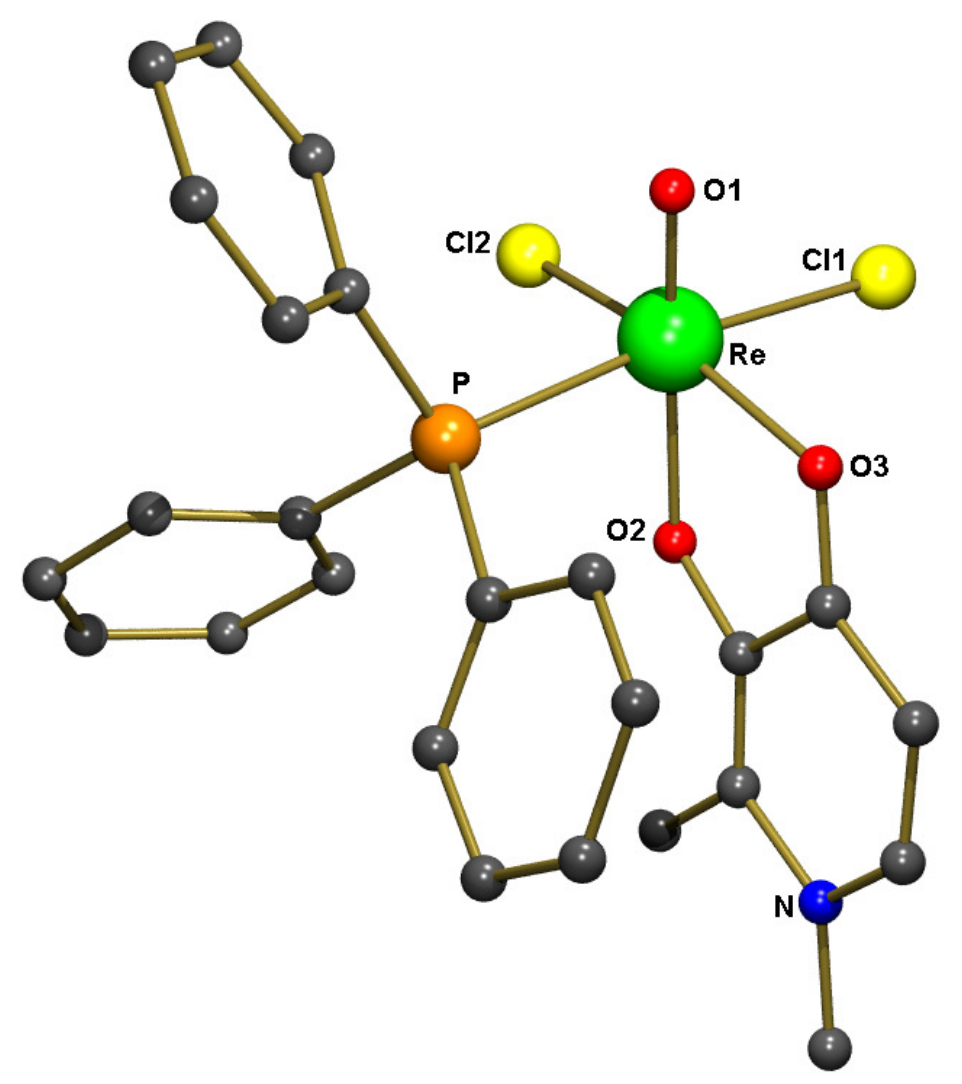


Figura 31 - Estrutura molecular do complexo 2. Para maior clareza, todos os átomos de hidrogênio foram omitidos.

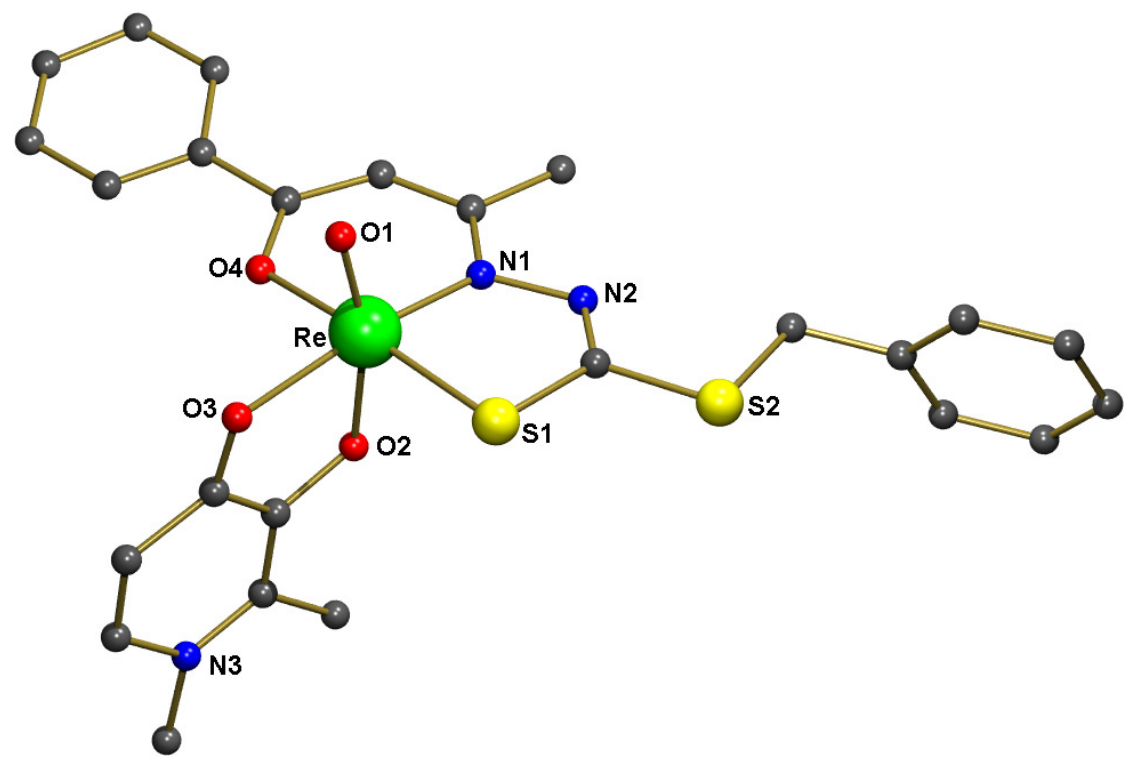

Figura 32 - Estrutura molecular do complexo 3. Para facilitar a visualização da estrutura do complexo todos os átomos de hidrogênio foram excluídos.

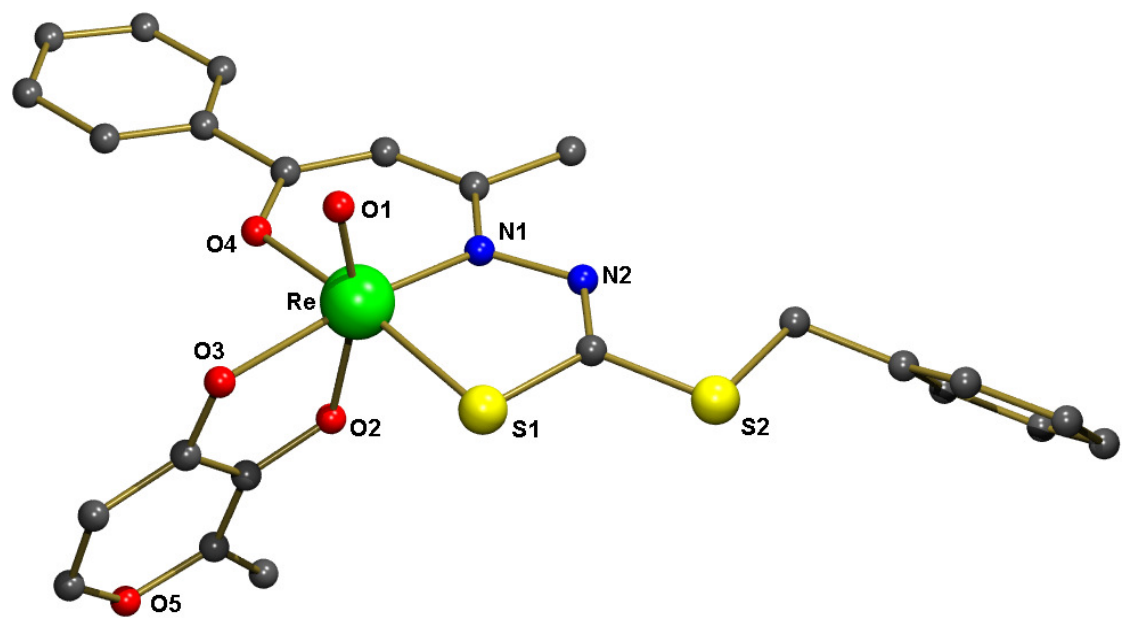


Tabela 6 - Dados cristalográficos de raios $X$ e resultados dos refinamentos das estruturas dos complexos [ReO(dmhp) $\left.\mathbf{C l}_{2}\left(\mathrm{PPh}_{3}\right)\right]$ (1), [ReO(bdtc)(dmhp)] (2) [ReO(bdtc)(mal)] (3).

\begin{tabular}{|c|c|c|c|}
\hline Complexo & 1 & 2 & 3 \\
\hline Fórmula molecular & $\mathrm{C}_{25,75} \mathrm{H}_{24} \mathrm{Cl}_{4} \mathrm{NO}_{3} \mathrm{PRe}$ & $\mathrm{C}_{25} \mathrm{H}_{25} \mathrm{~N}_{3} \mathrm{O}_{4} \mathrm{ReS}_{2}$ & $\mathrm{C}_{24} \mathrm{H}_{21} \mathrm{~N}_{2} \mathrm{O}_{5} \mathrm{ReS}_{2}$ \\
\hline Massa Molar g. $\mathrm{mol}^{-1}$ & 754,43 & 680,81 & 667,75 \\
\hline Temperatura $(\mathrm{K})$ & 293(2) & $200(2)$ & $200(2)$ \\
\hline Comprimento da radiação (pm) & 71,073 & 71,073 & 71,073 \\
\hline Sistema Cristalino & Monoclínico & Monoclínico & Monoclínico \\
\hline Grupo Espacial & $\mathrm{P} 2_{1}$ & $\mathrm{P} 2_{1} / \mathrm{c}$ & $\mathrm{P} 2_{1} / \mathrm{c}$ \\
\hline \multicolumn{4}{|l|}{ Parâmetros da cela unitária } \\
\hline$a(\mathrm{pm})$ & $984,20(2)$ & $1337,14(9)$ & $1074,61(10)$ \\
\hline$b(\mathrm{pm})$ & $3036,80(7)$ & $1461,01(6)$ & $1045,92(7)$ \\
\hline$c(\mathrm{pm})$ & $1033,50(2)$ & $2735,20(18)$ & $2196,1(3)$ \\
\hline$\alpha(\stackrel{\circ}{)}$ & 90 & 90 & 90 \\
\hline$\beta(\stackrel{\circ}{)})$ & $115,954(1)$ & $103,629(5)$ & $102,146(9)$ \\
\hline$\gamma\left({ }^{\circ}\right)$ & 90 & 90 & 90 \\
\hline Volume $\left(\mathrm{nm}^{3}\right)$ & $2,7774(1)$ & $5,1930(5)$ & $2,4131(4)$ \\
\hline Z & 4 & 4 & 4 \\
\hline Coeficiente de absorção $\left(\mathrm{mm}^{-1}\right)$ & 4,846 & 4,879 & 5,247 \\
\hline Tamanho do cristal $\left(\mathrm{mm}^{3}\right)$ & $0,149 \times 0,057 \times 0,013$ & $\begin{array}{c}0,167 \times 0,054 \times \\
0,097\end{array}$ & $\begin{array}{c}0,173 \times 0,135 \times \\
0,102 \\
\end{array}$ \\
\hline Forma e cor do cristal & Placas verdes & Prismas vermelhos & Prismas vermelhos \\
\hline Método / variação de $\theta(\stackrel{\circ}{)})$ & 2,98 até 25,00 & 2,69 até 29,28 & 2,72 até 29,32 \\
\hline Índices $(\mathrm{h}, \mathrm{k}, \mathrm{l})$ & $\begin{array}{l}-11 \rightarrow h \rightarrow 11, \\
-35 \rightarrow k \rightarrow 36, \\
-12 \rightarrow \mid \rightarrow 12\end{array}$ & $\begin{array}{l}-18 \rightarrow h \rightarrow 17, \\
-20 \rightarrow \mathrm{k} \rightarrow 19, \\
-35 \rightarrow \mid \rightarrow 37\end{array}$ & $\begin{array}{c}-14 \rightarrow h \rightarrow 14, \\
-13 \rightarrow \mathrm{k} \rightarrow 14, \\
-30 \rightarrow \mid \rightarrow 29\end{array}$ \\
\hline Reflexões coletadas & 33544 & 37664 & 22882 \\
\hline Reflexões independentes / $R_{\text {int }}$ & $9656 / 0,0611$ & $13939 / 0,0642$ & $6489 / 0,0798$ \\
\hline Correção de Absorção & Multi-scan $^{66}$ & Delabs $^{6 /}$ & Delabs $^{67}$ \\
\hline Transmissão min. / max. & $0,627 / 0,734$ & $0,134 / 0,605$ & $0,235 / 0,696$ \\
\hline Refinamento da estrutura & $\begin{array}{l}\text { Matriz completa dos } \\
\text { mínimos quadrados }\end{array}$ & $\begin{array}{l}\text { Matriz completa dos } \\
\text { mínimos quadrados }\end{array}$ & $\begin{array}{l}\text { Matriz completa dos } \\
\text { mínimos quadrados }\end{array}$ \\
\hline Tratamento dos hidrogênios & Calculados & Calculados & Calculados \\
\hline Fatores $R$ finais $[l>2 \sigma(I)]$ & $\begin{array}{l}R 1=0,0458 \\
\text { wR2 = 0,0931 }\end{array}$ & $\begin{array}{l}R 1=0,0445 \\
\text { wR2 = 0,0971 }\end{array}$ & $\begin{array}{l}R 1=0,0399 \\
w R 2=0,0716\end{array}$ \\
\hline "Goodness-of-fit" sobre $\mathrm{F}^{2}$ & 1,027 & 0,824 & 0,821 \\
\hline Programas usados & $\begin{array}{c}\text { SHELXS97 }{ }^{64} \mathrm{e} \\
\text { SHELXL }^{65}\end{array}$ & $\begin{array}{l}\text { SHELXS97 } 7^{64} \mathrm{e} \\
\text { SHELXL }\end{array}$ & $\begin{array}{l}\text { SHELXS977 } \\
\text { SHELXL }\end{array}$ \\
\hline
\end{tabular}


Tabela 7 - Principais distâncias $(\mathrm{pm})$ e ângulos $\left(^{\circ}\right)$ de ligação encontrados no complexo [ReO(dmhp) $\left.\mathrm{Cl}_{2}\left(\mathrm{PPh}_{3}\right)\right]$ (1).

\begin{tabular}{|cc|}
\hline Distâncias & $\mathbf{1}$ \\
\hline $\operatorname{Re}-\mathrm{O}(1)$ & $170,3(1)$ \\
\hline $\operatorname{Re}-\mathrm{O}(2)$ & $202,5(1)$ \\
\hline $\operatorname{Re}-\mathrm{O}(3)$ & $210,0(7)$ \\
\hline $\operatorname{Re}-\mathrm{Cl}(1)$ & $240,5(4)$ \\
\hline $\operatorname{Re}-\mathrm{Cl}(2)$ & $234,6(3)$ \\
\hline Re-P & $244,7(4)$ \\
\hline Angulos & \\
\hline $\mathrm{O}(1)-\operatorname{Re}-\mathrm{O}(2)$ & $163,9(4)$ \\
\hline $\mathrm{O}(1)-\operatorname{Re}-\mathrm{O}(3)$ & $92,2(5)$ \\
\hline $\mathrm{O}(1)-\operatorname{Re}-\mathrm{P}$ & $88,6(3)$ \\
\hline $\mathrm{O}(1)-\operatorname{Re}-\mathrm{Cl}(1)$ & $98,9(3)$ \\
\hline $\mathrm{O}(1)-\operatorname{Re}-\mathrm{Cl}(2)$ & $103,9(3)$ \\
\hline $\mathrm{O}(2)-\operatorname{Re}-\mathrm{O}(3)$ & $74,3(4)$ \\
\hline $\mathrm{O}(2)-\operatorname{Re}-\mathrm{P}$ & $83,3(3)$ \\
\hline $\mathrm{O}(2)-\operatorname{Re}-\mathrm{Cl}(1)$ & $88,9(3)$ \\
\hline $\mathrm{O}(2)-\operatorname{Re}-\mathrm{Cl}(2)$ & $90,2(3)$ \\
\hline $\mathrm{O}(3)-\operatorname{Re}-\mathrm{P}$ & $92,8(3)$ \\
\hline $\mathrm{O}(3)-\operatorname{Re}-\mathrm{Cl}(1)$ & $85,1(4)$ \\
\hline $\mathrm{O}(3)-\operatorname{Re}-\mathrm{Cl}(2)$ & $163,5(4)$ \\
\hline $\mathrm{Cl}(1)-\operatorname{Re}-\mathrm{Cl}(2)$ & $88,8(1)$ \\
\hline $\mathrm{Cl}(1)-\operatorname{Re}-\mathrm{P}$ & $172,3(1)$ \\
\hline $\mathrm{Cl}(2)-\operatorname{Re}-\mathrm{P}$ & $91,1(1)$ \\
\hline
\end{tabular}


Tabela 8 - Principais distâncias $(\mathrm{pm})$ e ângulos $\left(^{\circ}\right)$ de ligação encontrados nos complexos [ReO(bdtc)(dmhp)] (2) e [ReO(bdtc)(mal)] (3).

\begin{tabular}{|ccc|}
\hline Distâncias & $\mathbf{2}$ & $\mathbf{3}$ \\
\hline $\operatorname{Re}-\mathrm{O}(1)$ & $168,4(5)$ & $166,3(4)$ \\
\hline $\operatorname{Re}-\mathrm{O}(2)$ & $203,3(5)$ & $205,4(4)$ \\
\hline $\operatorname{Re}-\mathrm{O}(3)$ & $211,7(4)$ & $213,2(4)$ \\
\hline $\operatorname{Re}-\mathrm{O}(4)$ & $209,3(5)$ & $208,7(4)$ \\
\hline $\operatorname{Re}-\mathrm{N}(1)$ & $200,3(5)$ & $198,9(5)$ \\
\hline $\operatorname{Re}-\mathrm{S}(1)$ & $232,3(2)$ & $232,4(2)$ \\
\hline Angulos & & \\
\hline $\mathrm{O}(1)-\operatorname{Re}-\mathrm{O}(2)$ & $164,9(2)$ & $162,0(2)$ \\
\hline $\mathrm{O}(1)-\operatorname{Re}-\mathrm{O}(3)$ & $90,4(2)$ & $88,8(2)$ \\
\hline $\mathrm{O}(1)-\operatorname{Re}-\mathrm{O}(4)$ & $90,4(2)$ & $92,2(2)$ \\
\hline $\mathrm{O}(1)-\operatorname{Re}-\mathrm{N}(1)$ & $102,2(2)$ & $102,8(2)$ \\
\hline $\mathrm{O}(1)-\operatorname{Re}-\mathrm{S}(1)$ & $99,9(2)$ & $100,9(2)$ \\
\hline $\mathrm{O}(2)-\operatorname{Re}-\mathrm{O}(3)$ & $76,5(2)$ & $75,3(2)$ \\
\hline $\mathrm{O}(2)-\operatorname{Re}-\mathrm{O}(4)$ & $80,8(2)$ & $78,4(2)$ \\
\hline $\mathrm{O}(2)-\operatorname{Re}-\mathrm{N}(1)$ & $90,5(2)$ & $92,9(2)$ \\
\hline $\mathrm{O}(2)-\operatorname{Re}-\mathrm{S}(1)$ & $89,6(1)$ & $89,3(1)$ \\
\hline $\mathrm{O}(3)-\operatorname{Re}-\mathrm{O}(4)$ & $84,2(2)$ & $85,0(2)$ \\
\hline $\mathrm{O}(3)-\operatorname{Re}-\mathrm{N}(1)$ & $167,0(2)$ & $168,2(2)$ \\
\hline $\mathrm{O}(3)-\operatorname{Re}-\mathrm{S}(1)$ & $98,2(2)$ & $96,9(1)$ \\
\hline $\mathrm{O}(4)-\operatorname{Re}-\mathrm{N}(1)$ & $92,4(2)$ & $92,2(2)$ \\
\hline $\mathrm{O}(4)-\operatorname{Re}-\mathrm{S}(1)$ & $169,3(2)$ & $166,7(1)$ \\
\hline $\mathrm{N}(1)-\operatorname{Re}-\mathrm{S}(1)$ & $83,0(1)$ & $83,2(1)$ \\
\hline
\end{tabular}




\subsection{Complexos [ReO(bdtc)Cl( $\left.\left.\mathrm{PPh}_{3}\right)\right]$ (4), [ReO(bdtc)Br(PPh $)$ (5), [ReO(bdtn)Cl(PPh $)]$ (6), [ReO(bdtm)Cl(PPh $)]$ (7) e [TcO(bdtc)Cl] (8)}

As sínteses dos complexos 4, 5, 6, 7 e 8 partiram de um equivalente dos precursores $\left[\mathrm{ReOX}_{3}\left(\mathrm{PPh}_{3}\right)_{2}\right],(\mathbf{4}, \mathbf{6}$ e 7, $\mathrm{X}=\mathrm{Cl} ; \mathbf{5}, \mathrm{X}=\mathrm{Br})$, ou $\left(\mathrm{NBu}_{4}\right)\left[\mathrm{TcOCl}_{4}\right]$, (para 8) e um equivalente do ditiocarbazato desejado, $\mathbf{H}_{2}$ bdtc (4, 5 e 8), $\mathbf{H}_{2}$ bdtn (6) ou $\mathrm{H}_{\mathbf{2}}$ bdtm (7).

As estruturas dos complexos foram propostas com base na análise elementar, nos espectros de massas com ionização eletrospray (MS-ESI), nos dados espectroscópicos, obtidos através das técnicas de IV e RMN ${ }^{1} \mathrm{H}$ e ${ }^{31} \mathrm{P}$, e os produtos 4, 5 e 8 tiveram suas estruturas determinadas por difração de raios $X$ em monocristal.

\subsubsection{Espectroscopia de Absorção na Região do Infravermelho}

Novamente, dados de espectroscopia de absorção na região do infravermelho (Tabela 9) ofereceram informações que confirmaram a coordenação de todos os ligantes, entre eles, as fosfinas e os ditiocarbazatos aos centros metálicos de rênio.

A presença de trifenilfosfina foi confirmada em todos os espectros dos complexos 4-7, pela permanência dos seguintes modos vibracionais: $v(C C)_{\mathrm{PPh} 3}$ entre 1538-1530 cm $\mathrm{cm}^{-1}, 1489-1481 \mathrm{~cm}^{-1}$ e 1437-1434 cm ${ }^{-1} v(\mathrm{P}-\mathrm{C})_{\mathrm{PPh} 3} 1095$ a $1091 \mathrm{~cm}^{-1}$ e $v\left(\mathrm{C}_{6} \mathrm{H}_{5}\right)_{\mathrm{PPh} 3} 694$ a $691 \mathrm{~cm}^{-1}$ (Figuras 37, 39, 40 e 41, respectivamente). ${ }^{61,62}$

Outras duas regiões importantes são àquelas onde aparecem os estiramentos $\mathrm{M}=\mathrm{O}$ ( $\mathrm{M}=\mathrm{Re}$ ou Tc), cujo valor da banda tende a variar de acordo com as vizinhanças ligadas aos centros metálicos. A troca do ligante trans-posicionado ao grupo oxo causa uma maior alteração dos valores dessas bandas devido à mudança na capacidade dos metais em receber elétrons $\pi$ dos seus respectivos grupos oxo. Desta forma, uma variação acima do erro instrumental do equipamento (de $\pm 4 \mathrm{~cm}^{-1}$ ) permite uma relação direta como o sucesso de uma reação feita.

Nos complexos 4, 5, 6 e 7 as bandas referentes ao modo vibracional $v(R e=0)$ podem ser observadas entre 956 e $988 \mathrm{~cm}^{-1}$. Exceto no espectro do produto 5, cuja 
banda $(\mathrm{Re}=\mathrm{O})$ apresentou um deslocamento hipsocrômico (deslocamento da banda de absorção para uma região de número de onda maior), nos demais compostos, este mesmo estiramento exibiu um deslocamento batocrômico (deslocamento da banda de absorção para uma região de número de onda menor) em comparação ao mesmo modo vibracional dos seus precursores $\left[\mathrm{ReOCl}_{3}\left(\mathrm{PPh}_{3}\right)_{2}\right]$ e $\left[\mathrm{ReOBr}_{3}\left(\mathrm{PPh}_{3}\right)_{2}\right]$. As pequenas alterações dos valores das bandas $(\mathrm{Re}=\mathrm{O})$ entre os precursores metálicos e os complexos obtidos se devem ao fato de que não houve substituição do haleto $(\mathrm{Cl}$, em 4, 6 e 7; $\mathrm{Br}$, em 5) trans-posicionado ao grupo oxo, em nenhum dos complexos sintetizados, conforme foi comprovado por meio da determinação das estruturas de raios X de 4 e 5 (Figuras 59 e 61, respectivamente). Considerando que estas variações (entre 6 e $13 \mathrm{~cm}^{-1}$ ) estão acima do erro instrumental, elas indicam que as reações foram conduzidas com sucesso.

A coordenação de modo O,N,S-doadora dos ditiocarbazatos $\mathbf{H}_{2} \mathbf{b d t c}, \mathbf{H}_{\mathbf{2}} \mathbf{b d t n}$ e $\mathbf{H}_{2}$ bdtm ao rênio pôde ser inferida uma vez que os modos vibracionais $\delta\left(\mathrm{CH}_{2}\right)$, muito intensos entre 1441 e $1437 \mathrm{~cm}^{-1}$, e $v(\mathrm{O}-\mathrm{H})$, entre 3363 e $3327 \mathrm{~cm}^{-1}$, (que estavam presentes em todos os ligantes não coordenados) não apareceram nos espectros dos complexos obtidos, indicando a saída do hidrogênio do grupo hidroxila, o rompimento dos seus respectivos anéis pirazolínicos e a dupla desprotonação, o que foi comprovado por meio dos dados de difração de raios $X$ em monocristal no caso dos complexos 4 e 5 . $^{63}$

De forma análoga à discussão feita a respeito da banda $(\mathrm{C}=\mathrm{N})$ em 2 e 3, nos compostos de 4-8 também ocorreu um deslocamento batocrômico deste mesmo estiramento após a coordenação de todos os ditiocarbazatos aos centros metálicos, conforme pode ser visualizado na tabela 9. 
Tabela 9 - Principais bandas $\left(\mathrm{cm}^{-1}\right)$ atribuídas aos modos vibracionais dos complexos 4, 5, 6, 7 e 8, dos precursores $\left[\mathrm{ReOCl}_{3}\left(\mathrm{PPh}_{3}\right)_{2}\right],\left[\mathrm{ReOBr}_{3}\left(\mathrm{PPh}_{3}\right)_{2}\right]$ e $\left(\mathrm{NBu}_{4}\right)\left[\mathrm{TcOCl}_{4}\right]$ bem como dos agentes complexantes $\mathrm{H}_{2}$ bdtc, $\mathrm{H}_{2}$ bdtn e $\mathrm{H}_{2} \mathrm{bdtm}$.

\begin{tabular}{|c|c|c|c|c|c|c|c|c|}
\hline \multirow{2}{*}{$\begin{array}{l}\text { Complexos, } \\
\text { Precursores e } \\
\text { Ligantes }\end{array}$} & \multicolumn{8}{|c|}{ Modos Vibracionais } \\
\hline & $v(\mathrm{O}-\mathrm{H})$ & $v(C=N)$ & $v(S C S)$ & $\mathrm{v}(\mathrm{CC})_{\mathrm{PPh} 3}$ & $\delta\left(\mathrm{CH}_{2}\right)$ & $v(P-C)$ & $\beta\left(\mathrm{C}_{6} \mathrm{H}_{5}\right)_{\mathrm{PPh} 3}$ & $v(M=0)$ \\
\hline 4 & ---- & 1581 & 984 & $\begin{array}{c}1489 \text { e } \\
1435\end{array}$ & ----- & 1095 & 694 & 957 \\
\hline 5 & ----- & 1589 & 976 & $\begin{array}{c}1486 \mathrm{e} \\
1437\end{array}$ & ----- & 1092 & 693 & 988 \\
\hline 6 & ----- & 1601 & 979 & $\begin{array}{c}1488 \text { e } \\
1434\end{array}$ & ----- & 1091 & 693 & 963 \\
\hline 7 & ----- & 1611 & 975 & $\begin{array}{c}1488 \mathrm{e} \\
1434\end{array}$ & ----- & 1094 & 693 & 956 \\
\hline 8 & ---- & $\begin{array}{l}1547 \\
1527\end{array}$ & ----- & ----- & ----- & ----- & ----- & 976 \\
\hline$\left(\mathrm{NBu}_{4}\right)\left[\mathrm{TcOCl}_{4}\right]$ & ----- & $\begin{array}{ll}---- \\
\end{array}$ & $\begin{array}{ll}---- \\
\end{array}$ & ----- & ----- & ----- & $\begin{array}{ll}---- \\
\end{array}$ & 1026 \\
\hline$\left[\mathrm{ReOCl}_{3}\left(\mathrm{PPh}_{3}\right)_{2}\right]$ & ----- & ----- & ----- & $\begin{array}{c}1482 \text { e } \\
1434\end{array}$ & ----- & 1093 & 693 & 969 \\
\hline$\left[\mathrm{ReOBr}_{3}\left(\mathrm{PPh}_{3}\right)_{2}\right]$ & ----- & ----- & ----- & $\begin{array}{c}1481 \mathrm{e} \\
1435\end{array}$ & ----- & 1092 & 691 & 981 \\
\hline $\mathrm{H}_{2}$ bdtc & 3359 & 1629 & 981 & ----- & 1441 & ----- & ----- & ----- \\
\hline $\mathrm{H}_{2}$ bdtn & 3363 & 1629 & 979 & ----- & 1441 & ----- & ----- & ----- \\
\hline $\mathrm{H}_{2} \mathrm{bdtm}$ & 3327 & 1632 & 978 & ----- & 1437 & ----- & ----- & ----- \\
\hline
\end{tabular}

$\mathrm{M}=$ Tc somente no complexo 8 . Nos demais compostos $\mathrm{M}=\mathrm{Re}$. 
Figura 33 - Espectro do $\mathbf{H}_{2}$ bdtc.

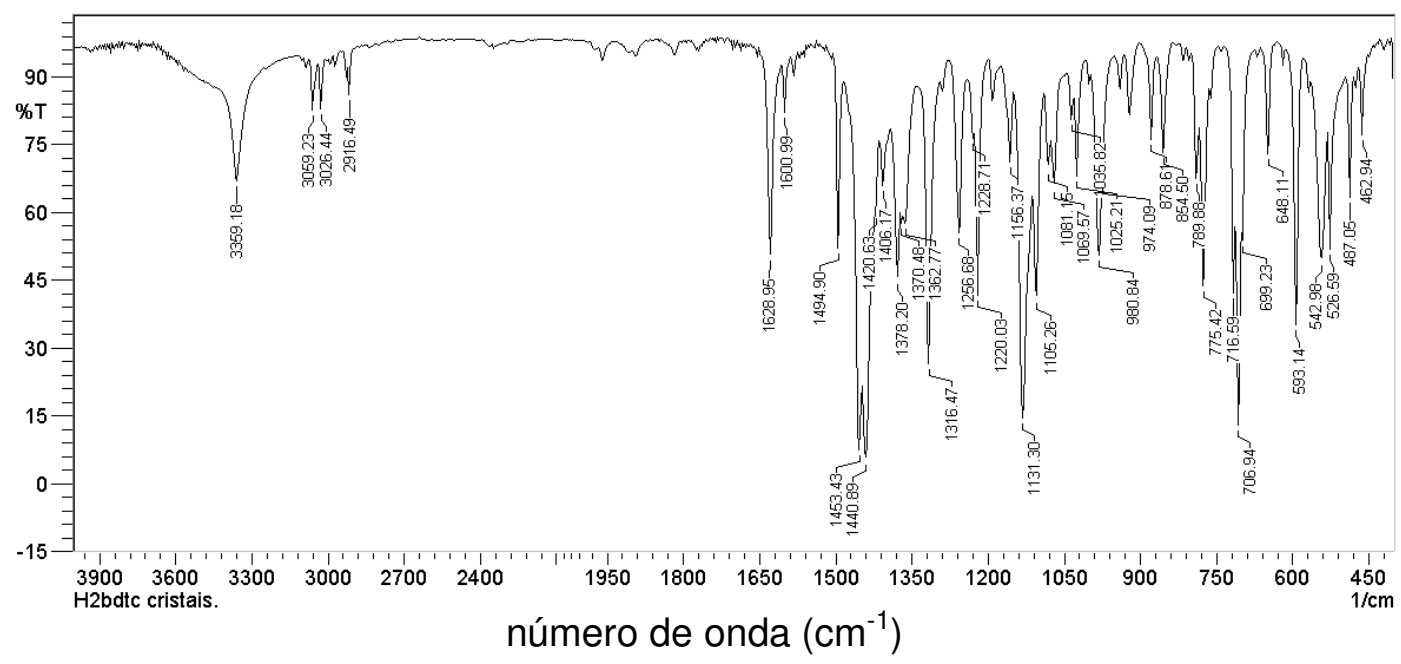

Figura 34 - Espectro do $\mathbf{H}_{2}$ bdtn.

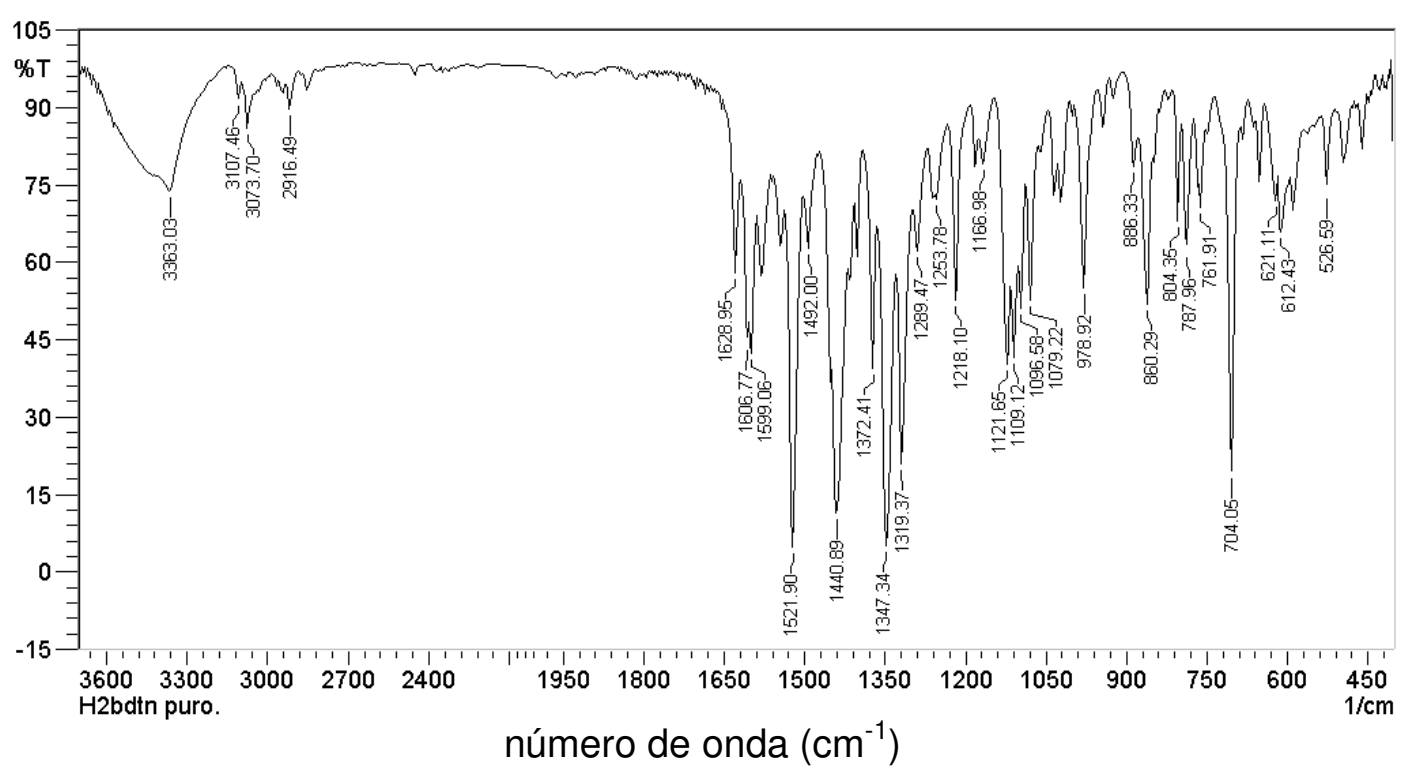


Figura 35 - Espectro do $\mathbf{H}_{2} \mathbf{b d t m}$.

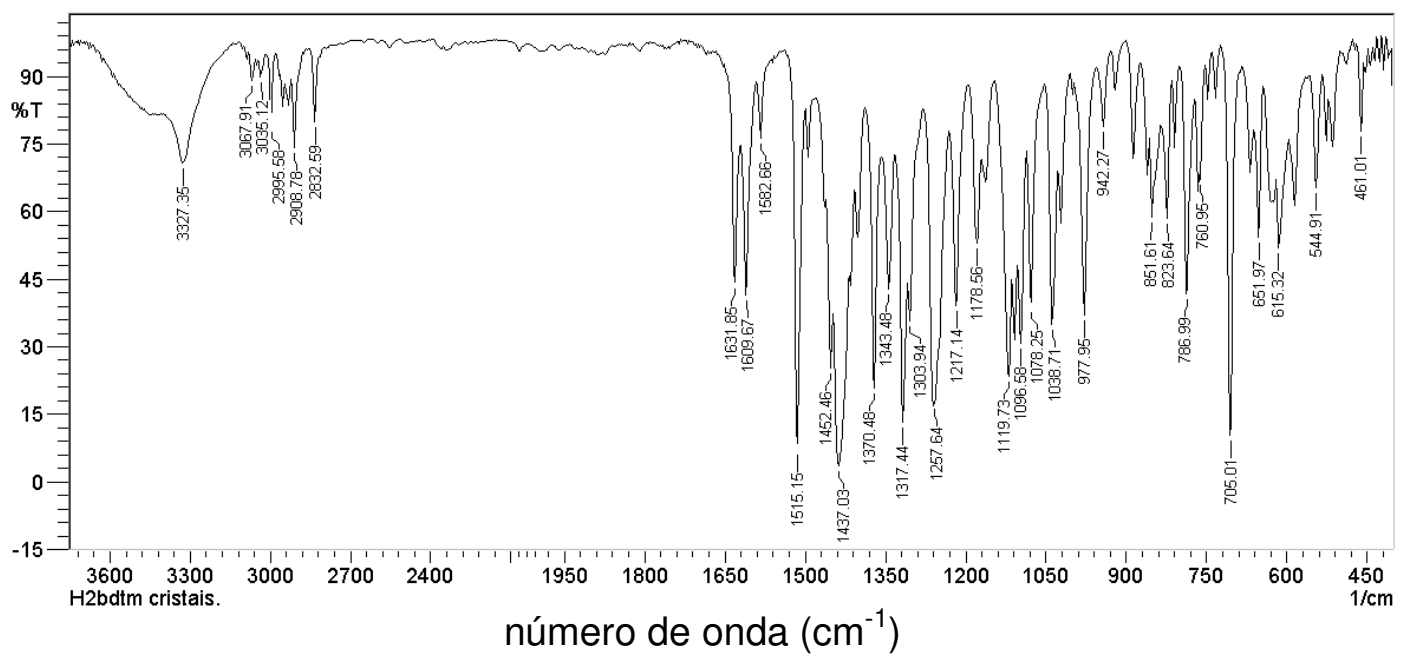

Figura 36 - Espectro do $\left[\mathrm{ReOCl}{ }_{3}\left(\mathrm{PPh}_{3}\right)_{2}\right]$.

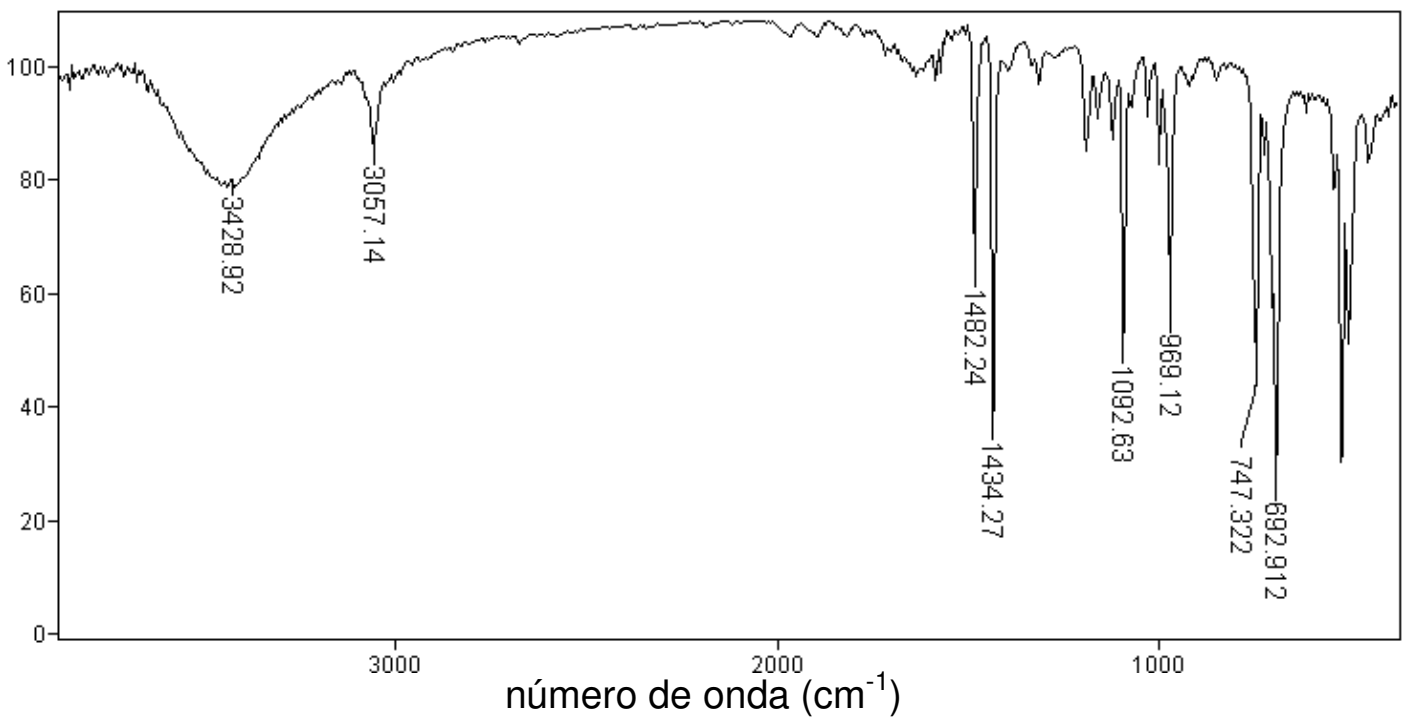


Figura 37 - Espectro do [ReO(bdtc) $\left.\mathrm{Cl}\left(\mathrm{PPh}_{3}\right)\right]$ (4).

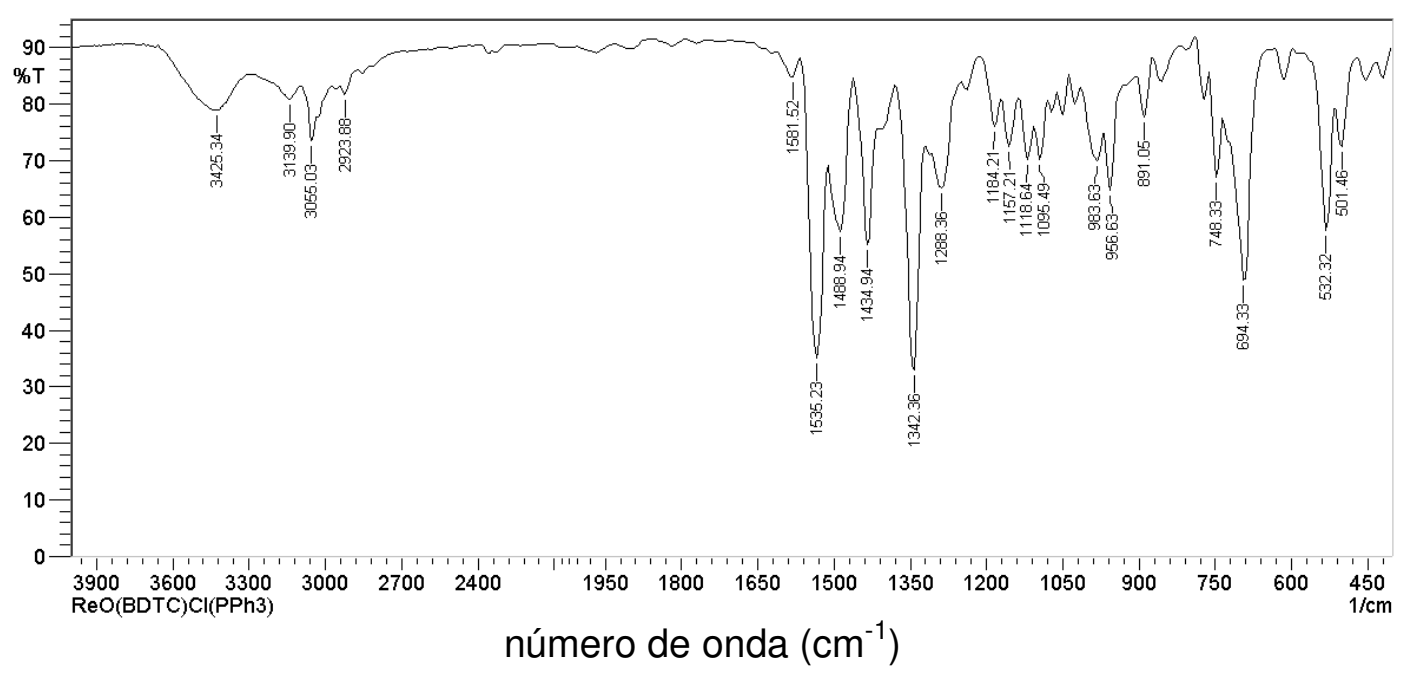

Figura 38 - Espectro do $\left[\operatorname{ReOBr}_{3}\left(\mathrm{PPh}_{3}\right)_{2}\right]$.

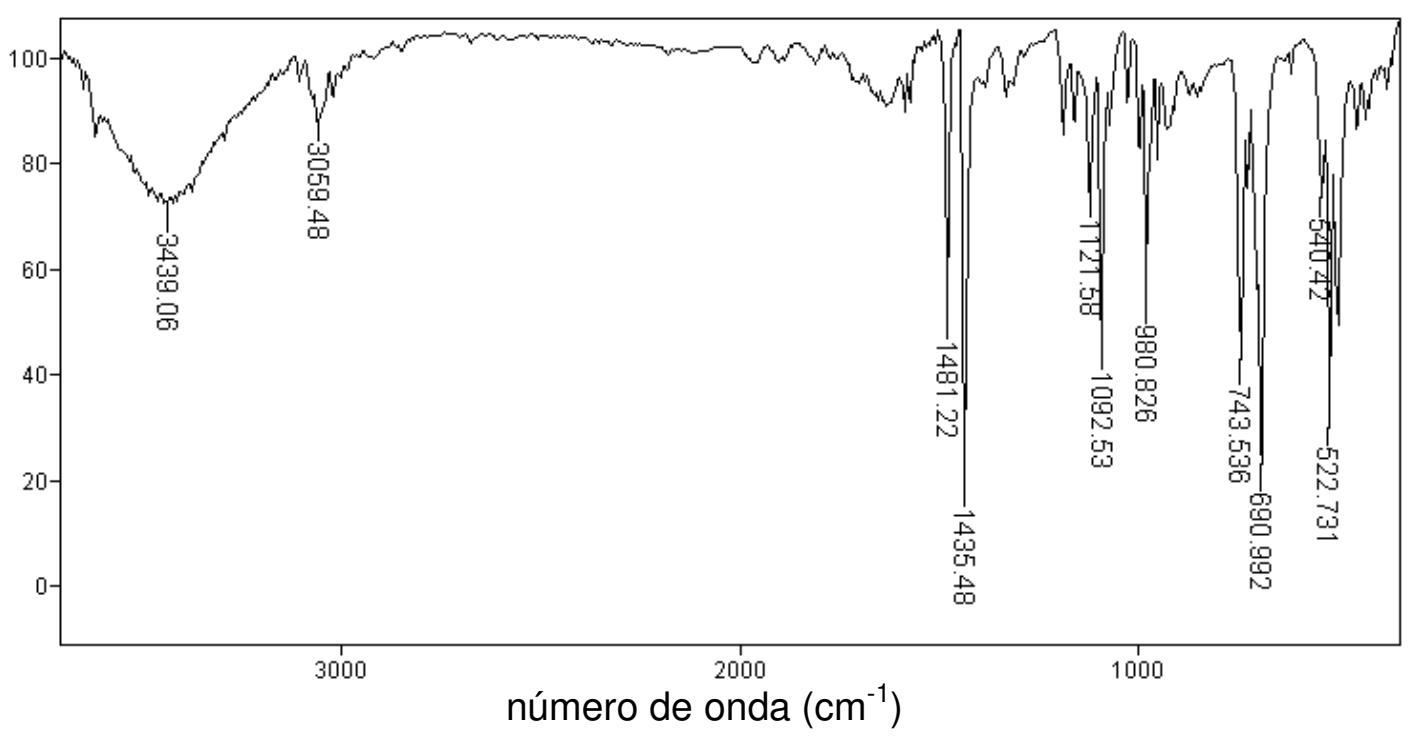


Figura 39 - Espectro do [ReO(bdtc) $\left.\mathrm{Br}\left(\mathrm{PPh}_{3}\right)\right]$ (5).

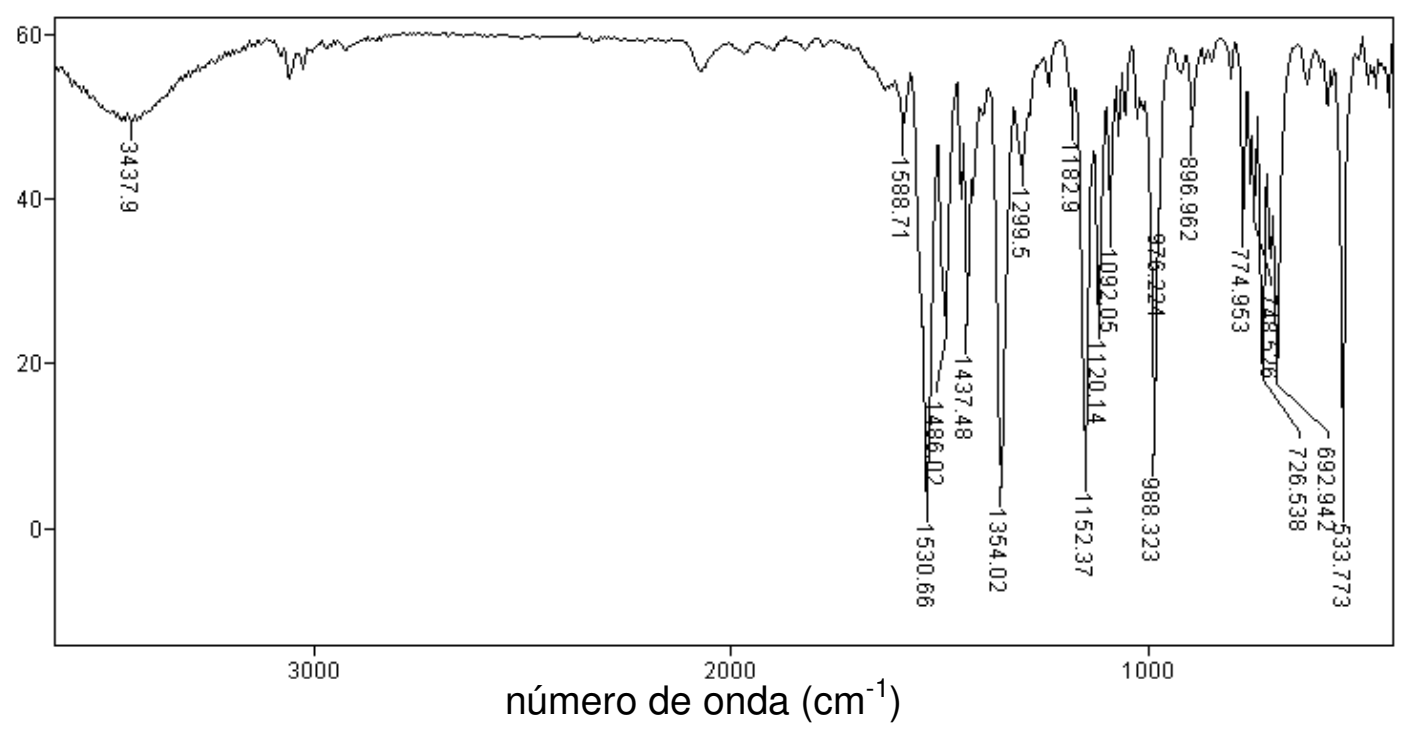

Figura 40 - Espectro do [ReO(bdtn)Cl(PPh $\left.\left.{ }_{3}\right)\right](6)$.

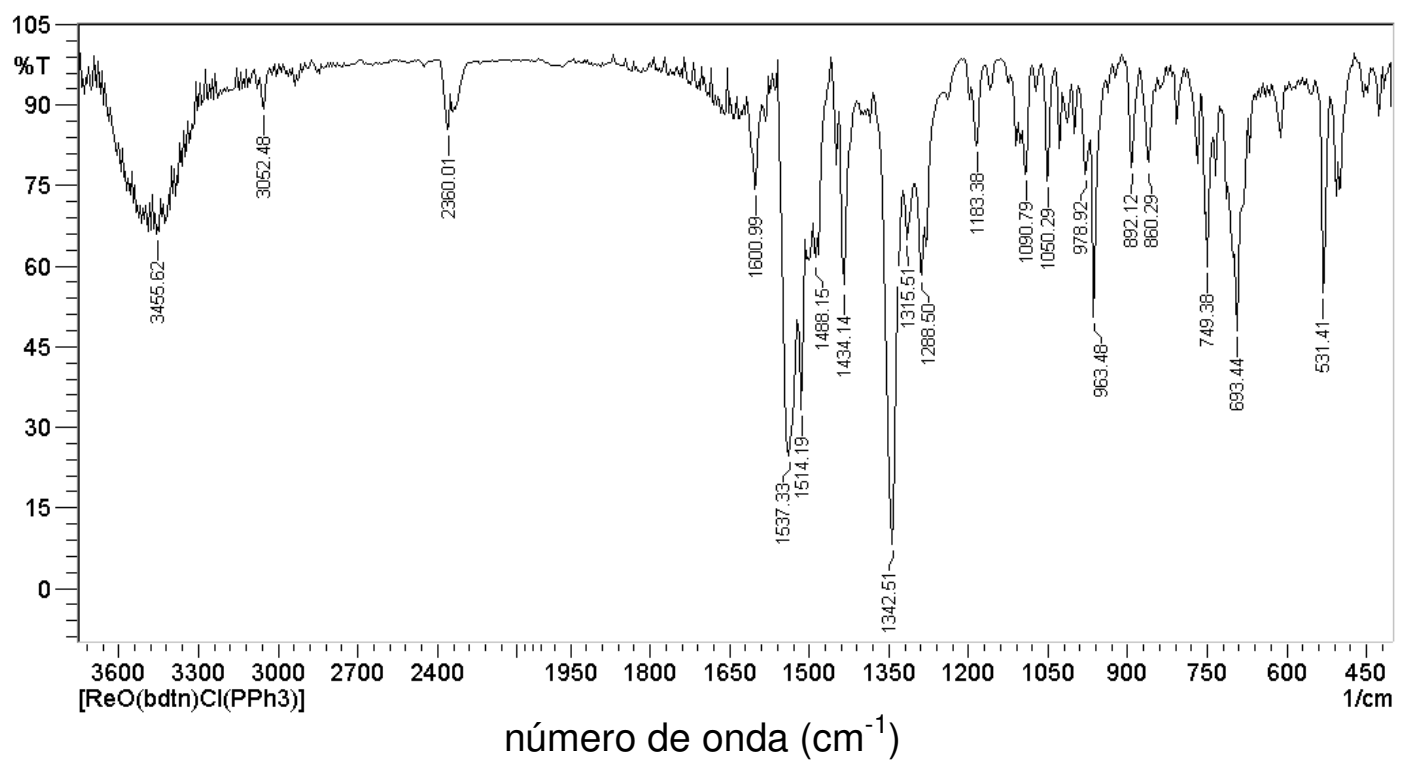


Figura 41 - Espectro do [ReO(bdtm) $\left.\mathrm{Cl}\left(\mathrm{PPh}_{3}\right)\right](\mathbf{7})$.

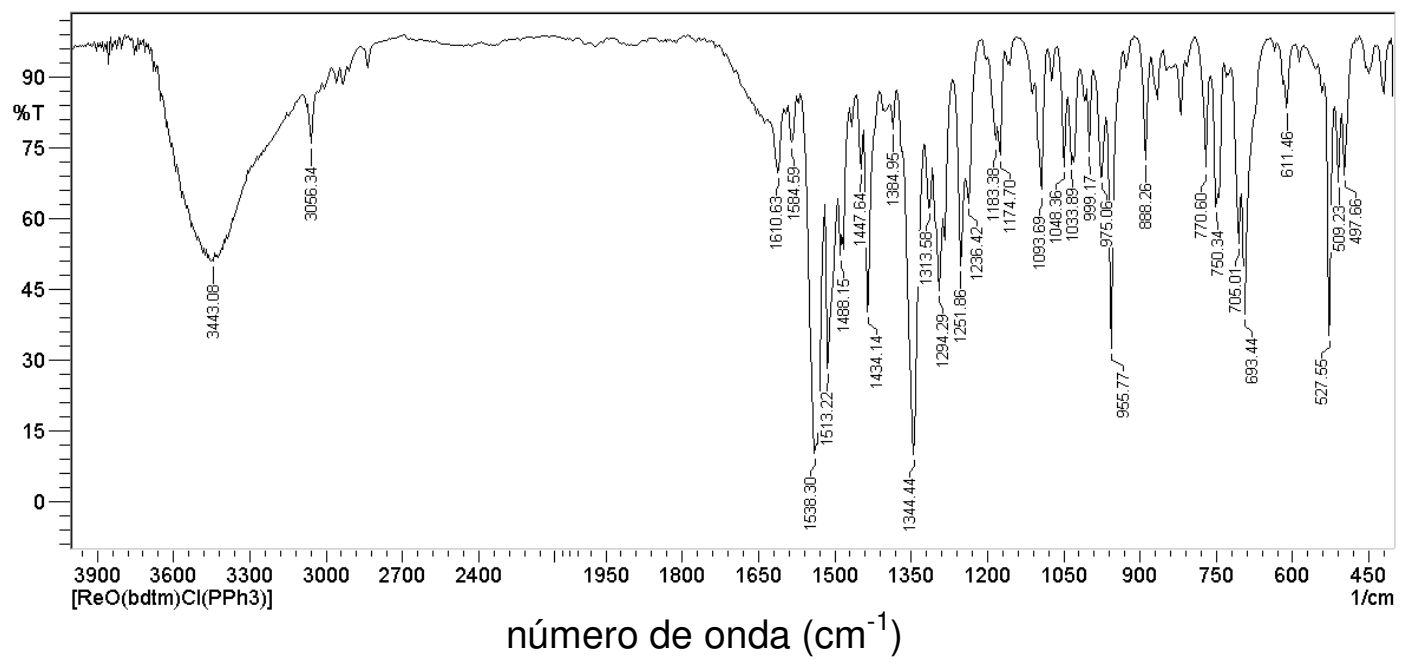

Figura 42 - Espectro do complexo de partida $\left(\mathrm{NBu}_{4}\right)\left[\mathrm{TcOCl}_{4}\right]$.

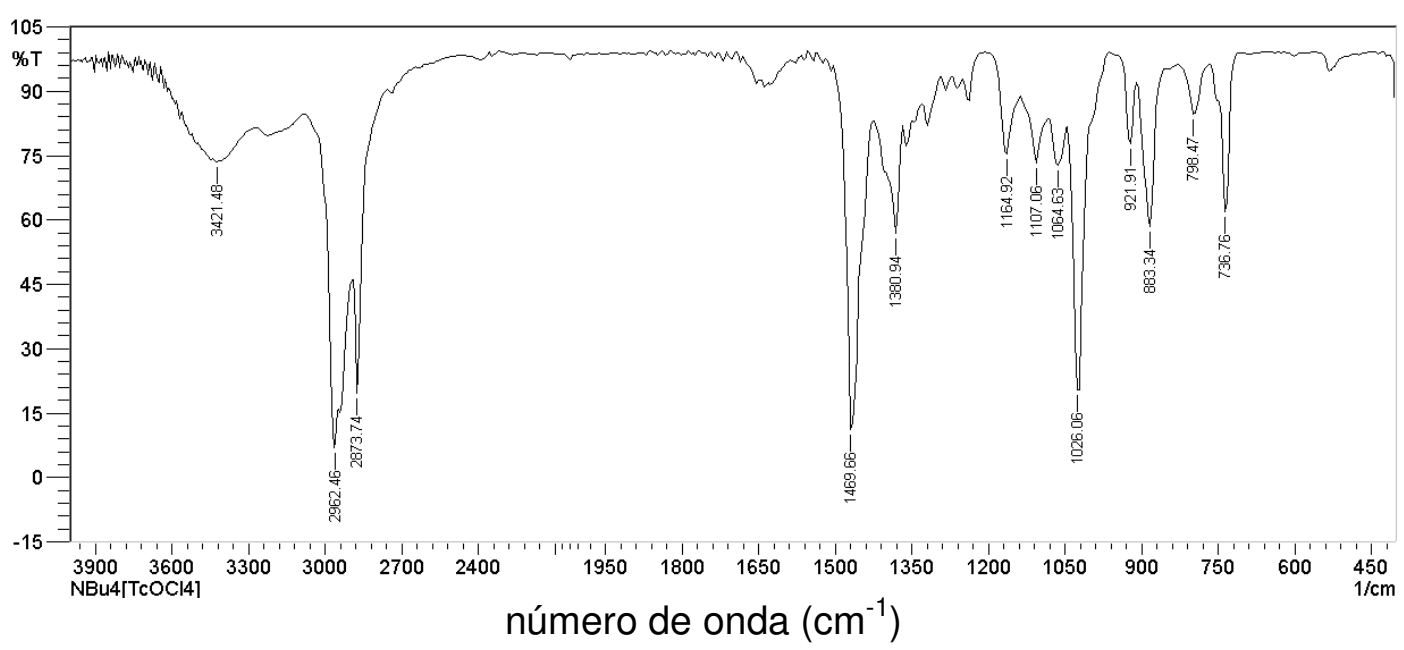


Figura 43 - Espectro do [TcO(bdtc)Cl] (8).

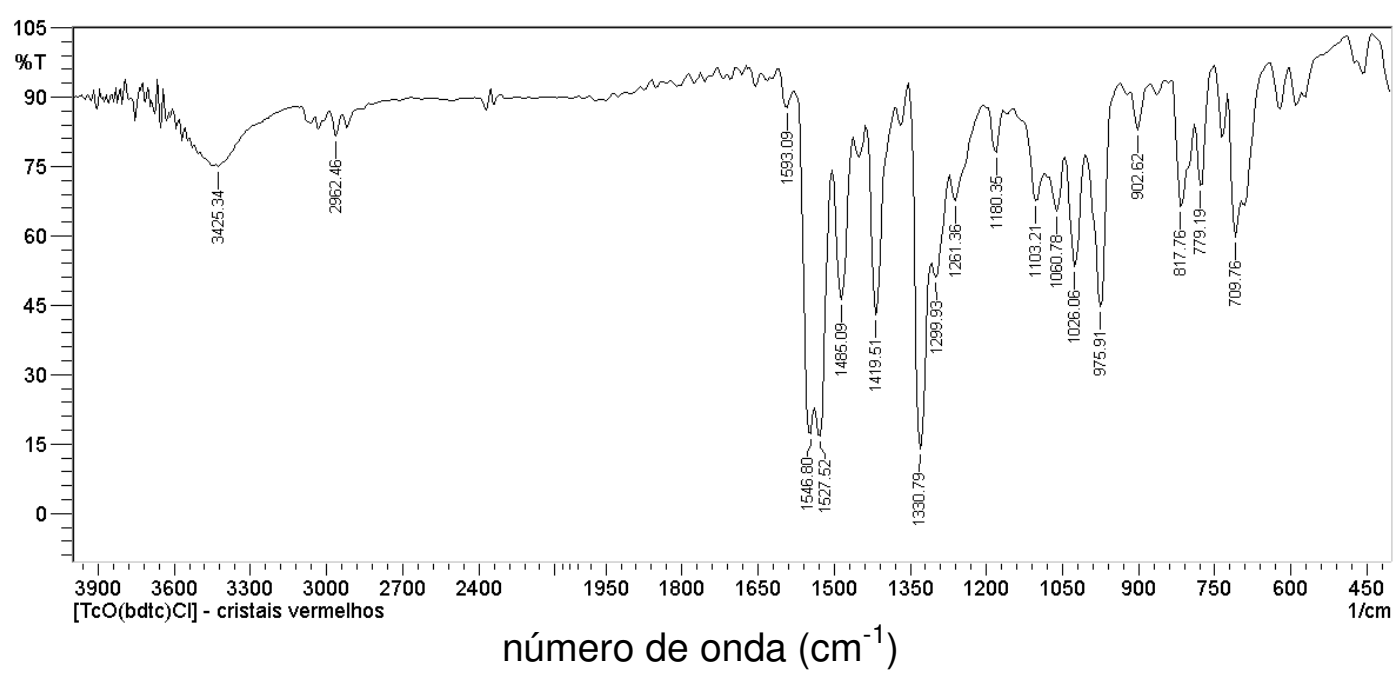




\subsubsection{Espectroscopia de Ressonância Magnética Nuclear (RMN ${ }^{1} \mathrm{H} \mathrm{e}$ $\left.{ }^{31} \mathrm{P}\right)$ para os complexos 4, 5, 6, 7 e 8}

Os espectros de $\mathrm{RMN}{ }^{31} \mathrm{P}$ dos precursores $\left[\mathrm{ReOCl}_{3}\left(\mathrm{PPh}_{3}\right)_{2}\right]$ e $\left[\mathrm{ReOBr}_{3}\left(\mathrm{PPh}_{3}\right)_{2}\right]$ exibem, respectivamente, simpletos em -18,5 e -26,9 ppm (Figuras 45 e 46, respectivamente), referentes ao deslocamento químico para seus átomos de fósforo de suas trifenilfosfinas em posição trans entre si.

Espectros deste mesmo núcleo obtidos para os produtos 4, 6 e 7, exibem simpletos com valores muito próximos entre -4,2 e -4,6 ppm (Figuras 48, 52 e 55, respectivamente). Esses números revelam que o ambiente químico ao redor das fosfinas nos complexos são praticamente iguais, comprovando que possuem esferas de coordenação análogas. $\mathrm{O}$ espectro de $\mathrm{RMN}{ }^{31} \mathrm{P}$ obtido para o produto 5 exibe apenas um sinal de produto de oxidação da trifenilfosfina ( $\mathrm{OPPh}_{3}$ livre) em 28,9 ppm (Figura 50$).{ }^{70}$ A oxidação de todo o produto 5 é favorecida devido sua reduzida quantidade de matéria em solução, cerca de $1 \mathrm{mg}$ em $0,7 \mathrm{~mL}$ de $\mathrm{CD}_{2} \mathrm{Cl}_{2}$.

Outro ponto relevante é que após a coordenação dos respectivos ditiocarbazatos, os átomos de fósforo das trifenilfosfinas sofreram um efeito de desblindagem eletrônica, em torno de 14 ppm, quando comparados às fosfinas de seus precursores metálicos. Um entendimento deste efeito pode ser obtido por meio da avaliação dos dados de distâncias de ligação Re-P (determinados por difração de raios $X$ em monocristal) e dos deslocamentos químicos obtidos para os compostos 1, 4 e outros descritos na literatura (Tabela 10). ${ }^{71}$

Tabela 10 - Dados de distância de ligação (pm) e $\mathrm{RMN}^{31} \mathrm{P}(161,70 \mathrm{MHz}$, em ppm) para 1, 4.

\begin{tabular}{|c|c|c|}
\hline Complexo & Distância de ligação Re-P & ${ }^{31} \mathbf{P}$ \\
\hline$\left[\mathrm{ReO}(\mathrm{bdtc}) \mathrm{Cl}\left(\mathrm{PPh}_{3}\right)\right](4)$ & $249,6(1)$ & $-4,2$ \\
\hline$\left[\mathrm{ReOCl}_{2}(3-\mathrm{OHpic})\left(\mathrm{PPh}_{3}\right)\right]$ & $247,7(1)$ & $-7,6$ \\
\hline$\left[\mathrm{ReOCl}_{2}(\mathrm{ak})\left(\mathrm{PPh}_{3}\right)\right]$ & $246,7(2)$ & $-16,3$ \\
\hline$\left[\mathrm{ReOCl}_{2}(\mathrm{mal})\left(\mathrm{PPh}_{3}\right)\right]$ & $246,1(2)$ & $-17,7$ \\
\hline$\left[\mathrm{ReOCl}_{2}(\mathrm{dmhp})\left(\mathrm{PPh}_{3}\right)\right](\mathbf{1})$ & $244,7(4)$ & $-22,1$ \\
\hline
\end{tabular}

Os valores da tabela 10 demonstram que a desblindagem eletrônica do átomo de fósforo é proporcional ao aumento da distância de ligação Re-P. Fosfinas são descritas na literatura com sendo ligantes $\sigma$-doadores e $\pi$-receptores. ${ }^{72}$ Neste 
sentido, e baseado nos dados de distância de ligação, pode-se afirmar que o centro metálico em 4 está mais deficiente em elétrons do que em 1, o que reduz o caráter de retrodoação do metal para o átomo de fosforo da fosfina, o que justifica o alongamento da ligação e sua desblindagem.

De forma semelhante ao que ocorreu com o grupo metila do $\mathbf{H}_{2}$ bdtc nos complexos 2 e 3, nos produtos de 4-8 também foi observado o deslocamento dos sinais referentes aos hidrogênios das metilas deste mesmo ditiocarbazato, bem como de seus derivados $\mathbf{H}_{\mathbf{2}} \mathbf{b d t n}$ e $\mathbf{H}_{\mathbf{2}} \mathbf{b d t m}$, para em regiões de campo mais baixo. Existe uma relação direta entre a desblindagem dos grupos metilas e a coordenação $\mathrm{N}$-doadora conforme pode ser melhor entendido pela visualização da figura 44. Isto é uma ratificação, via $\mathrm{RMN}{ }^{1} \mathrm{H}$, da doação eletrônica por meio do átomo de nitrogênio do ditiocarbazato, já comprovada pelos espectros de IV dos compostos através do enfraquecimento de seus estiramentos $(C=N)$.

Figura 44 - Proposta de deslocamento da nuvem eletrônica do nitrogênio em direção ao metal e consequente efeito indutivo que desblinda a metila. As setas indicam apenas o sentido do deslocamento dos elétrons e nada dizem a respeito do número de elétrons movimentados. Apenas o ligante ditiocarbazato é mostrado, os demais foram omitidos por questão de clareza.

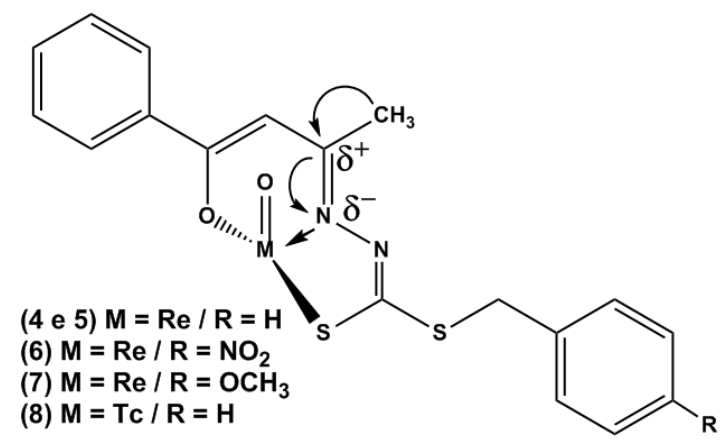

Os espectros de $\mathrm{RMN}^{1} \mathrm{H}$ dos complexos 4, 5, 6, 7 e 8 (Figuras 49, 51, 54, 57 e 58, respectivamente) apresentam os sinais esperados para os seus respectivos ligantes coordenados ao centro metálico e seus valores encontram-se descritos nas tabelas $11,12,13,14$ e 15, respectivamente. 
Figura 45 - Espectro de $\mathrm{RMN}{ }^{31} \mathrm{P}$ do precursor $\left[\mathrm{ReOCl}_{3}\left(\mathbf{P P h}_{3}\right)_{2}\right](121,47 \mathrm{MHz}$, $\mathrm{CH}_{2} \mathrm{Cl}_{2}$ ).

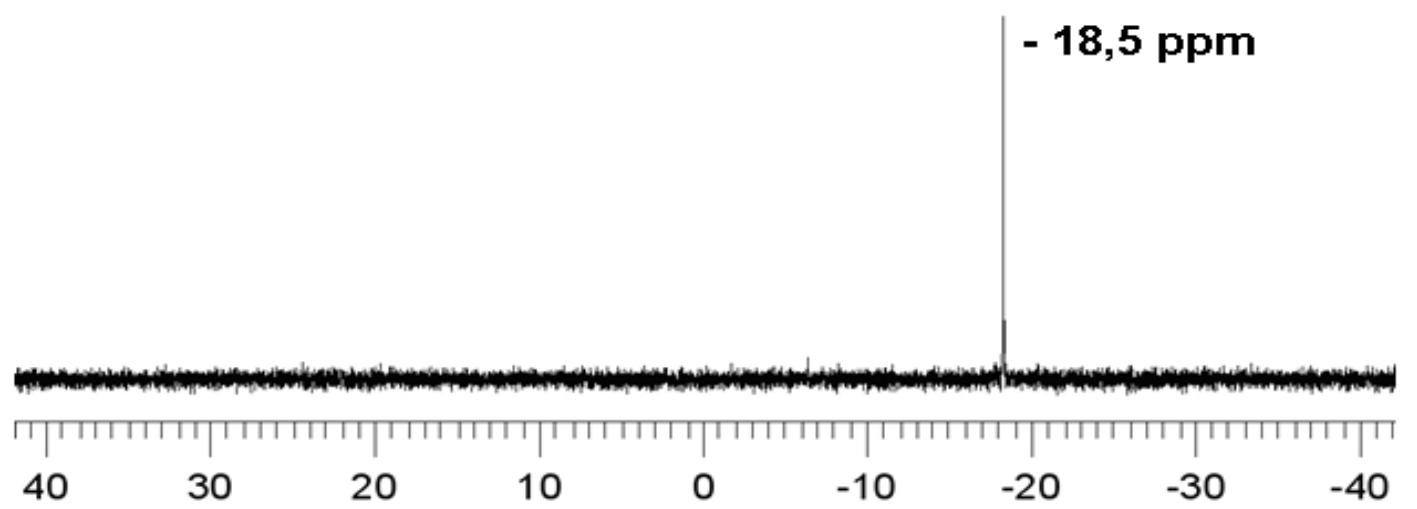

Figura 46 - Espectro de $\mathrm{RMN}{ }^{31} \mathrm{P}$ do precursor $\left[\mathrm{ReOBr}_{3}\left(\mathrm{PPh}_{3}\right)_{2}\right](121,47 \mathrm{MHz}$, $\mathrm{CD}_{2} \mathrm{Cl}_{2}$ ).

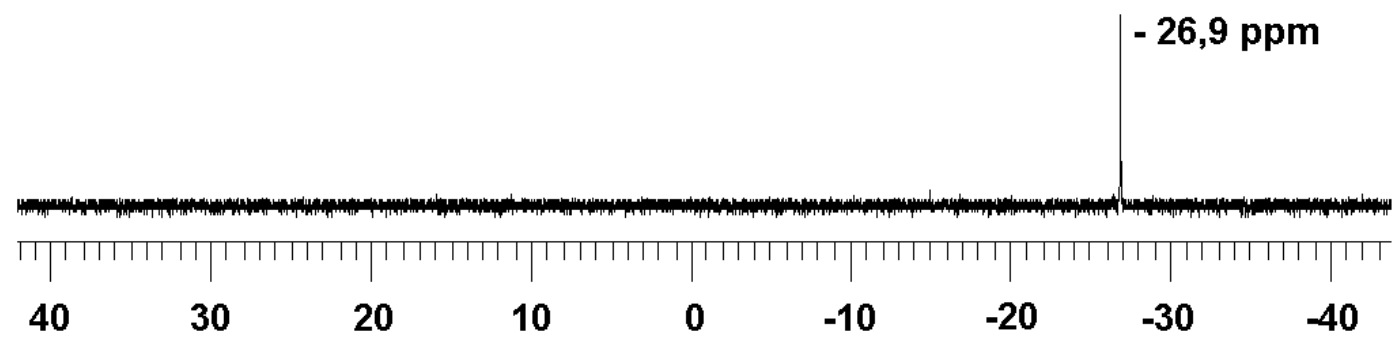

Figura 47 - Espectro de $\mathrm{RMN}{ }^{1} \mathrm{H}$ do $\mathbf{H}_{2}$ bdtc (400 $\mathrm{MHz}, \mathrm{CDCl}_{3}$ ).

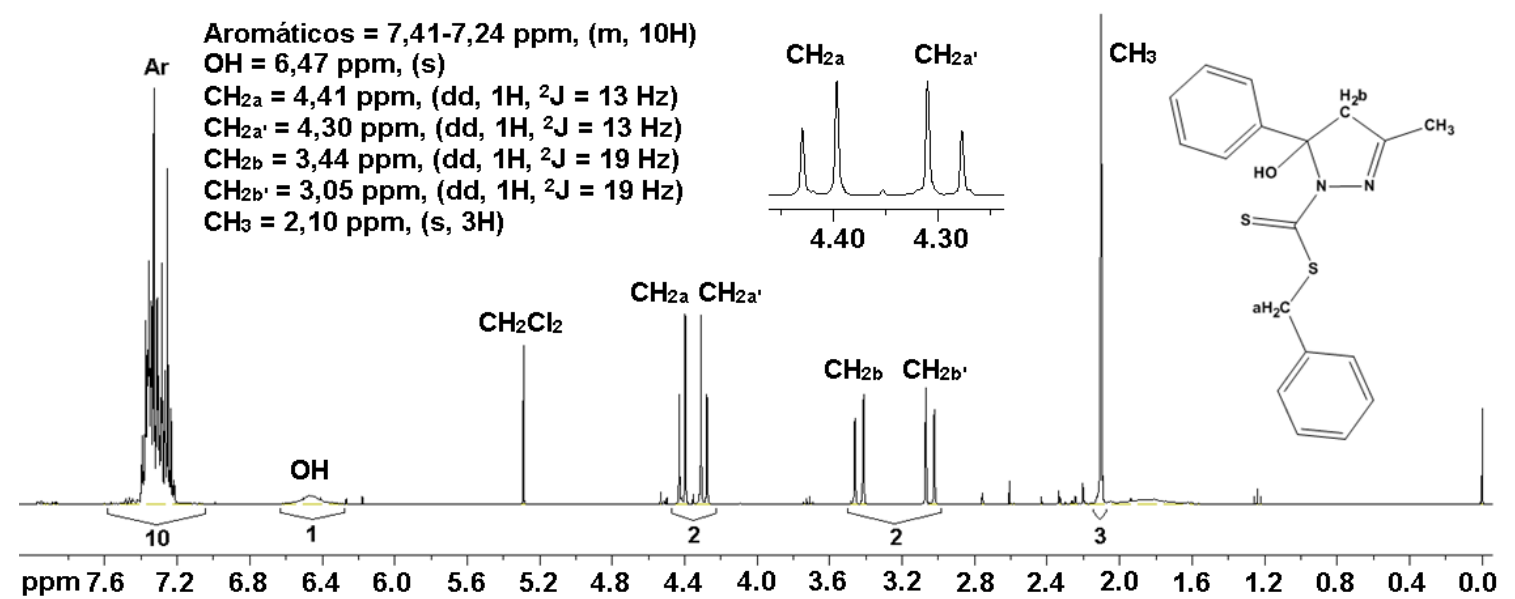


Figura 48 - Espectro de $\mathrm{RMN}^{31} \mathrm{P}$ do $\left[\mathbf{R e O}(\mathbf{b d t c}) \mathbf{C I}\left(\mathbf{P P h}_{3}\right)\right](4)\left(161,70 \mathrm{MHz}, \mathrm{CDCl}_{3}\right)$.

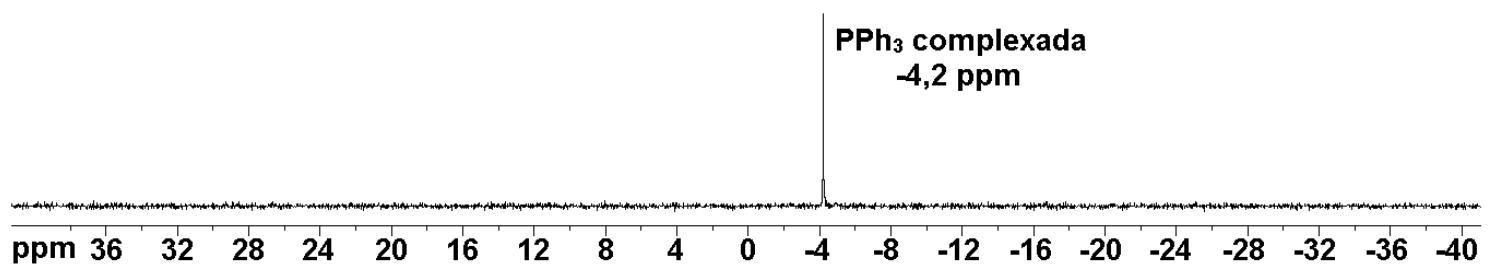

Figura 49 - Espectro de $\mathrm{RMN}{ }^{1} \mathrm{H}$ de $\left[\mathbf{R e O}(\mathbf{b d t c}) \mathbf{C l}\left(\mathbf{P P h}_{3}\right)\right](4)\left(400 \mathrm{MHz}, \mathrm{CDCl}_{3}\right)$.

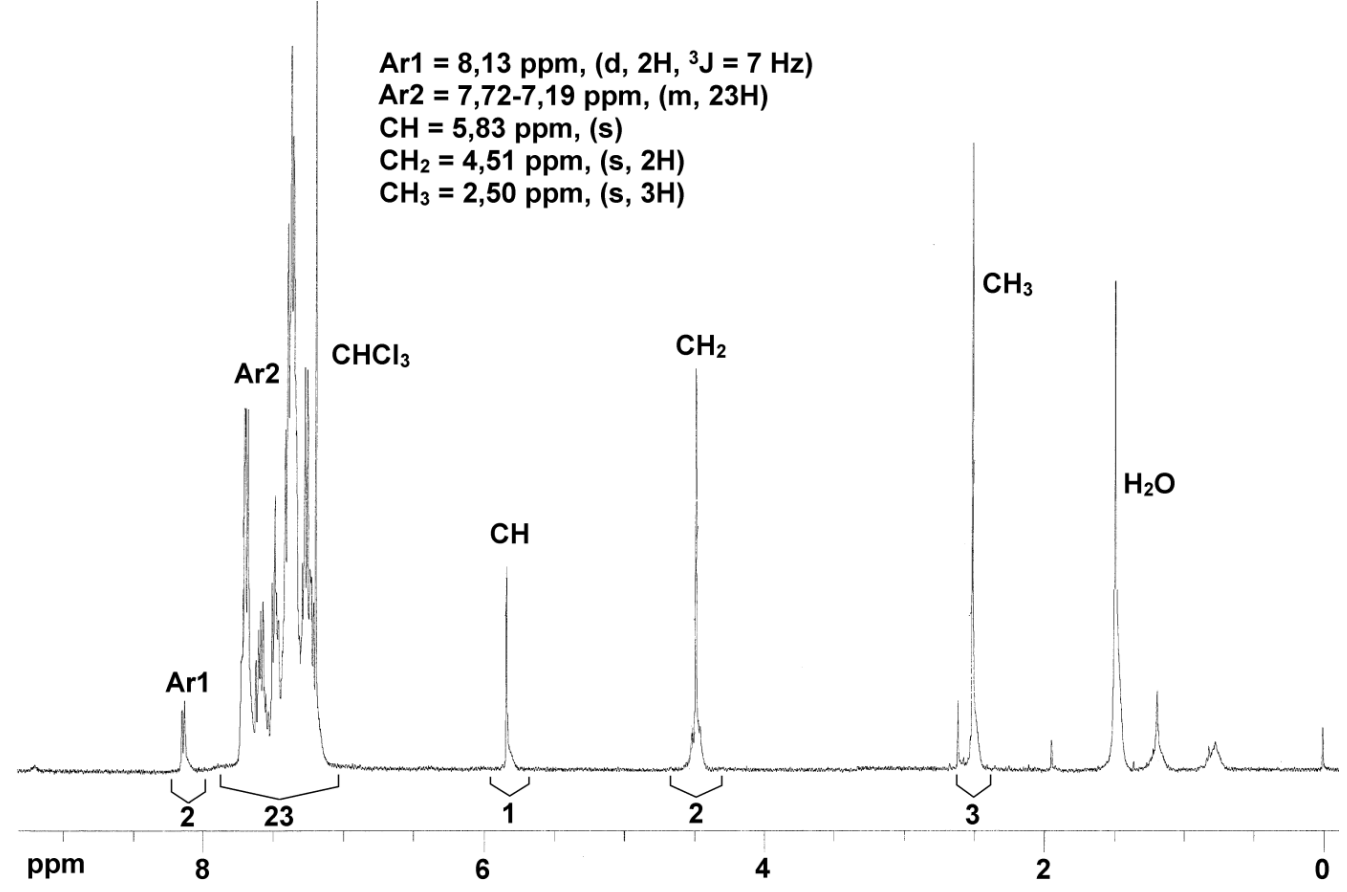

Tabela 11 - Dados de $\mathrm{RMN}^{1} \mathrm{H}(400 \mathrm{MHz})$ e ${ }^{31} \mathrm{P}(161,70 \mathrm{MHz})$ para 4 obtidos em $\mathrm{CDCl}_{3}$.

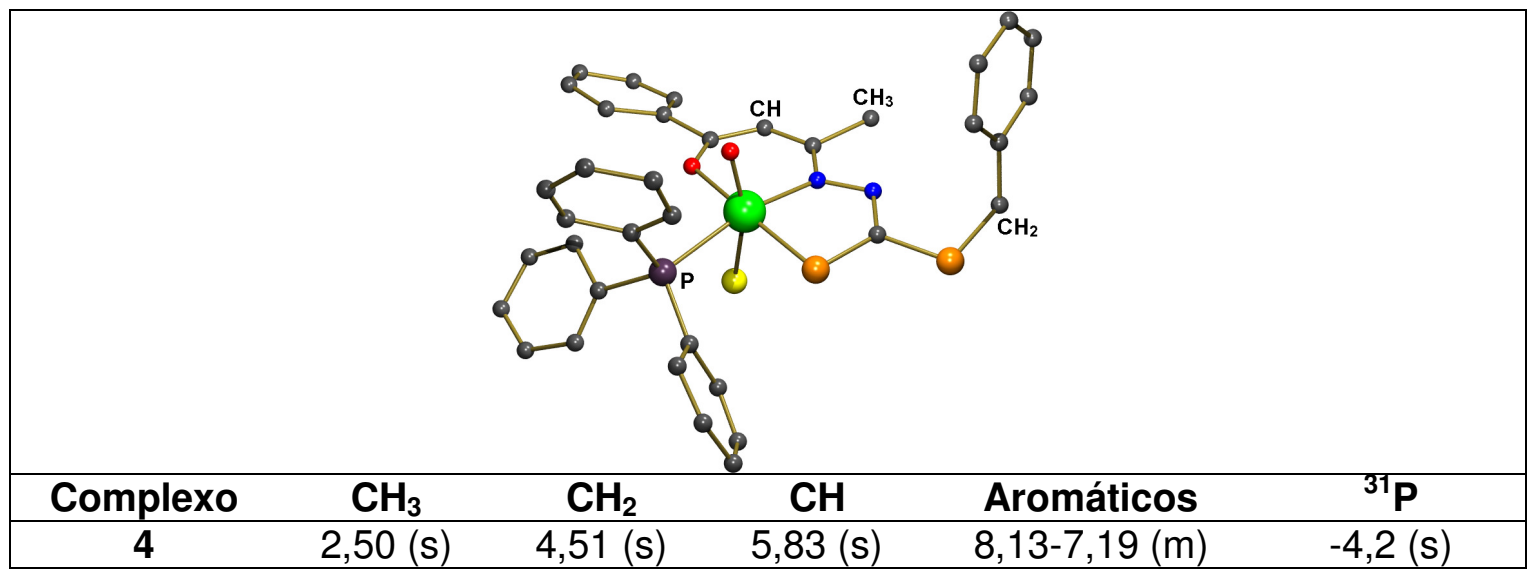


Figura 50 - Espectro de $\mathrm{RMN}{ }^{31} \mathrm{P}$ do $\left[\mathbf{R e O}(\mathbf{b d t c}) \operatorname{Br}\left(\mathbf{P P h}_{3}\right)\right](5)\left(81,0 \mathrm{MHz}, \mathrm{CD}_{2} \mathrm{Cl}_{2}\right)$.

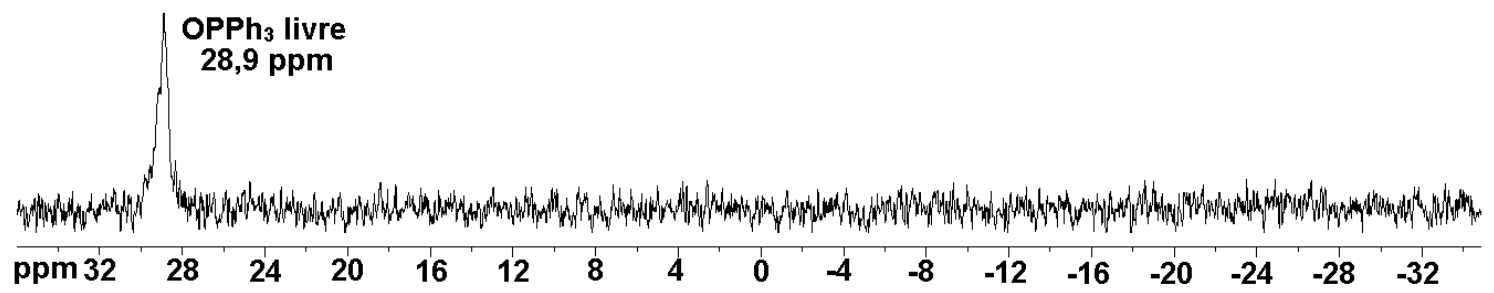

Figura 51 - Espectro de $\operatorname{RMN}^{1} \mathrm{H}$ do $\left[\mathbf{R e O}\left(\right.\right.$ bdtc) $\left.\mathbf{B r}\left(\mathbf{P P h}_{3}\right)\right](5)\left(200,1 \mathrm{MHz}, \mathrm{CD}_{2} \mathrm{Cl}_{2}\right)$.
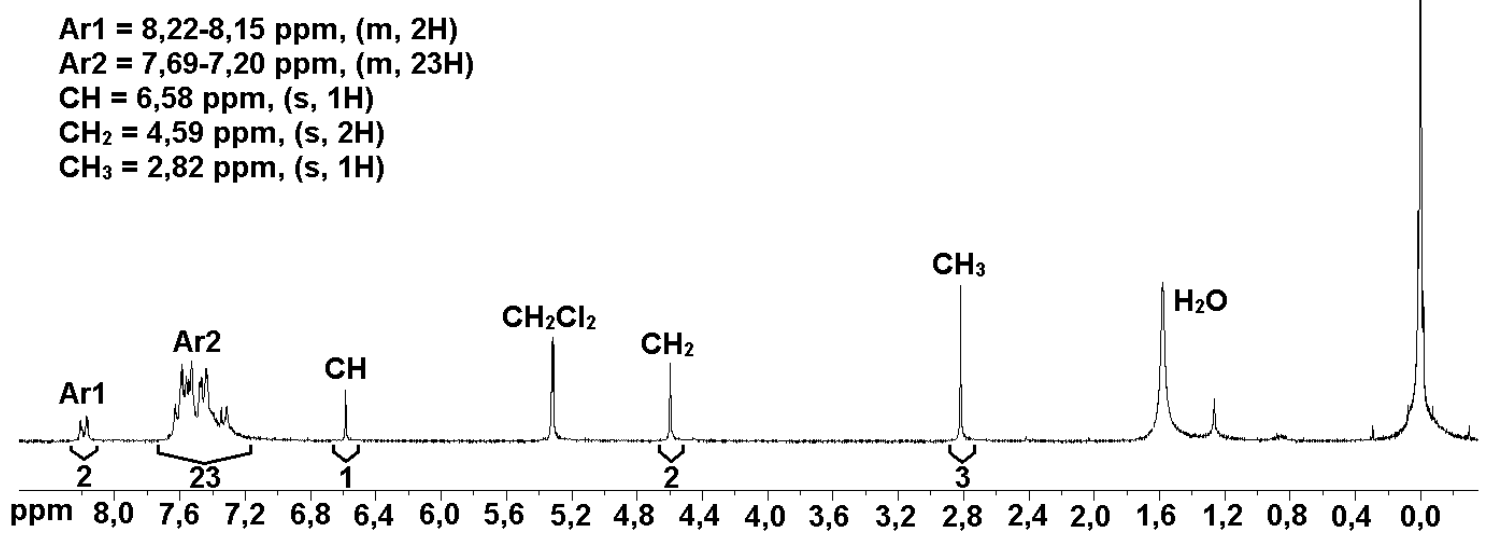

Tabela 12 - Dados de $\mathrm{RMN}^{1} \mathrm{H}(200,1 \mathrm{MHz})$ e ${ }^{31} \mathrm{P}(81,0 \mathrm{MHz})$ para 5 obtidos em $\mathrm{CD}_{2} \mathrm{Cl}_{2}$.

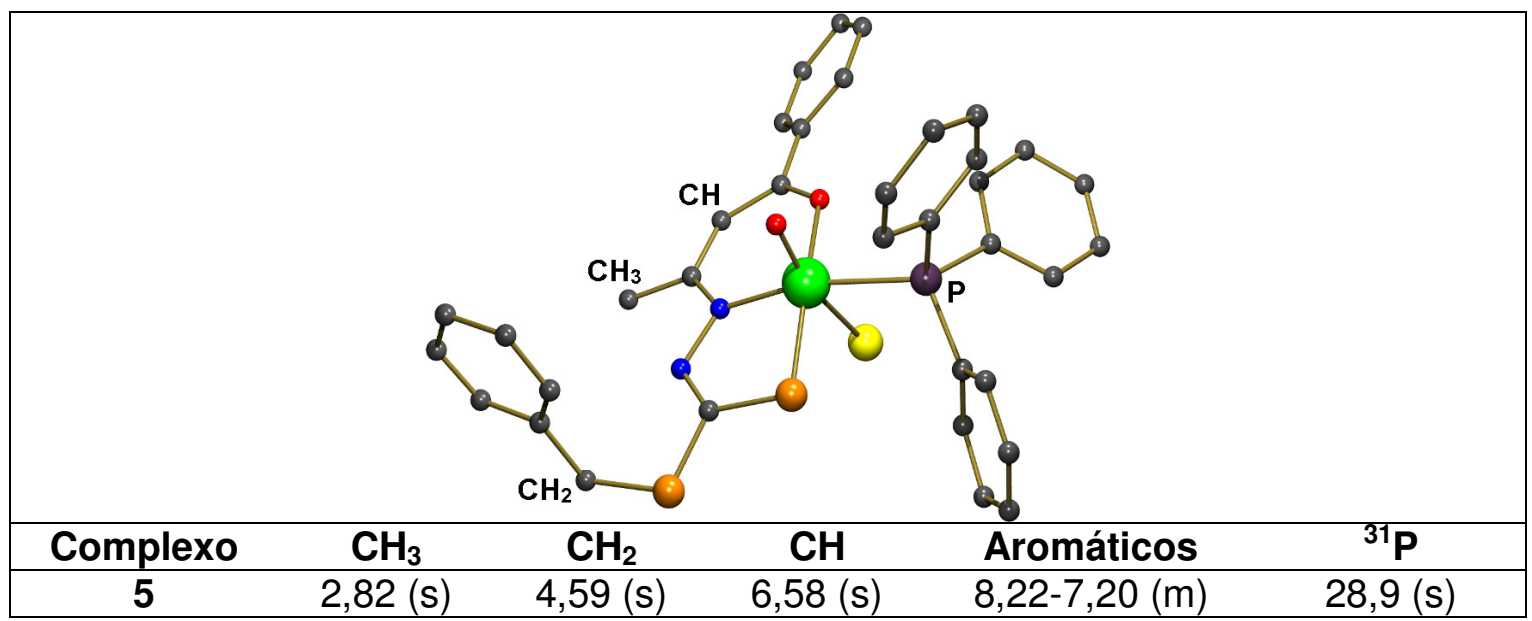


Figura 52 - Espectro de $\mathrm{RMN}^{31} \mathrm{P}$ do $\left[\mathbf{R e O}(\mathbf{b d t n}) \mathbf{C l}\left(\mathbf{P P h}_{3}\right)\right]$ (6) (161,70 MHz, $\left.\mathrm{CD}_{2} \mathrm{Cl}_{2}\right)$.

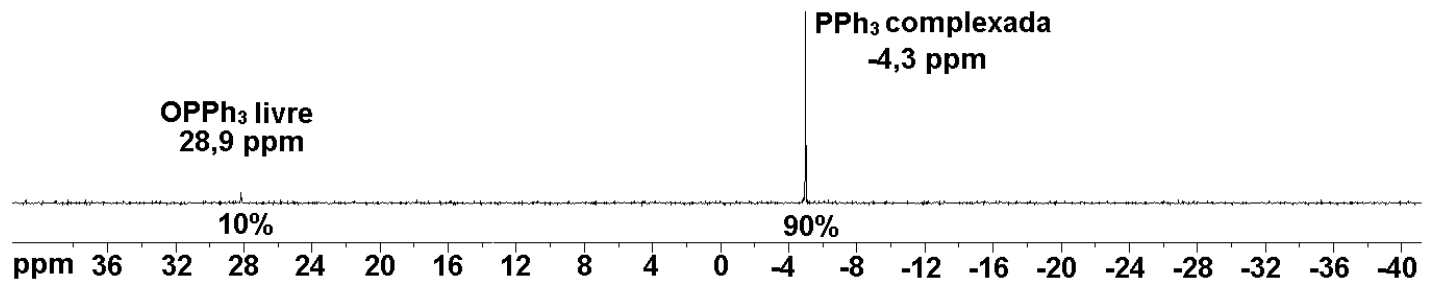

Figura 53 - Espectro de $\mathrm{RMN}{ }^{1} \mathrm{H}$ do $\mathbf{H}_{2}$ bdtn (400 MHz, $\mathrm{CDCl}_{3}$ ).

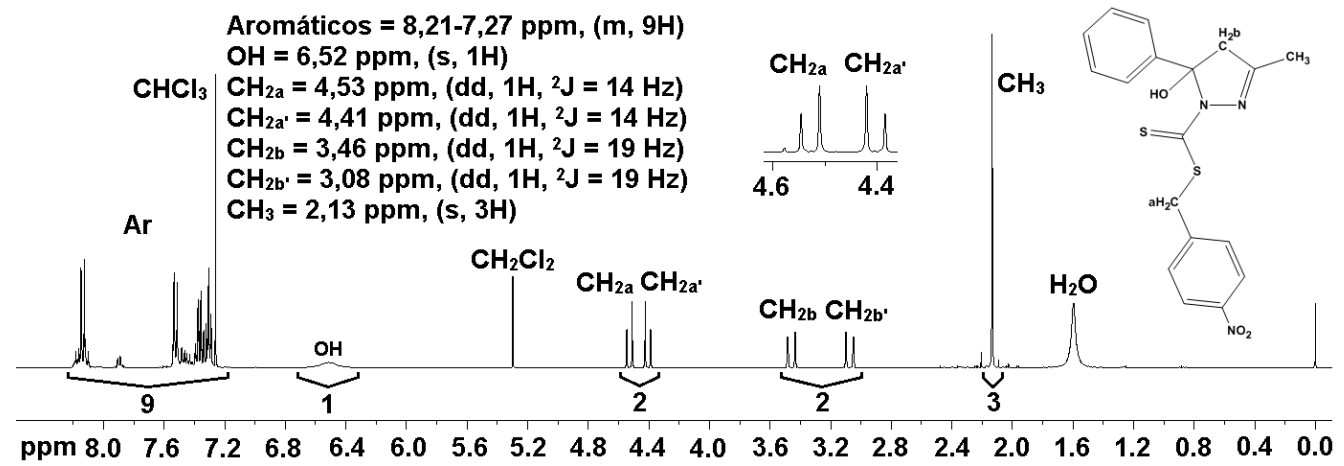

Figura 54 - Espectro de $\mathrm{RMN}^{1} \mathrm{H}$ do $\left[\mathbf{R e O}(\mathbf{b d t n}) \mathbf{C l}\left(\mathbf{P P h}_{3}\right)\right](6)\left(400 \mathrm{MHz}, \mathrm{CD}_{2} \mathrm{Cl}_{2}\right)$.
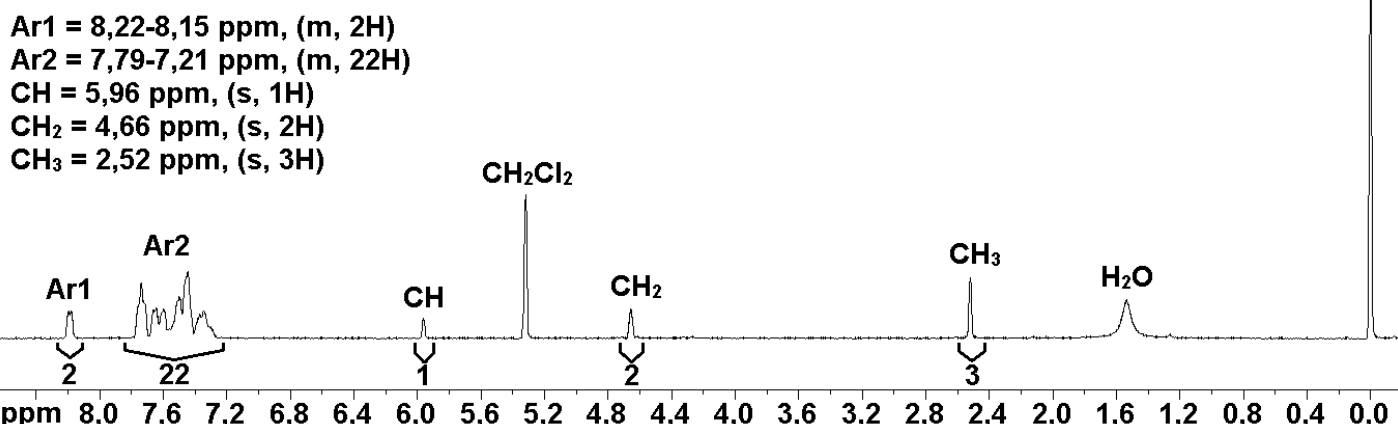

Tabela 13 - Dados de $\mathrm{RMN}^{1} \mathrm{H}(400 \mathrm{MHz}) \mathrm{e}^{31} \mathrm{P}(161,70 \mathrm{MHz})$ para 6 obtidos em $\mathrm{CD}_{2} \mathrm{Cl}_{2}$.

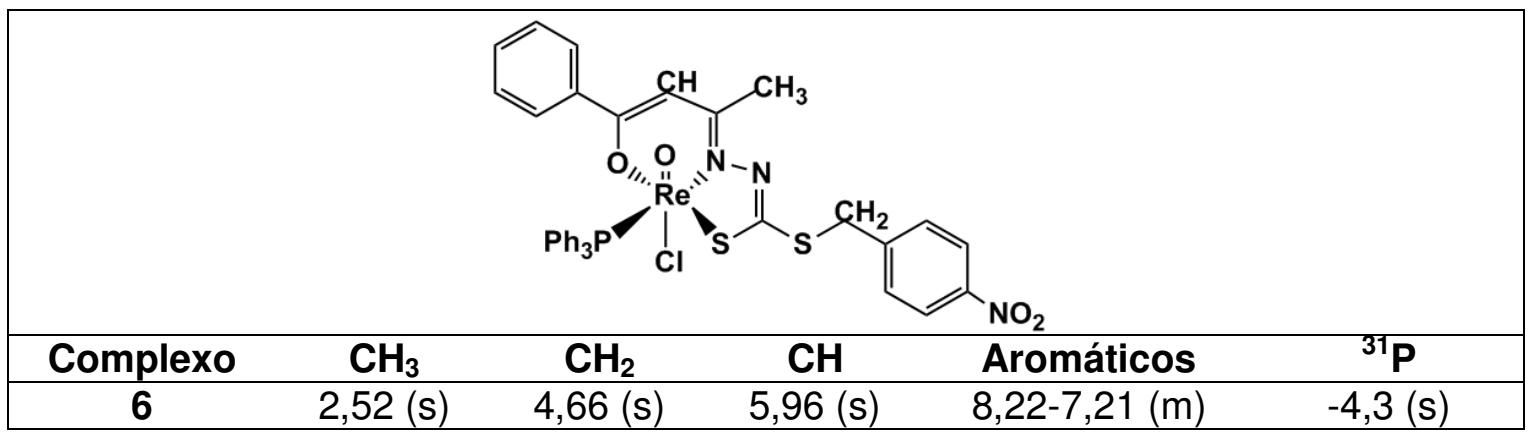


Figura 55 - Espectro de $\mathrm{RMN}{ }^{31} \mathrm{P}$ do $\left[\mathbf{R e O}(\mathbf{b d t m}) \mathbf{C I}\left(\mathrm{PPh}_{3}\right)\right](\mathbf{7})(161,70 \mathrm{MHz}$, $\mathrm{CD}_{2} \mathrm{Cl}_{2}$ ).

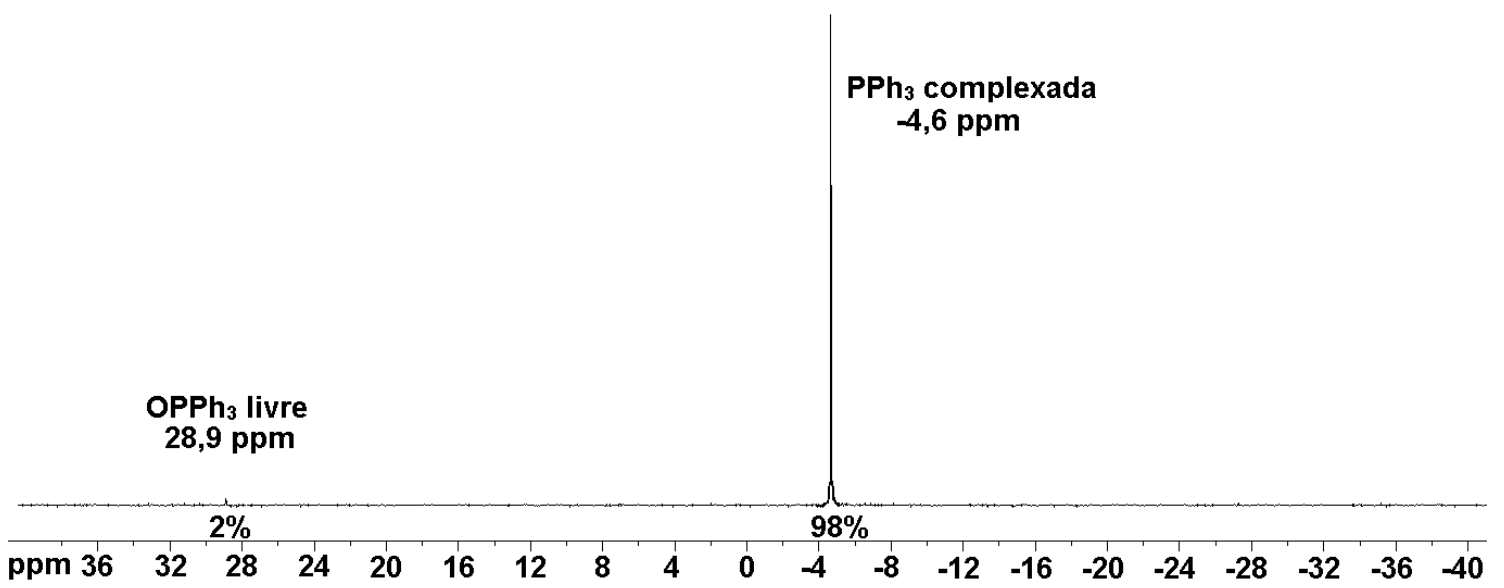

Figura 56 - Espectro de RMN ${ }^{1} \mathrm{H}$ do $\mathbf{H}_{2} \mathbf{b d t m}\left(400 \mathrm{MHz}, \mathrm{CDCl}_{3}\right)$.

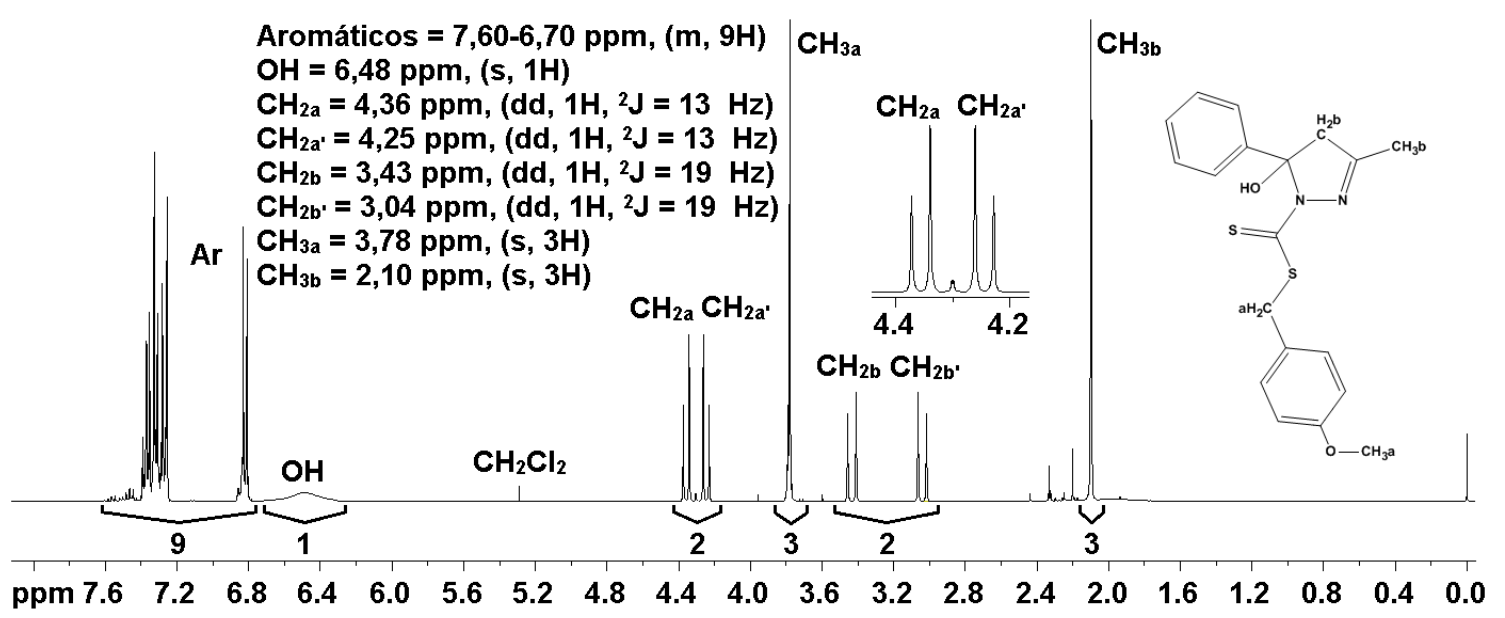


Figura 57 - Espectro de $\mathrm{RMN}{ }^{1} \mathrm{H}$ do $\left[\mathbf{R e O}(\mathbf{b d t m}) \mathbf{C l}\left(\mathbf{P P h}_{3}\right)\right](7)\left(400 \mathrm{MHz}, \mathrm{CD}_{2} \mathrm{Cl}_{2}\right)$.

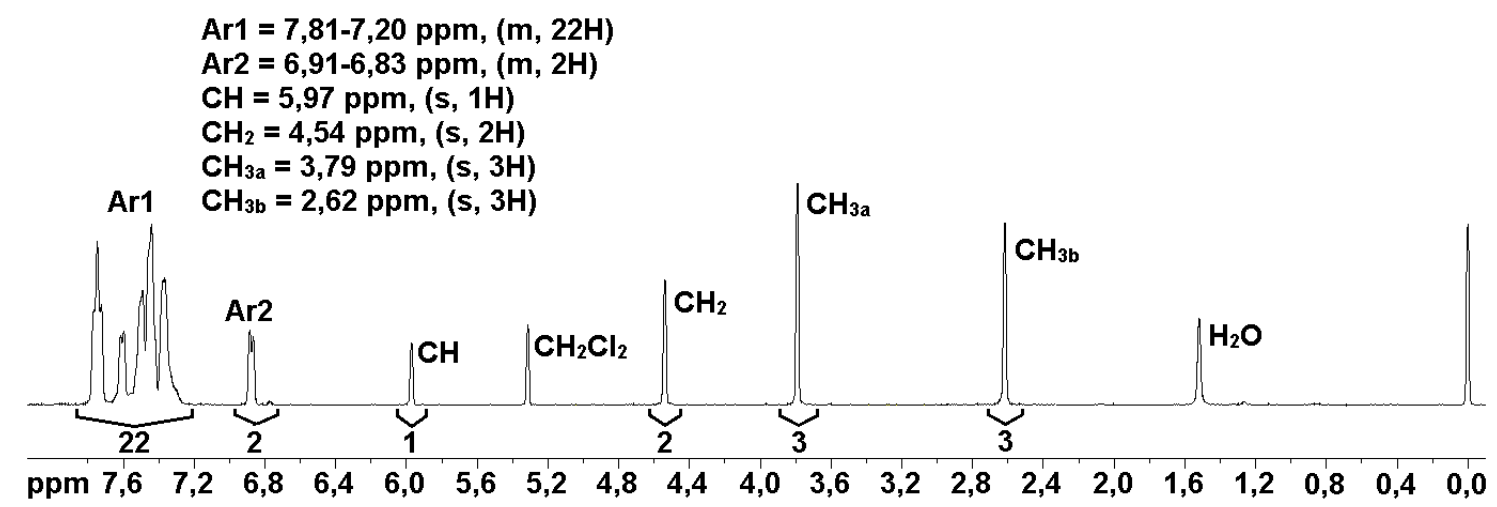

Tabela 14 - Dados de $\mathrm{RMN}^{1} \mathrm{H}(400 \mathrm{MHz}) \mathrm{e}^{31} \mathrm{P}(161,70 \mathrm{MHz})$ para 7 obtidos em $\mathrm{CD}_{2} \mathrm{Cl}_{2}$.

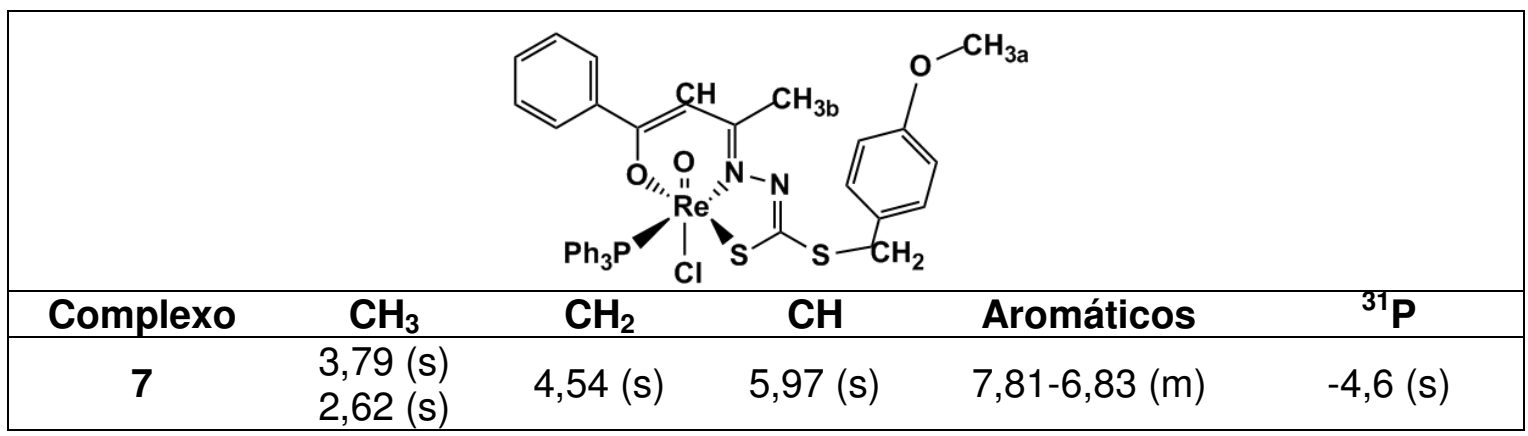


Figura 58 - Espectro de RMN ${ }^{1} \mathrm{H}$ do $[\mathrm{TcO}($ bdtc $) \mathbf{C l}](8)\left(400 \mathrm{MHz}, \mathrm{CDCl}_{3}\right)$.

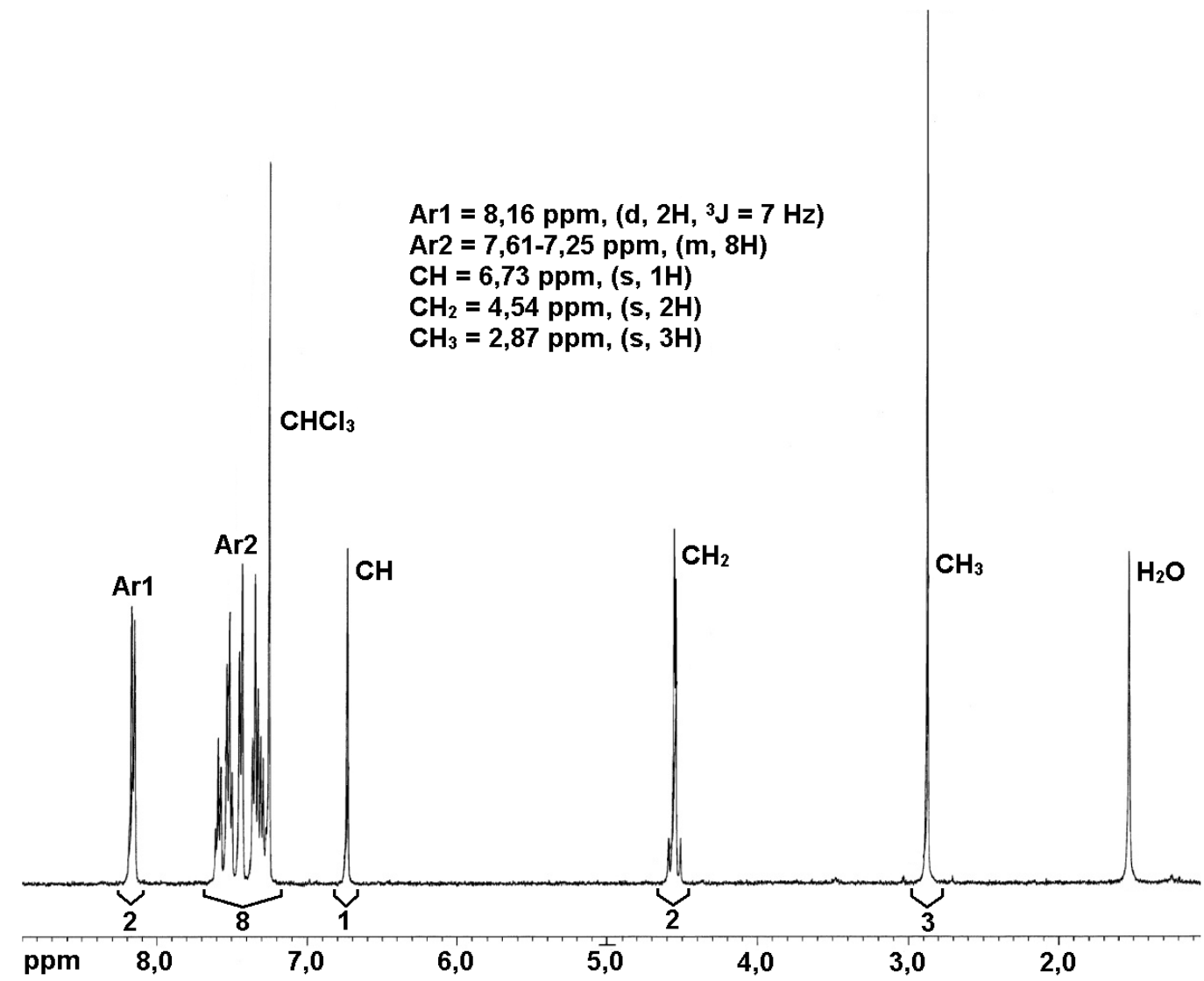

Tabela 15 - Dados de RMN ${ }^{1} \mathrm{H}\left(400 \mathrm{MHz}\right.$ ) para 8 obtidos em $\mathrm{CDCl}_{3}$.

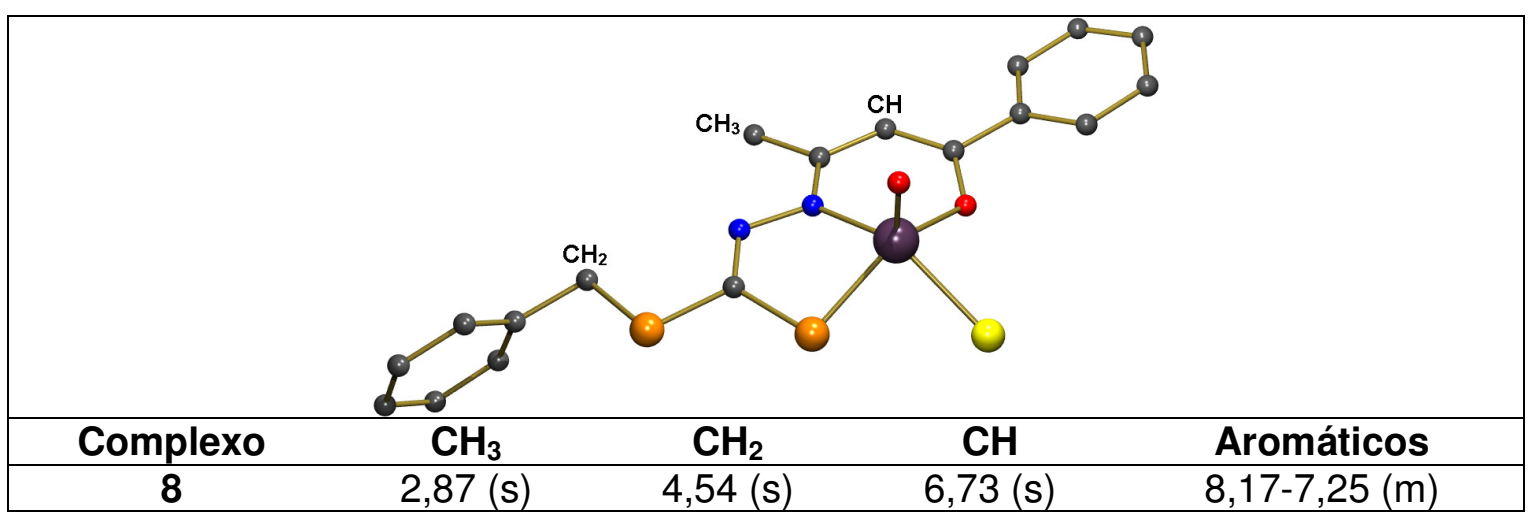




\subsubsection{Difração de Raios X em Monocristal dos Complexos 4, 5 e 8}

\section{Determinação das Estruturas Cristalinas e Moleculares}

Monocristais prismáticos roxos foram obtidos para os complexos 4 e 5 em solução de diclorometano e hexano (10:5 mL, respectivamente) após uma semana a $-15^{\circ} \mathrm{C}$. O produto 8 , por sua vez, é vermelho e cristalizou-se em uma mistura dos mesmo solventes, durante o mesmo período, porém, em um volume e com proporções diferentes entre eles (20:7 mL, respectivamente).

As constantes de cela dos complexos 4, 5 e 8 foram calculadas, respectivamente, a partir de 10100, 12175 e 10186 reflexões, coletadas com uma ampla variação do ângulo $2 \theta$, em todos os casos.

Os complexos 4 e 5 cristalizam-se no sistema cristalino monoclínico, grupo espacial $\mathrm{P} 2_{1} / \mathrm{n}$, possuem cela primitiva $(\mathrm{P})$, eixo de ordem 2 de rotação + translação em $b$ $\left(2_{1}\right)$, centro de inversão, plano de reflexão + translação diagonal $(n)$, com quatro moléculas de cada complexo em sua respectiva unidade assimétrica. Nota-se um aumento de volume da cela do composto 5, com 3,3543(6) $\mathrm{nm}^{3}$, em comparação com o valor encontrado em 4, de $3,3450(2) \mathrm{nm}^{3}$, em consequência da substituição dos ligantes $\mathrm{Cl}$, em 4 , por $\mathrm{Br}$, relativamente mais volumosos, em 5 . O composto 8 pertence ao grupo espacial $P \overline{1}$, o que indica que sua cela é primitiva $(P)$ e possui e centro de inversão $(\overline{1})$.

A solução das estruturas se deu por métodos diretos. ${ }^{64}$

Com exceção dos átomos de hidrogênio, que foram calculados a partir de posições idealizadas, todos os demais foram refinados com deslocamento térmico anisotrópico. ${ }^{65}$ Foram aplicadas, na solução das estruturas dos complexos 4 e 5 as correções de absorção Gaussian ${ }^{73}$ e Integração ${ }^{74}$, respectivamente. As demais informações referentes à determinação das estruturas são apresentadas na tabela 16. Informações referentes aos ângulos e distâncias de ligações selecionadas para os compostos 4 e 5 podem ser encontradas na tabela 17, enquanto os dados de 8 estão dispostos na tabela 18. 


\section{Discussão das Estruturas Cristalinas e Moleculares}

Os átomos de $\operatorname{Re}(\mathrm{V})$ central, nos complexos $\mathbf{4}$ e $\mathbf{5}$, encontram-se hexacoordenados, com geometrias de coordenação octaédricas distorcidas (Figuras 59 e 61). Fazem parte da esfera de coordenação destes compostos, compondo o plano equatorial, os átomos $O, N, S$-doadores oriundos do ânion bdtc $^{2-}$ e de fósforo de uma trifenilfosfina, enquanto oxigênio, proveniente de um grupo oxo e haletos $(\mathrm{Cl}$ em 4, e Br em 5) estão trans-posicionados entre si.

Com geometria de coordenação diferente, o átomo de Tc (V) no complexo 8 (Figura 62), apresenta-se pentacoordenado, sob a forma de uma pirâmide de base quadrada, com o átomo de Tc localizado a 70,4(1) pm acima do plano equatorial, formado pelos átomos de cloro, oxigênio, nitrogênio e enxofre, e na direção do grupo oxo que ocupa a posição axial.

Os comprimentos de ligação $\mathrm{M}=\mathrm{O}$ são de 169,1(2), 169,4(7) e 164,1 (3) pm e apresentam-se compatíveis com as ligações duplas $\mathrm{Re}=\mathrm{O}$, para os dois primeiros valores, e Tc=O, no caso para o último. ${ }^{8,61,62,68,75}$

Os comprimentos das ligações $\mathrm{Re}-\mathrm{Cl}$ e $\mathrm{Re}-\mathrm{P}$ encontram-se adequados para as suas respectivas ligações (Tabela 17). ${ }^{61,62,68}$

O modo de coordenação tridentado e dianiônico, do ligante bdtc $^{2-}$, assim como sua capacidade de formar dois anéis quelatos (um com seis e outro com cinco membros) como consequência da coordenação, contribui para a estabilidade dos produtos neutros formados. 
Figura 59 - Estrutura molecular do complexo 4. Para facilitar a visualização, os átomos de hidrogênio dos ligantes foram omitidos.

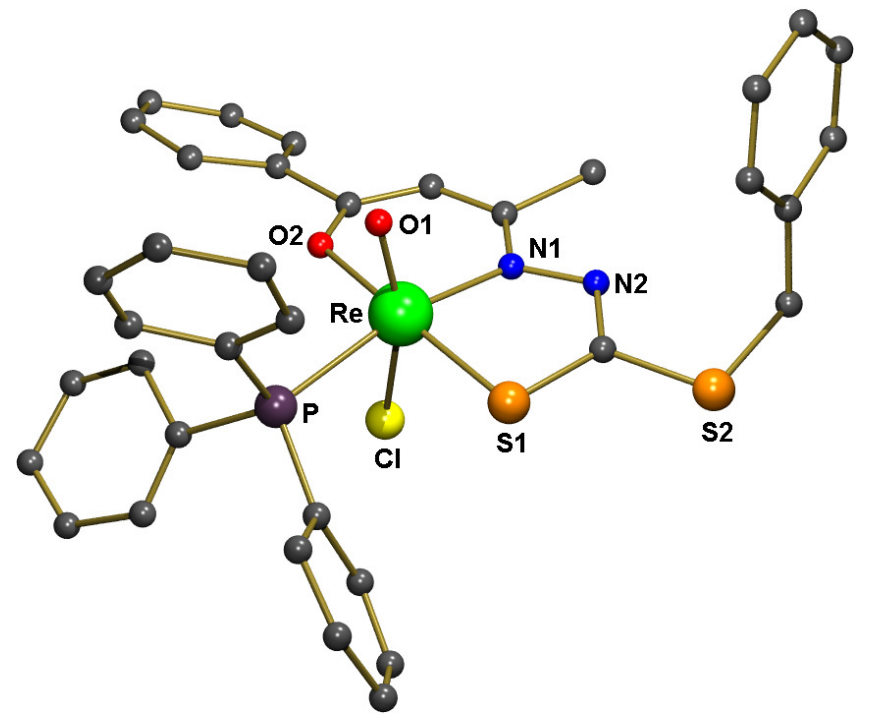

Figura 60 - Representação da cela unitária do complexo 4. Para facilitar a visualização, os átomos de hidrogênio dos ligantes foram omitidos.

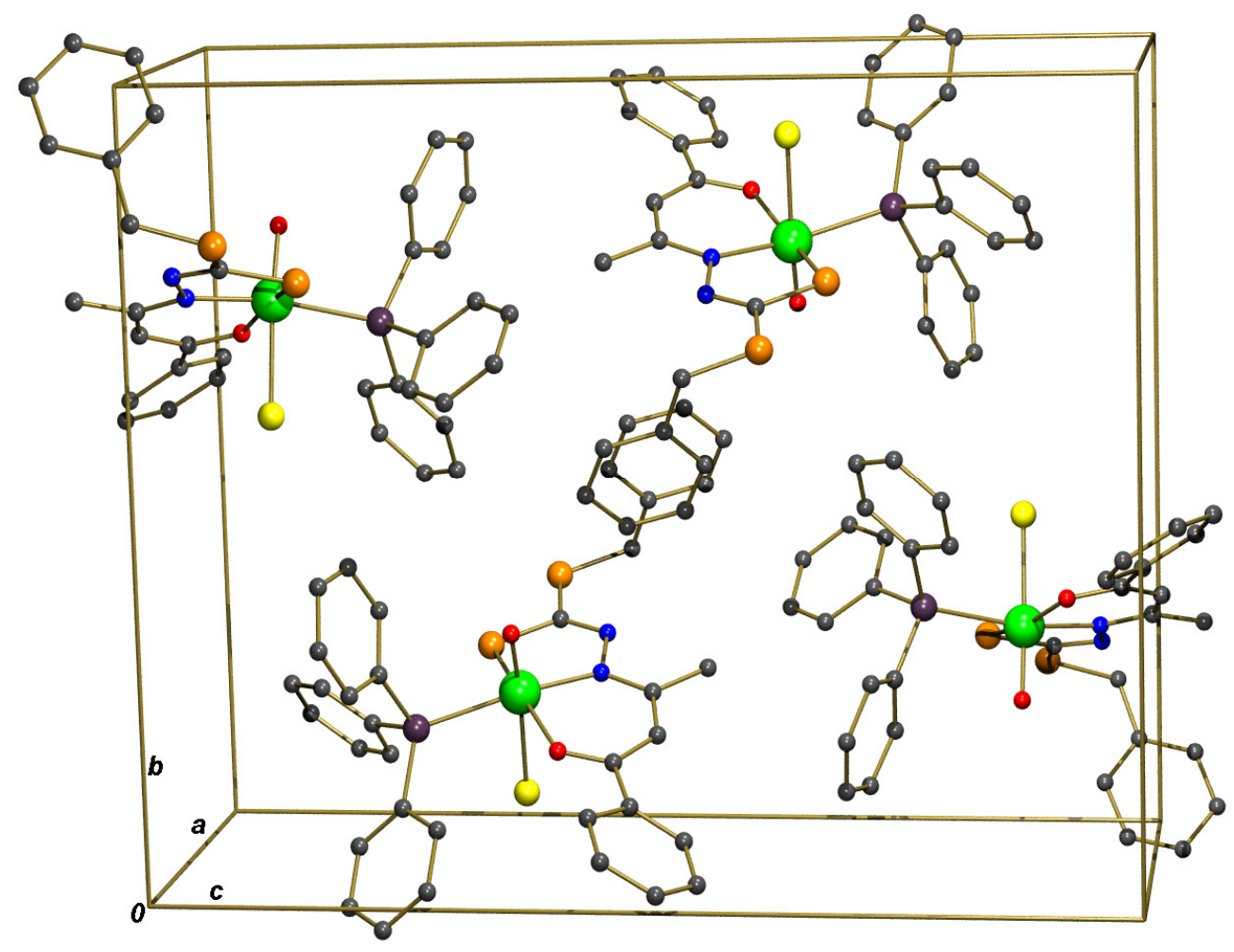


Figura 61 - Estrutura molecular do complexo 5. Para facilitar a visualização, os átomos de hidrogênio dos ligantes foram omitidos.

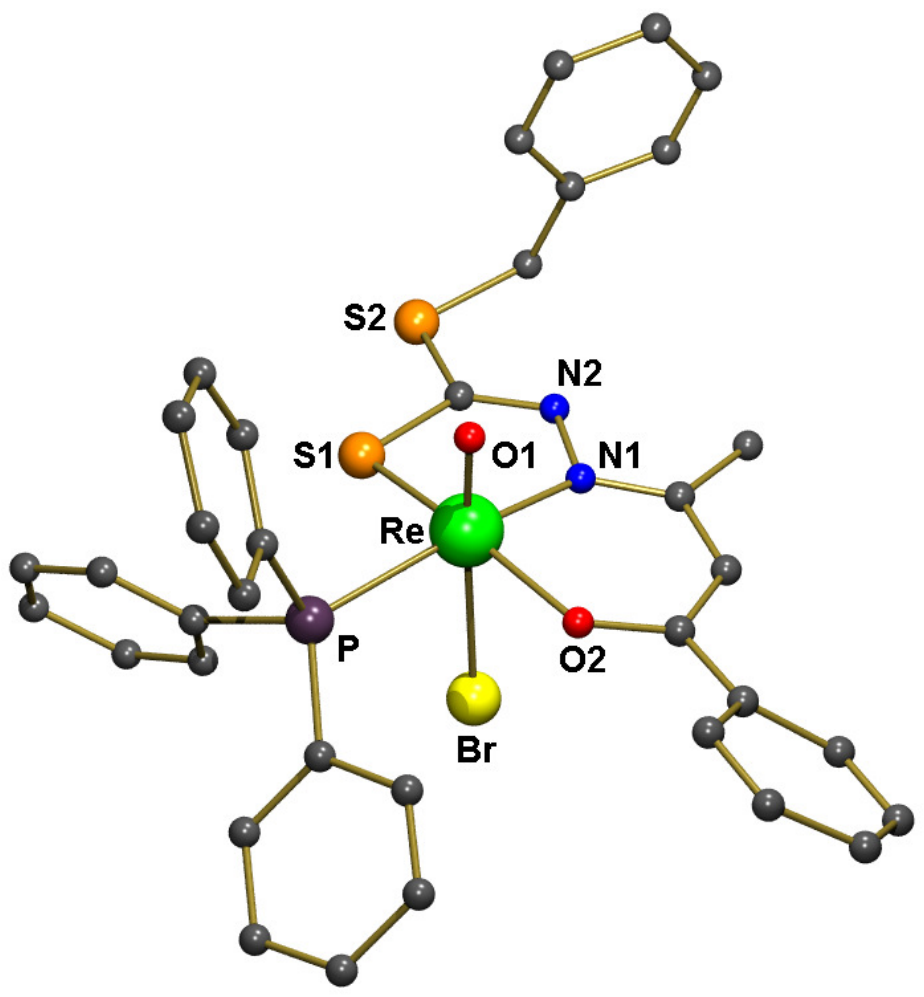

Figura 62 - Estrutura molecular do complexo 8. Para facilitar a visualização, os átomos de hidrogênio dos ligantes foram omitidos.

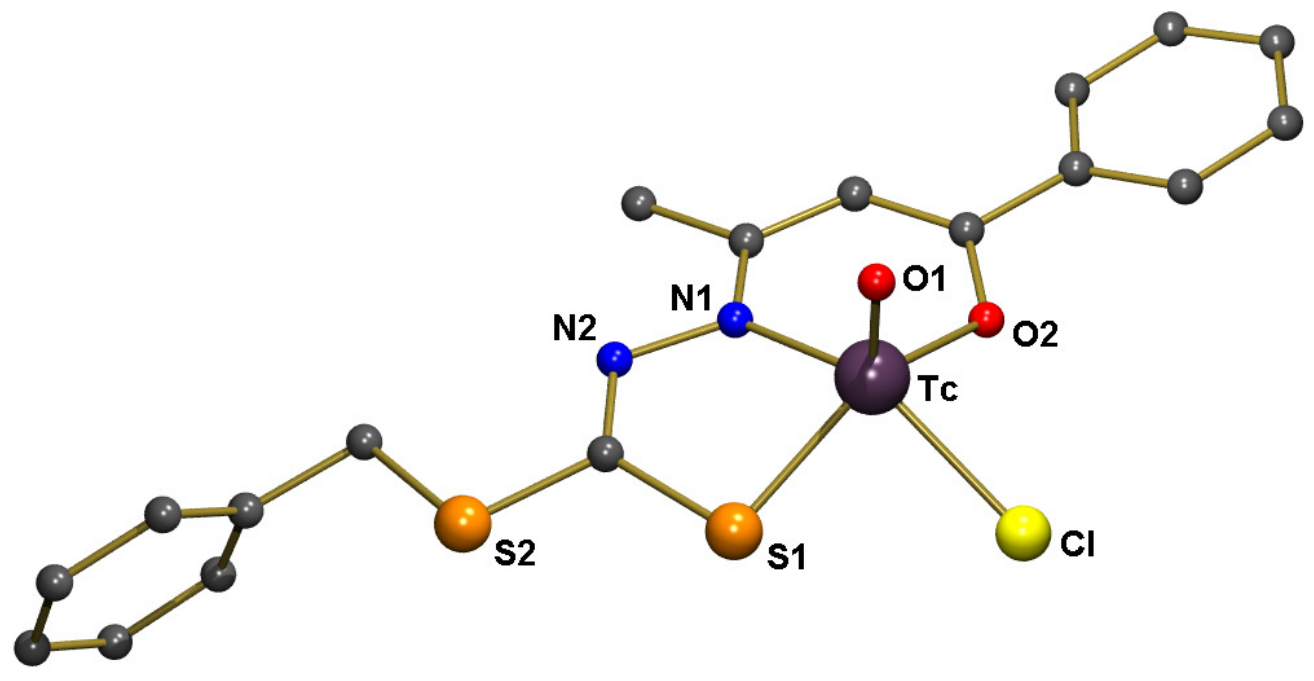


Figura 63 - Representação da cela unitária do complexo 8.

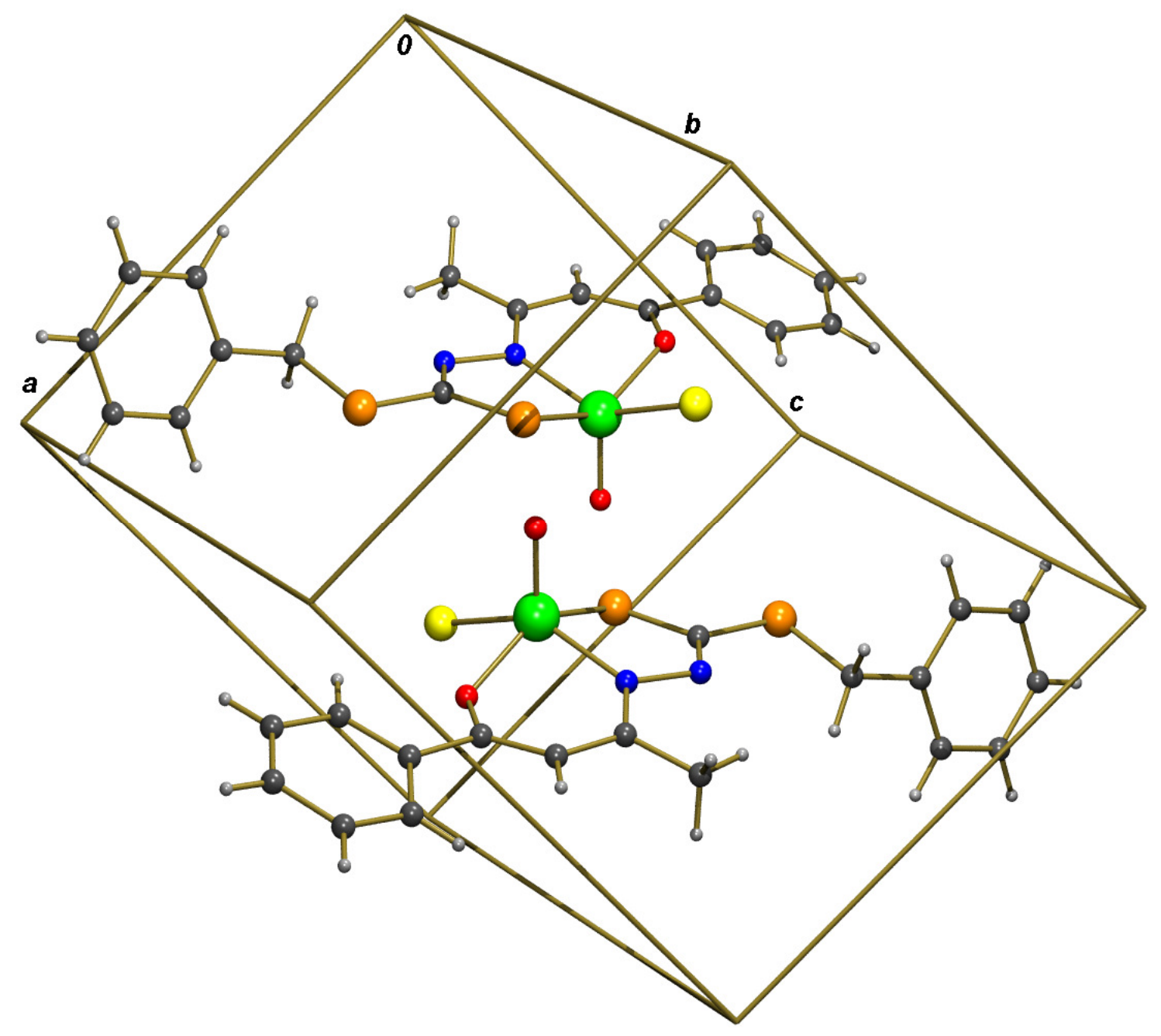


Tabela 16 - Dados cristalográficos de difração de raios $X$ e resultados dos refinamentos das estruturas dos complexos 4, 5 e 8.

\begin{tabular}{|c|c|c|c|}
\hline Complexo & 4 & 5 & 8 \\
\hline Fórmula molecular & $\mathrm{C}_{36} \mathrm{H}_{31} \mathrm{CIN}_{2} \mathrm{O}_{2} \mathrm{PReS}_{2}$ & $\mathrm{C}_{36} \mathrm{H}_{31} \mathrm{BrN}_{2} \mathrm{O}_{2} \mathrm{PReS}_{2}$ & $\mathrm{C}_{18} \mathrm{H}_{16} \mathrm{CIN}_{2} \mathrm{O}_{2} \mathrm{~S}_{2} \mathrm{TC}$ \\
\hline Massa Molar g. $\mathrm{mol}^{-1}$ & 840,37 & 884,83 & 489,90 \\
\hline Temperatura (K) & 293(2) & $200(2)$ & $200(2)$ \\
\hline Comprimento da radiação (pm) & 71,073 & 71,073 & 71,073 \\
\hline Sistema Cristalino & Monoclínico & Monoclínico & Triclínico \\
\hline Grupo Espacial & $\mathrm{P} 2_{1} / \mathrm{n}$ & $\mathrm{P} 2_{1} / \mathrm{n}$ & $\mathrm{P} \overline{1}$ \\
\hline \multicolumn{4}{|l|}{ Parâmetros da cela unitária } \\
\hline$a(\mathrm{pm})$ & $857,54(3)$ & $856,9(5)$ & $973,53(9)$ \\
\hline$b(\mathrm{pm})$ & $1742,56(7)$ & $1757,2(5)$ & $993,8(1)$ \\
\hline$c(\mathrm{pm})$ & $2238,54(9)$ & $2227,9(5)$ & $1088,8(1)$ \\
\hline$\alpha(\stackrel{\circ}{)}$ & 90 & 90 & $90,650(8)$ \\
\hline$\beta(\stackrel{\circ}{\circ})$ & $90,406(2)$ & $90,820(5)$ & $108,316(8)$ \\
\hline$\gamma(\stackrel{\circ}{*})$ & 90 & 90 & $107,056(8)$ \\
\hline Volume $\left(\mathrm{nm}^{3}\right)$ & $3,3450(2)$ & $3,3543(6)$ & $0,9498(2)$ \\
\hline Z & 4 & 4 & 2 \\
\hline Coeficiente de absorção $\left(\mathrm{mm}^{-1}\right)$ & 3,921 & 5,022 & 1,134 \\
\hline Tamanho do cristal $\left(\mathrm{mm}^{3}\right)$ & $0,184 \times 0,142 \times 0,102$ & $\begin{array}{c}0,320 \times 0,140 \times \\
0,040\end{array}$ & $\begin{array}{c}0,171 \times 0,133 \times \\
0,104\end{array}$ \\
\hline Forma e cor do cristal & Prismas roxos & Prismas roxos & Prismas vermelhos \\
\hline Método / variação de $\theta\left({ }^{\circ}\right)$ & 2,65 até 30,56 & 2,49 até 25,00 & 1,98 até 29,20 \\
\hline Índices (h, k, l) & $\begin{array}{c}-12 \rightarrow \mathrm{h} \rightarrow 12 \\
0 \rightarrow \mathrm{k} \rightarrow 24 \\
0 \rightarrow \mathrm{I} \rightarrow 32\end{array}$ & $\begin{array}{c}-10 \rightarrow \mathrm{h} \rightarrow 7 \\
-18 \rightarrow \mathrm{k} \rightarrow 20 \\
-26 \rightarrow 1 \rightarrow 26\end{array}$ & $\begin{array}{c}-13 \rightarrow \mathrm{h} \rightarrow 12 \\
-13 \rightarrow \mathrm{k} \rightarrow 13 \\
-14 \rightarrow \mathrm{l} \rightarrow 14\end{array}$ \\
\hline Reflexões coletadas & 10100 & 12175 & 10186 \\
\hline Reflexões independentes / $R_{\text {int }}$ & $10100 / 0,0000$ & $5791 / 0,1487$ & $5071 / 0,0583$ \\
\hline Correção de Absorção & Gaussian $^{13}$ & Integração $^{14}$ & Nenhuma \\
\hline Transmissão min. / max. & $0,652 / 1$ & $0,4284 / 0,8027$ & $-\cdots--$ \\
\hline Refinamento da estrutura & $\begin{array}{l}\text { Matriz completa dos } \\
\text { mínimos quadrados }\end{array}$ & $\begin{array}{l}\text { Matriz completa dos } \\
\text { mínimos quadrados }\end{array}$ & $\begin{array}{l}\text { Matriz completa dos } \\
\text { mínimos quadrados }\end{array}$ \\
\hline Tratamento dos hidrogênios & Calculados & Calculados & Calculados \\
\hline Fatores R finais $[\mathrm{l}>2 \sigma(\mathrm{I})]$ & $\begin{array}{l}R 1=0,0355 \\
w R 2=0,0828\end{array}$ & $\begin{array}{l}\mathrm{R} 1=0,0644 \\
\mathrm{wR} 2=0,0899\end{array}$ & $\begin{array}{l}\mathrm{R} 1=0,0463 \\
\mathrm{wR} 2=0,1142\end{array}$ \\
\hline "Goodness-of-fit" sobre F ${ }^{2}$ & 1,054 & 0,844 & 0,927 \\
\hline Programas usados & $\begin{array}{l}\text { SHELXS97 } \\
\text { SHELX4 }^{65} \mathrm{e}\end{array}$ & $\begin{array}{l}\text { SHELXS97 } \\
\text { SHELXL }\end{array}$ & $\begin{array}{l}\text { SHELXS97 } \\
\text { SHELXL }\end{array}$ \\
\hline
\end{tabular}


Tabela 17 - As principais distâncias (pm) e ângulos $\left(^{\circ}\right)$ de ligação encontrados nos complexos 4 e 5.

\begin{tabular}{|ccc|}
\hline Distâncias & $\mathbf{4}(\mathrm{X}=\mathrm{Cl})$ & $\mathbf{5}(\mathrm{X}=\mathrm{Br})$ \\
\hline $\mathrm{Re}-\mathrm{O}(1)$ & $169,1(2)$ & $169,4(7)$ \\
\hline $\operatorname{Re}-\mathrm{O}(2)$ & $211,0(2)$ & $209,2(9)$ \\
\hline $\operatorname{Re}-\mathrm{N}(1)$ & $203,5(3)$ & $207,1(5)$ \\
\hline $\operatorname{Re}-\mathrm{S}(1)$ & $230,3(1)$ & $229,3(4)$ \\
\hline $\operatorname{Re}-\mathrm{P}$ & $249,6(1)$ & $248,2(3)$ \\
\hline $\operatorname{Re}-\mathrm{X}$ & $246,1(1)$ & $262,2(2)$ \\
\hline Ângulos & & \\
\hline $\mathrm{O}(1)-\operatorname{Re}-\mathrm{O}(2)$ & $89,9(1)$ & $90,6(4)$ \\
\hline $\mathrm{O}(1)-\operatorname{Re}-\mathrm{N}(1)$ & $101,6(1)$ & $100,8(4)$ \\
\hline $\mathrm{O}(1)-\operatorname{Re}-\mathrm{S}(1)$ & $102,67(9)$ & $101,8(3)$ \\
\hline $\mathrm{O}(1)-\operatorname{Re}-\mathrm{P}$ & $91,13(8)$ & $92,7(2)$ \\
\hline $\mathrm{O}(1)-\operatorname{Re}-\mathrm{X}$ & $165,16(8)$ & $166,4(3)$ \\
\hline $\mathrm{O}(2)-\operatorname{Re}-\mathrm{N}(1)$ & $90,2(1)$ & $89,5(4)$ \\
\hline $\mathrm{O}(2)-\operatorname{Re}-\mathrm{S}(1)$ & $166,47(8)$ & $166,7(3)$ \\
\hline $\mathrm{O}(2)-\operatorname{Re}-\mathrm{P}$ & $95,68(7)$ & $95,0(2)$ \\
\hline $\mathrm{O}(2)-\operatorname{Re}-\mathrm{X}$ & $77,89(8)$ & $77,4(2)$ \\
\hline $\mathrm{N}(1)-\operatorname{Re}-\mathrm{S}(1)$ & $82,58(9)$ & $83,7(3)$ \\
\hline $\mathrm{N}(1)-\operatorname{Re}-\mathrm{P}$ & $166,01(9)$ & $165,7(3)$ \\
\hline $\mathrm{N}(1)-\operatorname{Re}-\mathrm{X}$ & $87,05(9)$ & $85,7(3)$ \\
\hline $\mathrm{S}(1)-\operatorname{Re}-\mathrm{P}$ & $89,05(3)$ & $89,1(1)$ \\
\hline $\mathrm{S}(1)-\operatorname{Re}-\mathrm{X}$ & $90,29(4)$ & $90,7(1)$ \\
\hline $\mathrm{P}-\operatorname{Re}-\mathrm{X}$ & $81,79(2)$ & $82,02(9)$ \\
\hline
\end{tabular}

Tabela 18 - As principais distâncias $(\mathrm{pm})$ e ângulos $\left(^{\circ}\right)$ de ligação encontrados no complexo 8.

\begin{tabular}{|cc|}
\hline Distâncias & $\mathbf{8}$ \\
\hline Tc-O(1) & $164,1(3)$ \\
\hline Tc-O(2) & $199,3(3)$ \\
\hline Tc-N(1) & $202,4(3)$ \\
\hline Tc-S(1) & $225,8(1)$ \\
\hline Tc-Cl & $234,0(1)$ \\
\hline Angulos & \\
\hline $\mathrm{O}(1)-\mathrm{Tc}-\mathrm{O}(2)$ & $110,5(2)$ \\
\hline $\mathrm{O}(1)-\mathrm{Tc}-\mathrm{N}(1)$ & $107,3(1)$ \\
\hline $\mathrm{O}(1)-\mathrm{Tc}-\mathrm{S}(1)$ & $108,2(1)$ \\
\hline $\mathrm{O}(1)-\mathrm{Tc}-\mathrm{Cl}$ & $110,7(1)$ \\
\hline $\mathrm{O}(2)-\mathrm{Tc}-\mathrm{N}(1)$ & $87,6(1)$ \\
\hline $\mathrm{O}(2)-\mathrm{Tc}-\mathrm{S}(1)$ & $141,2(1)$ \\
\hline $\mathrm{O}(2)-\mathrm{Tc}-\mathrm{Cl}$ & $81,0(1)$ \\
\hline $\mathrm{N}(1)-\mathrm{Tc}-\mathrm{S}(1)$ & $81,3(1)$ \\
\hline $\mathrm{N}(1)-\mathrm{Tc}-\mathrm{Cl}$ & $141,9(1)$ \\
\hline $\mathrm{S}(1)-\mathrm{Tc}-\mathrm{Cl}$ & $85,2(1)$ \\
\hline & \\
\hline
\end{tabular}




\subsubsection{Testes Realizados no Centro de Medicina Nuclear, da Universidade de São Paulo}

Um dos principais objetivos desta tese está relacionado com 0 desenvolvimento de novos radiofármacos de ${ }^{99 m} \mathrm{Tc}$ a partir dos complexos modelos de rênio sintetizados, caracterizados e apresentados neste trabalho. Tornou-se imprescindível unir esforços com o grupo de pesquisa do Serviço de Medicina Nuclear, do Departamento de Radiologia do Hospital das Clínicas da Universidade de São Paulo, em São Paulo.

Todos os testes envolvendo o isótopo metaestável de tecnécio, ${ }^{99 \mathrm{~m}} \mathrm{Tc}$, foram realizados pela farmacêutica Alyne Eloise Lafratta, sob a supervisão do pesquisador e químico, Dr. Fábio Luís Navarro Marques.

Conforme relatado anteriormente, complexos com coeficiente de partição (Log P) entre 1 e 2,5, carga neutra, estáveis in vitro e in vivo e que apresentam massa molar abaixo de $600 \mathrm{~g} / \mathrm{mol}$, são canditatos em potencial para estudos de perfusão cerebral. As análises físico-químicas descritas nas próximas páginas comprovam que o complexo $\left[{ }^{99 \mathrm{~m}} \mathrm{TcO}(\mathbf{b d t c}) \mathbf{C l}\right]$ preenche todos os pré-requisitos, justificando estudos futuros in vivo para determinar sua biodistribuição no organismo.

\section{Equipamentos e Sistemas Utilizados}

- Calibradores de doses, Victoreen, USA, modelo 34-056 e Capintec, modelo CRC-15R;

- Contador tipo poço, 1480 Automatic Gamma Counter Wallc wizard 3", Perkin Elmer precisely, Finlândia, 2005;

- Cromatógrafo Líquido de Alta Eficiência, Software Class-VP, Shimadzu Corporation, Japan;

- Flow Scintillation Analyzer, Radiomatic 610TR, Software ProFSA, Perkin Elmer, USA;

- Coluna C18 (4,6 x 250 mm, 4 um) - Synergi-Hidro-RP, Phenomenex - USA;

- Cuba para eletroforese, Elphor, DR Bender \& Dr Hobein, Karlsruhe München Zürich, conectada a uma fonte contínua E-C Apparatus, modelo nº FB105 LVD, EC 105; 
- Vórtex, Quimis, São Paulo, modelo Q-220A;

- Agitador magnético com chapa aquecedora, Quimis, São Paulo, modelo Q-261-22;

- Balança analítica eletrônica, Mettler, Suíça, modelo AE 200;

- Cilindro de nitrogênio, IBG Gases Especiais, São Paulo;

- Frascos de vidro tipo penicilina, Euroglass; rolhas plásticas, Farmacap.

- Filtro Millipore (Millex $\left.{ }^{\circledR}\right)$; Bedford, MA 01730 U.S.A, $\left(0,2 \mu \mathrm{m}, \mathrm{d}=13 \mathrm{~mm}^{2}\right.$ );

- Filtro Nylon Membrane (Nalgene $\left.{ }^{\circledR}\right),\left(0,45 \mu \mathrm{M}, \mathrm{d}=7 \mathrm{~mm}^{2}\right)$;

- Suportes cromatográficos (fitas cromatográficas): papel W3, W \& R Balston Ltd.

\section{Reagentes e Solventes Utilizados}

- Ditiocarbazato $\mathbf{H}_{2}$ bdtc, sintetizado no grupo do Prof. Dr. Victor M. Deflon;

- [ReO(bdtc)(Hbdtc)], sintetizado no grupo do Prof. Dr. Victor M. Deflon;

- $\mathrm{SnCl}_{2} \cdot 2 \mathrm{H}_{2} \mathrm{O}$, Sigma-Aldrich;

- $\mathrm{NaHPO}_{4} \cdot 12 \mathrm{H}_{2} \mathrm{O}, \mathrm{EEL}$;

- $\mathrm{NaH}_{2} \mathrm{PO}_{4} \cdot \mathrm{H}_{2} \mathrm{O}, \mathrm{EEL}$;

- $\mathrm{NaOH}, \mathrm{Vetec}$;

- $\mathrm{NaCO}_{3}$, Baker Analyzed;

- Dimetilsulfóxido, Carlo Erba;

- Água Mili Q;

- Solução fisiológica ( $\mathrm{NaCl}$ 0,9 \%), Baxter;

- Acetona, Nuclear;

- Clorofórmio, Nuclear;

- Metanol, Labcenter;

- Acetonitrila, Merck;

- Tetrahidrofurano, Vetec;

- 1-Octanol Rein, Merck; 


\subsubsection{Métodos de Preparo do Complexo com ${ }^{99 \mathrm{~m}} \mathrm{Tc}$}

Foram utilizados quatro métodos diferentes para o preparo do complexo contendo ${ }^{99 \mathrm{~m}} \mathrm{Tc}$.

- Preparo convencional;

- Preparo utilizando resina com estanho;

- Preparo por transquelação;

- Preparo baseado em uma metodologia desenvolvida na Universidade de Kyoto.

Os dois métodos de preparo mais eficazes encontram-se descritos abaixo.

\section{Preparo convencional do complexo contendo o isótopo ${ }^{99 \mathrm{~m}} \mathrm{Tc}$}

As soluções foram previamente desaeradas com gás inerte (nitrogênio). Foi adicionado $1 \mathrm{mg}$ do agente complexante $\mathbf{H}_{\mathbf{2}}$ bdtc a um frasco tipo penicilina e, posteriormente, solubilizado em $1 \mathrm{~mL}$ de DMSO. Uma alíquota de $300 \mu \mathrm{L}$ foi retirada e transferida para outro frasco tipo penicilina. Em seguida, foram adicionados $300 \mu \mathrm{L}$ de uma solução de pertecnetato de sódio, $\mathrm{Na}\left[{ }^{99 \mathrm{~m}} \mathrm{TcO}_{4}\right]$, com atividade de $10 \mathrm{mCi}$. A solução foi novamente borbulhada com $\mathrm{N}_{2}(\mathrm{~g})$ por 5 minutos. Posteriormente, foram adicionados $20 \mu \mathrm{L}$ de solução de $\mathrm{SnCl}_{2} \cdot 2 \mathrm{H}_{2} \mathrm{O}\left(2,5 \mathrm{mg}\right.$ de $\mathrm{SnCl}_{2}+10 \mu \mathrm{L}$ de $\mathrm{HCl} 37 \%$ + $10 \mathrm{~mL}$ de água). A solução desaerada, uma terceira vez, por mais 10 minutos. Foram adicionados à solução, $20 \mu \mathrm{L}$ de solução tampão fosfato $0,1 \mathrm{~N}(\mathrm{pH}=7,4)$, sendo borbulhada com $\mathrm{N}_{2}(\mathrm{~g})$ uma última vez, por mais 10 minutos. Foi adicionado $0,640 \mu \mathrm{L}$ de solução tampão fosfato $0,1 \mathrm{~N}(\mathrm{pH}=7,4)$. $\mathrm{O} \mathrm{pH}$ final da solução foi de 7,4 . 


\section{Preparo do complexo de ${ }^{99 \mathrm{~m}} \mathrm{Tc}$ com resina de estanho}

As soluções utilizadas foram previamente borbulhadas com $\mathrm{N}_{2}(\mathrm{~g})$. Em um frasco tipo penicilina, foi adicionado $1 \mathrm{mg}$ do ligante $\mathrm{H}_{2}$ bdtc, que na sequência, foi solubilizado em $1 \mathrm{~mL}$ de DMSO. Uma alíquota de $300 \mu \mathrm{L}$ desta solução foi coletada e transferida para outro frasco tipo penicilina. Em seguida, foram adicionados $300 \mu \mathrm{L}$ de solução de pertecnetato de sódio, $\mathrm{Na}\left[{ }^{99 m} \mathrm{TcO}_{4}\right]$, com atividade de $10 \mathrm{mCi}$. A solução foi, novamente, desaerada com $\mathrm{N}_{2}(\mathrm{~g})$ por 5 minutos. Posteriormente, foram adicionados $1 \mathrm{mg}$ de resina de estanho e, uma vez mais, a solução foi borbulhada por mais 5 minutos com $\mathrm{N}_{2}(\mathrm{~g})$. A operação de filtração do conteúdo do frasco foi feita utilizando-se um filtro NALGENE $\left(0,45 \mu \mathrm{M}, \mathrm{d}=7 \mathrm{~mm} \mathrm{~m}^{2}\right)$. Uma última vez a solução foi desaerada com $\mathrm{N}_{2}(\mathrm{~g})$ por mais 5 minutos e posteriormente foi adicionado $0,640 \mu \mathrm{L}$ de solução tampão fosfato $0,1 \mathrm{~N}(\mathrm{pH}=7,4)$ para completar o volume. $\mathrm{O} \mathrm{pH}$ final da solução foi de 7,4 .

\subsubsection{Parâmetros Físico-Químicos de Avaliação do Complexo contendo o isótopo ${ }^{99 \mathrm{~m}} \mathrm{Tc}$}

\section{Eficiência de Marcação e da Pureza Radioquímica}

\section{Cromatografia Líquida de Alta Eficiência (CLAE)}

Amostras dos complexos foram injetadas em um cromatógrafo para CLAE, equipado com uma coluna de C18 (4,6 x $250 \mathrm{~mm}, 4 \mu \mathrm{m})$. Foram utilizadas as fases móveis: (A) THF: $\mathrm{H}_{2} \mathrm{O}: \mathrm{MeOH}$ (70:20:10), (B) acetona: $\mathrm{H}_{2} \mathrm{O}: \mathrm{MeOH}$ (66:22:12); (C) Acetona em modo isocrático.

A caracterização estrutural do complexo de ${ }^{99 m}$ Tc foi feita com base no complexo padrão, [ReO(bdtc)(Hbdtc)] (9), co-injetado, juntamente com uma alíquota da solução de $\mathrm{Na}\left[{ }^{99 m} \mathrm{TcO}_{4}\right]$, o cromatograma, registrado com o detector de ultravioleta $(340 \mathrm{~nm})$, pode ser visualizado na figura 64. Em seguida, foi injetada uma alíquota da solução obtida pelo método de preparo tradicional e os radiocromatogramas, registrados com 0 detector de cintilação podem ser visualizados nas figuras 65 e 66 . 
Embora os tempos de retenção para o $\mathrm{Na}\left[{ }^{99 \mathrm{~m}} \mathrm{TcO}_{4}\right]$ e $\circ\left[{ }^{99 \mathrm{~m}} \mathrm{TcO}\right.$ (bdtc) Cl] sejam idênticos, a confirmação da obtenção do complexo desejado foi confirmada por cromatografia em papel.

Figura 64 - Cromatograma obtido após a co-injeção do complexo padrão [ReO(bdtc)(Hbdtc)] e Na[ $\left.{ }^{99 \mathrm{~m}} \mathrm{TcO}_{4}\right]$ com detecção em ultravioleta (340 nm).

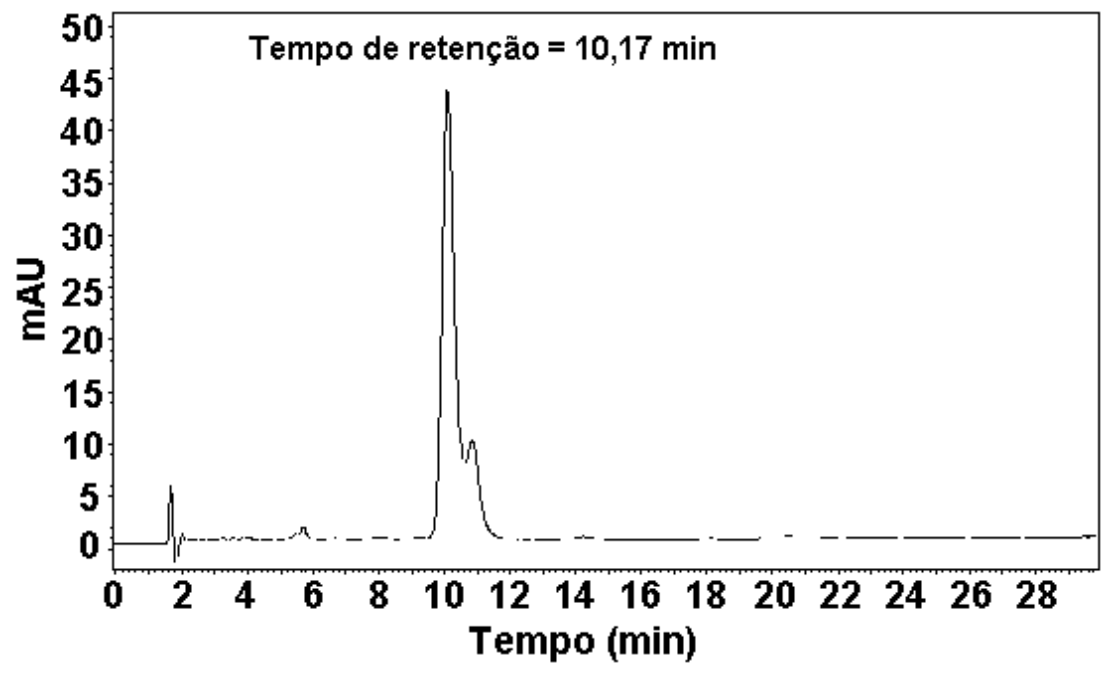

Figura 65 - Radiocromatograma da solução contendo $\mathrm{Na}\left[{ }^{99 \mathrm{~m}} \mathrm{TcO}_{4}\right] \mathrm{e}$ [99m $\mathrm{TcO}(\mathrm{bdtc}) \mathrm{Cl}$ ], preparada de acordo com o método convencional.

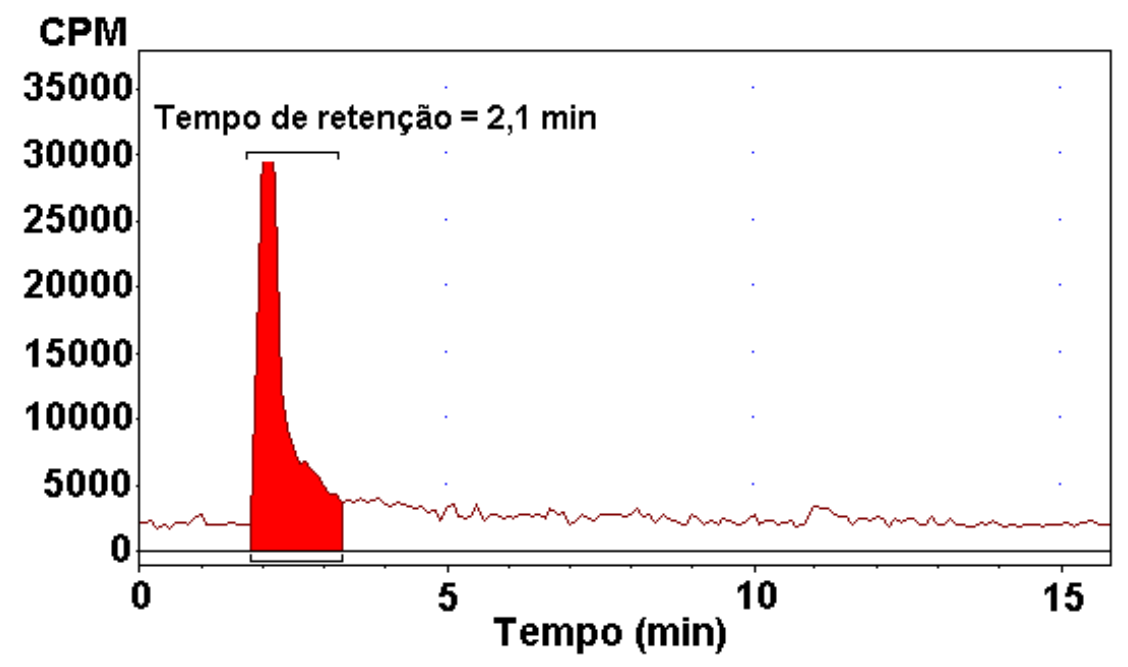


Figura 66 - Radiocromatograma da solução contendo $\mathrm{Na}\left[{ }^{99 m} \mathrm{TcO}_{4}\right]$ e [ $\left.{ }^{99 \mathrm{~m}} \mathrm{TcO}(\mathrm{bdtc}) \mathrm{Cl}\right]$, preparada de acordo com o método convencional, aquecida à $55^{\circ} \mathrm{C}$ por 5 minutos e filtrada.

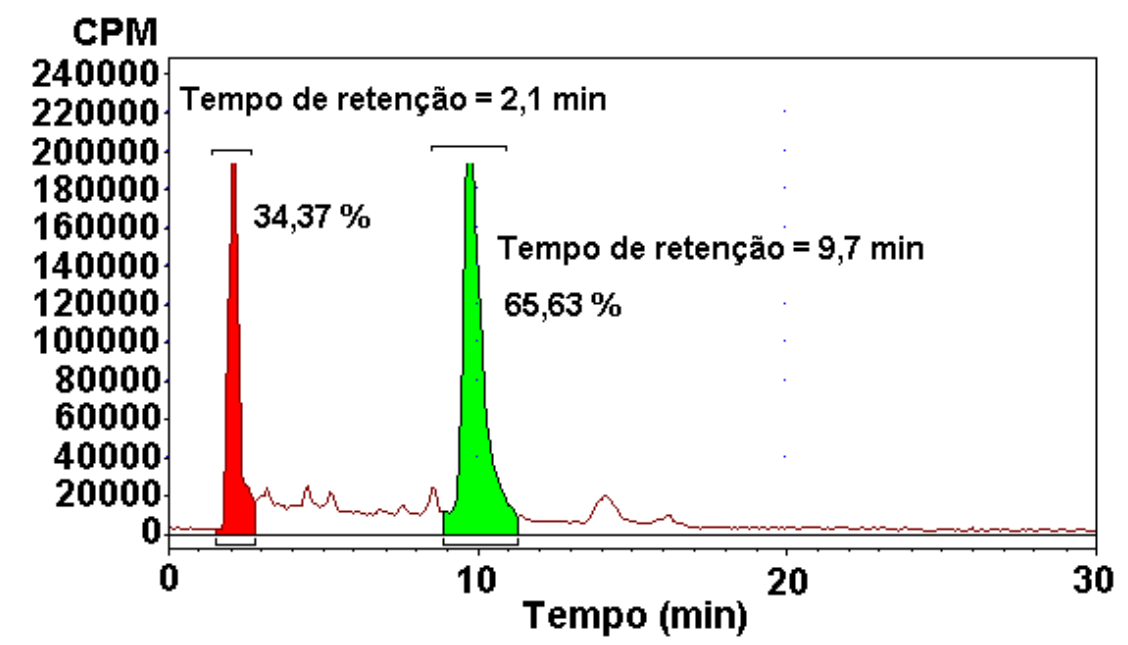

Com base nos radiocromatogramas pode-se verificar a formação de dois produtos distintos, evidenciados por seus tempos de retenção diferentes. Levandose em conta as diferenças nas estruturas determinadas para os complexos [TcO(bdtc)Cl] (8) e [ReO(bdtc)(Hbdtc)] (9), sintetizados e caracterizados neste trabalho, seria plausível admitir que os tempos de retenção fossem diferentes. Todavia, como nas metodologias adotadas para o preparo de compostos de ${ }^{99 \mathrm{~m}} \mathrm{Tc}$ o agente complexante está sempre em excesso e em proporções inviáveis de serem reproduzidas em escala de síntese em laboratório, a formação do produto [ $\left.{ }^{99 \mathrm{~m}} \mathrm{TcO}(\mathbf{b d t c})(\mathbf{H b d t c})\right]$, análogo ao de rênio (9), torna-se provável.

Assim sendo, admite-se que nas figuras 65 e 66 os picos com tempo de retenção de 2,1 min sejam correspondentes ao complexo $\left[{ }^{99 m} \mathbf{T c O}(\mathbf{b d t c}) \mathbf{C l}\right]$. Acredita-se na obtenção do produto $\left[{ }^{99 m} \mathrm{TcO}(\mathbf{b d t c})(\mathbf{H b d t c})\right]$ em razão da semelhança entre os tempos de retenção de 10,17 min (Figura 64), atribuído ao complexo de rênio padrão (9), e 9,7 min (Figura 66), verificado para este composto. 


\section{Cromatografia em papel}

Realizada com papel Whatman $3 \mathrm{~mm}$, utilizando acetona ou solução de $\mathrm{NaCl}$ 0,9\% como solventes. Os papéis foram colocados em cubas com os solventes e, posteriormente, analisados em um detector AR-2000 RC Scanner Bioscan®.

Por meio do uso desta técnica não foi possível fazer a distinção entre as espécies [ $\left.{ }^{99 \mathrm{~m}} \mathrm{TcO}(\mathbf{b d t c}) \mathbf{C l}\right]$ e $\left[{ }^{99 \mathrm{~m}} \mathrm{TcO}\right.$ (bdtc)(Hbdtc)], entretanto, a diferenciação entre esses compostos e o $\mathrm{Na}\left[{ }^{99 \mathrm{~m}} \mathrm{TCO}_{4}\right]$ pôde ser feita.

Os perfis obtidos por esta técnica são iguais para os dois complexos de ${ }^{99 m}$ Tc. Contudo, a sua validade está em confirmar a existência das espécies $\left[{ }^{99 \mathrm{~m}} \mathrm{TcO}_{2}\right]$ e $\left[{ }^{99 \mathrm{~m}} \mathrm{TcO}_{4}\right]$, consideradas impurezas no processo de radiomarcação e que não puderam ser identificadas por HPLC.

Avaliação da eficiência de marcação do complexo $\left[^{99 m} \mathrm{TcO}(\boldsymbol{b d t c}) \boldsymbol{C l}\right]$ feita pelo método convencional

A figura 67 demonstra que $\circ\left[{ }^{99 \mathrm{~m}} \mathrm{TcO}_{2}\right.$ ] foi obtido em quantidades mínimas, da ordem de $4 \%$, como subproduto da preparação do complexo ${ }^{99 \mathrm{~m}} \mathrm{TcO}$ (bdtc)Cl]. Por sua vez, a figura 68 revela que não foi detectado tecnécio na forma livre, como íons $\left.{ }^{99 \mathrm{~m}} \mathrm{TcO}_{4}\right]^{\top}$, revelando a eficiência do método de marcação do composto.

Figura 67 - Cromatografia em papel, cuba contendo acetona como solvente.

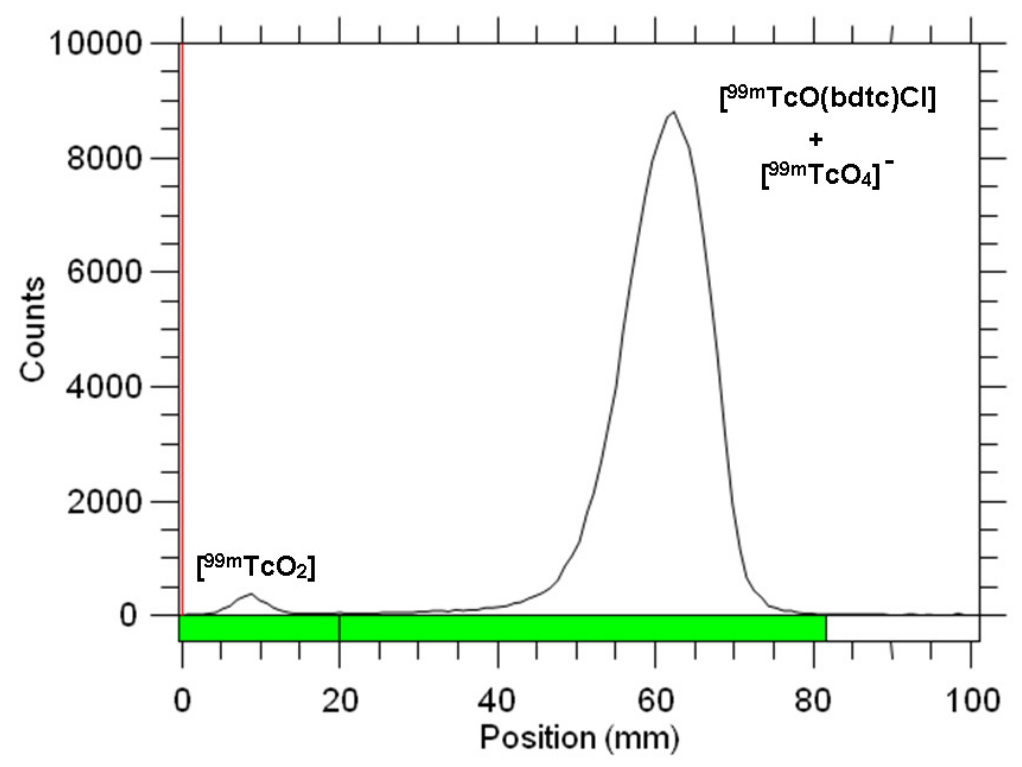


Figura 68 - Cromatografia em papel, cuba contendo solução de $\mathrm{NaCl}$ 0,9 \% como solvente.

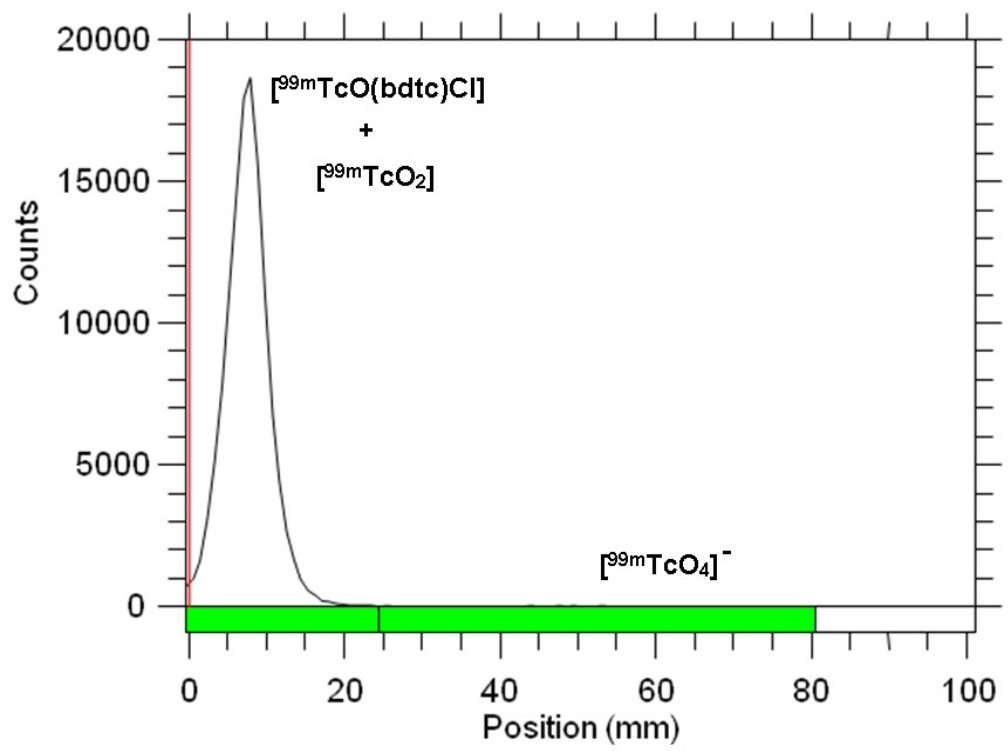

Avaliação da eficiência de marcação do complexo [99m TcO(bdtc)Cl] feita pelo método de resina com estanho

A figura 69 comprova que houve formação da impureza [ ${ }^{99 m} \mathrm{TcO}_{2}$ ], em uma concentração aproximada de $3,5 \%$, no decorrer do processo de marcação do complexo [ $\left.{ }^{99 \mathrm{~m}} \mathrm{TcO}(\mathbf{b d t c}) \mathbf{C l}\right]$.

Figura 69 - Cromatografia em papel, cuba contendo acetona como solvente.

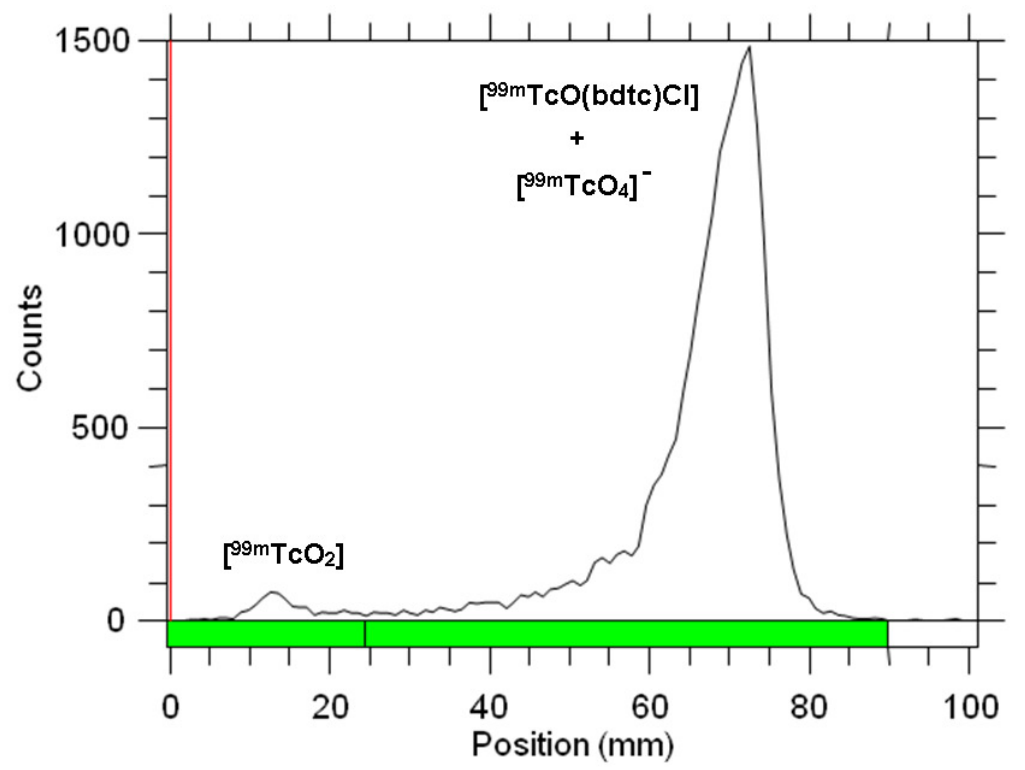


Por sua vez, a figura 70 torna claro que não foi detectado tecnécio na forma livre, como íons [ $\left.{ }^{99 \mathrm{~m}} \mathrm{TcO}_{4}\right]$ ], comprovando de maneira conclusiva a eficiência do método de marcação adotado para obtenção do [ $\left.{ }^{99 \mathrm{~m}} \mathrm{TcO}(\mathbf{b d t c}) \mathbf{C l}\right]$.

Figura 70 - Cromatografia em papel, cuba contendo solução de $\mathrm{NaCl}$ 0,9 \% como solvente.

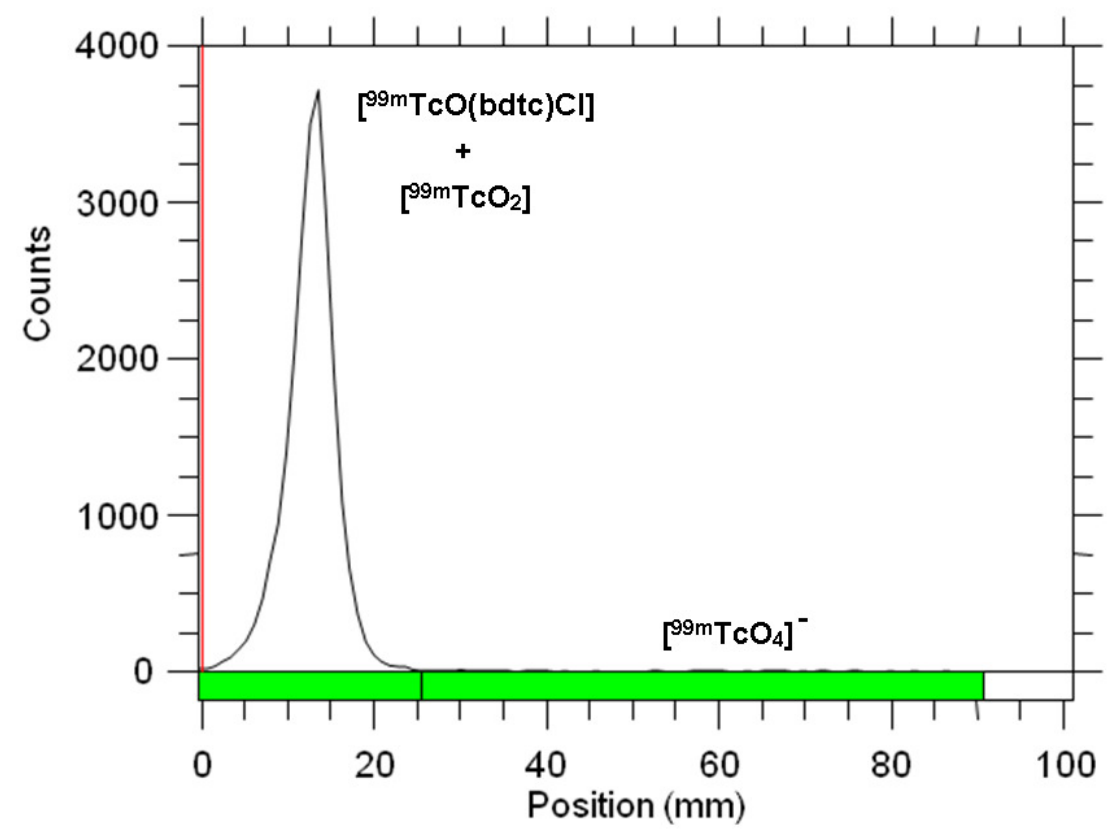

\section{Determinação do coeficiente de partição}

Em tubos de ensaio foram adicionados $2,7 \mathrm{~mL}$ de solução fisiológica $\mathrm{NaCl}$ $0,9 \%, 3,0 \mathrm{~mL}$ de $n$-octanol e, de forma independente, $0,3 \mathrm{~mL}$ da solução contendo o [ $\left.{ }^{99 \mathrm{~m}} \mathrm{TcO}(\mathrm{bdtc}) \mathrm{Cl}\right]$. Os tubos foram tampados, agitados em vortex por 1 minuto e deixados em repouso de 15 a 20 minutos. Alíquotas de $1,0 \mathrm{~mL}$ de cada fase foram retiradas e a atividade foi aferida com o auxílio de um curiômetro. $O$ coeficiente foi determinado dividindo o valor da atividade encontrada na fase orgânica ( $n$-octanol) pelo valor da atividade na fase aquosa, PBS ( $\mathrm{NaCl} 0,9 \%)$ e expresso como valor logarítmico deste quociente (Log P) (Figura 71, Tabela 19). A determinação da lipofilicidade é uma forma de associar as propriedades físico-químicas àquelas biológicas de um produto específico, haja vista que a capacidade de captação de um 
radiofármaco por um tecido ou órgão alvo é determinada, entre outros fatores, pelo caráter lipofílico.

Figura 71 - Determinação do coeficiente de partição do complexo [ $\left.{ }^{99 \mathrm{~m}} \mathrm{TcO}(\mathrm{bdtc}) \mathrm{Cl}\right]$.

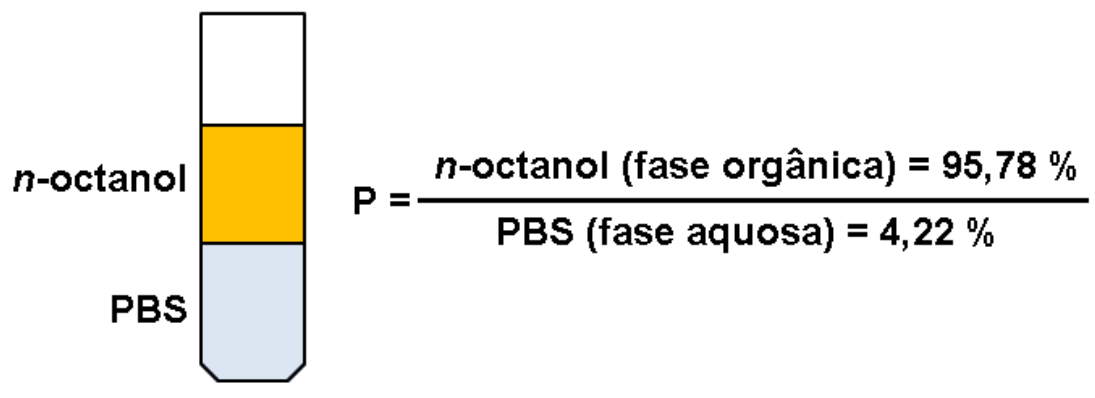

Tabela 19 - Coeficiente de partição do complexo [ $\left.{ }^{99 m} \mathrm{TcO}(\mathbf{b d t c}) \mathbf{C l}\right]$.

\begin{tabular}{|c|c|}
\hline Complexo & Log P \\
\hline$\left[{ }^{99 m} \mathrm{TcO}(\right.$ bdtc)Cl] & 1,360 \\
\hline
\end{tabular}




\section{Eletroforese}

Avaliação da eficiência de marcação e da carga do complexo [ $\left.{ }^{99 m} \mathrm{TcO}(\boldsymbol{b d t c}) \mathrm{Cl}\right]$ utilizando eletroforese

Uma cuba para eletroforese horizontal previamente lavada com água purificada e preenchida em solução eletrolítica de PBS (50 mM, pH 7,4):metanol (1:1). Fitas de papel Whatman ํo 1, com dimensões de $1,5 \times 28 \mathrm{~cm}$, foram umedecidas no próprio tampão e fixadas na cuba. Uma gota da solução contendo o composto radioativo foi depositada no meio da fita e uma tensão elétrica de $275 \mathrm{~V}$ foi mantida durante 1 ou 2 horas. As fitas foram secas e cortadas em frações de $1 \mathrm{~cm}$ e a radioatividade foi medida no detector AR-2000 RC Scanner Bioscan $\AA$. Os resultados são expressos como porcentagem da radioatividade total $/ \mathrm{cm}$.

Com o intuito de um melhor entendimento dos dados obtidos por meio do uso dessa técnica de análise, inicialmente, foi feita uma avaliação do perfil relativo ao ânion pertecnetato, $\left.{ }^{99 \mathrm{~m}} \mathrm{TcO}_{4}\right]^{-}$. De acordo com o previsto, o [ $\left.{ }^{99 \mathrm{~m}} \mathrm{TcO}_{4}\right]^{-}$migrou em direção ao ânodo (pólo positivo), a partir da origem (ponto com distância igual a 0 $\mathrm{cm}$ ), a uma distância de $5 \mathrm{~cm}$, conforme mostrado na figura 72 .

Figura 72 - Gráfico de eletroforese do $\left[{ }^{99 \mathrm{~m}} \mathrm{TcO}_{4}\right]^{-}$obtido durante um período de 2 horas.

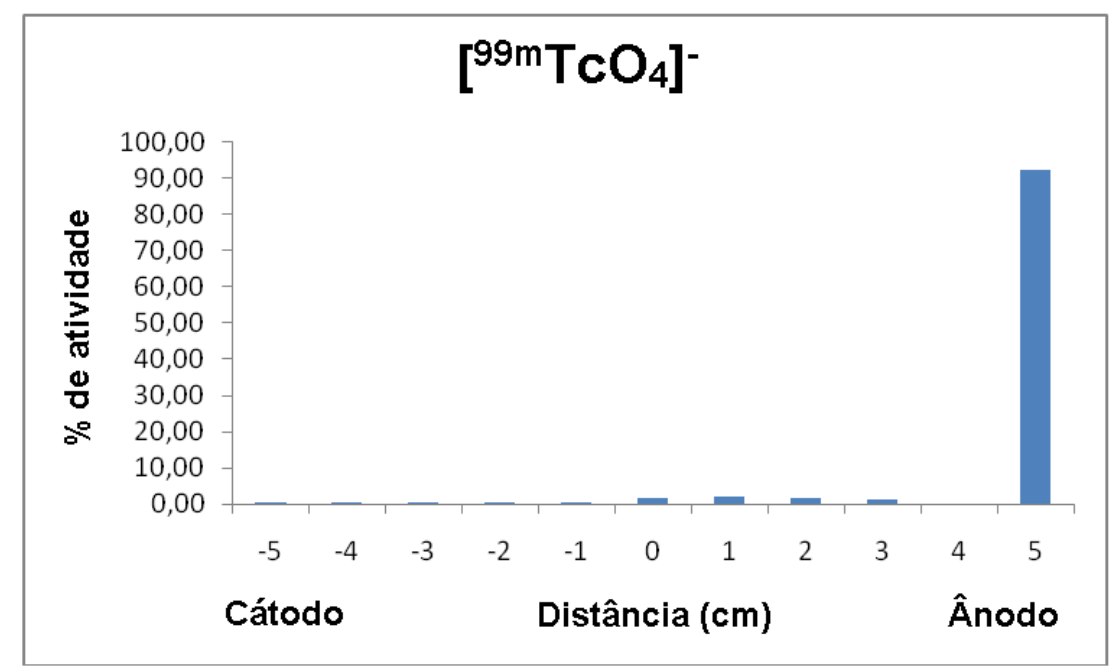


Duas informações relevantes podem ser inferidas a partir do gráfico de eletroforese do [ $\left.{ }^{99 \mathrm{~m}} \mathrm{TcO}(\mathbf{b d t c}) \mathbf{C l}\right]$ (Figura 73): a eficiência do método de marcação e a carga do complexo. Um baixo percentual de atividade radioativa observado na região de migração atribuída ao $\left[{ }^{99 \mathrm{~m}} \mathrm{TcO}_{4}\right]^{-}$demonstra a eficiência do método convencional de marcação adotado. Levando em consideração que apenas espécies carregadas (cátions ou ânios) podem migrar em direção ao cátodo ou ao ânodo, a neutralidade da carga complexo [ $\left.{ }^{99 \mathrm{~m}} \mathrm{TcO}(\mathbf{b d t c}) \mathrm{Cl}\right]$ pôde ser deduzida uma vez que mais de $80 \%$ da atividade radioativa, relacionada ao complexo, não sofreu qualquer tipo de migração.

Figura 73 - Gráfico de eletroforese do [ $\left.{ }^{99 \mathrm{~m}} \mathrm{TcO}(\mathbf{b d t c}) \mathrm{Cl}\right]$ obtido durante um período de 1 hora.

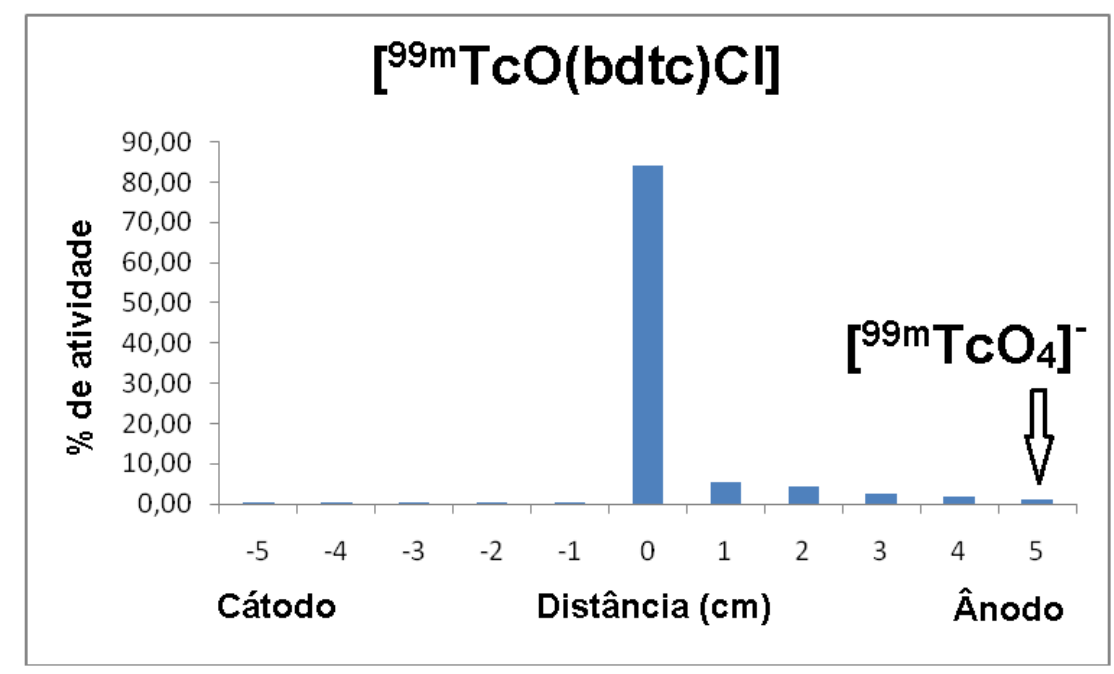


O gráfico de corrida eletroforética obtido para o $\left[{ }^{99 m} \mathrm{TcO}(\mathrm{bdtc}) \mathrm{Cl}\right]$ durante 0 período de duas horas (Figura 74) indica que há formação de espécies com carga negativa que, portanto, migraram em direção ao ânodo. A maior parte dessas espécies deslocaram-se $1 \mathrm{~cm}$, revelando que não se tratam de $\left[{ }^{99 \mathrm{~m}} \mathrm{TcO}_{4}\right]$. A ausência do deslocamento de espécies com carga positiva, como [ ${ }^{99 \mathrm{~m}} \mathrm{TcO}$ (bdtc) $]^{+}$, em direção ao cátodo, é um indício da permanência do átomo de cloro na esfera de coordenação do centro metálico. Mesmo havendo a formação de subprodutos, observou-se que a atividade radioativa atribuída ao complexo [ $\left.{ }^{99 \mathrm{~m}} \mathrm{TcO}(\mathbf{b d t c}) \mathbf{C l}\right]$ sofreu uma redução aproximada de $25 \%$ do primeiro experimento (Figura 73) em relação ao supracitado.

Figura 74 - Gráfico de eletroforese do [ $\left.{ }^{99 \mathrm{~m}} \mathrm{TcO}(\mathbf{b d t c}) \mathbf{C l}\right]$ obtido durante um período de 2 horas.

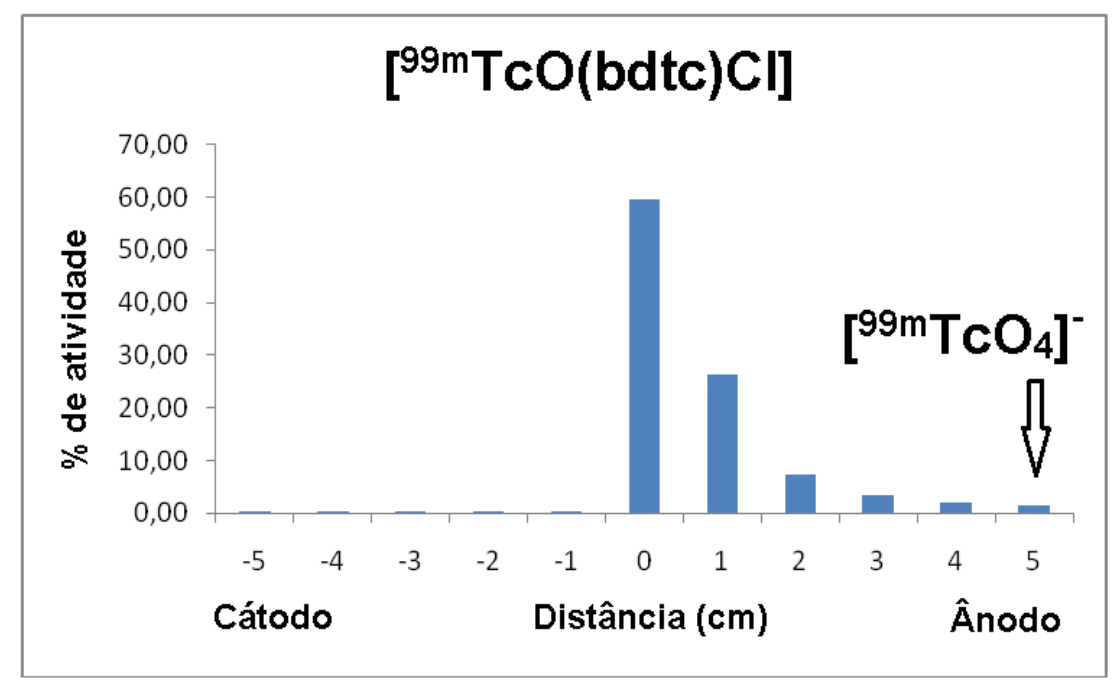




\subsection{Complexos [ReO(bdtc)(Hbdtc)] (9), [ReO(bdtn)(Hbdtn)] (10), [ReO(bdtm)(Hbdtm)] (11)}

Os complexos 9, 10 e 11 foram sintetizados a partir de um equivalente do precursor $\left(\mathrm{NBu}_{4}\right)\left[\mathrm{ReOCl}_{4}\right]$ e dois equivalentes do ditiocarbazato desejado, $\mathbf{H}_{2}$ bdtc (9), $\mathrm{H}_{2}$ bdtn (10) ou $\mathrm{H}_{2}$ bdtm (11).

Inicialmente, as estruturas dos complexos foram propostas com base na análise elementar, nos espectros de massas com ionização eletrospray (MS-ESI), nos dados espectroscópicos obtidos através das técnicas de infravermelho e ressonância magnética nuclear de hidrogênio e, posteriormente, confirmadas por meio da determinação de suas estruturas a partir dos dados de difração de raios $X$ em monocristal.

\subsubsection{Espectroscopia de Absorção na Região do Infravermelho}

A coordenação O,N,S-doadora e tridentada dos ditiocarbazatos $\mathbf{b d t c}^{2-}$, $\mathbf{b d t n}^{2-}$ e bdtm ${ }^{2-}$ ao rênio, pôde ser inferida, também nos produtos 9, 10 e 11 (Figuras 79, 80 e 81, respectivamente), pelas mesmas razões que foram discutidas anteriormente, entre elas: a ausência dos modos vibracionais $\delta\left(\mathrm{CH}_{2}\right)$ e $v(\mathrm{O}-\mathrm{H})$ e o deslocamento batocrômico da banda $\mathrm{C}=\mathrm{N}$.

Entretanto, a utilização da espectroscopia vibracional de absorção na região do infravermelho ofereceu informações que confirmaram, além da presença de todos os ligantes, um novo modo de coordenação dos ditiocarbazatos que, até então, não havia sido verificado: $N, S$-doador e monoaniônico. Esta forma de se ligar ao centro metálico está associada à formação de uma carbonila nos ligantes e isto pôde ser comprovado facilmente através do surgimento de uma banda intensa, referente ao modo vibracional $v(\mathrm{C}=\mathrm{O})$, na região em torno de $1683 \mathrm{~cm}^{-1} \mathrm{em}$ todos os compostos. 
Os ligantes $\mathbf{H}_{\mathbf{2}} \mathbf{b d t n}$ e $\mathbf{H}_{\mathbf{2}} \mathbf{b d t m}$ diferem estruturalmente do $\mathbf{H}_{\mathbf{2}} \mathbf{b d t c}$ apenas devido à presença respectiva dos grupos nitro $\left(\mathrm{NO}_{2}\right)$ e metóxido $\left(\mathrm{OCH}_{3}\right)$ substituídos na posição para do anel benzílico. A presença destes substituintes pôde ser comprovada nos espectros de IV dos ligantes e de seus complexos pela observação de bandas de elevada intensidade em 1347, 1258 e $1217 \mathrm{~cm}^{-1}$, sendo que a primeira corresponde à deformação axial simétrica do modo vibracional $v\left(\mathrm{NO}_{2}\right)^{76,77}$, enquanto

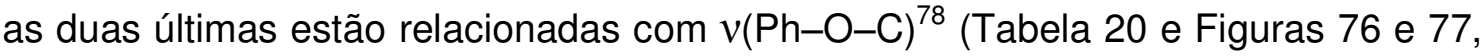
respectivamente).

Todos os complexos apresentados nesta discussão apresentam um deslocamento batocrômico de suas bandas $\mathrm{Re}=\mathrm{O}$, em relação ao seu precursor metálico $\left(\mathrm{NBu}_{4}\right)\left[\mathrm{ReOCl}_{4}\right]$. Esta variação, que chega a um máximo de $53 \mathrm{~cm}^{-1}$, indica que as sínteses foram conduzidas com eficácia, e que deram origem a novas substâncias. Estas alterações podem ser entendidas em termos da disponibilidade do centro metálico em receber elétrons $\pi$ do grupo oxo. No complexo de partida, $\left(\mathrm{NBu}_{4}\right)\left[\mathrm{ReOCl}_{4}\right]$, o rênio está ligado a apenas 5 átomos, com geometria piramidal de base quadrada e sua sexta posição de coordenação, trans ao grupo oxo, não está sendo ocupada por nenhum outro átomo. A presença de átomos doadores transposicionados ao grupo oxo interfere diretamente na capacidade do metal em aceitar elétrons $\pi$ do grupo oxo, enfraquecendo a ligação $\mathrm{Re}=\mathrm{O}$ e justificando 0 deslocamento de sua banda para regiões de menor número de onda nos espectros dos complexos.

Tabela 20 - Principais bandas $\left(\mathrm{cm}^{-1}\right)$ atribuídas aos modos vibracionais dos complexos 9, 10 e 11 e seu precursor $\left(\mathrm{NBu}_{4}\right)\left[\mathrm{ReOCl}_{4}\right]$, bem como dos agentes complexantes $\mathbf{H}_{2}$ bdtc, $\mathbf{H}_{2}$ bdtn e $\mathbf{H}_{2}$ bdtm.

\begin{tabular}{|c|c|c|c|c|c|c|c|c|}
\hline \multirow{2}{*}{$\begin{array}{l}\text { Complexos, } \\
\text { Precursores e } \\
\text { Ligantes }\end{array}$} & \multicolumn{8}{|c|}{ Modos Vibracionais } \\
\hline & $v(\mathrm{O}-\mathrm{H})$ & $\mathrm{v}\left(\mathrm{NO}_{2}\right)$ & $v(\mathrm{Ph}-\mathrm{O}-\mathrm{C})$ & $v(\mathrm{C}=\mathrm{N})$ & $v(S C S)$ & $v(C=0)$ & $\delta\left(\mathrm{CH}_{2}\right)$ & $v(\operatorname{Re}=0)$ \\
\hline 9 & ----- & ---- & $-\cdots--$ & 1601 & 984 & 1682 & ----- & 949 \\
\hline 10 & ---- & 1345 & ---- & 1599 & 976 & 1683 & $-\cdots--$ & 952 \\
\hline 11 & ---- & ----- & $\begin{array}{l}1251 \\
1216\end{array}$ & 1609 & 972 & 1684 & ----- & 950 \\
\hline$\left(\mathrm{NBu}_{4}\right)\left[\mathrm{ReOCl}_{4}\right]$ & ----- & ----- & ----- & ----- & ----- & ----- & ----- & 1002 \\
\hline $\mathrm{H}_{2}$ bdtc & 3360 & ---- & $-\cdots--$ & 1629 & 981 & ---- & 1441 & $-\cdots--$ \\
\hline $\mathrm{H}_{2}$ bdtn & 3363 & 1347 & ---- & 1629 & 979 & $-\cdots--$ & 1441 & $-\cdots--$ \\
\hline $\mathrm{H}_{2} \mathrm{bdtm}$ & 3327 & ----- & $\begin{array}{l}1258 \\
1217\end{array}$ & 1632 & 978 & ---- & 1437 & ---- \\
\hline
\end{tabular}


Figura 75 - Espectro do $\mathbf{H}_{2}$ bdtc.

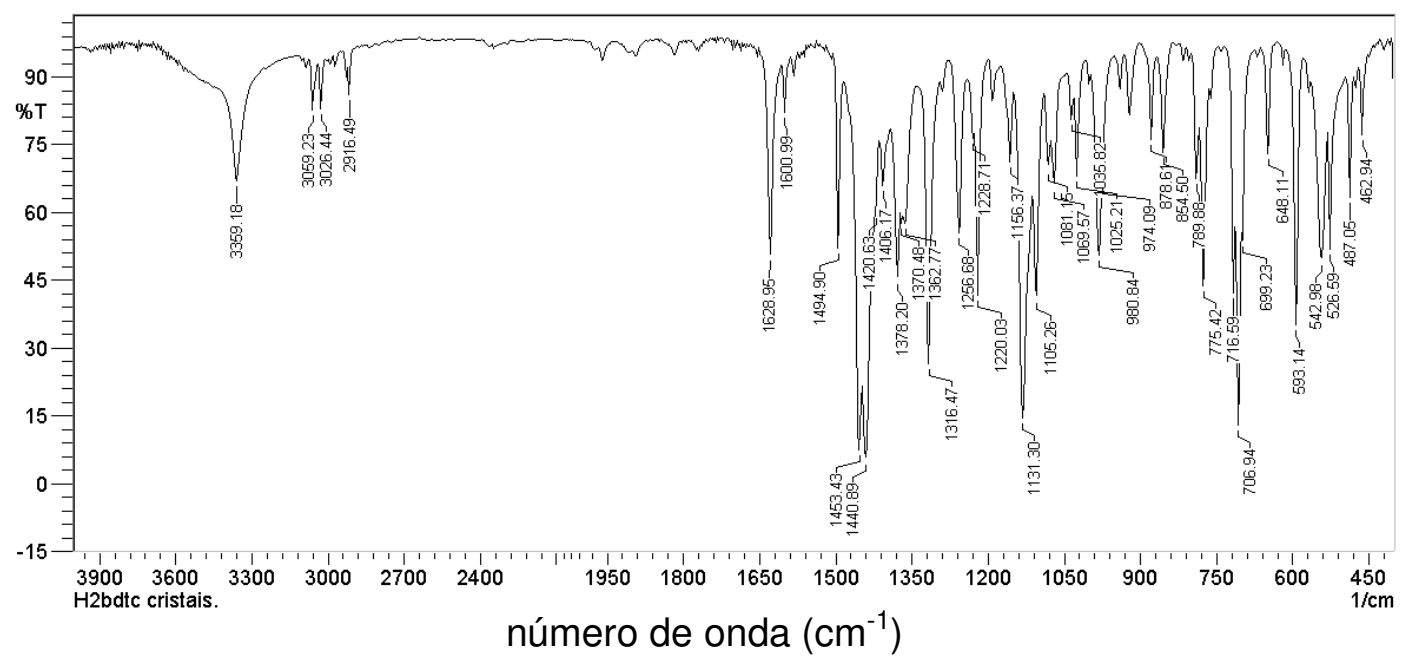

Figura 76 - Espectro do $\mathbf{H}_{2}$ bdtn.

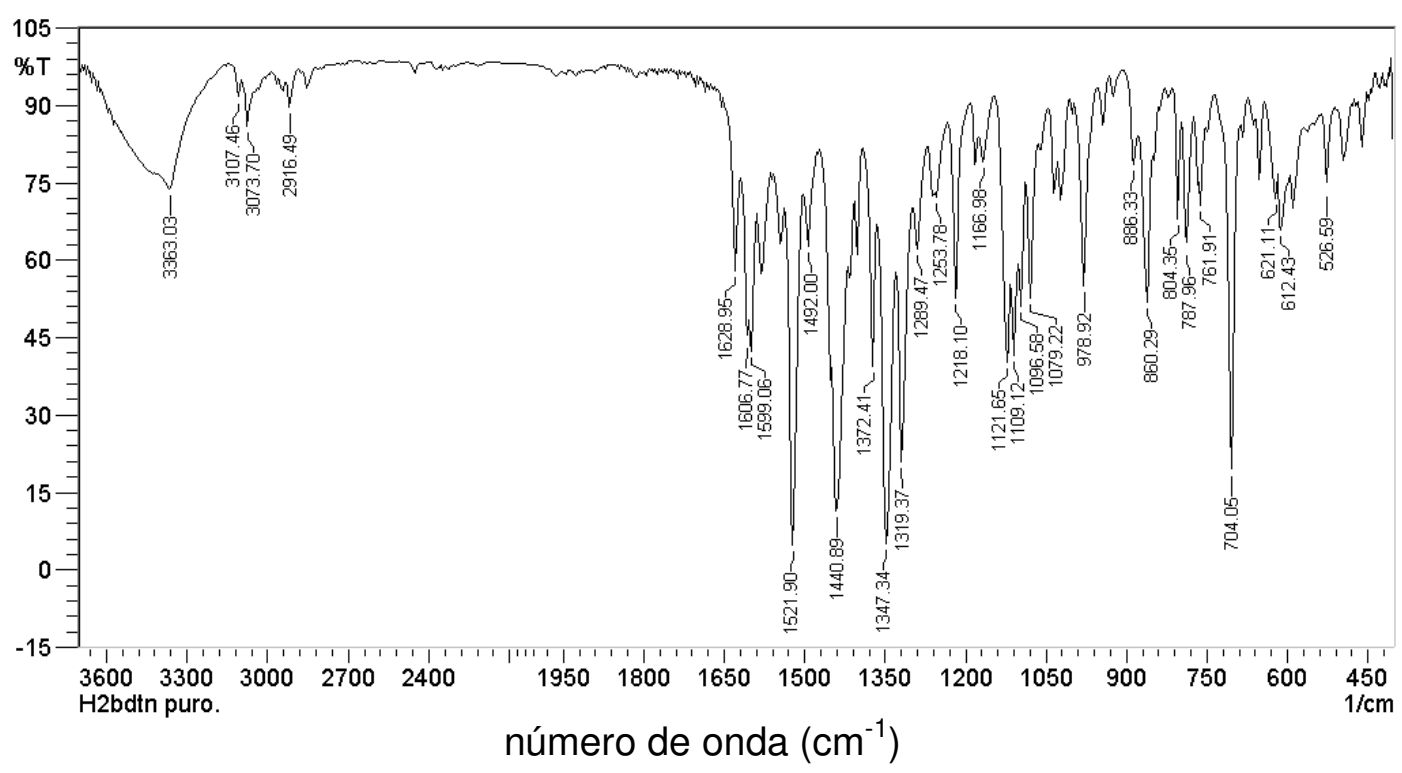


Figura 77 - Espectro do $\mathbf{H}_{2} \mathbf{b d t m}$.

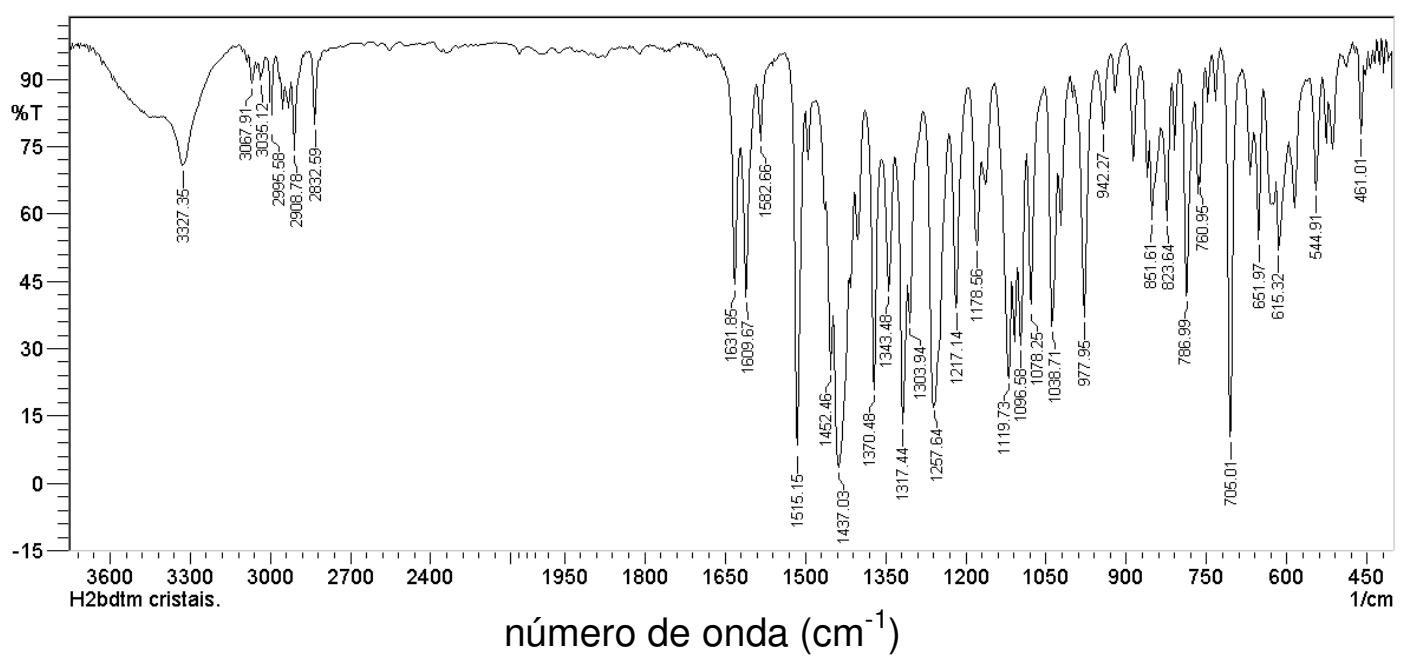

Figura 78 - Espectro do $\left(\mathrm{NBu}_{4}\right)\left[\mathrm{ReOCl}_{4}\right]$.

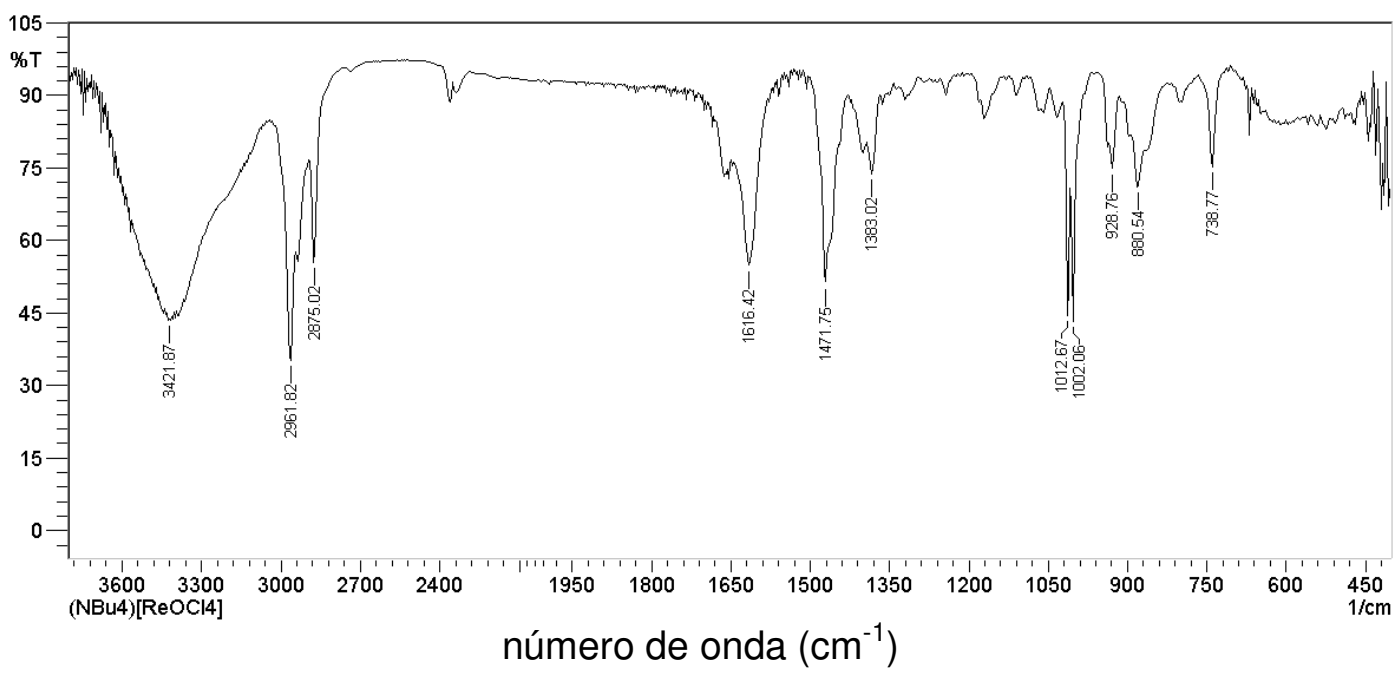


Figura 79 - Espectro do [ReO(bdtc)(Hbdtc)] (9).

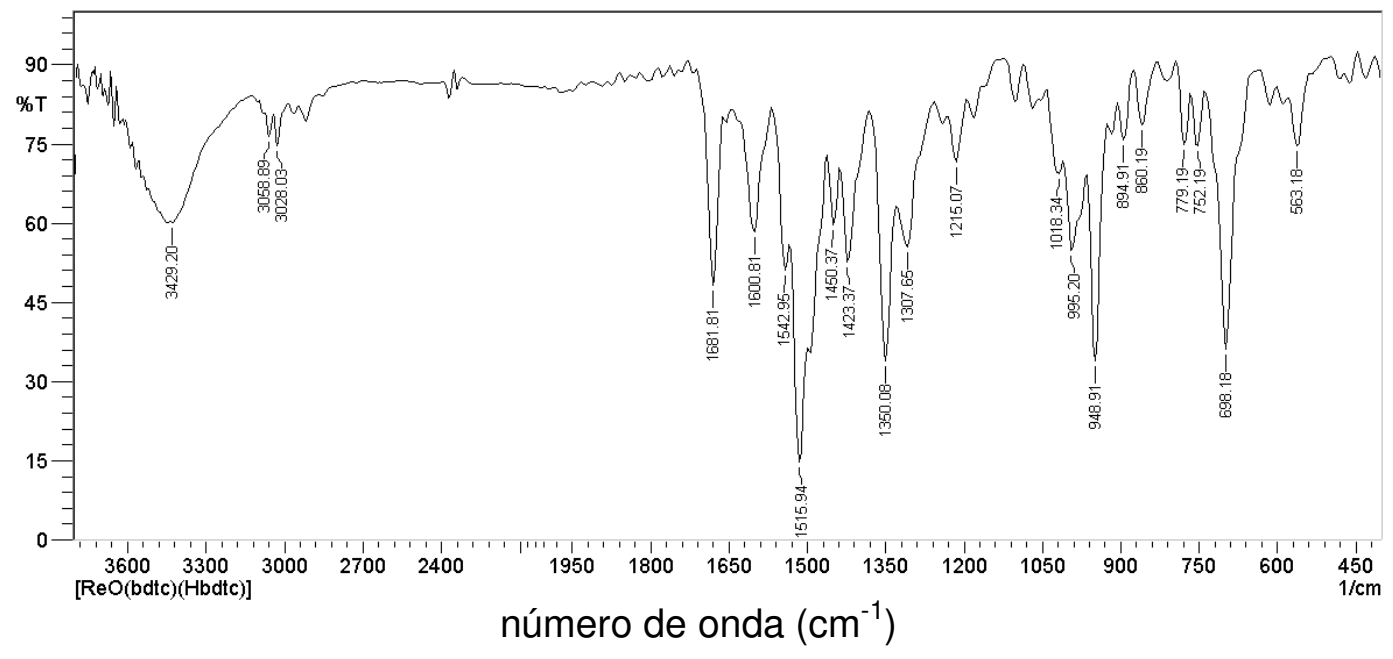

Figura 80 - Espectro do [ReO(bdtn)(Hbdtn)] (10).

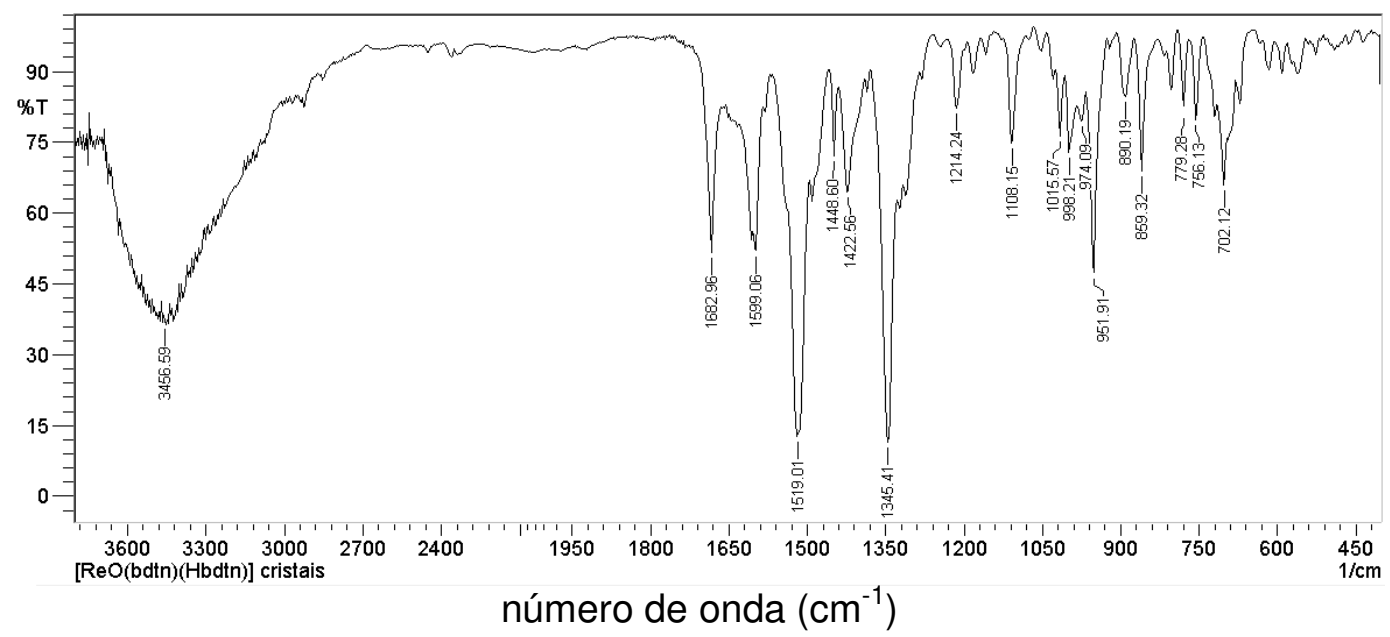

Figura 81 - Espectro do [ReO(bdtm)(Hbdtm)] (11).

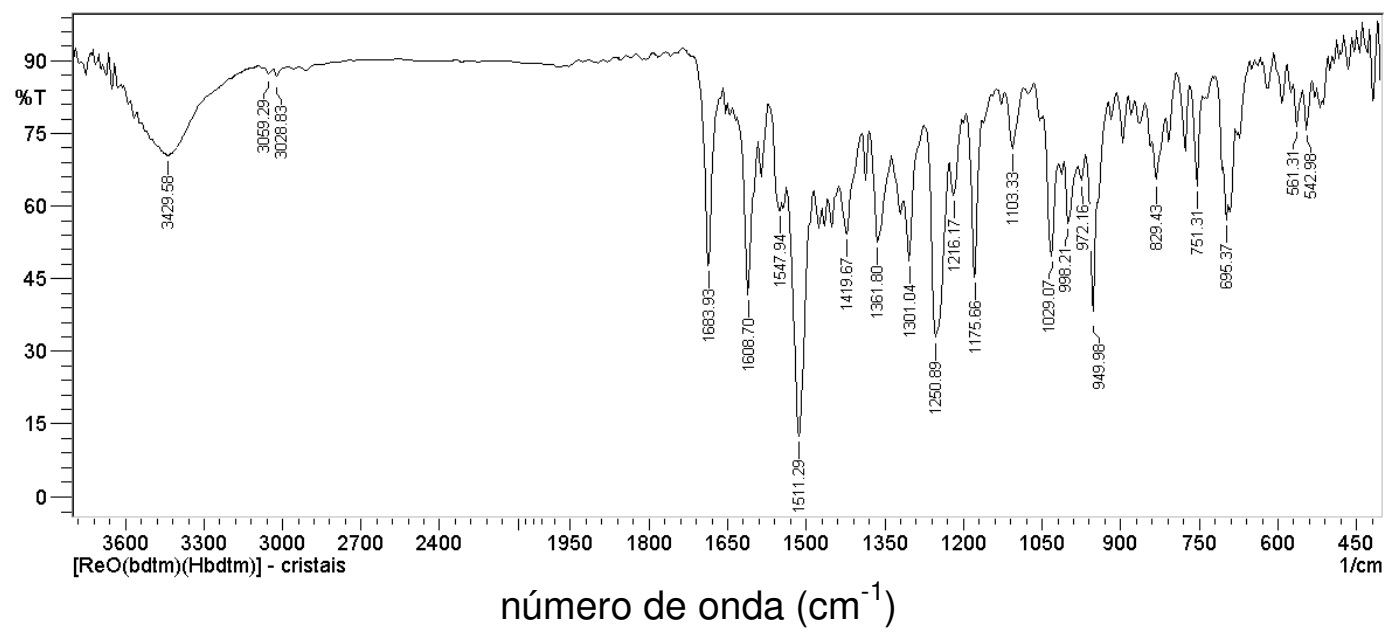




\subsubsection{Espectroscopia de Ressonância Magnética Nuclear (RMN ${ }^{1} \mathrm{H}$ ) para os complexos 9,10 e 11}

Os compostos 9, 10 e 11 foram caracterizados por $\mathrm{RMN}^{1} \mathrm{H}$ e a partir de seus espectros fica evidente que todos os hidrogênios metilênicos são distintos quimicamente, pois, de outro modo, não existiria acoplamento dos hidrogênios geminais que dão origem aos duplos dupletos observados. Isso ocorre devido ao centro estereogênico existente nestes complexos.

A distinção entre os hidrogênios metilênicos pôde ser feita, no caso dos compostos 9 e 11, de acordo com os seguintes fundamentos:

1. valores das constantes de acoplamento "J" e sinais com perfis similares devido ao efeito "telhado";

2. maior doação de densidade eletrônica ao metal, portanto, devem ser mais desblindados aqueles hidrogênios oriundos dos ditiocarbazatos coordenados de forma dianiônica;

3. hidrogênios metilênicos próximos a uma carbonila devem ser, em teoria, mais desblindados do que os demais;

4. comparação com os complexos 4 e 7 que apresentam, respectivamente, os mesmos ditiocarbazatos de 9 e 11.

Deste modo, com o intuito de exemplificar a validade dos fundamentos descritos acima, no espectro de 9, figura 83, os sinais correspondentes aos hidrogênios identificados como $\mathrm{CH}_{2 a^{\prime}}$ e $\mathrm{CH}_{2 a}$ " foram atribuídos em razão de apresentarem os mesmos valores de "J", demonstrarem perfis condizentes com o mesmo efeito telhado e por exibirem o hidrogênio com maior efeito de desblindagem, em função da proximidade com a carbonila. Por sua vez, os sinais $\mathrm{CH}_{2 b^{\prime}}, \mathrm{CH}_{2 b}$ ", $\mathrm{CH}_{2 c^{\prime}}$ e $\mathrm{CH}_{2 c^{\prime}}$, exibem os mesmos valores de $\mathrm{J}$, indicando a presença de átomos vizinhos ligados de maneira semelhante e, portanto, estes sinais só poderiam ser atribuídos aqueles hidrogênios ligados aos carbonos situados entre os átomos de enxofre e os anéis aromáticos. Posteriormente, os sinais $\mathrm{CH}_{2 b}$ e $\mathrm{CH}_{2 b}$ " foram identificados como provenientes do bdtc $^{2-}$, por se tratar do modo de coordenação em que o ligante contribuiu com uma maior doação de densidade eletrônica ao centro metálico. 
Os hidrogênios metilênicos do produto 10 não puderam ser distinguidos uns dos outros, devido à proximidade de seus sinais.

Cada centro metálico possui em sua esfera de coordenação dois ditiocarbazatos ligados de formas diferentes. $O$ que em termos de seus espectros significa dizer que existem dois conjuntos de sinais, um para cada modo de coordenação dos ligantes, sendo que apenas os hidrogênios dos anéis aromáticos apresentaram deslocamentos químicos na mesma região do espectro.

A doação de densidade eletrônica dos ditiocarbazatos para o metal pode ser avaliada, com clareza, por meio do efeito de desblindagem dos grupos metílicos, ou seja, observação do simpleto característico em uma região do espectro de campo magnético mais fraco.

O modo de coordenação dianiônico dos ligantes bdtc ${ }^{2-}$, bdtn ${ }^{2-}$ e bdtm $^{2-}$ nos espectros de RMN ${ }^{1} \mathrm{H}$ dos complexos pode ser constatado pela ausência do sinal atribuído ao grupo hidroxila, evidenciando a coordenação O-doadora, e pela observação do sinal referente ao grupo $\mathrm{CH}$, de acordo com as estruturas determinadas por DRX.

Dessa forma, os espectros de $\mathrm{RMN}^{1} \mathrm{H}$ dos complexos 9, 10 e 11 (Figuras 83, 85 e 87, respectivamente) apresentam os sinais esperados para os seus respectivos ligantes coordenados aos centros metálicos e seus valores encontram-se descritos nas tabelas 21, 22 e 23.

Figura 82 - Espectro de $\mathrm{RMN}{ }^{1} \mathrm{H}$ do $\mathbf{H}_{\mathbf{2}}$ bdtc (400 $\mathrm{MHz}, \mathrm{CDCl}_{3}$ ).

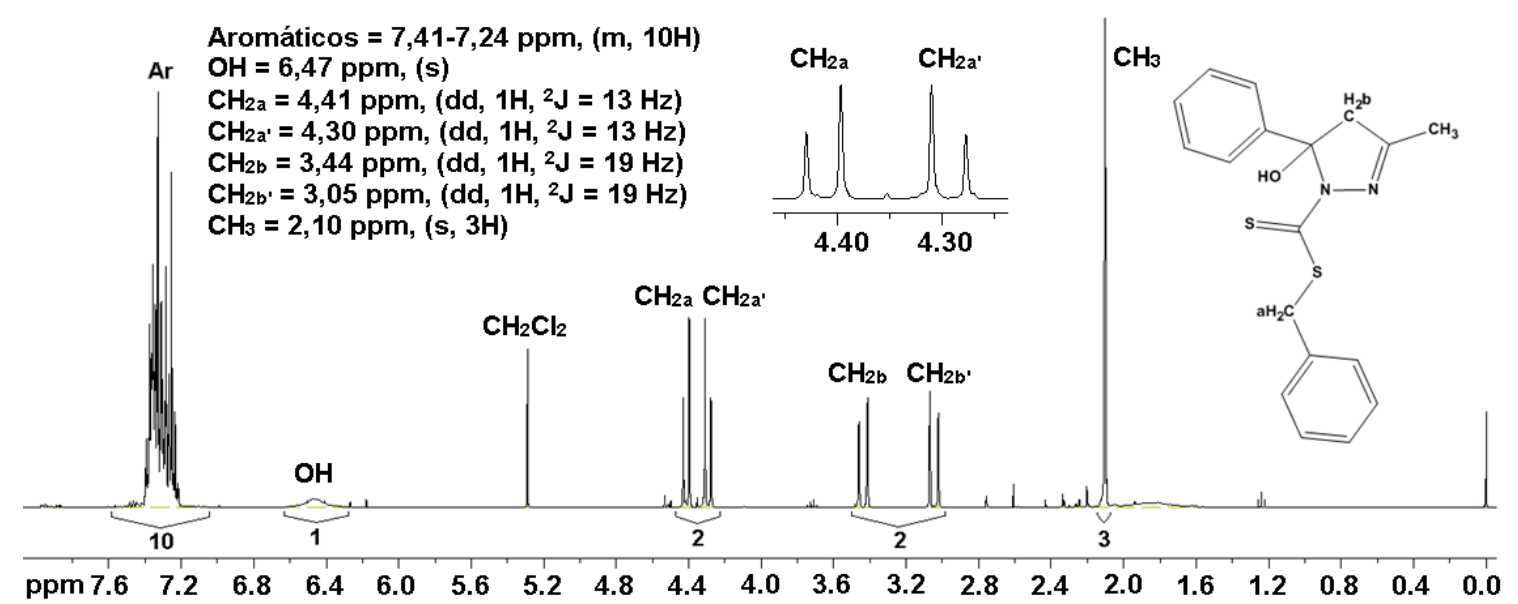


Figura 83 - Espectro de RMN ${ }^{1} \mathrm{H}$ do [ReO(bdtc)(Hbdtc)] (9) (400 MHz, $\left.\mathrm{CDCl}_{3}\right)$.

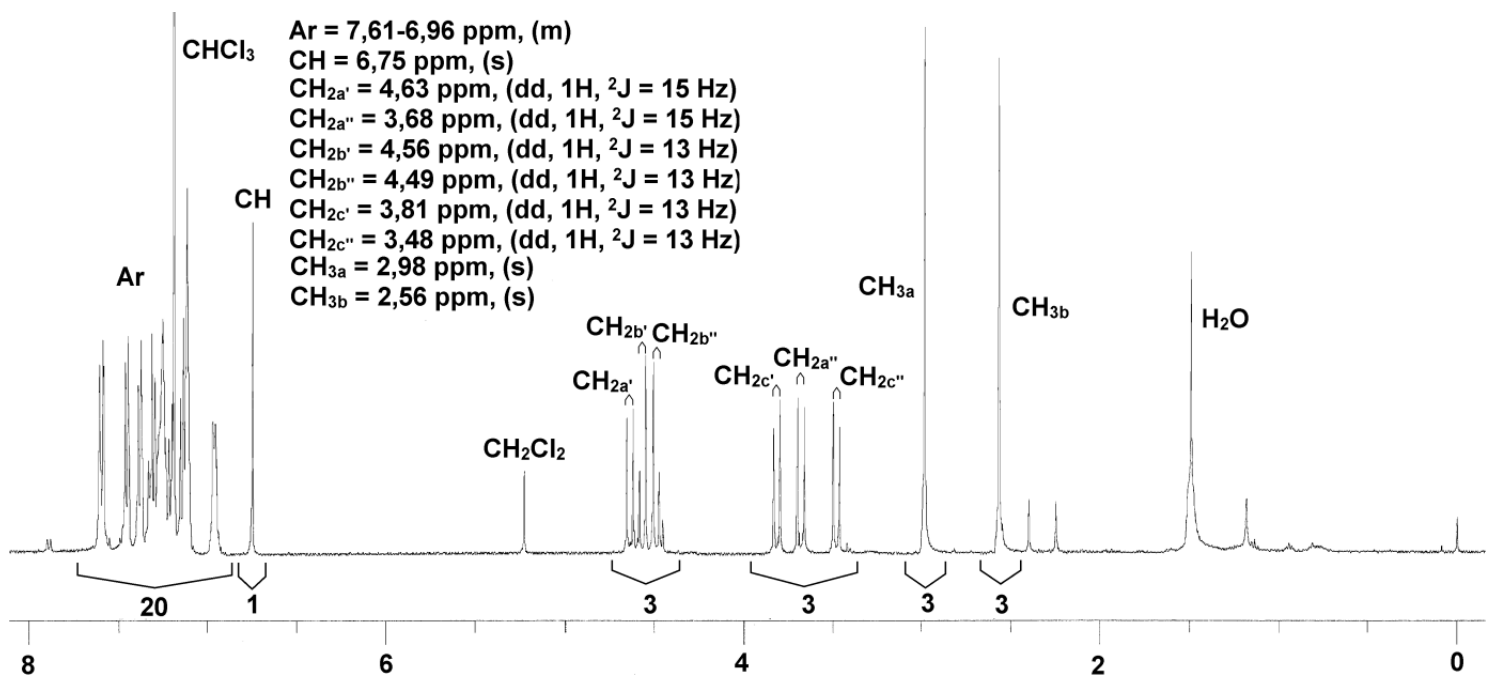

Tabela 21 - Dados de $\mathrm{RMN}{ }^{1} \mathrm{H}(400 \mathrm{MHz})$ para 9 obtidos em $\mathrm{CDCl}_{3}$.

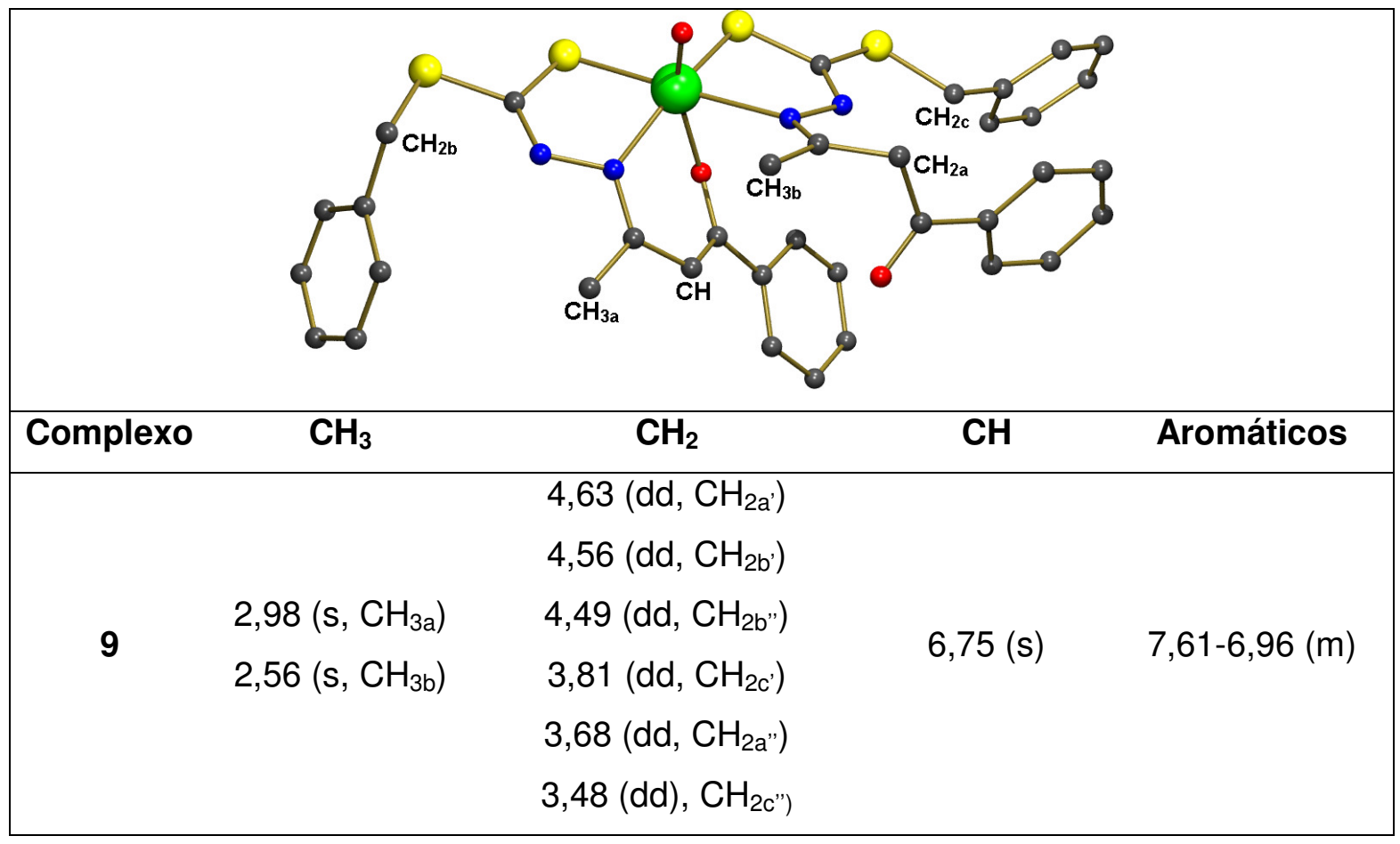


Figura 84 - Espectro de $\mathrm{RMN}{ }^{1} \mathrm{H}$ do $\mathbf{H}_{2}$ bdtn $\left(400 \mathrm{MHz}, \mathrm{CDCl}_{3}\right)$.

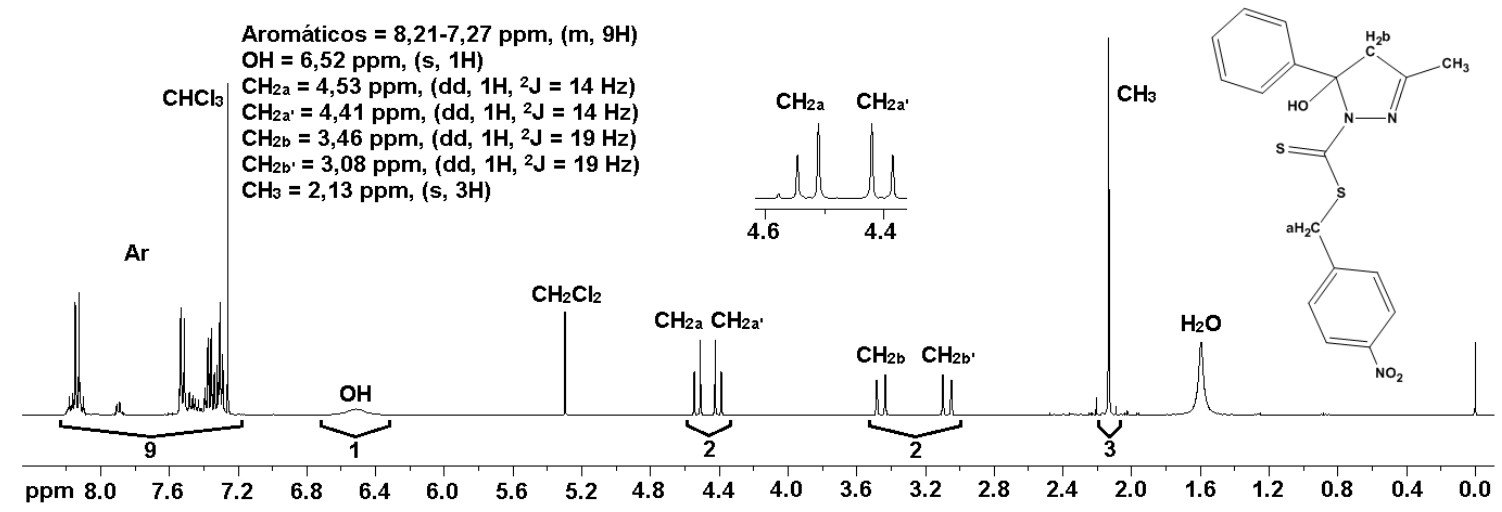

Figura 85 - Espectro de $\mathrm{RMN}{ }^{1} \mathrm{H}$ de $\left[\mathrm{ReO}\right.$ (bdtn)(Hbdtn)] (10) $\left(400 \mathrm{MHz}, \mathrm{CD}_{2} \mathrm{Cl}_{2}\right)$.
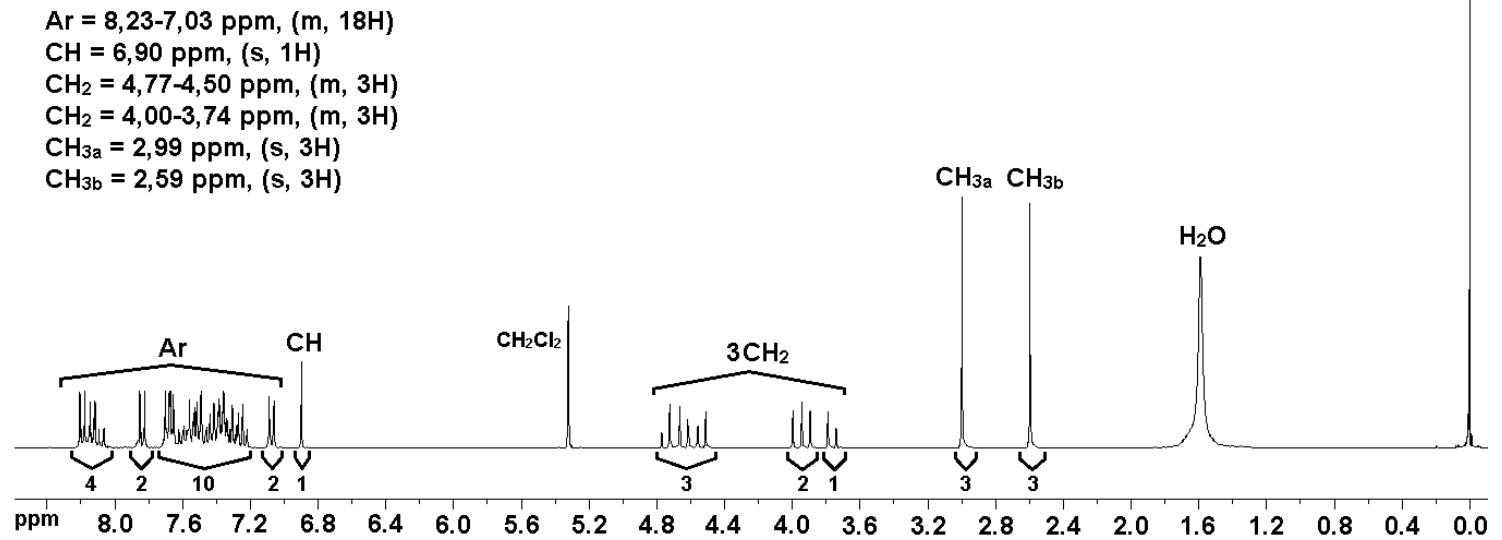

Tabela 22 - Dados de $\mathrm{RMN}{ }^{1} \mathrm{H}(400 \mathrm{MHz})$ para 10 obtidos em $\mathrm{CD}_{2} \mathrm{Cl}_{2}$.

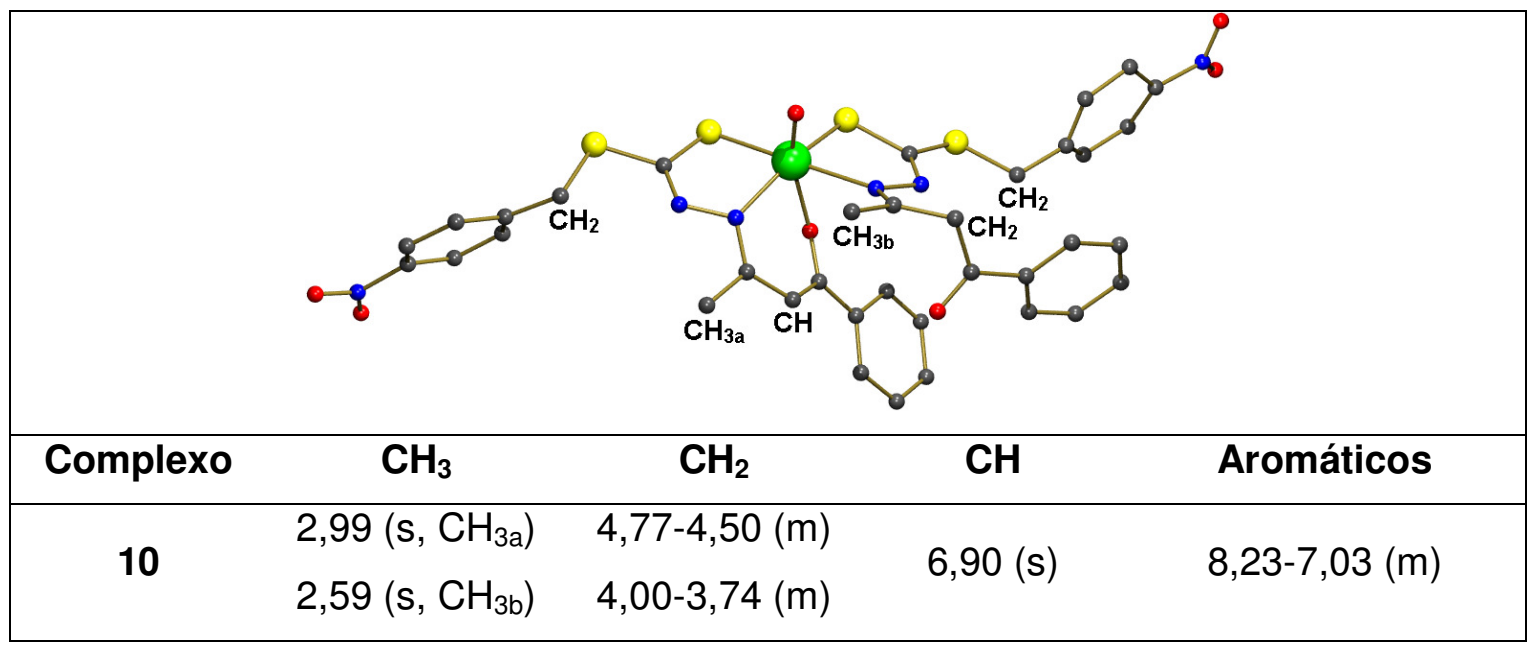


Figura 86 - Espectro de RMN ${ }^{1} \mathrm{H}$ do $\mathrm{H}_{2} \mathbf{b d t m}\left(400 \mathrm{MHz}, \mathrm{CDCl}_{3}\right)$.

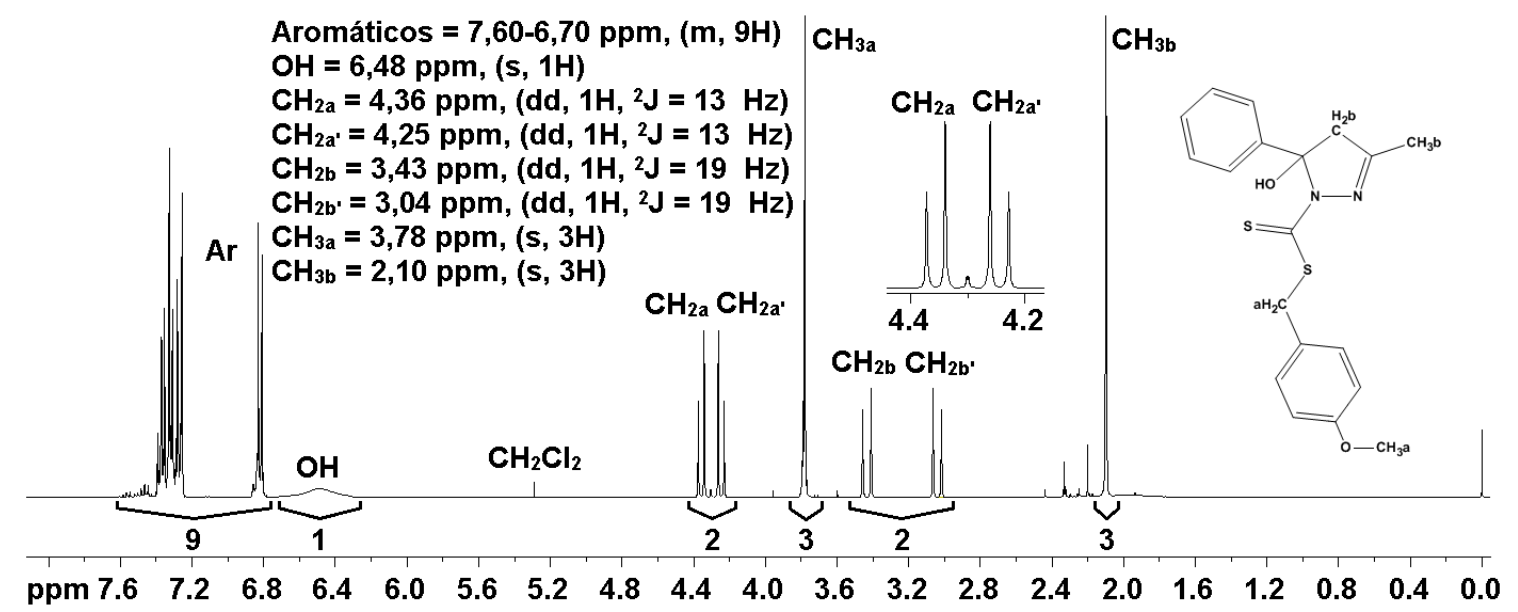

Figura 87 - Espectro de $\mathrm{RMN}{ }^{1} \mathrm{H}$ do $[\mathbf{R e O}(\mathbf{b d t m})(\mathrm{Hbdtm})](\mathbf{1 1})\left(400 \mathrm{MHz}, \mathrm{CD}_{2} \mathrm{Cl}_{2}\right)$.
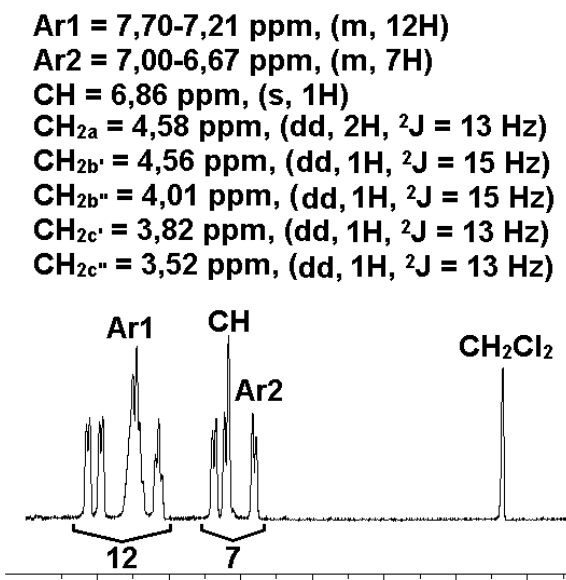

$\mathrm{CH}_{3 \mathrm{a}}=3,78 \mathrm{ppm},(\mathrm{s}, 3 \mathrm{H})$

$\mathrm{CH}_{3 \mathrm{~b}}=3,74 \mathrm{ppm},(\mathrm{s}, 3 \mathrm{H})$

$\mathrm{CH}_{3 \mathrm{c}}=3,11 \mathrm{ppm},(\mathrm{s}, 3 \mathrm{H})$

$\mathrm{CH}_{3 \mathrm{~d}}=2,63 \mathrm{ppm},(\mathrm{s}, 3 \mathrm{H})$

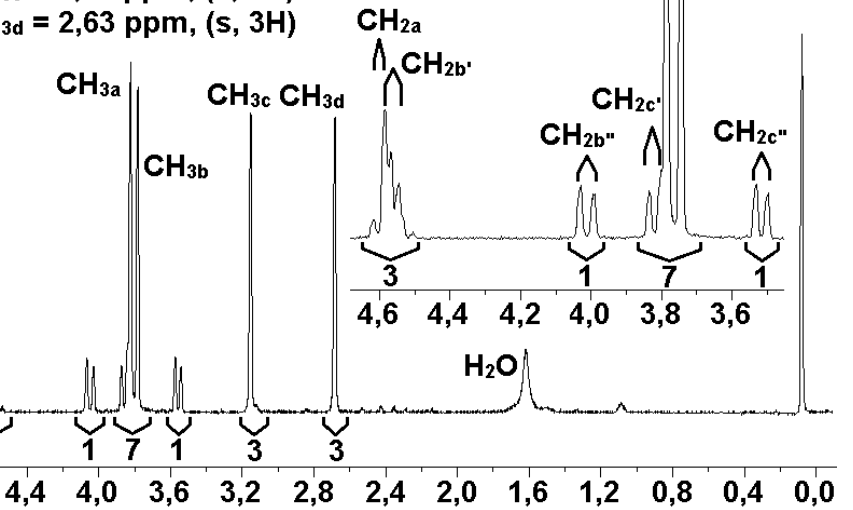


Tabela 23 - Dados de $\mathrm{RMN}{ }^{1} \mathrm{H}(400 \mathrm{MHz})$ para 11 obtidos em $\mathrm{CD}_{2} \mathrm{Cl}_{2}$.

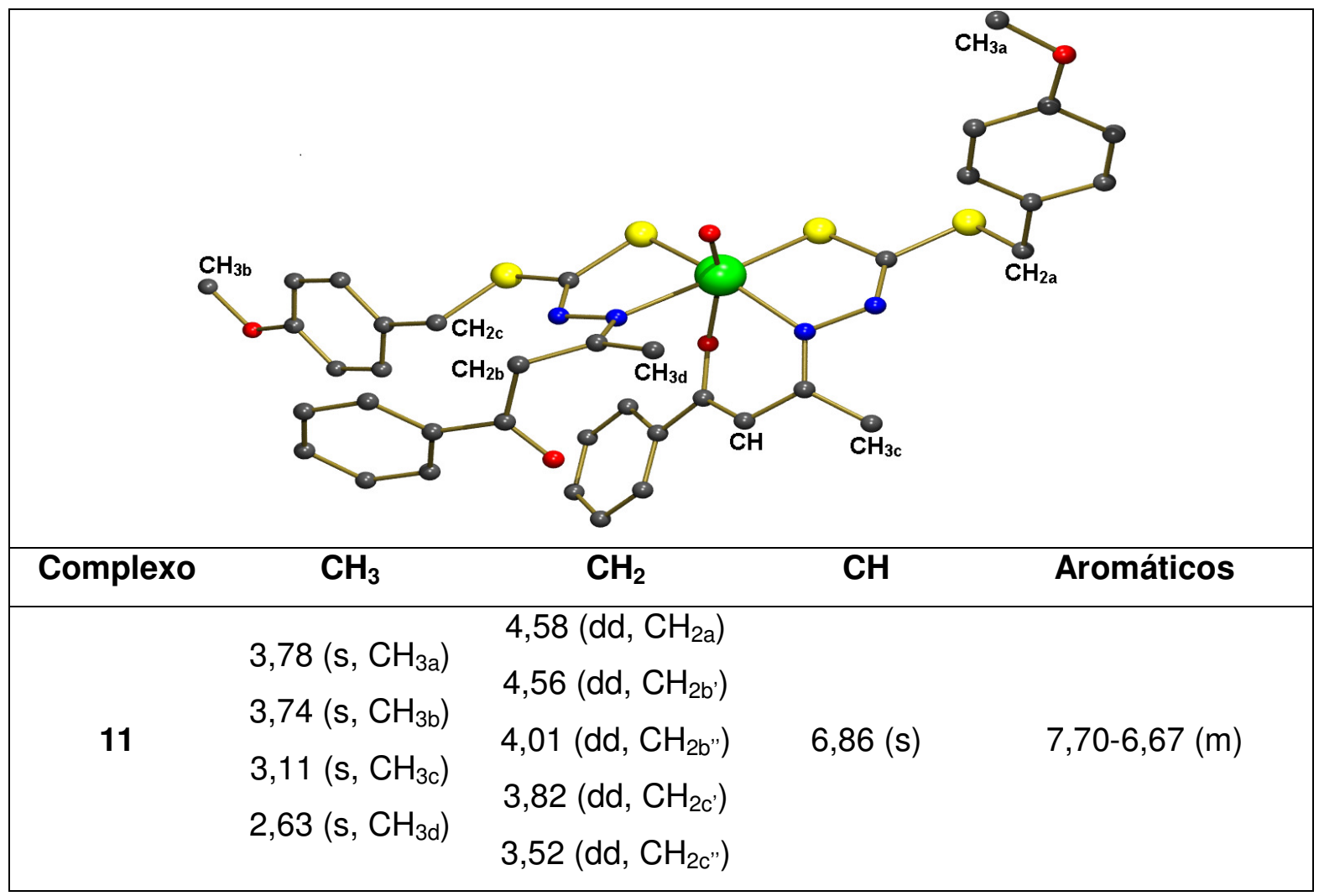




\subsubsection{Difração de Raios X em Monocristal dos Complexos 9, 10 e 11}

\section{Determinação das Estruturas Cristalinas e Moleculares}

Os compostos 9, 10 e 11 cristalizaram-se sob a forma de prismas vermelhos após a evaporação lenta de suas soluções, durante um período de dois dias.

As constantes de cela dos complexos 9, 10 e 11 foram calculadas, respectivamente, a partir de 6120, 37664 e 21883 reflexões, coletadas com uma ampla variação do ângulo $2 \theta$, em todos os casos.

Os complexos cristalizaram-se no sistema cristalino triclínico, grupo espacial $P \overline{1}$, o que indica que suas celas unitárias são primitivas $(P)$ e que possuem um centro de inversão $(\overline{1})$, com duas moléculas de cada complexo em suas respectivas unidades assimétricas. Ocorreu um aumento gradativo do volume das celas dos complexos como consequência da substituição de um hidrogênio em $\mathbf{9}$, pelos grupos mais volumosos $\mathrm{NO}_{2}$, em 10, e $\mathrm{OCH}_{3}$, em 11.

A correção de absorção multi-scan ${ }^{66}$ foi aplicada somente à solução da estrutura do complexo 10.

Métodos diretos foram utilizados nas soluções de todas as estruturas. ${ }^{64}$

Todos os átomos foram refinados com deslocamento térmico anisotrópico, exceto os de hidrogênio, que foram calculados a partir de posições idealizadas. ${ }^{65}$

Outras informações referentes à determinação das estruturas são apresentadas na tabela 24. Dados referentes aos ângulos e distâncias de ligações selecionadas para estes compostos podem ser encontrados na tabela 25. 


\section{Discussão das Estruturas Cristalinas e Moleculares}

Todos os átomos de $\operatorname{Re}(\mathrm{V})$ central encontram-se hexacoordenados, com geometrias de coordenação octaédricas distorcidas (Figuras 88, 90 e 91).

Nos complexos 9, 10 e 11 os ditiocarbazatos coordenaram-se de duas formas distintas ao mesmo centro metálico. Uma delas, tridentada, dianiônica e O,N,S-doadora. Entretanto, diferente dos outros compostos, nos quais este modo de coordenação estava presente de forma planar, a formação dos anéis quelatos ocorreu de modo facial, com a torção da parte do ligante que contém o oxigênio em direção ao eixo axial. A segunda forma coordenação foi bidentada, monoaniônica e N,S-doadora, com os átomos de nitrogênio e enxofre ocupando as posições remanescentes do plano equatorial no octaedro. Este último modo de coordenação associado à formação de uma carbonila nos ligantes, conforme discutido anteriormente na parte sobre IV, foi comprovado de maneira incontestável, por meio da elucidação das estruturas dos três complexos e as distâncias de ligação $\mathrm{C}=\mathrm{O}$, nestas carbonilas, estão compreendidas entre 121,9(9) e 123,3(8) pm.

Apesar dos anéis quelatos com seis e cinco membros não serem planares, seus desvios da planaridade são muito pequenos (Figura 88), como pode ser observado na estrutura de 9 e há indicativos de deslocalização de densidade eletrônica $\pi$ devido aos comprimentos de ligação observados entre seus átomos. As ligações C-S, C-N e C-O nos anéis estão dentro do intervalo entre ligações simples e duplas.

Os comprimentos de ligação Re=O são de 168,0(4), 169,7(6) e 166,5(5) pm e apresentam-se compatíveis com as ligações duplas. , $^{8,71,79}$ 
Figura 88 - Estrutura molecular do complexo 9. Para facilitar a visualização, os átomos de hidrogênio dos ligantes foram omitidos.

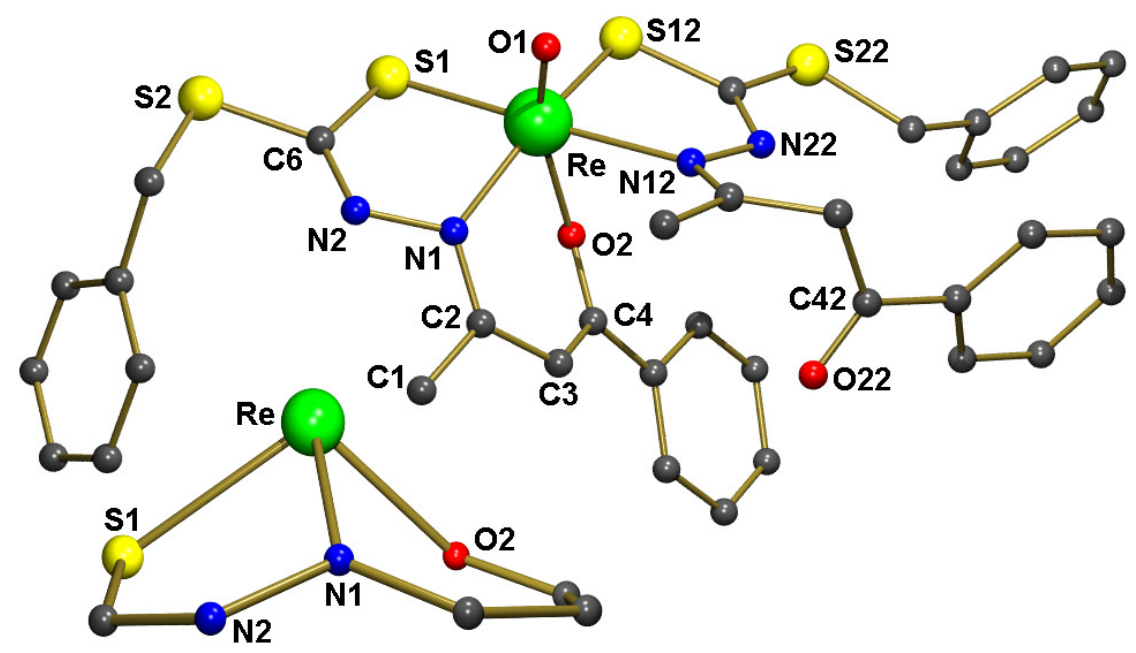

Figura 89 - Cela unitária do complexo 9.

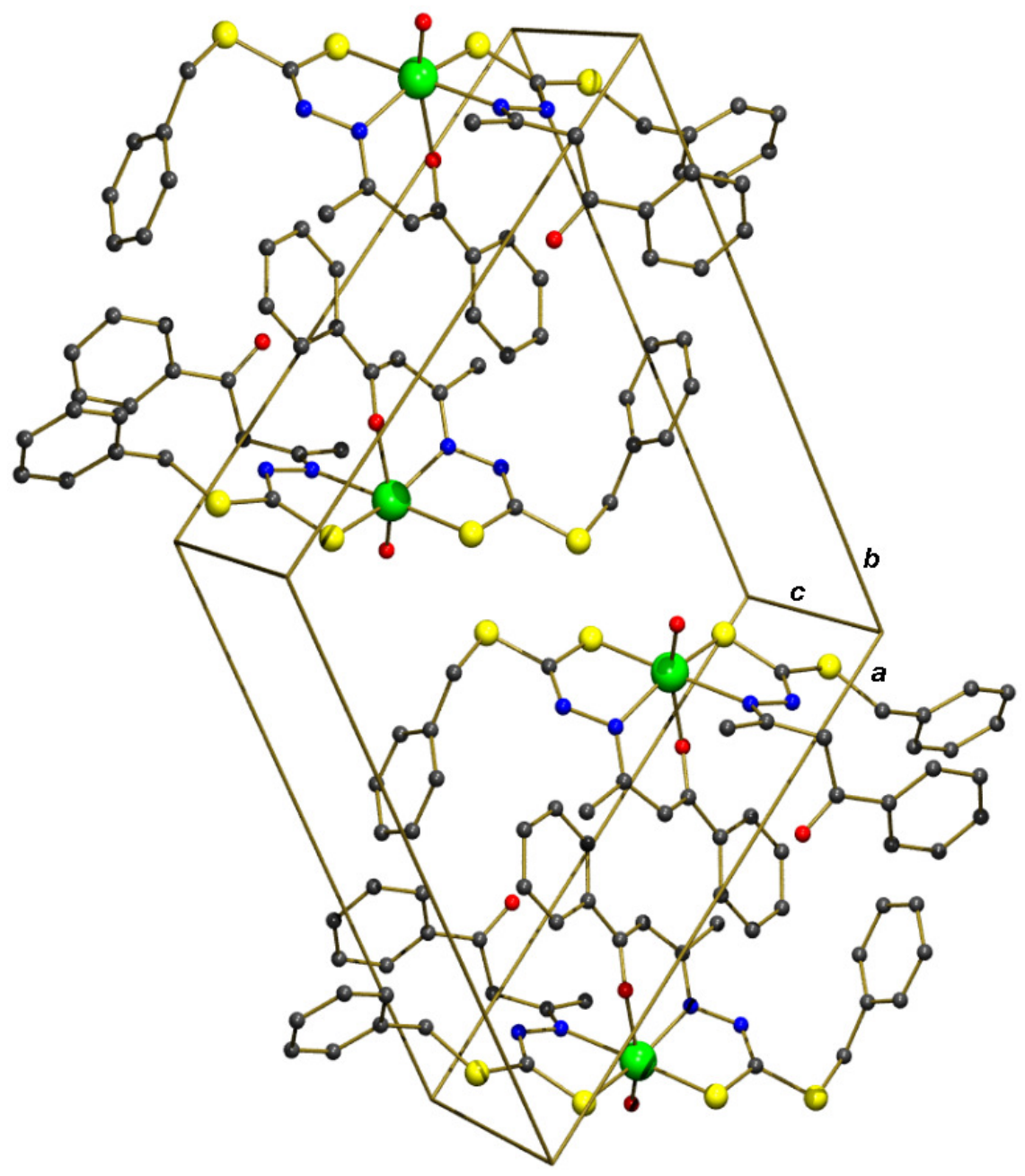


Figura 90 - Estrutura molecular do complexo 10. Para facilitar a visualização, os átomos de hidrogênio dos ligantes foram omitidos.

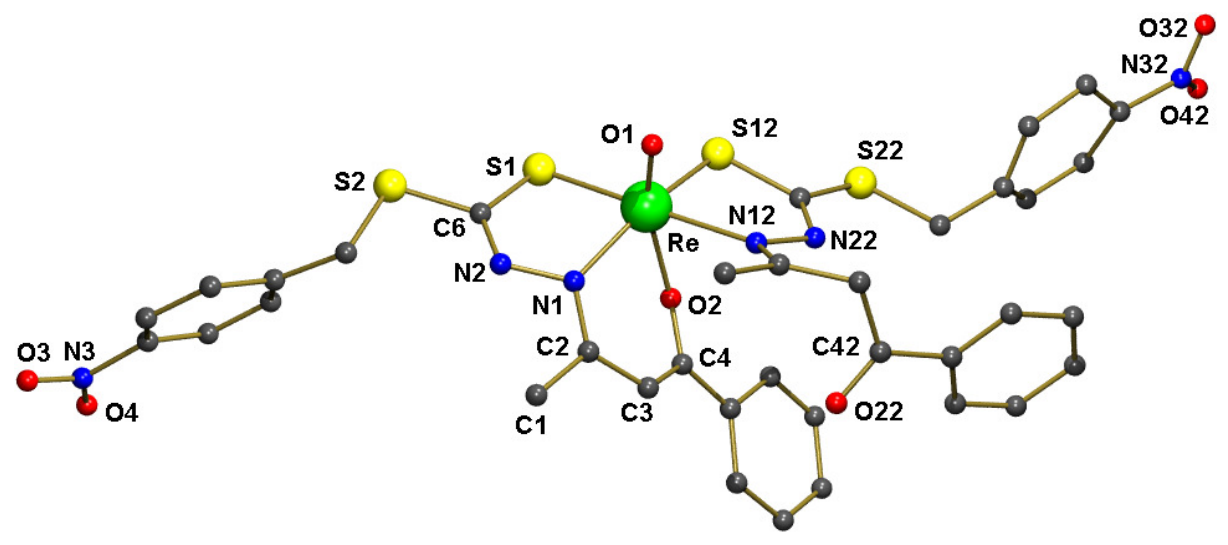

Figura 91 - Estrutura molecular do complexo 11. Para facilitar a visualização, os átomos de hidrogênio dos ligantes foram omitidos.

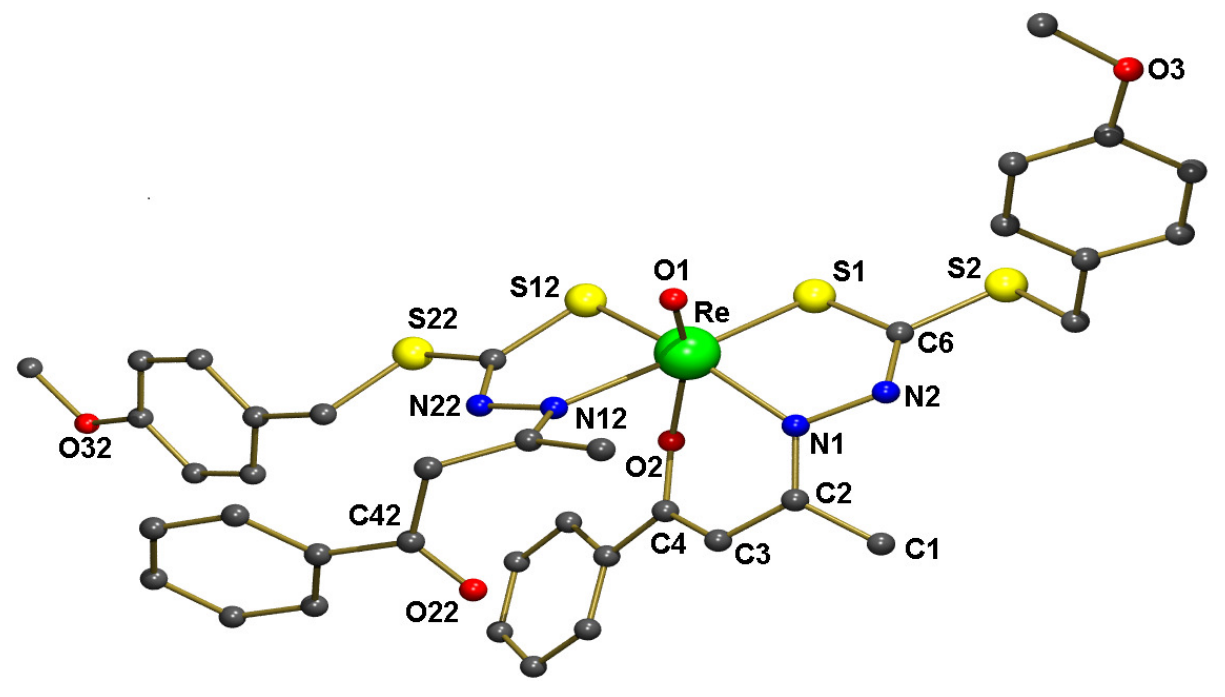


Tabela 24 - Dados cristalográficos de difração de raios $X$ e resultados dos refinamentos das estruturas dos complexos 9, 10 e 11.

\begin{tabular}{|c|c|c|c|}
\hline Complexo & 9 & 10 & 11 \\
\hline Fórmula molecular & $\mathrm{C}_{36} \mathrm{H}_{33} \mathrm{~N}_{4} \mathrm{O}_{3} \mathrm{ReS}_{4}$ & $\mathrm{C}_{36} \mathrm{H}_{31} \mathrm{~N}_{6} \mathrm{O}_{7} \mathrm{ReS}_{4}$ & $\mathrm{C}_{38} \mathrm{H}_{37} \mathrm{~N}_{4} \mathrm{O}_{5} \mathrm{ReS}_{4}$ \\
\hline Massa Molar g.mol ${ }^{-1}$ & 884,10 & 974,11 & 944,16 \\
\hline Temperatura (K) & $200(2)$ & $200(2)$ & $200(2)$ \\
\hline Comprimento da radiação (pm) & 71,073 & 71,073 & 71,073 \\
\hline Sistema Cristalino & Triclínico & Triclínico & Triclínico \\
\hline Grupo Espacial & $\mathrm{P}_{\overline{1}}^{-}$ & $P_{1}^{-}$ & $\mathrm{P}^{-}$ \\
\hline \multicolumn{4}{|l|}{ Parâmetros da cela unitária } \\
\hline$a(\mathrm{pm})$ & $817,24(2)$ & $1337,14(9)$ & $840,98(9)$ \\
\hline$b(\mathrm{pm})$ & $1509,73(4)$ & $1461,01(6)$ & $1370,9(2)$ \\
\hline$c(\mathrm{pm})$ & $1616,81(4)$ & $2735,20(18)$ & $1794,2(2)$ \\
\hline 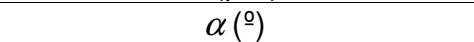 & $110,804(2)$ & $81,441(5)$ & $106,782(8)$ \\
\hline$\beta(\stackrel{\circ}{\circ})$ & $98,755(2)$ & $87,225(5)$ & $99,500(8)$ \\
\hline$\gamma(\stackrel{\circ}{*})$ & $95,717(2)$ & $78,823(5)$ & $99,911(8)$ \\
\hline Volume $\left(\mathrm{nm}^{3}\right)$ & $1,81737(8)$ & $1,8747(15)$ & $1,8997(3)$ \\
\hline $\mathrm{Z}$ & 2 & 2 & 2 \\
\hline Coeficiente de absorção $\left(\mathrm{mm}^{-1}\right)$ & 3,614 & 3,521 & 3,467 \\
\hline Tamanho do cristal $\left(\mathrm{mm}^{3}\right)$ & $0,125 \times 0,096$ & $\begin{array}{c}0,165 \times 0,132 \times \\
0,090\end{array}$ & $\begin{array}{c}0,156 \times 0,119 \times \\
0,092\end{array}$ \\
\hline Forma e cor do cristal & Prismas vermelhos & Prismas vermelhos & Prismas vermelhos \\
\hline Método / variação de $\theta(\stackrel{\circ}{)})$ & 2,65 até 24,77 & 1,80 até 26,74 & 3,29 até 29,33 \\
\hline Índices (h, k, l) & $\begin{array}{c}-9 \rightarrow \mathrm{h} \rightarrow 9, \\
-17 \rightarrow \mathrm{k} \rightarrow 16, \\
-0 \rightarrow 1 \rightarrow 19\end{array}$ & $\begin{array}{l}-10 \rightarrow \mathrm{h} \rightarrow 10, \\
-17 \rightarrow \mathrm{k} \rightarrow 15, \\
-22 \rightarrow \mathrm{l} \rightarrow 22\end{array}$ & $\begin{array}{l}-11 \rightarrow \mathrm{h} \rightarrow 11, \\
-18 \rightarrow \mathrm{k} \rightarrow 18, \\
-24 \rightarrow \mathrm{l} \rightarrow 24\end{array}$ \\
\hline Reflexões coletadas & 6120 & 37664 & 21883 \\
\hline Reflexões independentes / $R_{\text {int }}$ & $6120 / 0,0000$ & 7872 / 0,1246 & $10234 / 0,1001$ \\
\hline Correção de Absorção & Nenhuma & Multi-scan ${ }^{66}$ & Nenhuma \\
\hline Transmissão min. / max. & ----- & $0,5328 / 0,5830$ & $-\cdots---$ \\
\hline Refinamento da estrutura & $\begin{array}{l}\text { Matriz completa dos } \\
\text { mínimos quadrados }\end{array}$ & $\begin{array}{l}\text { Matriz completa dos } \\
\text { mínimos quadrados }\end{array}$ & $\begin{array}{l}\text { Matriz completa dos } \\
\text { mínimos quadrados }\end{array}$ \\
\hline Tratamento dos hidrogênios & Calculados & Calculados & Calculados \\
\hline Fatores $R$ finais $[l>2 \sigma(I)]$ & $\begin{array}{r}R 1=0,0387 \\
w R 2=0,0748\end{array}$ & $\begin{array}{l}R 1=0,0534 \\
w R 2=0,0824\end{array}$ & $\begin{array}{l}\mathrm{R} 1=0,0476 \\
\mathrm{wR} 2=0,0940\end{array}$ \\
\hline "Goodness-of-fit" sobre F" & 1,116 & 0,861 & 0,809 \\
\hline Programas usados & $\begin{array}{l}\text { SHELXS97 } \\
\text { SHELXL }^{65}\end{array}$ & $\begin{array}{l}\text { SHELXS9764 e } \\
\text { SHELXL }\end{array}$ & $\begin{array}{l}\text { SHELXS97 } \\
\text { SHELXL }\end{array}$ \\
\hline
\end{tabular}


Tabela 25 - As principais distâncias (pm) e ângulos $\left(^{\circ}\right)$ de ligação encontrados nos complexos 9,10 e 11.

\begin{tabular}{|cccc|}
\hline Distâncias & $\mathbf{9}$ & $\mathbf{1 0}$ & $\mathbf{1 1}$ \\
\hline $\mathrm{Re}-\mathrm{O}(1)$ & $168,0(4)$ & $169,7(6)$ & $166,5(5)$ \\
\hline $\operatorname{Re}-\mathrm{O}(2)$ & $206,1(4)$ & $206,2(6)$ & $204,6(4)$ \\
\hline $\mathrm{Re}-\mathrm{N}(1)$ & $207,1(5)$ & $207,2(7)$ & $210,2(5)$ \\
\hline $\operatorname{Re}-\mathrm{N}(12)$ & $225,5(5)$ & $223,9(9)$ & $222,6(5)$ \\
\hline $\operatorname{Re}-\mathrm{S}(1)$ & $230,8(2)$ & $232,1(3)$ & $230,7(2)$ \\
\hline $\operatorname{Re}-\mathrm{S}(12)$ & $233,5(2)$ & $231,8(2)$ & $232,1(2)$ \\
\hline $\mathrm{C}(4)-\mathrm{O}(2)$ & $130,4(7)$ & $132,5(11)$ & $132,7(7)$ \\
\hline $\mathrm{C}(42)-\mathrm{O}(22)$ & $123,3(8)$ & $121,91(1)$ & $121,9(9)$ \\
\hline $\mathrm{C}(2)-\mathrm{N}(1)$ & $133,0(7)$ & $134,4(12)$ & $131,3(8)$ \\
\hline $\mathrm{C}(6)-\mathrm{N}(2)$ & $128,2(8)$ & $127,4(12)$ & $129,7(8)$ \\
\hline $\mathrm{C}(6)-\mathrm{S}(1)$ & $175,9(7)$ & $177,0(9)$ & $177,0(6)$ \\
\hline$\hat{A} n g u l o s$ & & & \\
\hline $\mathrm{O}(1)-\operatorname{Re}-\mathrm{O}(2)$ & $156,9(2)$ & $156,9(3)$ & $158,4(2)$ \\
\hline $\mathrm{O}(1)-\operatorname{Re}-\mathrm{N}(1)$ & $98,6(2)$ & $99,4(3)$ & $100,1(2)$ \\
\hline $\mathrm{O}(1)-\operatorname{Re}-\mathrm{N}(12)$ & $82,9(2)$ & $83,8(3)$ & $84,3(2)$ \\
\hline $\mathrm{O}(1)-\operatorname{Re}-\mathrm{S}(1)$ & $98,1(2)$ & $99,6(2)$ & $99,9(2)$ \\
\hline $\mathrm{O}(1)-\operatorname{Re}-\mathrm{S}(12)$ & $102,2(2)$ & $102,0(2)$ & $102,7(2)$ \\
\hline $\mathrm{O}(2)-\operatorname{Re}-\mathrm{N}(1)$ & $78,5(2)$ & $79,1(3)$ & $78,3(2)$ \\
\hline $\mathrm{O}(2)-\operatorname{Re}-\mathrm{N}(12)$ & $75,7(2)$ & $74,4(3)$ & $75,5(2)$ \\
\hline $\mathrm{O}(2)-\operatorname{Re}-\mathrm{S}(1)$ & $103,7(1)$ & $102,8(2)$ & $100,9(1)$ \\
\hline $\mathrm{O}(2)-\operatorname{Re}-\mathrm{S}(12)$ & $82,9(1)$ & $82,2(2)$ & $81,5(1)$ \\
\hline $\mathrm{N}(1)-\operatorname{Re}-\mathrm{N}(12)$ & $103,5(2)$ & $104,3(3)$ & $104,9(2)$ \\
\hline $\mathrm{N}(1)-\operatorname{Re}-\mathrm{S}(1)$ & $79,2(1)$ & $79,1(2)$ & $79,5(1)$ \\
\hline $\mathrm{N}(1)-\operatorname{Re}-\mathrm{S}(12)$ & $159,1(1)$ & $158,5(2)$ & $157,1(1)$ \\
\hline $\mathrm{N}(12)-\operatorname{Re}-\mathrm{S}(1)$ & $177,0(1)$ & $174,8(2)$ & $173,3(1)$ \\
\hline $\mathrm{N}(12)-\operatorname{Re}-\mathrm{S}(12)$ & $81,0(1)$ & $80,5(2)$ & $80,4(1)$ \\
\hline $\mathrm{S}(1)-\operatorname{Re}-\mathrm{S}(12)$ & $96,05(6)$ & $94,9(1)$ & $93,58(6)$ \\
\hline & & & \\
\hline & & & \\
\hline
\end{tabular}




\subsection{Complexos [ReO(bdtc)(cisa)] (12) e [ReO(bdtc)(cism)] (13)}

Os complexos 12 e 13 foram preparados, respectivamente, a partir da substituição da trifenilfosfina e do átomo de cloro, no produto [ReO(bdtc) $\left.\mathrm{Cl}\left(\mathrm{PPh}_{3}\right)\right]$ (4), pelos agentes complexantes Hcisa e Hcism.

Assim como nos demais compostos apresentados neste trabalho, as estruturas dos complexos foram propostas com base na análise elementar, nos espectros de massas com ionização eletrospray (MS-ESI), nos dados espectroscópicos obtidos através das técnicas de infravermelho e ressonância magnética nuclear de hidrogênio, e confirmadas por meio da determinação de suas estruturas a partir dos dados de difração de raios $\mathrm{X}$ em monocristal.

As estruturas determinas para estes dois novos compostos comprovaram um rearranjo no modo de coordenação do bdtc $^{2-}$, inicialmente planar em 4, para facial nestes dois produtos. Uma explicação para a alteração na forma de coordenação foi encontrada por meio de cálculos das energias dos complexos, envolvendo os diferentes modos de coordenação e a partir de suas respectivas estruturas previamente otimizadas. Os cálculos foram baseados na DFT (Density Functional Theory) e utilizando-se o pacote de programas Gaussian $03 .^{80}$ Esses resultados podem ser encontrados no tópico 4.4.4 desta discussão. 


\subsubsection{Espectroscopia de Absorção na Região do Infravermelho}

Assim como em outros produtos previamente discutidos neste trabalho, a presença do ânion bdtc $^{2-}$ coordenado ao centro metálico de forma $0, N, S$-doadora e tridentada pôde ser inferida, também nesses dois compostos, pelos mesmos motivos já abordados anteriormente, e para evitar repetições, não serão detalhados novamente.

Os espectros de IV dos complexos 12 e 13 (Figuras 95 e 97, respectivamente) exibem bandas que são atribuídas ao $v(\mathrm{Re}=\mathrm{O})$, pouco deslocadas em relação ao precursor metálico 4 (Figura 93), em 953, 949 e $957 \mathrm{~cm}^{-1}$, respectivamente. Esses valores estão de acordo outros descritos na literatura para este mesmo estiramento. ${ }^{8,79}$ A diferença entre os valores das bandas $\mathrm{Re}=\mathrm{O}$, no precursor 4 e em 12, está dentro do erro instrumental de $\pm 4 \mathrm{~cm}^{-1}$. Portanto, tendo-se como base apenas este modo vibracional, não se pôde confirmar que a reação obteve êxito.

No entanto, a partir de uma análise mais rigorosa dos espectros de IV obtidos para esses produtos constatou-se alguns fatos que corroboraram com a saída da $\mathrm{PPh}_{3}$ e a coordenação bidentada e N,S-doadora dos ligantes cisa ${ }^{1-}$ (Figura 94) e cism $^{1-}$ (Figura 96) aos centros metálicos, originando novos produtos. Entre estes fatos destacam-se: 1) a ausência das bandas $v(C C)_{\mathrm{PPh} 3}$, em 1482 e $1436 \mathrm{~cm}^{-1}$, $v(\mathrm{P}-\mathrm{C})$, em $1095 \mathrm{~cm}^{-1}$ e $v\left(\mathrm{C}_{6} \mathrm{H}_{5}\right)_{\mathrm{PPh} 3}$, em $694 \mathrm{~cm}^{-1}$, que são características do ligante trifenilfosfina; 2) a presença de bandas referentes às aminas primárias ${ }^{81}$ na região entre 3321 e $3259 \mathrm{~cm}^{-1}$, provenientes dos ligantes cisa ${ }^{1-}$ e cism ${ }^{1-}$ e, por último, a não visualização de bandas atribuídas ao modo vibracional $v(\mathrm{~S}-\mathrm{H})^{81}$, na região entre 2027 e $2016 \mathrm{~cm}^{-1}$, indicando a desprotonação do átomo de enxofre como consequência de sua coordenação. Os principais modos vibracionais atribuídos aos complexos 4, 12 e 13, bem como aos ligantes bdtc $^{2-}$, cisa ${ }^{1-}$ e cism $^{1-}$, podem ser visualizados na tabela 26 . 
Tabela 26 - Principais bandas $\left(\mathrm{cm}^{-1}\right)$ atribuídas aos modos vibracionais dos complexos 12 e 13, precursor [ReO(bdtc)Cl( $\left.\mathrm{PPh}_{3}\right)$ ] (4) e agentes complexantes $\mathrm{H}_{2}$ bdtc, Hcisa e Hcism.

\begin{tabular}{|c|c|c|c|c|c|c|c|c|}
\hline \multirow{2}{*}{$\begin{array}{c}\text { Complexos, } \\
\text { Precursores } \\
\text { e Ligantes }\end{array}$} & \multicolumn{8}{|c|}{ Modos Vibracionais } \\
\hline & $\mathrm{v}\left(\mathrm{NH}_{2}\right)$ & $v(\mathrm{O}-\mathrm{H})$ & $v(\mathrm{~S}-\mathrm{H})$ & $v(C=N)$ & $v(C=0)$ & $v(S C S)$ & $\beta\left(\mathrm{C}_{6} \mathrm{H}_{5}\right)_{\mathrm{PPh} 3}$ & $v(R e=0)$ \\
\hline 4 & ----- & ----- & ----- & ---- & ----- & * & 694 & 957 \\
\hline 12 & $\begin{array}{l}3321 \\
3263\end{array}$ & ----- & ----- & 1581 & ----- & 984 & ----- & 953 \\
\hline 13 & $\begin{array}{l}3298 \\
3259\end{array}$ & ----- & ----- & 1589 & 1740 & 976 & ----- & 949 \\
\hline $\mathrm{H}_{2}$ bdtc & ----- & 3360 & ----- & 1629 & ----- & 981 & ----- & ----- \\
\hline Hcisa & * & ----- & 2027 & ----- & ----- & ----- & ----- & ----- \\
\hline Hcism & * & ----- & 2016 & ----- & 1744 & ----- & ----- & ----- \\
\hline
\end{tabular}

O sinal $\left(^{*}\right)$ indica que a banda não pode ser identificada por estar dentro de uma janela larga de absorção.

Figura 92 - Espectro do $\mathrm{H}_{2}$ bdtc.

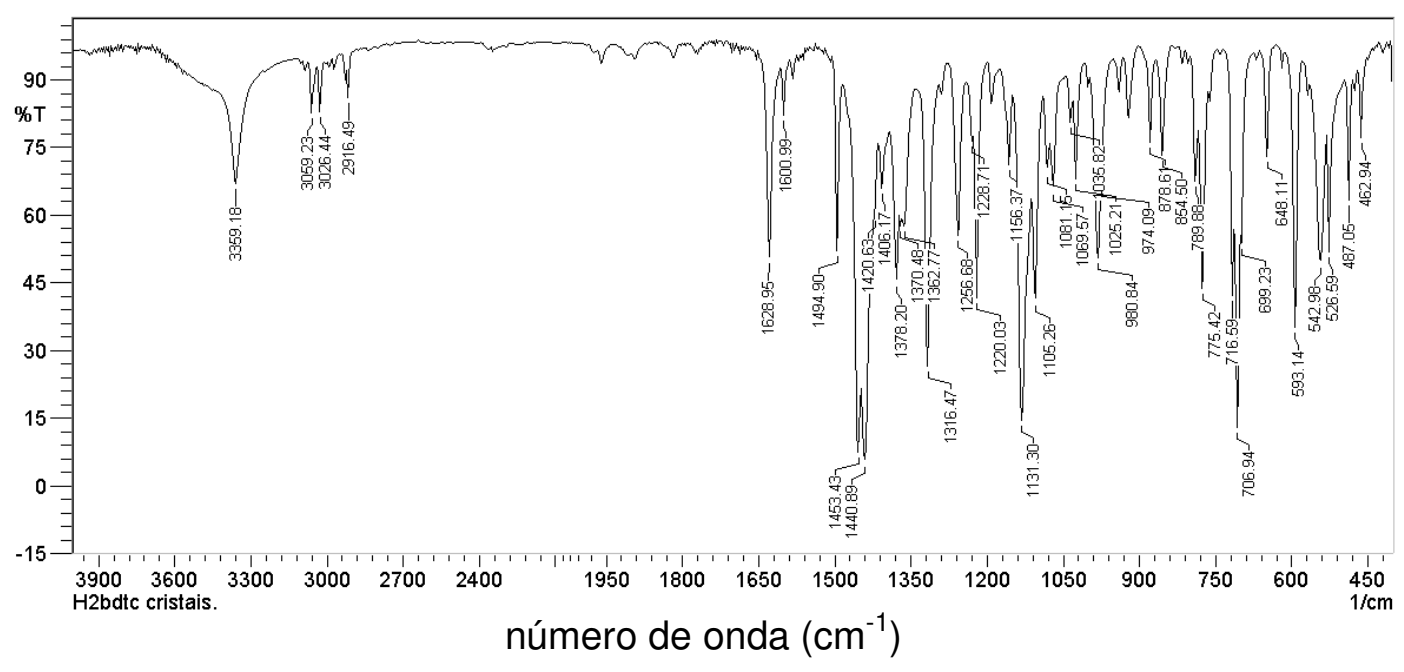


Figura 93 - Espectro do [ReO(bdtc) $\left.\mathrm{Cl}\left(\mathrm{PPh}_{3}\right)\right]$ (4).

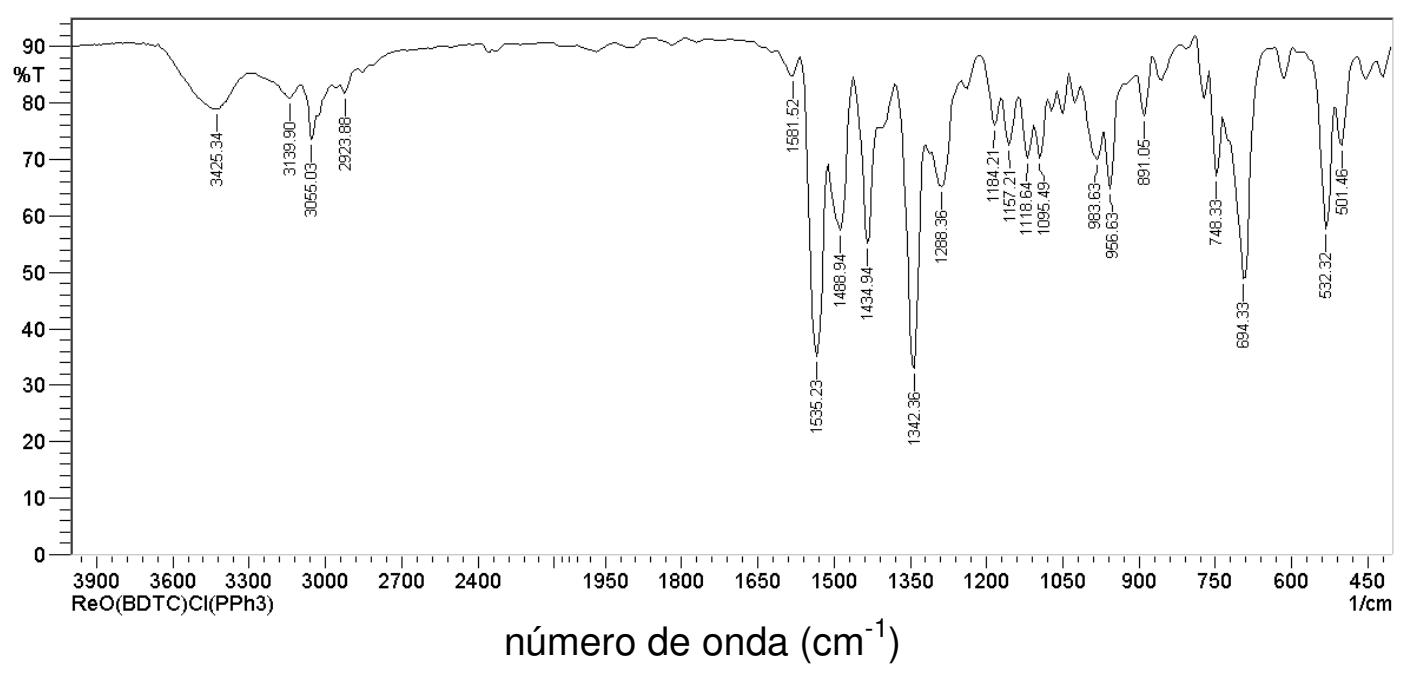

Figura 94 - Espectro do agente complexante Hcisa.

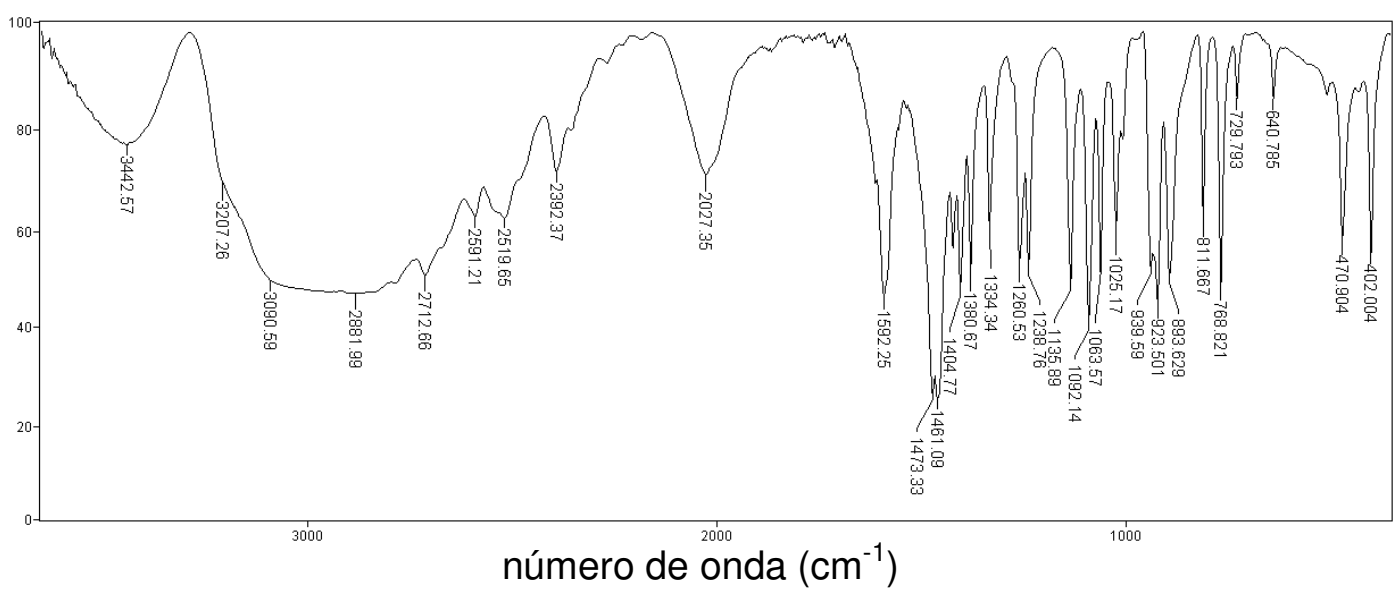


Figura 95 - Espectro do [ReO(bdtc)(cisa)] (12).

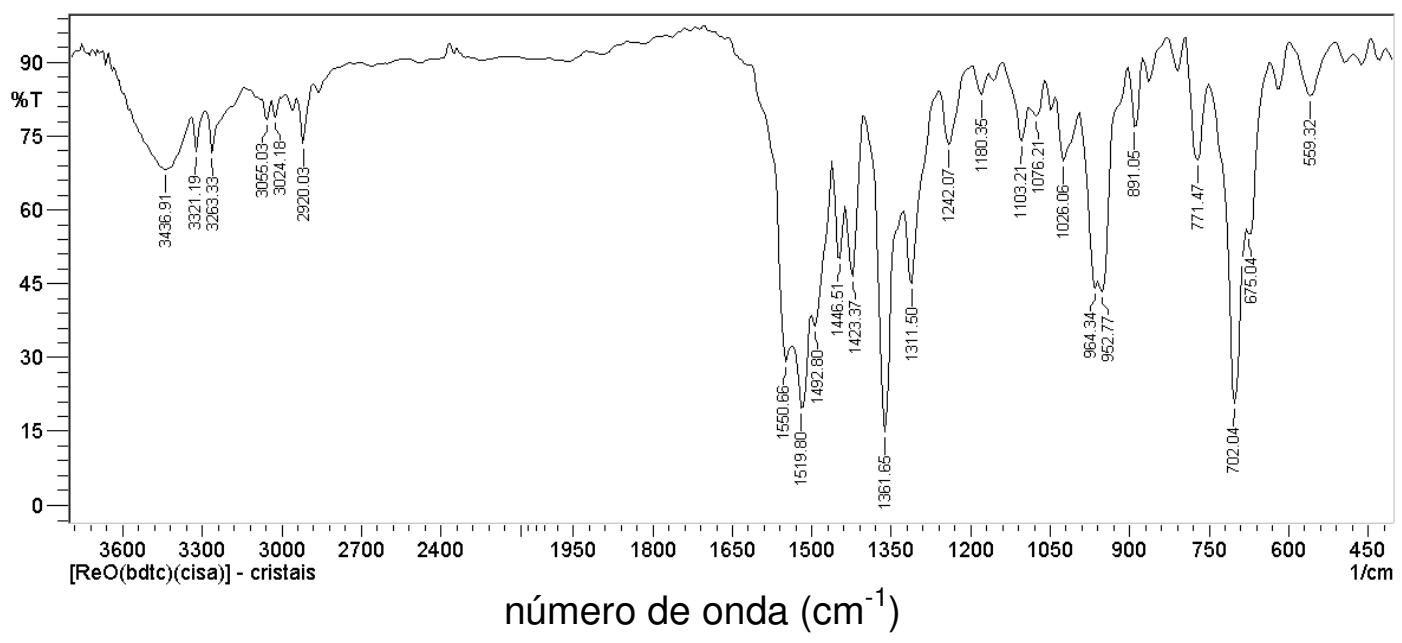

Figura 96 - Espectro do agente complexante Hcism.

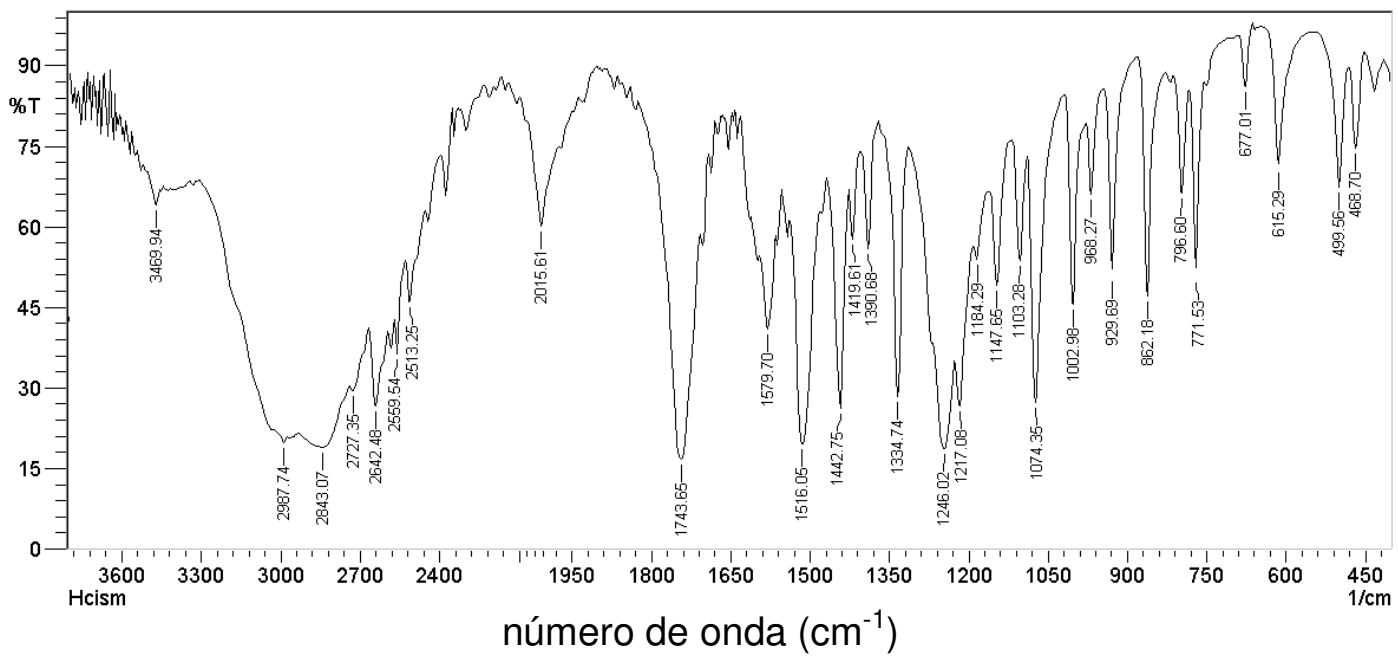


Figura 97 - Espectro do [ReO(bdtc)(cism)] (13).

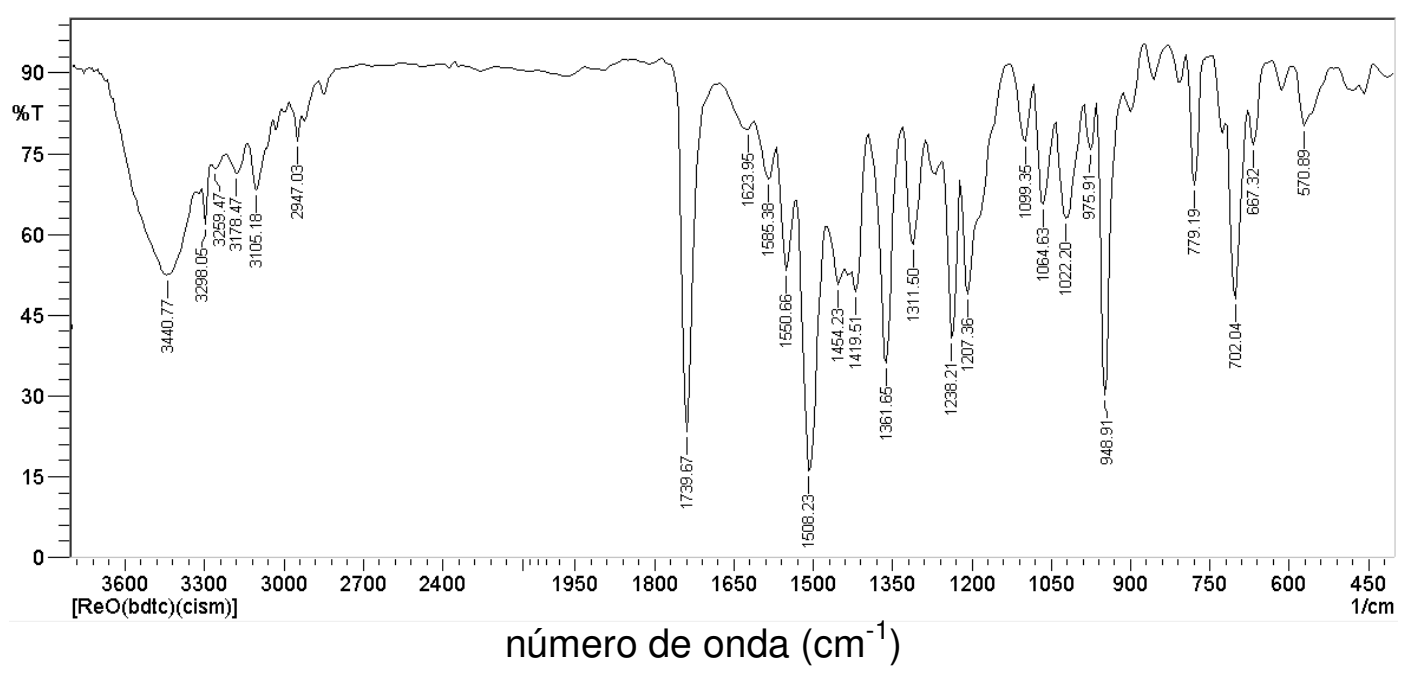




\subsubsection{Espectroscopia de Ressonância Magnética Nuclear (RMN ${ }^{1} \mathrm{H} \mathrm{e}$ $\left.{ }^{31} \mathrm{P}\right)$ para os complexos 12 e 13}

Um experimento de $\mathrm{RMN}{ }^{31} \mathrm{P}$ foi feito com o produto 12 com o intuito de avaliar a eficácia dos métodos de síntese e purificação. A abundância isotópica de $100 \%$ do ${ }^{31} \mathrm{P}$ faz com que este núcleo seja facilmente detectado, mesmo em

pequenas concentrações. Por esta razão, a ausência de sinal, mesmo após 512 varreduras, comprova que espécies contendo fósforo, como o próprio precursor metálico 4, $\mathrm{OPPh}_{3}$ ou $\mathrm{PPh}_{3}$, não estão presentes no produto obtido (Figura 98).

Os espectros de RMN ${ }^{1} \mathrm{H}$ obtidos para 12 e 13 (Figuras 100 e 102, respectivamente) demonstram, como consequência da coordenação do bdtc ${ }^{2-}$ ao centro metálico, um efeito de deslocamento do sinal dos hidrogênios metílicos do ligante livre (Figura 99) para uma região de campo mais baixo nos complexos. Esta desblindagem é coerente com a proposta de deslocalização de elétrons $\pi$ nos anéis quelatos, e com a coordenação via átomo de nitrogênio que também contribui para diminuição da densidade eletrônica no ambiente químico da metila.

Diferentemente dos sinais acoplados, referentes aos grupos metilênicos, observados nos espectros do $\mathbf{H}_{\mathbf{2}}$ bdtc livre e do ânion bdtc ${ }^{2-}$ presente no composto 13, este mesmo grupo, no produto 12 , foi verificado como um simpleto e atribuído ao sinal $\mathrm{CH}_{2 a}$, na figura 100 .

Os sinais correspondentes aos dois grupos metilênicos, oriundos do ligante cisa ${ }^{1-}$, também foram identificados no espectro do seu respectivo produto. $O$ primeiro $\mathrm{CH}_{2}$ foi identificado como dois conjuntos separados de sinais sob a forma de multipletos $\left(\mathrm{CH}_{2 b}\right.$ e $\mathrm{CH}_{2 b}$ "). O segundo conjunto foi observado como um duplo dupleto $\left(\mathrm{CH}_{2 \mathrm{c}^{\prime}}\right.$ e $\left.\mathrm{CH}_{2 \mathrm{c}^{\prime}}\right)$, evidenciando um certo grau de rigidez no anel quelato de cinco membros fazendo com que os seus hidrogênios axiais e equatoriais sejam magneticamente distintos e com uma constante de acoplamento geminal, $2 \mathrm{~J}=11 \mathrm{~Hz}$.

A presença do ligante cism $^{1-}$ no espectro do composto 13 foi comprovada pela observação dos seguintes sinais: $\mathrm{H}_{\mathrm{a}}$ e $\mathrm{H}_{\mathrm{c}}$, em 3,94 e 3,91 ppm, como um duplo dupleto $\left({ }^{2} \mathrm{~J}=13 \mathrm{~Hz}\right.$ e $\left.{ }^{3} \mathrm{~J}=4 \mathrm{~Hz}\right)$ formado pelos hidrogênios $\mathrm{H}_{\mathrm{a}}$, referente ao grupo 
$\mathrm{CH}$, e $\mathrm{H}_{\mathrm{c}}$, que representa um dos hidrogênios do grupo $\mathrm{CH}_{2} ; \mathrm{H}_{\mathrm{b}}$, em 2,81 ppm, referente ao outro hidrogênio metilênico e $\mathrm{CH}_{3 \mathrm{a}}$, em 3,59 ppm, atribuído aos hidrogênios do grupo metila.

Não foi possível atribuir qual é o valor do deslocamento químico correspondente ao $\mathrm{H}_{\mathrm{a}}$ ou $\mathrm{H}_{\mathrm{c}}$ devido à proximidade dos sinais. Entretanto, a distinção entre os hidrogênios geminais $\mathrm{H}_{b}$ e $\mathrm{H}_{c}$ pôde ser feita utilizando-se a curva de Karplus (Figura 101), que correlaciona os valores dos seus respectivos acoplamentos vicinais ${ }^{3} \mathrm{~J}$, com ângulo $\phi$ existente entre esses átomos. ${ }^{82}$ Apenas um valor de constante de acoplamento, $\mathrm{J}=13 \mathrm{~Hz}$, pôde ser calculado a partir do pico atribuído ao $\mathrm{H}_{\mathrm{b}}$. Este pico, em teoria, poderia ser tratado como um tripleto por apresentar uma relação com intensidades 1:2:1. No entanto, não corresponde ao acoplamento de um hidrogênio com dois outros magneticamente equivalentes, o que de fato caracteriza um tripleto. Sua multiplicidade pode ser explicada como consequência da sobreposição parcial de dois dupletos, provenientes de um duplo dupleto, onde a frequência de absorção mais à direita de um é a mesma daquela mais à esquerda do outro. Quando isso acontece, o pico do meio torna-se duas vezes mais intenso do que os dois laterais, de modo similar ao que ocorre em um tripleto, mas com duas constantes de acoplamento ${ }^{2} \mathrm{~J} \mathrm{e}{ }^{3} \mathrm{~J}$ com valores muito próximos, ou como neste caso, iguais.

Os valores de todos os deslocamentos químicos de ${ }^{1} \mathrm{H}$, bem como de suas constantes de acoplamento nos complexos 12 e 13, podem ser observados, respectivamente, nas figuras 100 e 102.

Figura 98 - Espectro de $\mathrm{RMN}^{31} \mathrm{P}$ do [ReO(bdtc)(cisa)] (12) $\left(161,70 \mathrm{MHz}, \mathrm{CDCl}_{3}\right)$.

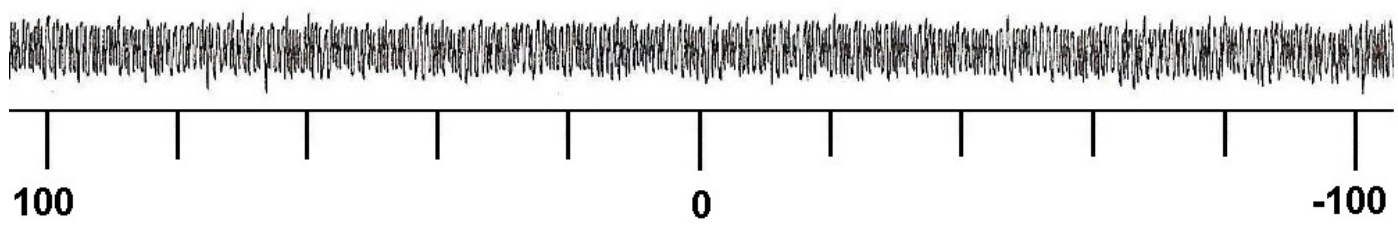


Figura 99 - Espectro de $\mathrm{RMN}{ }^{1} \mathrm{H}$ do $\mathbf{H}_{2}$ bdtc $\left(400 \mathrm{MHz}, \mathrm{CDCl}_{3}\right)$.

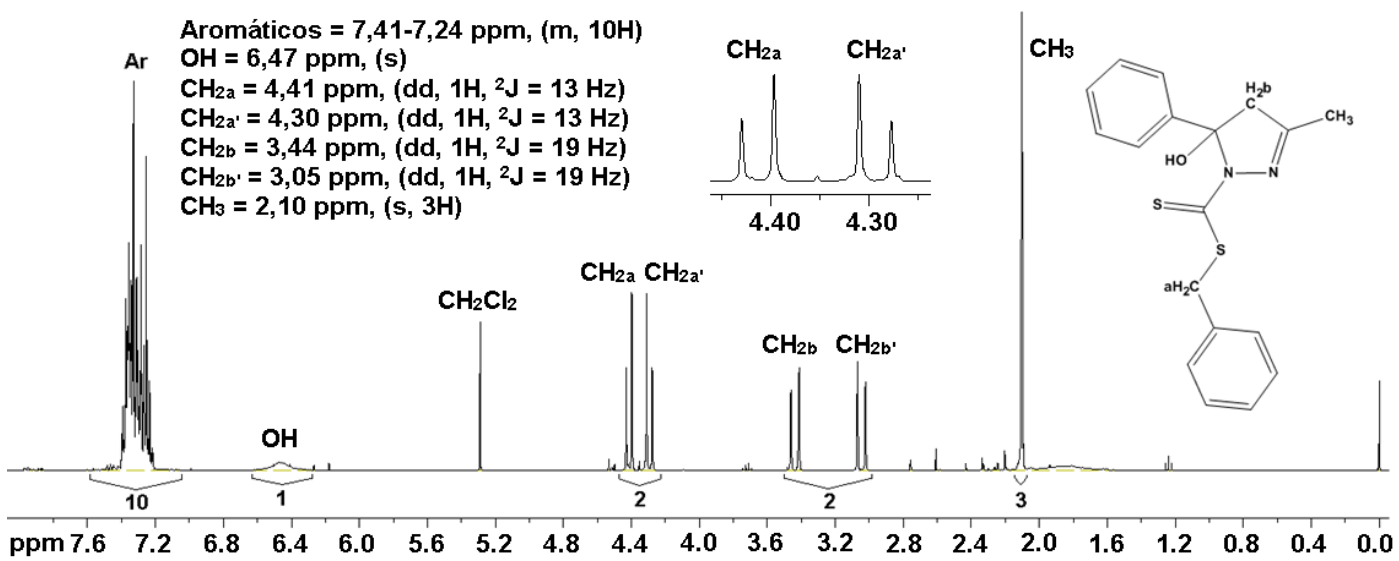

Figura 100 - Espectro de $\mathrm{RMN}^{1} \mathrm{H}$ do [ReO(bdtc)(cisa)] (12) (400 MHz, $\left.\mathrm{CDCl}_{3}\right)$.

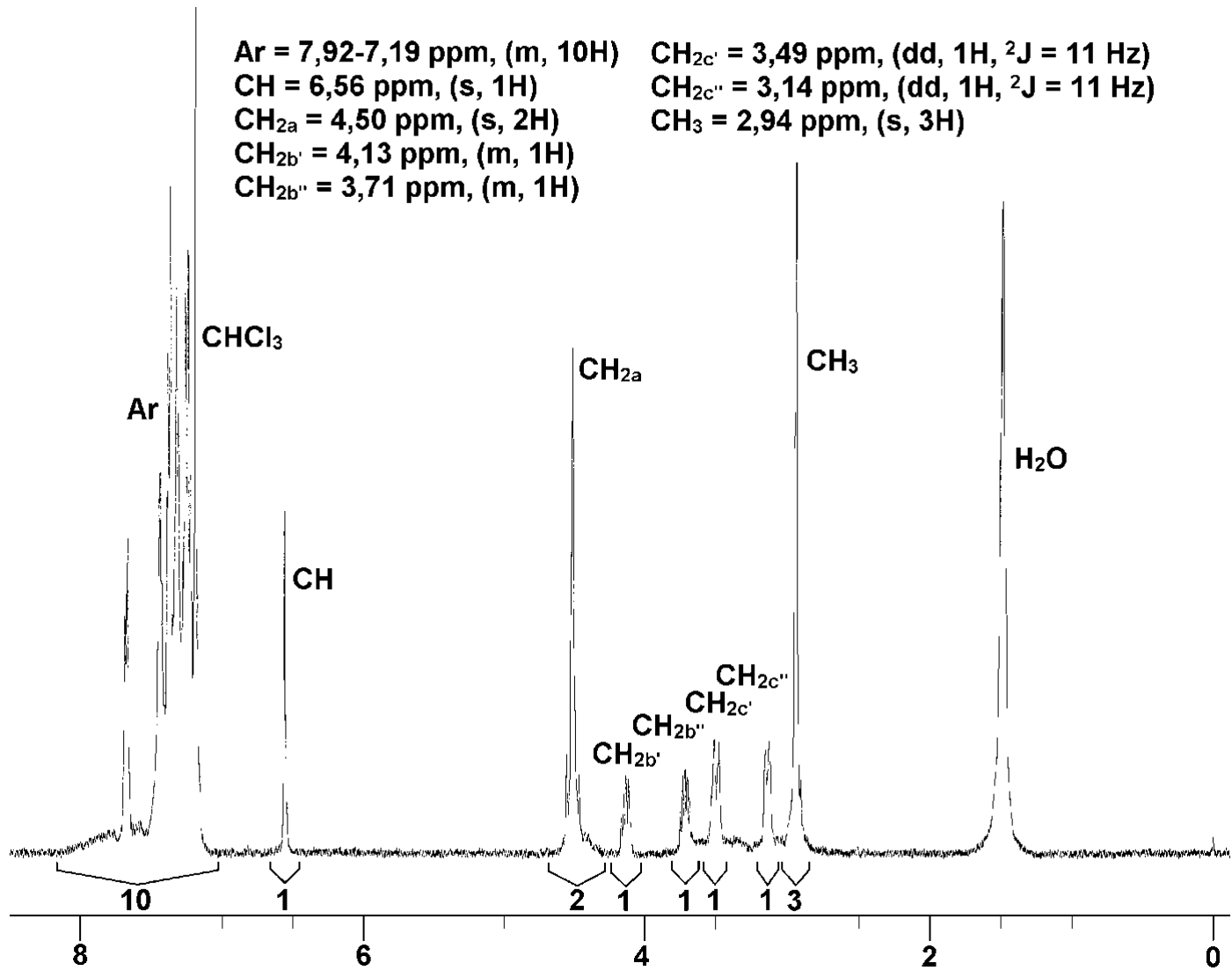


Tabela 27 - Dados de RMN ${ }^{1} \mathrm{H}(400 \mathrm{MHz})$ para 12 obtidos em $\mathrm{CDCl}_{3}$.

\begin{tabular}{|c|c|c|c|c|}
\hline Complexo & $\mathrm{CH}_{3}$ & $\mathrm{CH}_{2}$ & $\mathrm{CH}$ & Aromáticos \\
\hline 12 & $2,94(\mathrm{~s})$ & $\begin{array}{l}\left.\text { 4,50(s, } \mathrm{CH}_{2 \mathrm{a}}\right) \\
4,13\left(\mathrm{~m}, \mathrm{CH}_{2 \mathrm{~b}}\right) \\
3,71\left(\mathrm{~m}, \mathrm{CH}_{2 \mathrm{~b}}\right) \\
\left.\text { 3,49(dd, } \mathrm{CH}_{2 \mathrm{c}}\right) \\
3,14\left(\mathrm{dd}, \mathrm{CH}_{2 \mathrm{c}}\right)\end{array}$ & $6,56(\mathrm{~s})$ & $7,92-7,19(\mathrm{~m})$ \\
\hline
\end{tabular}

Figura 101 - Curva de Karplus. Em destaque está representado o anel de cinco membros formado pelo ligante cism $^{1-}$ e o rênio. Em razão de uma maior clareza dos ângulos $\phi$, existentes entre os $\mathrm{H}_{\mathrm{a}}, \mathrm{H}_{\mathrm{b}}$ e $\mathrm{H}_{\mathrm{c}}$, foi omitido o grupo $\left(-\mathrm{COOCH}_{3}\right)$, ligado ao carbono que contém o $\mathrm{H}_{\mathrm{a}}$.

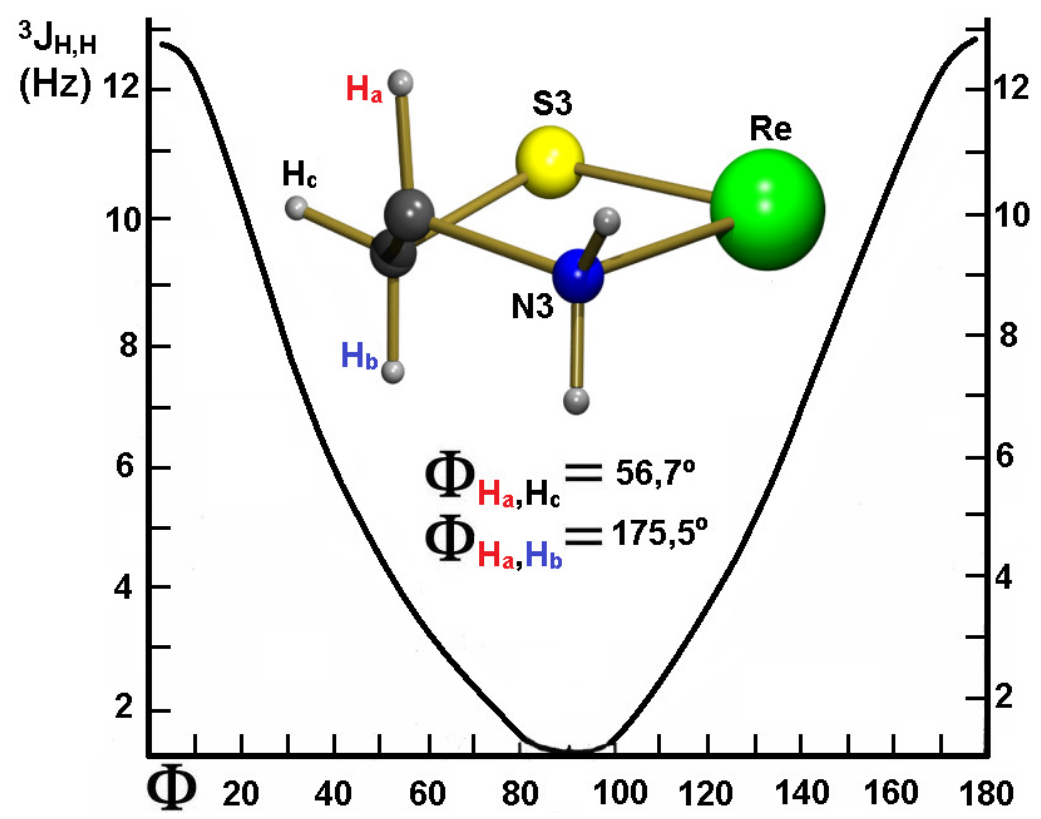


Figura 102 - Espectro de $\mathrm{RMN}^{1} \mathrm{H}$ do [ReO(bdtc)(cism)] (13) $\left(400 \mathrm{MHz}, \mathrm{CDCl}_{3}\right)$.

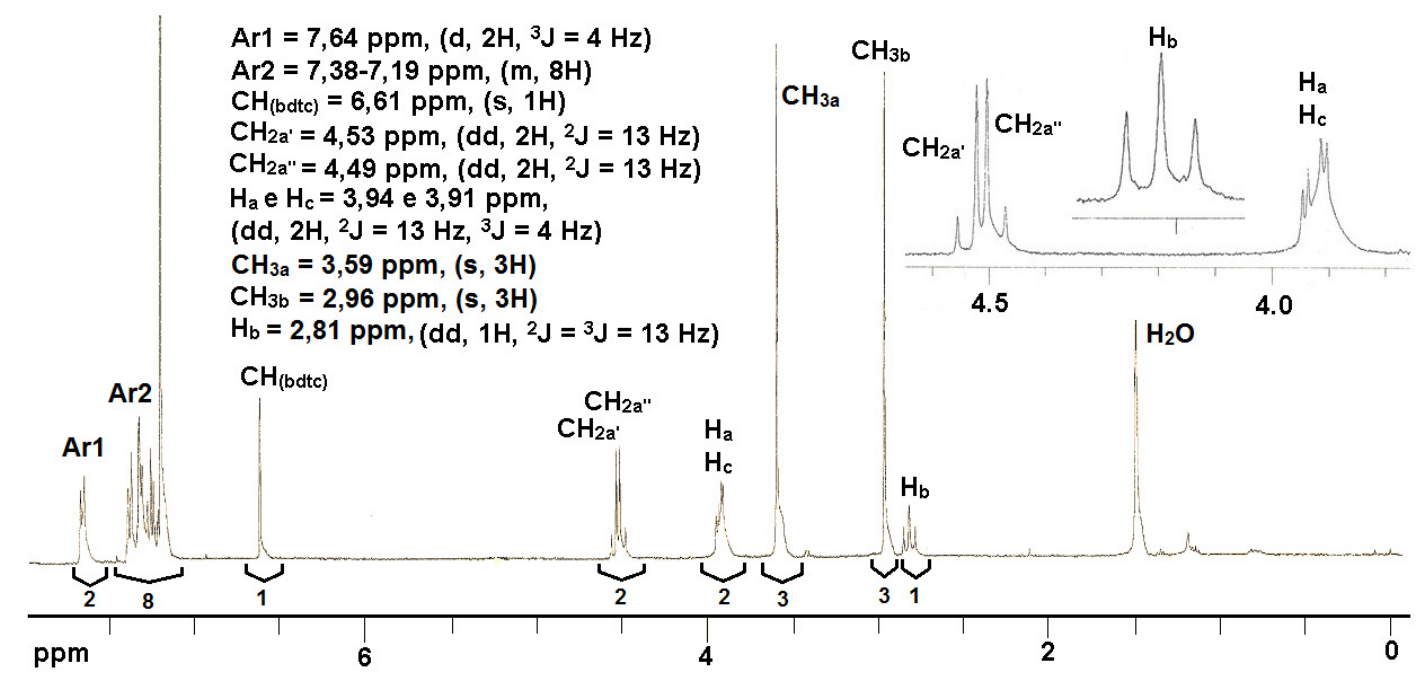

Tabela 28 - Dados de RMN ${ }^{1} \mathrm{H}(400 \mathrm{MHz})$ para 13 obtidos em $\mathrm{CDCl}_{3}$.

\begin{tabular}{|c|c|c|c|c|}
\hline & & 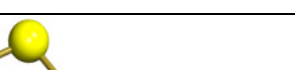 & $\mathrm{H}_{2 \mathrm{aO}}$ & $-\infty$ \\
\hline Complexo & $\mathrm{CH}_{3}$ & $\mathrm{CH}_{2}$ & $\mathrm{CH}$ & Aromáticos \\
\hline 13 & $\begin{array}{l}3,59\left(\mathrm{~s}, \mathrm{CH}_{3 \mathrm{a}}\right) \\
2,96\left(\mathrm{~s}, \mathrm{CH}_{3 \mathrm{~b}}\right)\end{array}$ & $\begin{array}{c}4,53\left(\mathrm{dd}, \mathrm{CH}_{2 \mathrm{a}^{\prime}}\right) \\
4,49\left(\mathrm{dd}, \mathrm{CH}_{2 \mathrm{a}^{\prime \prime}}\right) \\
2,81\left(\mathrm{dd}, \mathrm{H}_{\mathrm{b}}\right)\end{array}$ & $6,61(\mathrm{~s})$ & $7,64-7,19(\mathrm{~m})$ \\
\hline
\end{tabular}




\subsubsection{Difração de Raios X em Monocristal dos Complexos 12 e 13}

\section{Determinação das Estruturas Cristalinas e Moleculares}

Os compostos 12 e 13 cristalizaram-se sob a forma de blocos e placas vermelhas, respectivamente, conforme descrito no capítulo de sínteses.

Suas respectivas constantes de cela foram calculadas a partir de 14950 e 17593 reflexões, coletadas com uma larga variação do ângulo $2 \theta$.

O complexo 12 cristalizou-se no sistema cristalino monoclínico, grupo espacial $P 2_{1} / c$, significando que possui cela primitiva $(P)$, eixo de ordem 2 de rotação + translação em $b\left(2_{1}\right)$, centro de inversão, plano de reflexão + translação horizontal em $c$, com quatro moléculas em sua unidade assimétrica.

O produto 13, por sua vez, cristalizou-se no sistema cristalino ortorrômbico, grupo espacial $P 2_{1} 2_{1} 2_{1}$, o que indica cela primitiva $(P)$, eixos de ordem 2 de rotação + translação nas direções a $\left(2_{1}\right), b\left(2_{1}\right)$ e $c\left(2_{1}\right)$, com quatro moléculas em sua unidade assimétrica.

A correção de absorção multi-scan ${ }^{66}$ foi aplicada somente à solução da estrutura do complexo 13.

Métodos diretos foram utilizados nas soluções de ambas as estruturas. ${ }^{64}$

Todos os átomos foram refinados com deslocamento térmico anisotrópico, exceto os de hidrogênio, que foram calculados a partir de posições idealizadas. ${ }^{65}$

Outras informações relativas à determinação das estruturas são apresentadas na tabela 29. Dados referentes aos ângulos e distâncias de ligações selecionadas para estes compostos podem ser encontrados na tabela 30. 


\section{Discussão das Estruturas Cristalinas e Moleculares}

Todos os átomos de Re (V) centrais encontram-se hexacoordenados, com geometrias octaédricas distorcidas (Figuras 103 e 105, respectivamente), o que pode ser avaliado por meio do desvio do ângulo O1-Re-O2 em 24ํe em relação ao valor de $180^{\circ}$ que seria encontrado em um octaedro regular.

Nos complexos 12 e 13, o ditiocarbazato coordenou-se de modo tridentado, dianiônico, facial e $O, N, S$-doador. Seus ligantes, respectivamente, cisa ${ }^{1-}$ e cism ${ }^{1-}$, formaram quelatos $N, S$-doadores de cinco membros, não planares, o que explica o fato de cada hidrogênio dos grupos $\mathrm{CH}_{2}$ serem magneticamente distintos no espectro de RMN ${ }^{1} \mathrm{H}^{83}$

Foram encontrados comprimentos de ligação $R e=O$ para o composto 12 de $168,6(7)$ e de 169,3(5) pm para o produto 13, ambos compatíveis com ligações duplas. . $^{8,61,79}$

Podem ser visualizadas na rede cristalina do produto 12 apenas ligações de hidrogênio intermoleculares do tipo N3-H'..SS3b formando uma cadeia infinita (Figura 104). Suas moléculas foram empilhadas ao longo da direção [010], paralela ao eixo cristalográfico.

$\mathrm{Na}$ rede cristalina do complexo 13, são observadas ligações de hidrogênio intramoleculares fracas do tipo $\mathrm{N} 3-\mathrm{H}^{\prime \prime} \cdots \mathrm{O} 3$, desfavorecidas devido ao ângulo fechado de $102^{\circ}$, e ligações intermoleculares do tipo N3-H' $\cdots$ S3b, que por sua vez interligam as moléculas formando uma cadeia infinita (Figura 106). Estes grupos estão empilhados ao logo da direção [001], paralela ao eixo cristalográfico. 
Figura 103 - Estrutura molecular do complexo 12. Para facilitar a visualização, os átomos de hidrogênio dos ligantes foram omitidos.

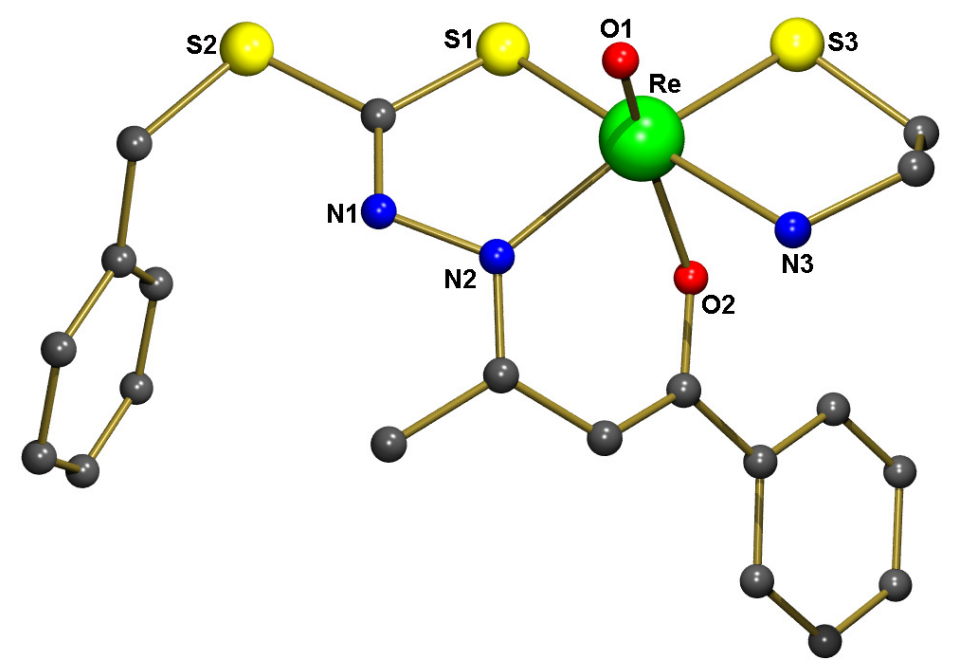

Figura 104 - Ligações de hidrogênio intermoleculares observadas na rede cristalina do complexo 12. Os átomos de hidrogênio foram omitidos para maior clareza, exceto aqueles que participam das ligações de hidrogênio, indicadas por linhas tracejadas. $\mathrm{N} 3-\mathrm{H}^{\prime}=90 \mathrm{pm} ; ;$ H' $\cdots \mathrm{S} 3 \mathrm{~b}=262 \mathrm{pm}, \mathrm{N} 3-\mathrm{H}^{\prime} \cdots \mathrm{S} 3 \mathrm{~b}=149^{\circ} ; \mathrm{N} 3 \cdots \mathrm{S} 3 \mathrm{~b}=342,3(9) \mathrm{pm}$. Operador de simetria utilizado para gerar o átomo equivalente de S3b: $-x+1, y-1 / 2$, $-z+1 / 2$.

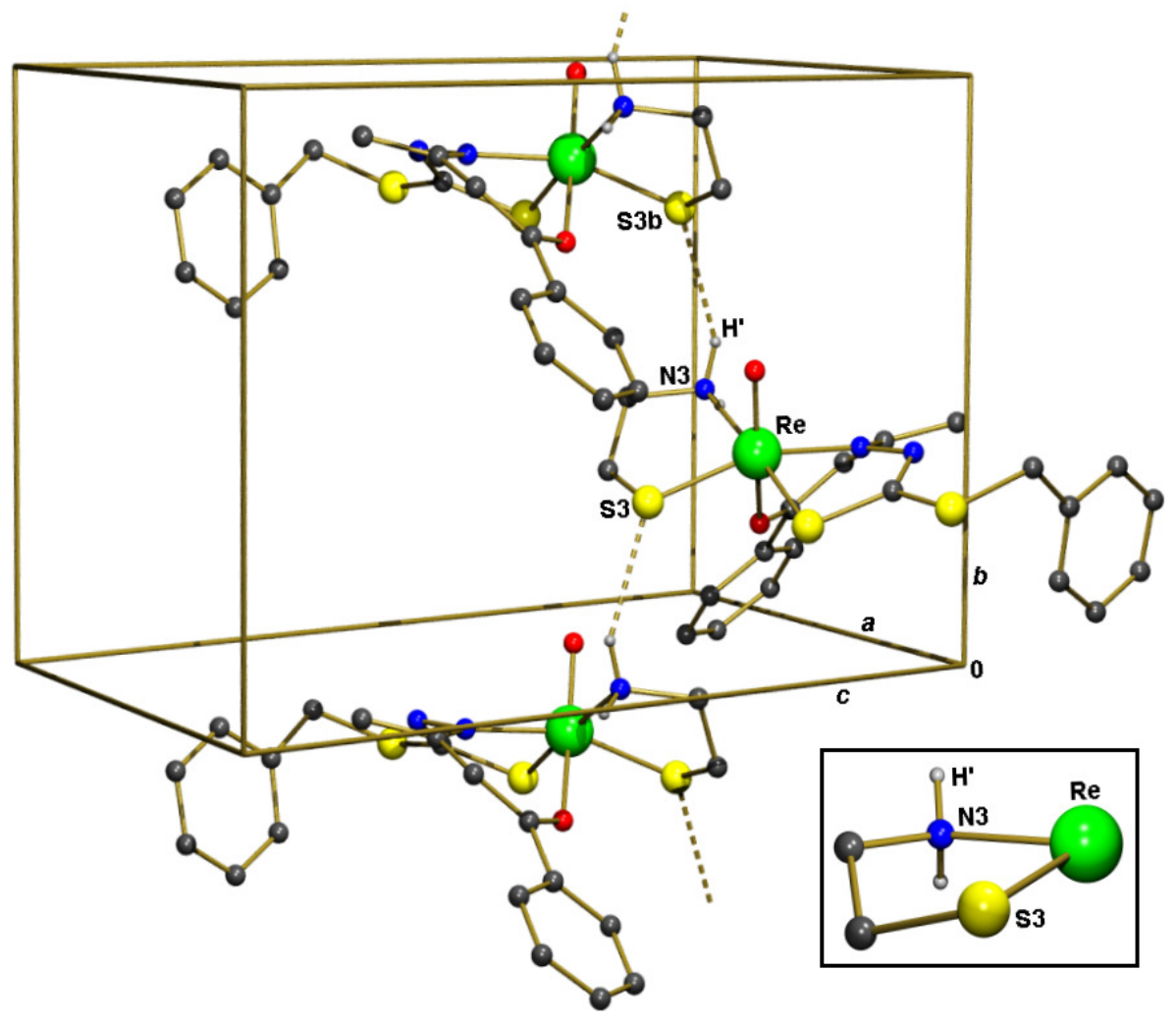


Figura 105 - Estrutura molecular do complexo 13. Para facilitar a visualização, os átomos de hidrogênio dos ligantes foram omitidos.

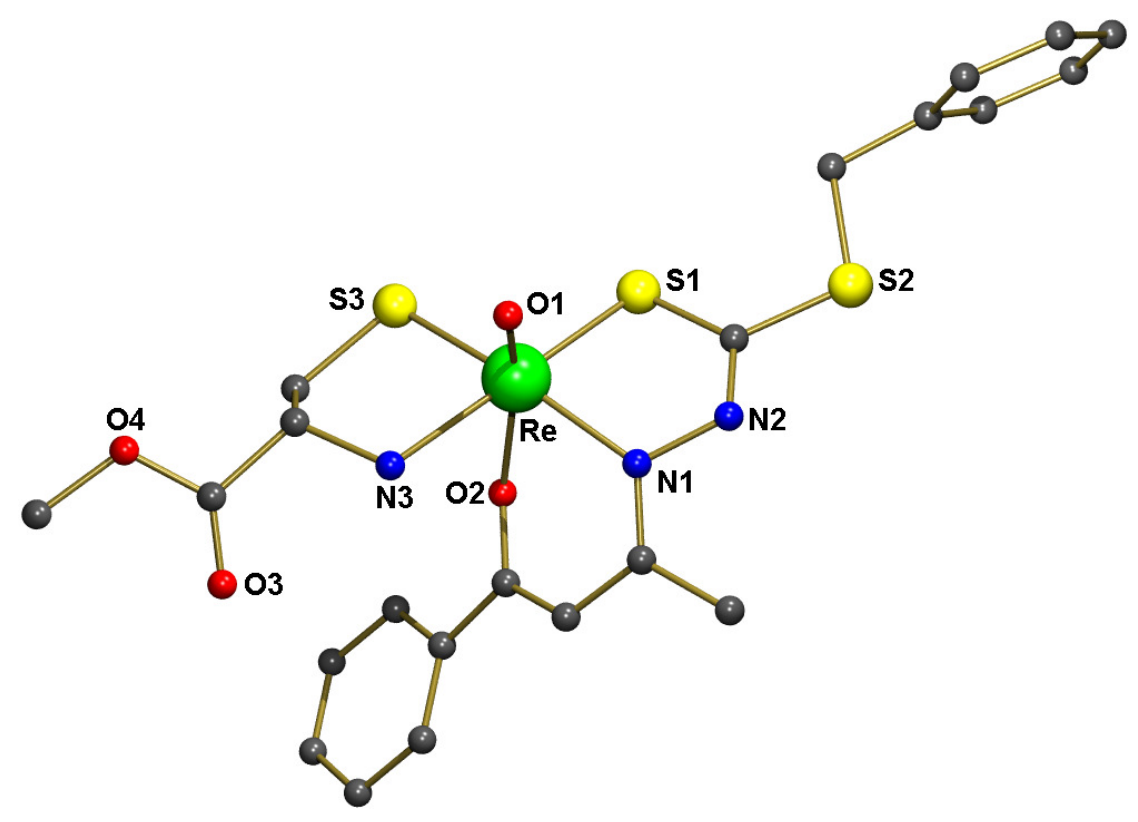


Figura 106 - Ligações de hidrogênio intermoleculares e intramoleculares observadas na rede cristalina do complexo 13. Os átomos de hidrogênio, exceto aqueles que participam das ligações de hidrogênio, indicadas por linhas tracejadas, foram omitidos para maior clareza. N3-H' $=90 \mathrm{pm} ; \mathrm{H}^{\prime} \cdots \mathrm{S} 3 \mathrm{~b}=246 \mathrm{pm}, \mathrm{N} 3-\mathrm{H}^{\prime} \cdots \mathrm{S} 3 \mathrm{~b}=153^{\circ}$; $\mathrm{N} 3 \cdots \mathrm{S} 3 \mathrm{~b}=328,4(5) \mathrm{pm}$. N3-H" $=90 \mathrm{pm} ; \mathrm{H}^{\prime} \cdots \mathrm{O} 3=244 \mathrm{pm}, \mathrm{N} 3-\mathrm{H}^{\prime} \cdots \mathrm{O} 3=102^{\circ}$; $\mathrm{N} 3 \cdots \mathrm{O} 3=277,6(8) \mathrm{pm}$. Operador de simetria utilizado para gerar o átomo equivalente de S3b: $x, y, z-1$.

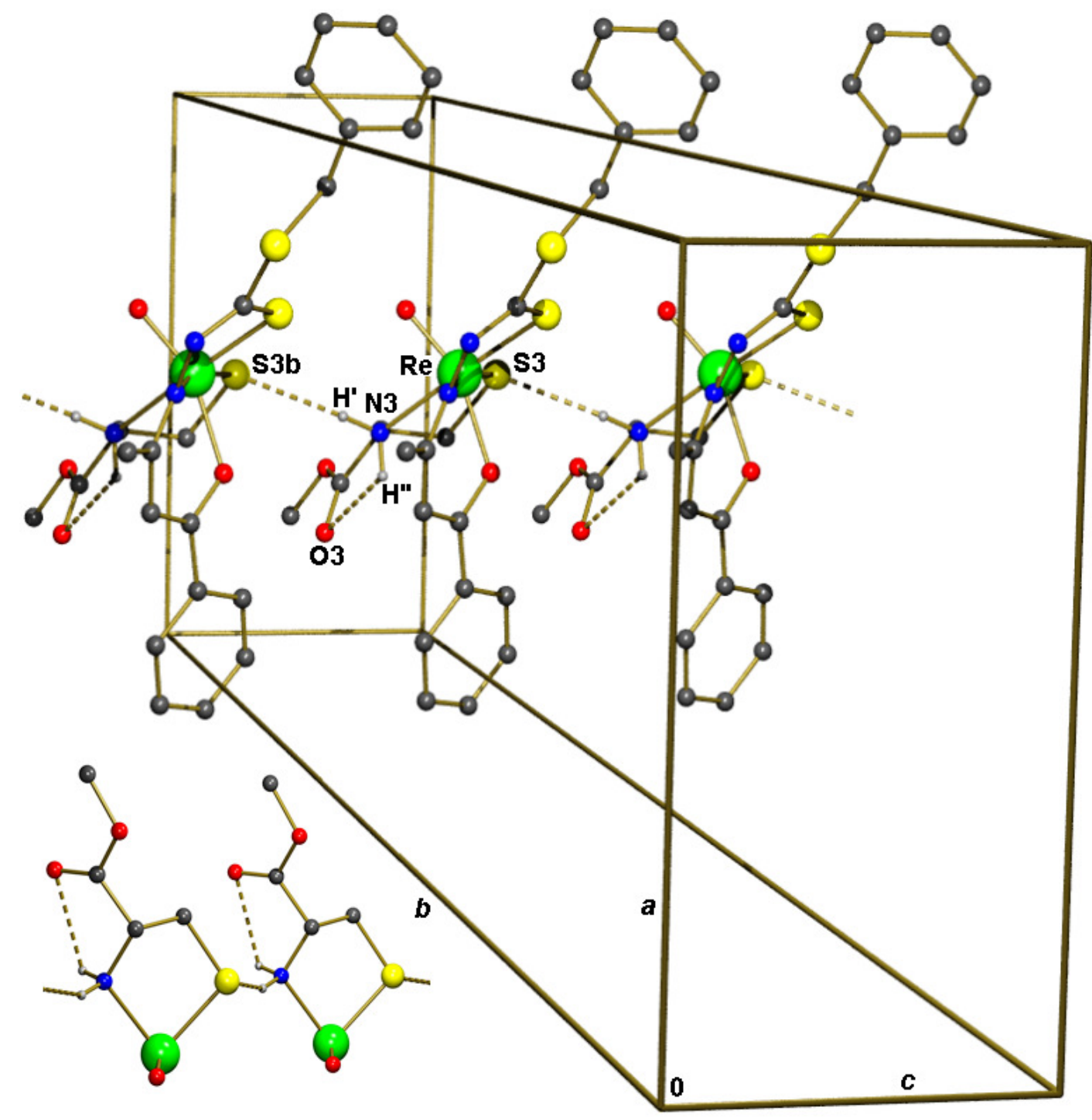


Tabela 29 - Dados cristalográficos de difração de raios $\mathrm{X}$ e resultados dos refinamentos das estruturas dos complexos 12 e 13.

\begin{tabular}{|c|c|c|}
\hline Complexo & 12 & 13 \\
\hline Fórmula molecular & $\mathrm{C}_{20} \mathrm{H}_{22} \mathrm{~N}_{3} \mathrm{O}_{2} \mathrm{ReS}_{3}$ & $\mathrm{C}_{22} \mathrm{H}_{24} \mathrm{~N}_{3} \mathrm{O}_{4} \mathrm{ReS}_{3}$ \\
\hline Massa Molar g. $\mathrm{mol}^{-1}$ & 618,79 & 676,82 \\
\hline Temperatura $(\mathrm{K})$ & $200(2)$ & $200(2)$ \\
\hline Comprimento da radiação (pm) & 71,073 & 71,073 \\
\hline Sistema Cristalino & Monoclínico & Ortorrômbico \\
\hline Grupo Espacial & $\mathrm{P} 2_{1} / \mathrm{c}$ & $\mathrm{P} 2_{1} 2_{1} 2_{1}$ \\
\hline \multicolumn{3}{|l|}{ Parâmetros da cela unitária } \\
\hline$a(\mathrm{pm})$ & $1218,2(3)$ & $1101,37(3)$ \\
\hline$b(\mathrm{pm})$ & $1050,7(2)$ & $4102,2(1)$ \\
\hline$c(\mathrm{pm})$ & $1784,4(4)$ & $570,76(1)$ \\
\hline$\alpha\left(\frac{0}{)}\right)$ & 90 & 90 \\
\hline$\beta(\stackrel{\circ}{)}$ & $109,346(17)$ & 90 \\
\hline$\gamma(\stackrel{0}{)}$ & 90 & 90 \\
\hline Volume $\left(\mathrm{nm}^{3}\right)$ & $2,1549(8)$ & $2,5787(1)$ \\
\hline Z & 4 & 4 \\
\hline Coeficiente de absorção $\left(\mathrm{mm}^{-1}\right)$ & 5,952 & 4,987 \\
\hline Tamanho do cristal $\left(\mathrm{mm}^{3}\right)$ & $0,210 \times 0,190 \times 0,180$ & $0,55 \times 0,10 \times 0,05$ \\
\hline Forma e cor do cristal & Prismas vermelhos & Placas vermelhas \\
\hline Método / variação de $\theta\left(^{\circ}\right)$ & 1,77 até 29,26 & 1,91 até 30,55 \\
\hline Índices $(\mathrm{h}, \mathrm{k}, \mathrm{l})$ & $\begin{array}{l}-16 \rightarrow \mathrm{h} \rightarrow 16, \\
-13 \rightarrow \mathrm{k} \rightarrow 14, \\
-24 \rightarrow \mid \rightarrow 20\end{array}$ & $\begin{array}{c}-7 \rightarrow h \rightarrow 15, \\
-56 \rightarrow k \rightarrow 58, \\
-8 \rightarrow \mid \rightarrow 7\end{array}$ \\
\hline Reflexões coletadas & 14950 & 17593 \\
\hline Reflexões independentes / $R_{\text {int }}$ & $5789 / 0,1243$ & $7730 / 0,0390$ \\
\hline Correção de Absorção & Nenhuma & Multi-scan ${ }^{66}$ \\
\hline Transmissão min. / max. & ----- & $0,580 / 0,7886$ \\
\hline Refinamento da estrutura & $\begin{array}{l}\text { Matriz completa dos } \\
\text { mínimos quadrados }\end{array}$ & $\begin{array}{l}\text { Matriz completa dos } \\
\text { mínimos quadrados }\end{array}$ \\
\hline Tratamento dos hidrogênios & Calculados & Calculados \\
\hline Fatores $R$ finais $[I>2 \sigma(I)]$ & $\begin{array}{r}R 1=0,0495 \\
w R 2=0,1041\end{array}$ & $\begin{array}{r}R 1=0,0438 \\
w R 2=0,0766\end{array}$ \\
\hline "Goodness-of-fit" sobre $\mathrm{F}^{2}$ & 0,833 & 1,076 \\
\hline Programas usados & $\begin{array}{l}\text { SHELXS97 } \\
\text { SHELXL }^{65}\end{array}$ & $\begin{array}{l}\text { SHELXS97 } \\
\text { SHELXL }^{65}\end{array}$ \\
\hline
\end{tabular}


Tabela 30 - Principais distâncias (pm) e ângulos $\left(^{\circ}\right)$ de ligação encontrados nos complexos 12 e 13. O segundo valor mostrado para o produto 12 refere-se aos comprimentos e ângulos de ligação determinados por meio da DFT.

\begin{tabular}{|ccc|}
\hline Distâncias & $\mathbf{1 2}$ (DRX / DFT) & $\mathbf{1 3}$ \\
\hline $\operatorname{Re}-\mathrm{O}(1)$ & $168,6(7) / 171,8$ & $169,3(5)$ \\
\hline $\operatorname{Re}-\mathrm{O}(2)$ & $208,7(6) / 208,8$ & $207,0(4)$ \\
\hline $\operatorname{Re}-\mathrm{N}(1)$ & $209,3(7) / 210,9$ & $208,0(5)$ \\
\hline $\operatorname{Re}-\mathrm{N}(3)$ & $225,0(7) / 227,9$ & $225,3(5)$ \\
\hline $\operatorname{Re}-\mathrm{S}(1)$ & $230,7(2) / 241,5$ & $231,7(2)$ \\
\hline $\operatorname{Re}-\mathrm{S}(3)$ & $231,0(3) / 240,1$ & $232,1(1)$ \\
\hline Ângulos & & \\
\hline $\mathrm{O}(1)-\operatorname{Re}-\mathrm{O}(2)$ & $156,4(3) / 155,0$ & $156,3(2)$ \\
\hline $\mathrm{O}(1)-\operatorname{Re}-\mathrm{N}(1)$ & $95,7(3) / 97,8$ & $96,1(2)$ \\
\hline $\mathrm{O}(1)-\operatorname{Re}-\mathrm{N}(3)$ & $82,5(3) / 80,6$ & $82,4(2)$ \\
\hline $\mathrm{O}(1)-\operatorname{Re}-\mathrm{S}(1)$ & $99,7(3) / 98,7$ & $100,0(2)$ \\
\hline $\mathrm{O}(1)-\operatorname{Re}-\mathrm{S}(3)$ & $104,8(3) / 103,0$ & $101,3(2)$ \\
\hline $\mathrm{O}(2)-\operatorname{Re}-\mathrm{N}(1)$ & $78,5(3) / 78,3$ & $78,2(2)$ \\
\hline $\mathrm{O}(2)-\operatorname{Re}-\mathrm{N}(3)$ & $76,6(3) / 76,2$ & $76,5(2)$ \\
\hline $\mathrm{O}(2)-\operatorname{Re}-\mathrm{S}(1)$ & $101,7(2) / 104,8$ & $101,4(1)$ \\
\hline $\mathrm{O}(2)-\operatorname{Re}-\mathrm{S}(3)$ & $83,5(2) / 84,1$ & $86,7(1)$ \\
\hline $\mathrm{N}(1)-\operatorname{Re}-\mathrm{N}(3)$ & $102,7(3) / 102,0$ & $101,7(2)$ \\
\hline $\mathrm{N}(1)-\operatorname{Re}-\mathrm{S}(1)$ & $79,5(2) / 79,9$ & $79,6(2)$ \\
\hline $\mathrm{N}(1)-\operatorname{Re}-\mathrm{S}(3)$ & $159,3(3) / 159,0$ & $162,5(1)$ \\
\hline $\mathrm{N}(3)-\operatorname{Re}-\mathrm{S}(1)$ & $176,8(2) / 178,1$ & $177,2(1)$ \\
\hline $\mathrm{N}(3)-\operatorname{Re}-\mathrm{S}(3)$ & $82,9(2) / 84,7$ & $83,2(1)$ \\
\hline $\mathrm{S}(1)-\operatorname{Re}-\mathrm{S}(3)$ & $94,22(9) / 93,7$ & $94,9(5)$ \\
\hline & & \\
\hline
\end{tabular}




\subsubsection{Cálculos Computacionais Envolvendo o Complexo 12}

Os cálculos teóricos foram realizados utilizando o pacote de Programas Gaussian $03{ }^{68}$ As geometrias de 12 assim como a de seus demais possíveis isômeros foram otimizadas em B3LYP ${ }^{84,85} /$ LanL2DZ $^{85}$ e caracterizadas como pontos mínimos de energia por meio de cálculos de frequências vibracionais. As estruturas obtidas foram submetidas a cálculos de deslocamento químico utilizando o método CSGT. ${ }^{86}$ Os deslocamentos químicos foram então referenciados ao TMS (para este cálculo utilizou-se os métodos combinados Hartree-Fock ${ }^{86} / \mathrm{GIAO}^{86}$ ou B3LYP / GIAO, sigla que indica o uso do funcional de troca-correlação de Becke no qual está incluído o funcional de correlação desenvolvido por Lee, Yang e Parr, combinados, respectivamente, com os conjuntos de funções de base $6-31 \mathrm{G}(\mathrm{d})$, $6-311+G(2 d, p))$.

O processo de otimização utilizando-se o programa Gaussian, na plataforma Windows, é facilitado pelo uso de uma interface gráfica chamada GaussView, que permite desenhar, átomo por átomo, a molécula orgânica, o complexo ou mesmo o íon desejado.

Os valores de energia calculados demonstram que o composto 12 é o de menor energia e, portanto, o mais estável. A diferença de energia entre 12 e seus demais possíveis isômeros está entre 4,6 e 32,6 KJ / mol (Figura 107).

O diagrama dos orbitais de fronteira (Figura 108) demonstra que os elétrons predominantemente localizados no HOMO se encontram ao redor do centro metálico. A ocupação do LUMO, por sua vez, representa uma deslocalização de elétrons, através de um sistema $\pi$ conjugado existente no ditiocarbazato.

Os dados experimentais RMN ${ }^{1} \mathrm{H}$, IV e DRX foram comparados com os valores calculados pelo programa Gaussian. A concordância entre os valores teóricos e experimentais demonstram a utilidade do programa Gaussian na previsão não apenas da geometria mais estável, mas também o coloca como uma ferramenta válida no auxílio para a elucidação das frequências vibracionais, propriedades espectroscópicas e termodinâmicas. 
Figura 107 - Forma otimizada por cálculo DFT, baseada nas distâncias e ângulos determinados por Difração de Raios $\mathrm{X}$ em monocristal (12). Cada valor de $\Delta$ representa, em módulo, a diferença de energia entre o composto 12 e seus possíveis isômeros $12 a, 12 b$ e $12 c$.

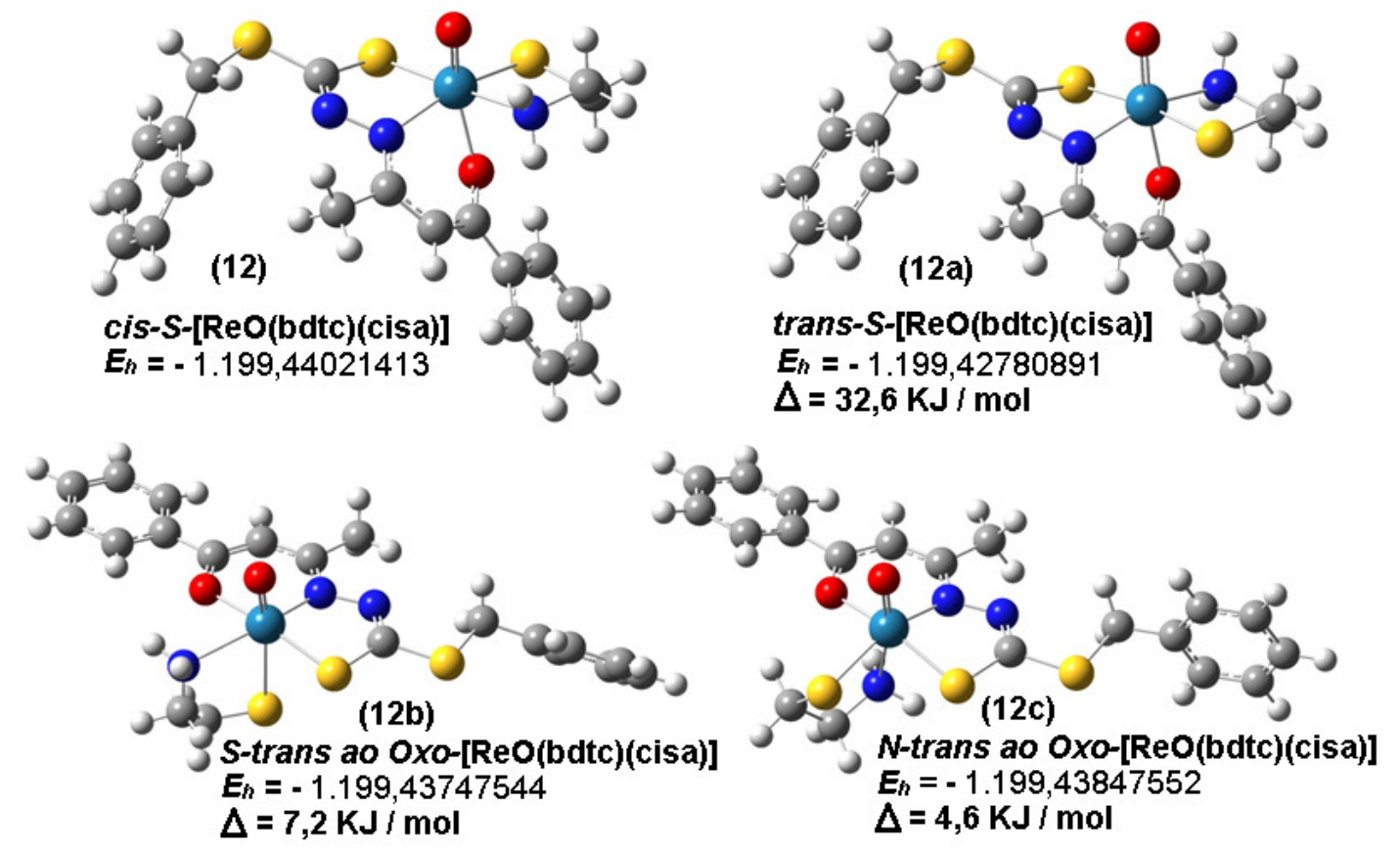

Figura 108 - Orbitais de fronteira HOMO e LUMO calculados para o complexo 12. As formas (a) representam uma visão lateral, onde o eixo formado pelos átomos O1-ReO2 está paralelo à folha de papel. As formas (b) representam uma visão através do eixo O1-Re-O2, perpendicular à folha de papel.
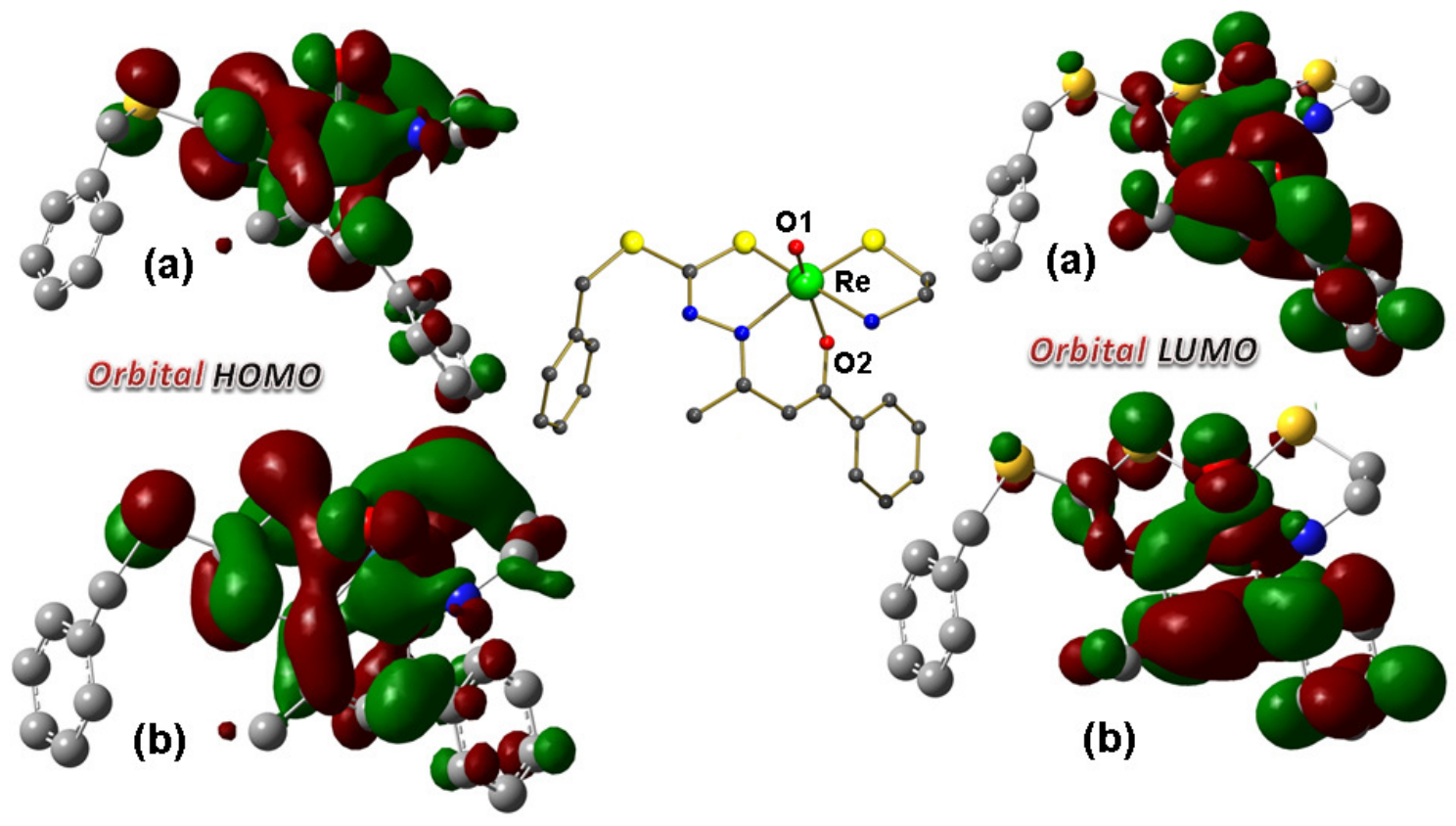
Tabela 31 - Comparação entre os deslocamentos químicos obtidos experimentalmente e calculados (exp. / calc.).

\begin{tabular}{|ccccc|}
\hline Complexo & $\mathrm{CH}_{3}$ & $\mathrm{CH}_{2}$ & $\mathbf{C H}$ & Aromáticos \\
\hline & & $4,50 / 4,76^{\mathrm{a}}$ & & \\
\multirow{4}{*}{$\mathbf{1 2}$} & $2,94 / 2,98^{\mathrm{a}, *}$ & $3,13 / 4,37$ & & \\
& & $3,71 / 4,12$ & $6,56 / 5,00^{\mathrm{a}}$ & $7,92-7,19 / 7,27-6,02^{\mathrm{a}}$ \\
& & $3,14 / 3,41$ & & \\
& & & \\
& & & & \\
& & &
\end{tabular}

$\left(^{*}\right)$ Este símbolo indica que apenas um, entre os três dos valores de deslocamentos químicos encontrados, está sendo comparado com o valor experimental. Os outros valores são 4,20 e 4,34 ppm. $\left({ }^{\mathrm{a}}\right)$ Este valor foi referenciado ao TMS HF/6-31G(d) GIAO. Os demais foram referenciados ao TMS B3LYP/6-311+G(2d,p) GIAO.

Tabela 32 - Comparação entre os dados de IV obtidos experimentalmente e calculados para o complexo 12.

\begin{tabular}{|c|c|c|c|c|}
\hline \multirow{2}{*}{ Método } & \multicolumn{4}{|c|}{ Modos Vibracionais } \\
\hline & $\mathrm{v}\left(\mathrm{NH}_{2}\right)$ & $v(C=N)$ & $v(S C S)$ & $v(\operatorname{Re}=0)$ \\
\hline Experimental & $\begin{array}{l}3321 \\
3263\end{array}$ & 1581 & 984 & 953 \\
\hline Teórico & $\begin{array}{l}3574 \\
3474\end{array}$ & 1582 & 952 & 974 \\
\hline
\end{tabular}




\subsection{Complexos [ReO(deba)(dmhp)] (14) e [ReO(deba)(bmhp)] (15)}

Os complexos 14 e 15, foram obtidos através de reações com estequiometria 1:1:1, respectivamente entre $\left(\mathrm{NBu}_{4}\right)[\mathrm{ReOCl} 4], \mathbf{H}_{2}$ deba, a deseja piridinona, Hdmhp (14) ou Hbmhp (15), com posterior adição de três gotas de $\mathrm{Et}_{3} \mathrm{~N}$, sob agitação. As reações foram conduzidas em etapa única, sem a necessidade de isolar o complexo intermediário, $[\mathrm{ReO}($ deba $) \mathrm{Cl}] .{ }^{56}$ Este último composto apresenta geometria piramidal de base quadrada onde um ligante cloro ocupa uma posição na base da pirâmide. A sexta posição de coordenação no complexo intermediário, posição trans ao grupo oxo, está vazia e com a saída do íon cloreto, facilitada pela adição da base, ocorreu à coordenação dos ânions das piridinonas $\mathbf{d m h}^{1-}$ e $\mathbf{b m h}^{1-}$, originando, respectivamente, os produtos 14 e 15.

As estruturas dos complexos foram propostas com base na análise elementar, nos espectros de massas com ionização eletrospray (MS-ESI), nos dados espectroscópicos obtidos através das técnicas de infravermelho e ressonância magnética nuclear de hidrogênio, e confirmadas com as estruturas determinadas a partir dos dados de difração de raios $\mathrm{X}$ em monocristal.

\subsubsection{Espectroscopia de Absorção na Região do Infravermelho}

Assim como para os demais compostos apresentados neste trabalho, os dados de espectroscopia de absorção na região do infravermelho (Tabela 33) ofereceram informações que ratificam a coordenação de todos os agentes complexantes utilizados aos centros metálicos de rênio.

Os espectros de IV dos complexos 14 e 15 (Figuras 113 e 114, respectivamente) demonstram um intenso deslocamento batocrômico relacionado à banda $\mathrm{C}=\mathrm{N}$, inicialmente em $1621 \mathrm{~cm}^{-1}$, no $\mathbf{H}_{2}$ deba não coordenado, para, respectivamente, 1516 e $1528 \mathrm{~cm}^{-1}$ nos produtos obtidos. Isso indica a formação de quelatos com um elevado grau de deslocalização de elétrons $\pi$ em seus anéis.

A ausência de absorções nas regiões em torno de 3424, 3147 e $3060 \mathrm{~cm}^{-1}$, onde os dois primeiros valores fazem referência ao modo vibracional $v(\mathrm{O}-\mathrm{H})$ e o último ao $v(\mathrm{~N}-\mathrm{H})$, indicam a dupla desprotonação do $\mathbf{H}_{\mathbf{2}} \mathbf{d e b a}$ (Figura 109) e a perda de um único hidrogênio pelo Hdmhp (Figura 110) durante a formação dos 
complexos. A visualização da banda referente ao $v(\mathrm{O}-\mathrm{H})$ do Hbmhp livre não foi possível uma vez que seu pico de absorção está situado dentro de uma intensa janela de absorção (Figura 111).

De modo análogo ao que ocorreu nos complexos 1 e 2, a coordenação dos ânions dmhp ${ }^{1-}$ e bmhp ${ }^{1-}$, originando os produtos 14 e 15, também foi confirmada por meio da observação de bandas em 1605 e $1603 \mathrm{~cm}^{-1}$, atribuídas aos estiramentos assimétricos $v(\mathrm{C}=\mathrm{O})$ de seus ligantes piridinonatos (Figuras 110 e 111, respectivamente). Essa diminuição do número de onda da banda originalmente em $1631 \mathrm{~cm}^{-1}$, atribuída ao $v(\mathrm{C}=\mathrm{O})$ de ambas piridinonas Hdmhp e Hbmhp, para valores entre 1605 e $1603 \mathrm{~cm}^{-1}$ nos complexos isolados, ocorre devido à redução da densidade eletrônica entre e carbono e o oxigênio da carbonila, em função da nova ligação formada com o centro metálico, reduzindo o caráter de dupla ligação $\mathrm{C}=0 .{ }^{71}$

As absorções das bandas $\mathrm{Re}=\mathrm{O}$, nos compostos 14 e 15, podem ser visualizadas, respectivamente, em 967 e $960 \mathrm{~cm}^{-1}$ e estão de acordo com valores encontrados na literatura para este modo vibracional. ${ }^{8,61,79}$

Figura 109 - Espectro do $\mathbf{H}_{2}$ deba.

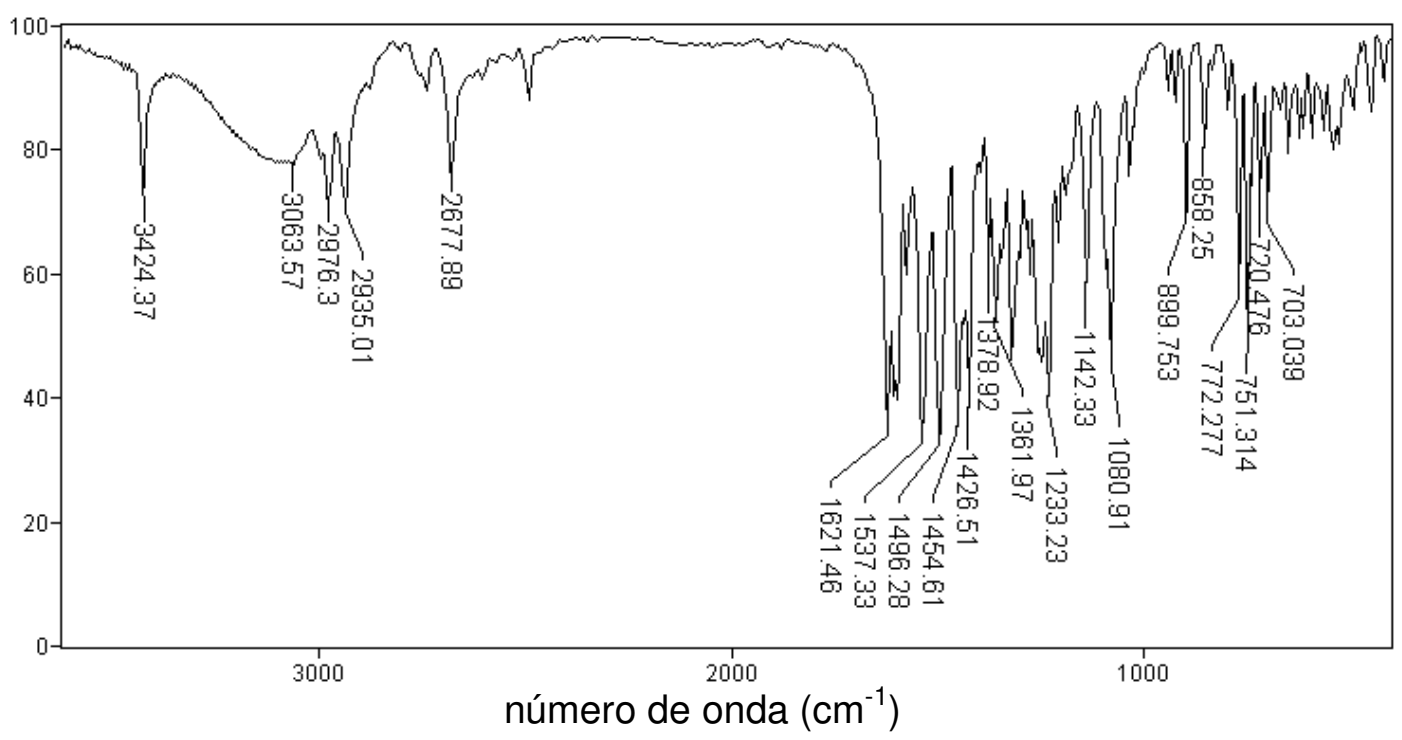


Figura 110 - Espectro do Hdmhp.

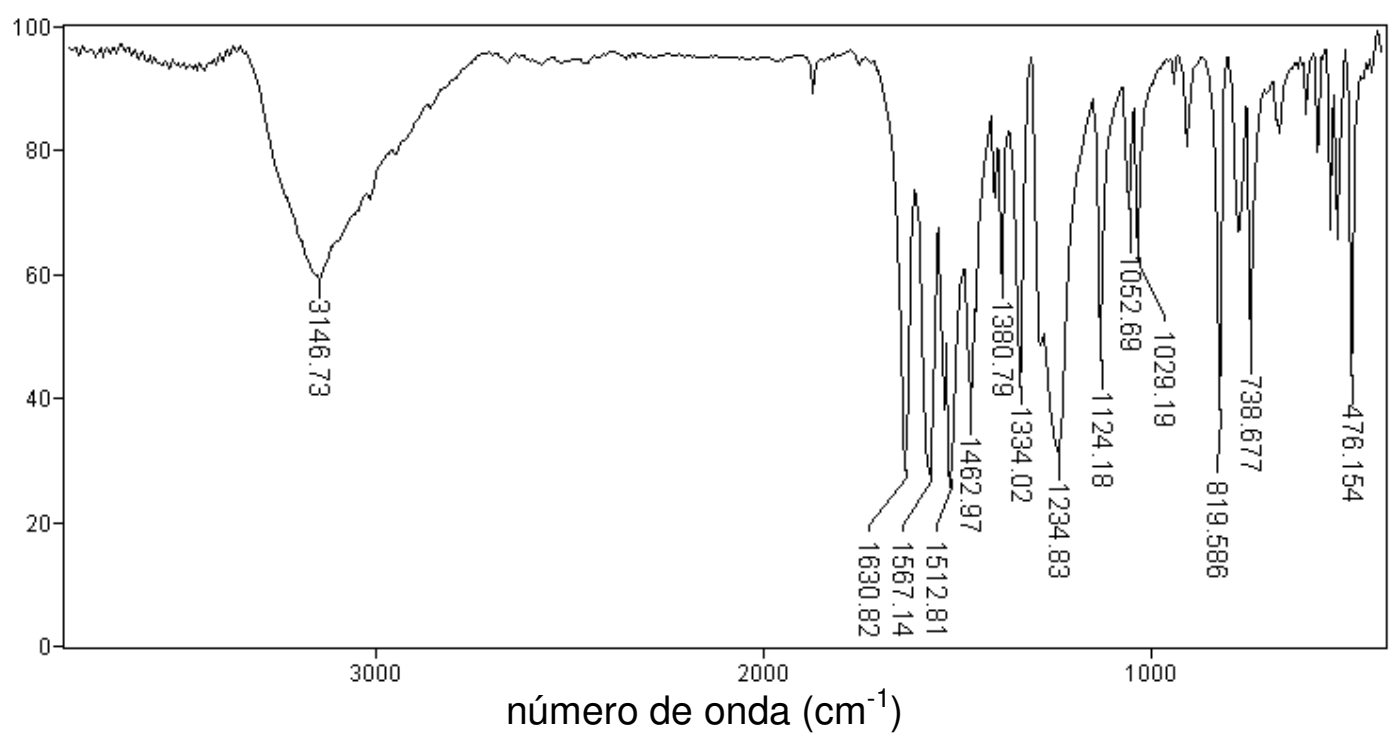

Figura 111 - Espectro do Hbmhp.

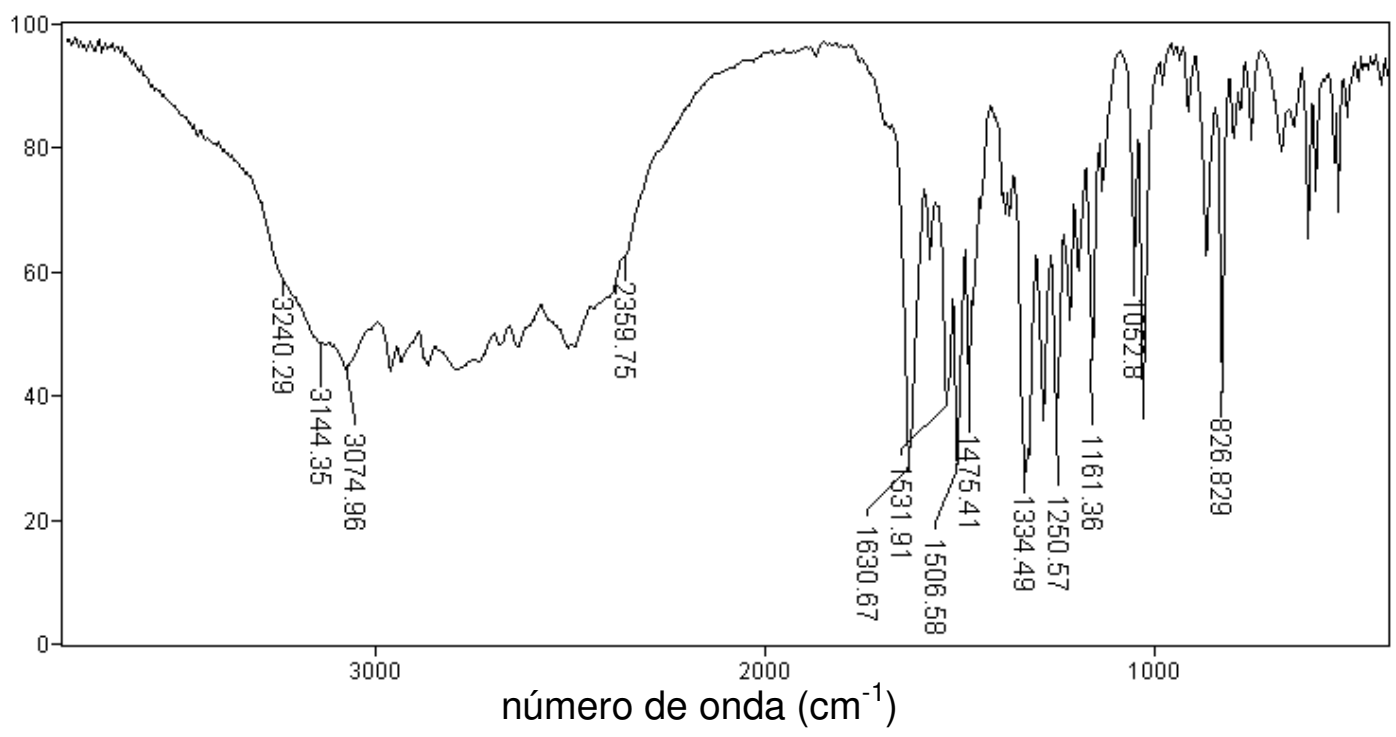


Figura 112 - Espectro do $\left(\mathrm{NBu}_{4}\right)\left[\mathrm{ReOCl}_{4}\right]$.

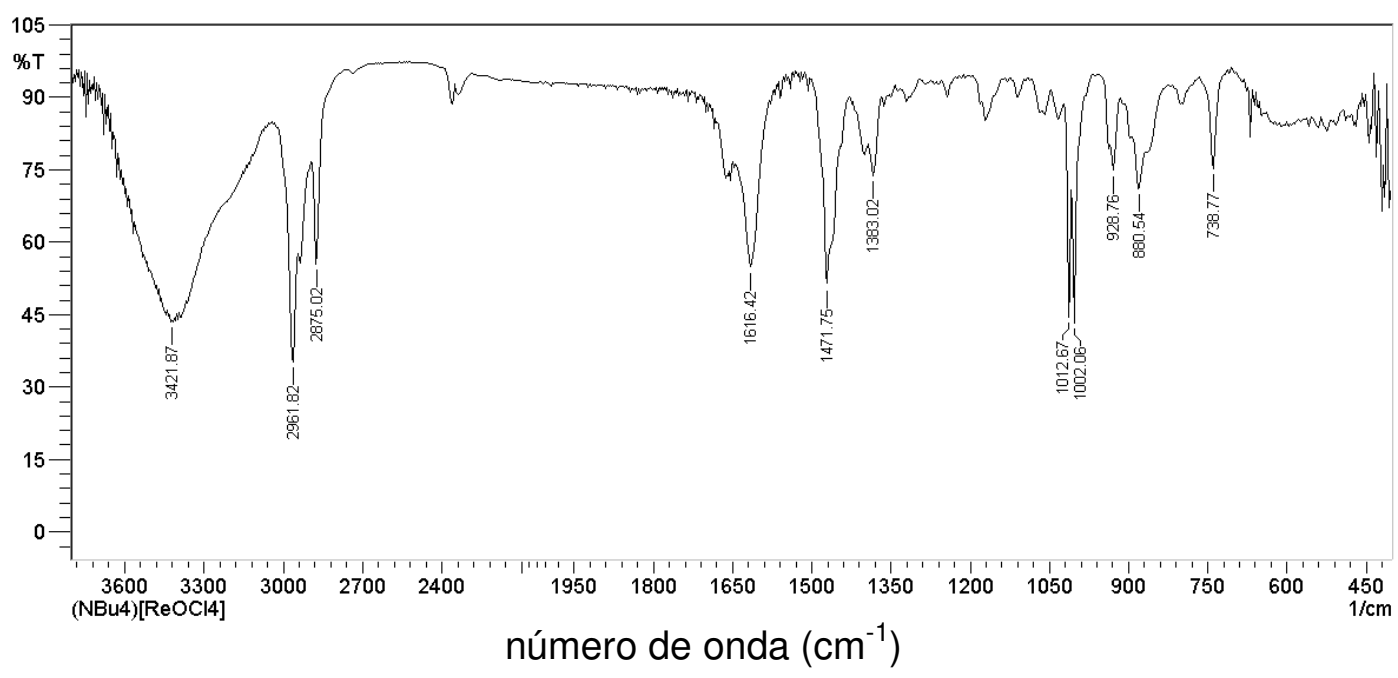

Figura 113 - Espectro do [ReO(deba)(dmhp)] (14).

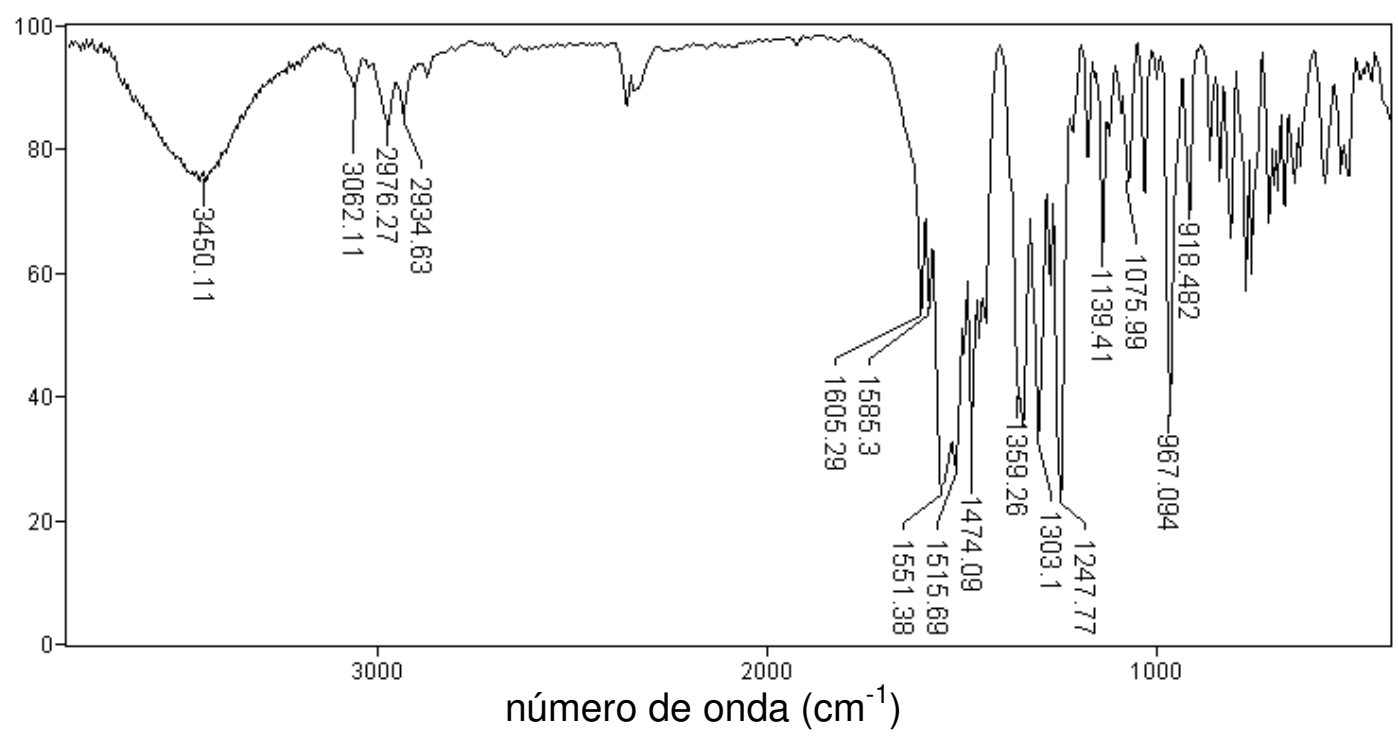


Figura 114 - Espectro do [ReO(deba)(bmhp)] (15).

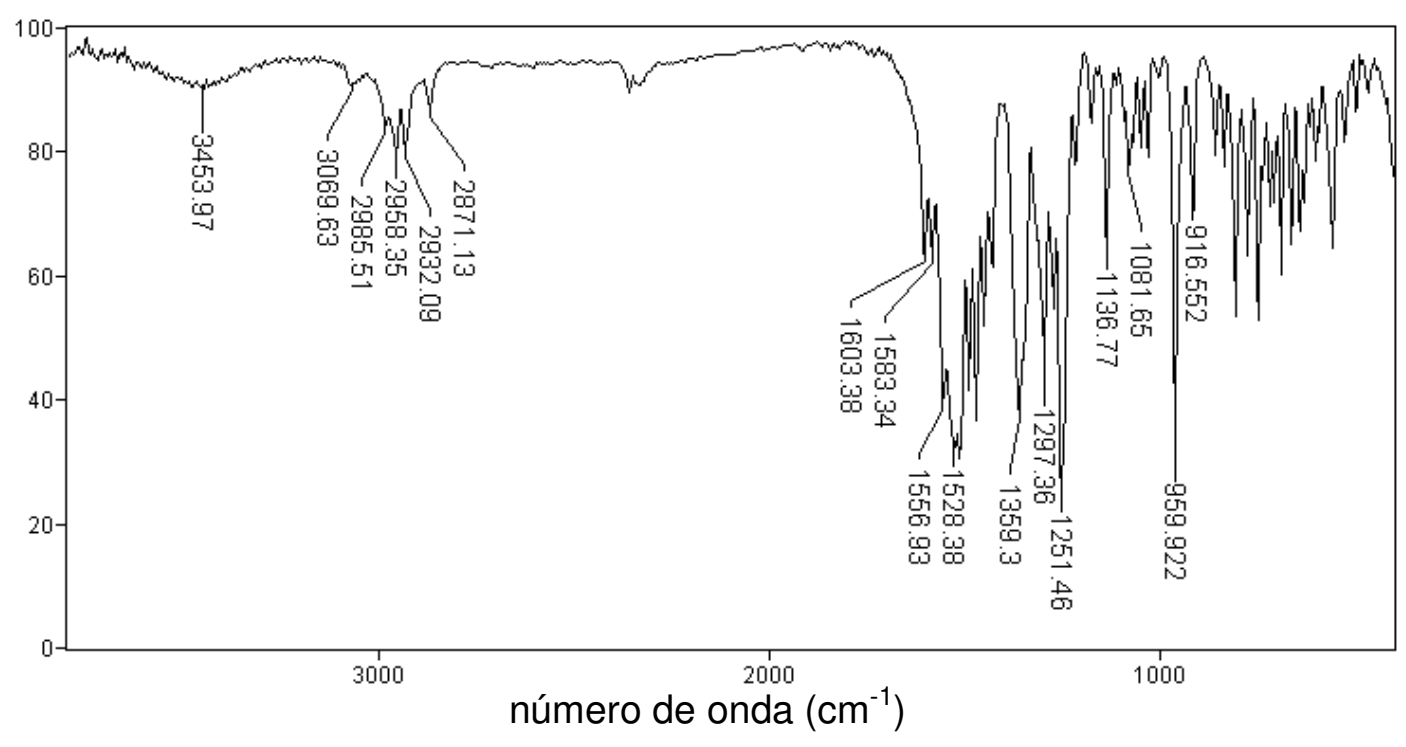

Tabela 33 - Principais bandas $\left(\mathrm{cm}^{-1}\right)$ atribuídas aos modos vibracionais dos complexos 14 e 15 e dos agentes complexantes $\mathrm{H}_{2}$ deba, Hdmhp e Hbmhp.

\begin{tabular}{|c|c|c|c|c|c|}
\hline \multirow{2}{*}{$\begin{array}{l}\text { Complexos, } \\
\text { Precursores e } \\
\text { Ligantes }\end{array}$} & \multicolumn{5}{|c|}{ Modos Vibracionais } \\
\hline & $v(\mathrm{O}-\mathrm{H})$ & $v(\mathrm{~N}-\mathrm{H})$ & $v(C=0)$ & $v(C=N)$ & $v(\operatorname{Re}=0)$ \\
\hline 14 & ----- & ----- & 1603 & 1516 & 967 \\
\hline 15 & $\begin{array}{l}---- \\
\end{array}$ & $\begin{array}{ll}---- \\
\end{array}$ & 1605 & 1528 & 960 \\
\hline $\mathrm{H}_{2}$ deba & 3424 & 3060 & ----- & 1621 & ----- \\
\hline Hdmhp & 3148 & ----- & 1631 & ----- & ----- \\
\hline Hbmhp & n.o. & ----- & 1631 & $\begin{array}{ll}---- \\
\end{array}$ & ----- \\
\hline
\end{tabular}

n.o. = valor não observado. 


\subsubsection{Espectroscopia de Ressonância Magnética Nuclear (RMN ${ }^{1} \mathrm{H} \mathrm{e}$ ${ }^{13} \mathrm{C}$ ) para os complexos 14 e 15}

Os sinais observados nos espectros de RMN ${ }^{1} \mathrm{H}$ dos complexos 14 e 15 demonstraram a existência de pelo menos dois isômeros em solução. Este fato pôde ser facilmente comprovado, no caso do produto 14 , por meio da visualização de quatro sinais atribuídos às metilas do ligante $\mathrm{dmhp}^{1-}$, quando inicialmente, eram esperados apenas dois. Os valores das curvas integrais para dois sinais de hidrogênios metílicos " $\mathrm{CH}_{3 c}$ ", em isômeros distintos, revelaram percentuais de $64 \mathrm{e}$ $36 \%$ entre as formas isoméricas detectadas (Figura 116). Todos os demais sinais referentes aos hidrogênios do composto 14 também se encontram duplicados. No produto 15 , em função de uma proporção muito maior de um isômero em relação ao outro, 92 e 8 \% (Figura 119), apenas os sinais mais intensos, como, por exemplo, os hidrogênios metílicos e metínicos oriundos do $\mathbf{b m h p}{ }^{1-}$, puderam ser visualizados de forma duplicada.

Considerando que os íons piridinonatos $\mathbf{d m h}^{1-} \mathrm{e}^{1-} \mathbf{b m h}^{1-}$ formem quelatos de cinco membros ao se coordenarem ao centro metálico por meio de seus átomos de oxigênio, provenientes do grupo carbonila e da desprotonação da hidroxila, a formação dos isômeros (A e C) poderia ocorrer em decorrência da alternância no modo de coordenação O,O-doadora, conforme demonstrado na figura 115. 
Figura 115 - Hipótese de formação dos isômeros A e C.
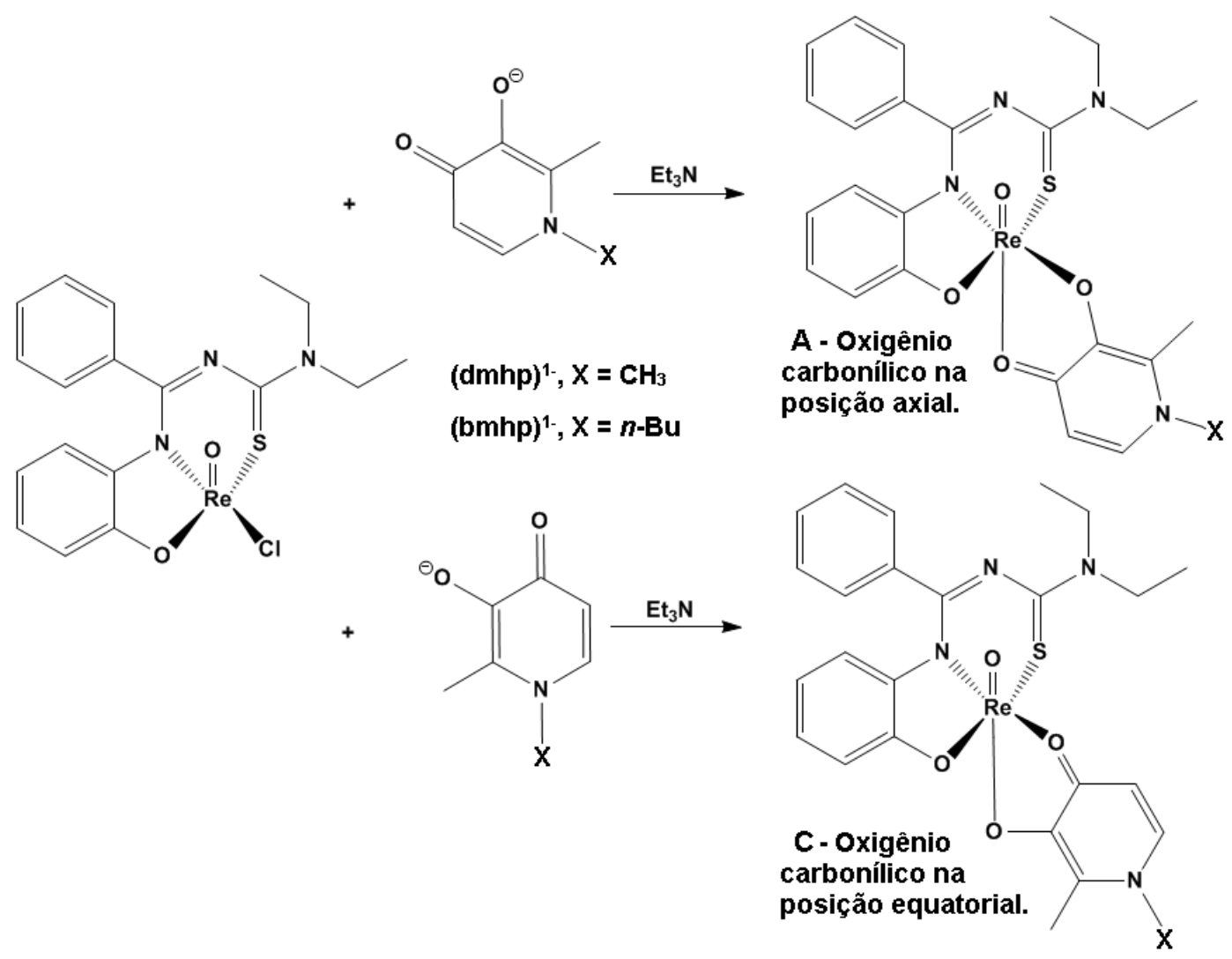

Admitindo-se como verdadeira a hipótese descrita pela figura 115, em termos probabilísticos, seria plausível a formação de quantidades iguais de cada isômero. No caso do produto 14, esta igualdade não foi observada e a comparação entre os sinais atribuídos às metilas (dos isômeros) ligadas ao nitrogênio do $\mathbf{d m h}^{1-}$, em diferentes temperaturas, evidencia a conversão do isômero A em C com o abaixamento da temperatura. Este fato pôde ser comprovado pela redução na intensidade do pico situado em $3,74 \mathrm{ppm}$, detectado a $20 \stackrel{\circ}{\circ}$ e atribuído ao isômero A, e aumento do pico com deslocamento químico igual a 3,70 ppm, observado a $-70 \stackrel{\circ}{ } \mathrm{C}$, relativo ao isômero $\mathbf{C}$ (Figura 121 ).

Com o intuito de verificar uma possível coalescência entre os sinais, e neste caso, poder calcular a energia livre de ativação para a conversão entre esses isômeros, experimentos de $\mathrm{RMN}{ }^{1} \mathrm{H}$ e ${ }^{13} \mathrm{C}$ foram realizados em diferentes temperaturas, de $20 \stackrel{\circ}{ } \mathrm{C}$ até $-90 \stackrel{\circ}{ } \mathrm{C}$, com uma rampa de decréscimo de temperatura de $20 \stackrel{\circ}{\circ}$, respeitando-se o ponto de congelamento do $\mathrm{CD}_{2} \mathrm{Cl}_{2}$ de $-96,7 \stackrel{\circ}{\circ} \mathrm{C}$. 
$\mathrm{O}$ espectro de $\mathrm{RMN}{ }^{13} \mathrm{C}$ de 14 , obtido a $20{ }^{\circ} \mathrm{C}$, exibiu, além de outros sinais, dois que foram especificamente atribuídos ao carbono quaternário carbonílico de cada isômero, sendo um deles pouco intenso e com absorção em 182,52 ppm e outro, duas vezes mais intenso que o primeiro e com deslocamento químico igual a $182,38 \mathrm{ppm}$.

Com a redução da temperatura esperava-se que apenas um sinal fosse visualizado, indicando que a coalescência havia sido alcançada. No entanto, a partir de $-70 \stackrel{\circ}{\circ}$, mesmo que de modo limitado em função da baixa intensidade dos picos, foram observados três sinais. Em $-90 \stackrel{\circ}{\circ}$, com clareza, três sinais puderam ser visualizados em 181,67, 180,78 e 179,45 ppm (Figura 117).

Os dois grupos etilas, provenientes do ligante deba ${ }^{2-}$, nos dois complexos apresentados nesta discussão, são magneticamente diferentes um do outro e apresentam quatro conjuntos de sinais em cada complexo.

Com base nos deslocamentos químicos de ${ }^{1} \mathrm{H} \mathrm{e}{ }^{13} \mathrm{C}$ descritos anteriormente, uma hipótese foi proposta com o intuito de explicar o comportamento dos complexos 14 e 15 em solução. Seus pontos fundamentais estão descritos abaixo:

1. Os dados confirmam a conversão do isômero $\mathbf{A}$ em $\mathbf{C}$ com a redução da temperatura (Figura 121);

2. No espectro de $\mathrm{RMN}{ }^{13} \mathrm{C}$ de 14 , o sinal em 182,52 ppm, detectado a $20{ }^{\circ} \mathrm{C}$, corresponde ao átomo de carbono da carbonila no isômero C (Figura 117), onde o ânion dmhp ${ }^{1-}$ estaria, de modo análogo ao bmhp ${ }^{1-}$ em 15, coordenado de modo mais forte ao centro metálico, devido ao uma maior doação de densidade eletrônica do oxigênio carbonílico para o centro metálico, o que desblindaria com maior eficácia o átomo de carbono ligado a ele. Neste sentido, dados de difração de raios $\mathrm{X}$ em monocristal, obtidos para o complexo 15, corroboram com esta possibilidade ao exibir distâncias de ligação mais longas entre os átomos de carbono e oxigênio carbonílicos, $\mathrm{C}(64)=\mathrm{O}(3)=130,1(9) \mathrm{pm}$, enquanto em 14 (isômero A), o valor correspondente à mesma ligação é 125(2) pm;

3. O sinal intenso em $182,38 \mathrm{ppm}$, observado a $20{ }^{\circ} \mathrm{C}$, no espectro de $\mathrm{RMN}^{13} \mathrm{C}$ de 14, corresponde aos isômeros A e B (Figura 117). A detecção de apenas um sinal se justifica devido à interconversão muito rápida existente entre os isômeros; 
4. A - $90 \stackrel{\circ}{\circ}$, os sinais $181,67,180,78$ e 179,45 ppm, que podem ser visualizados no espectro de RMN ${ }^{13} \mathrm{C}$ de 14 (Figura 117), correspondem respectivamente, aos isômeros C, A e B (Figura 118). Como consequência da redução da energia do sistema, causada pelo abaixamento da temperatura, a interconversão que antes era muito rápida, tornou-se lenta ou deixou de ocorrer, permitindo que o sinal de cada isômero fosse detectado separadamente, originando os três sinais;

5. A comparação (Figura 120) entre os sinais atribuídos aos hidrogênios "Hy" e "Hx" (hidrogênios ligados aos anéis das piridinonas, Tabelas 34 e 36), nos compostos 14 e 15, permite concluir que os sinais mais intensos, em seus respectivos espectros, estão de acordo com as estruturas que foram determinadas por DRX (Figuras 122 e 125, respectivamente).

6. No espectro de $\mathrm{RMN}{ }^{1} \mathrm{H}$ de $\mathbf{1 5}$ existe uma grande diferença nas porcentagens dos isômeros A e C, sendo 8 \% para o primeiro e 92 \% para o terceiro. Acredita-se que essa grande diferença seja consequência de ligações mais curtas e difíceis de serem rompidas quando o ligante bmhp ${ }^{1-}$ está coordenado conforme descrito na estrutura que representa o isômero $\mathbf{C}$, determinada por DRX para 15.

Os espectros de RMN ${ }^{1} \mathrm{H}$ de 14 e 15 (Figuras 116 e 119, respectivamente) apresentaram os sinais esperados para os seus devidos ligantes coordenados ao rênio e seus deslocamentos químicos encontram-se descritos nas tabelas 34 e 36 . 
Figura 116 - Espectro de $\mathrm{RMN}{ }^{1} \mathrm{H}$ de [ReO(deba)(dmhp)] (14) $\left(400 \mathrm{MHz}, \mathrm{CD}_{2} \mathrm{Cl}_{2}\right)$.

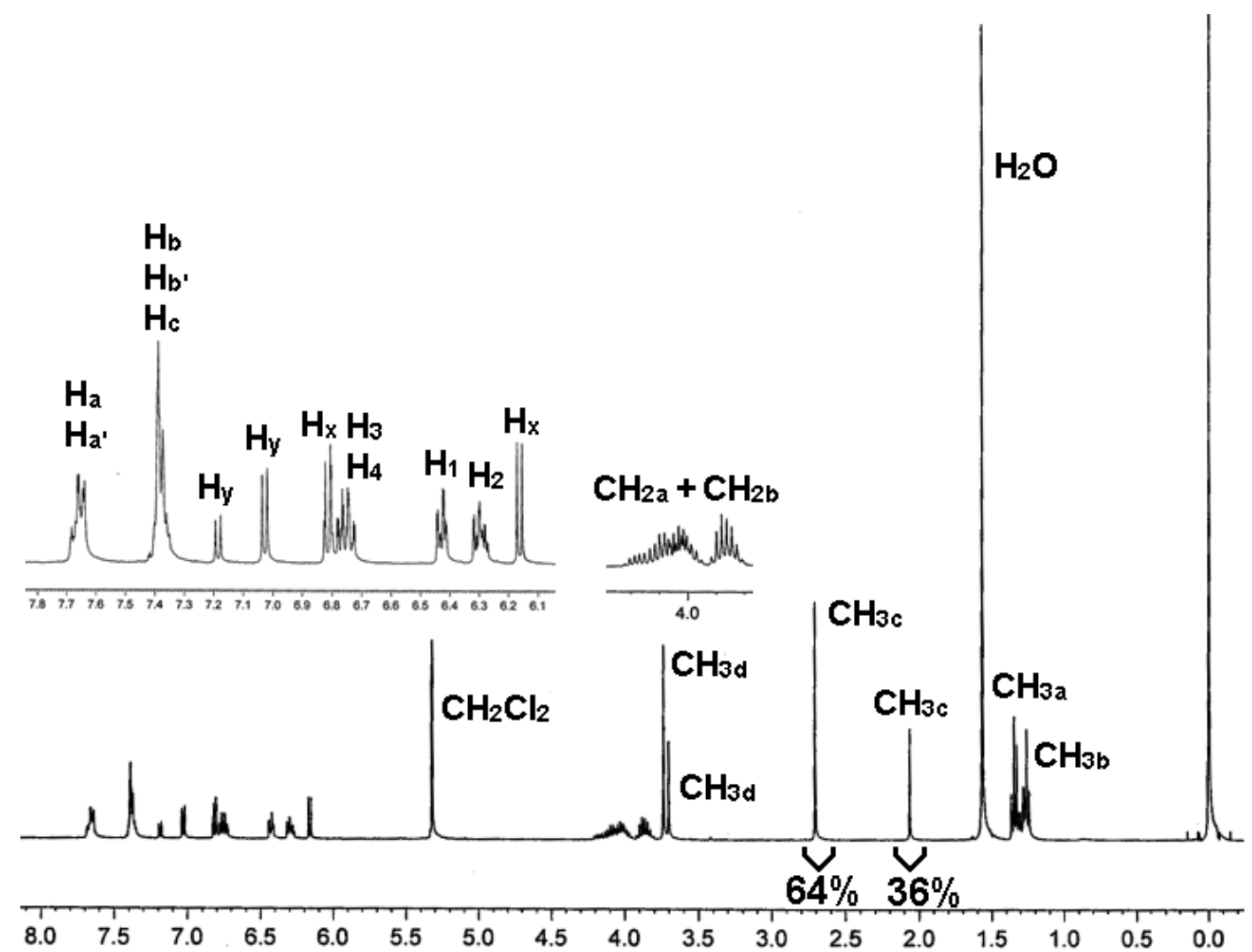


Tabela 34 - Dados de $\mathrm{RMN}{ }^{1} \mathrm{H}(400 \mathrm{MHz})$ para 14 obtidos em $\mathrm{CD}_{2} \mathrm{Cl}_{2}$.

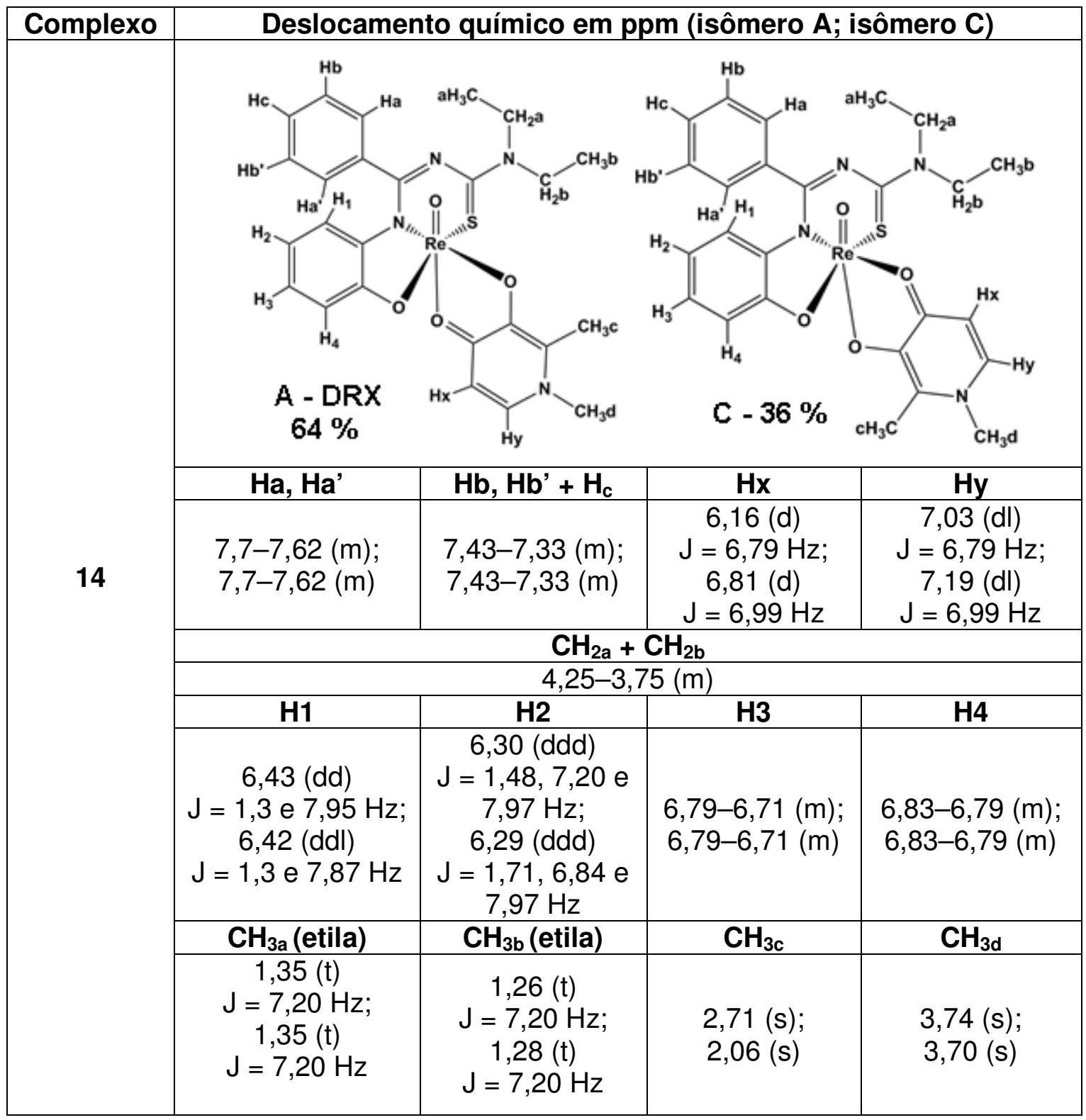


Figura 117 - Espectros de $\mathrm{RMN}{ }^{13} \mathrm{C}$ de [ReO(deba)(dmhp)] (14) $(100,64 \mathrm{MHz}$, $\mathrm{CD}_{2} \mathrm{Cl}_{2}$ ), com variação de temperatura. A, B e C referem-se ao deslocamento químico do carbono carbonílico nos seus respectivos isômeros.

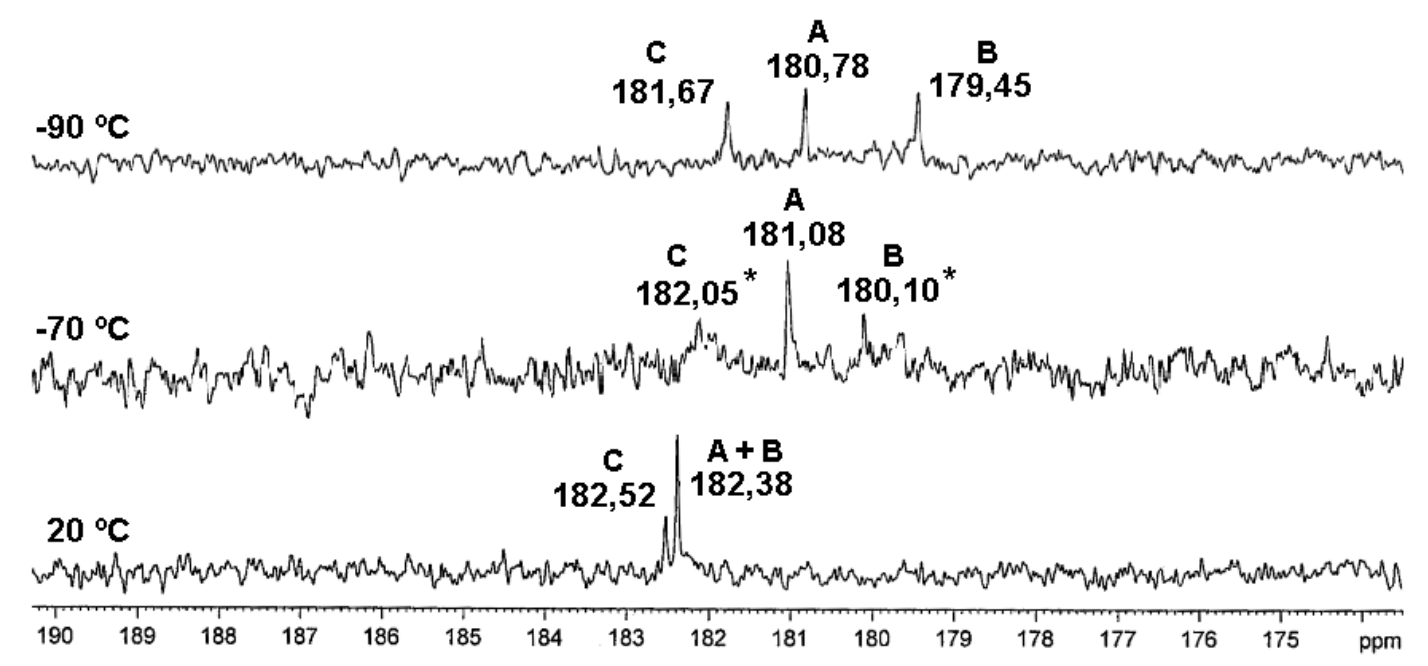

Figura 118 - Isomêros prováveis de [ReO(deba)(dmhp)] (14) em solução.

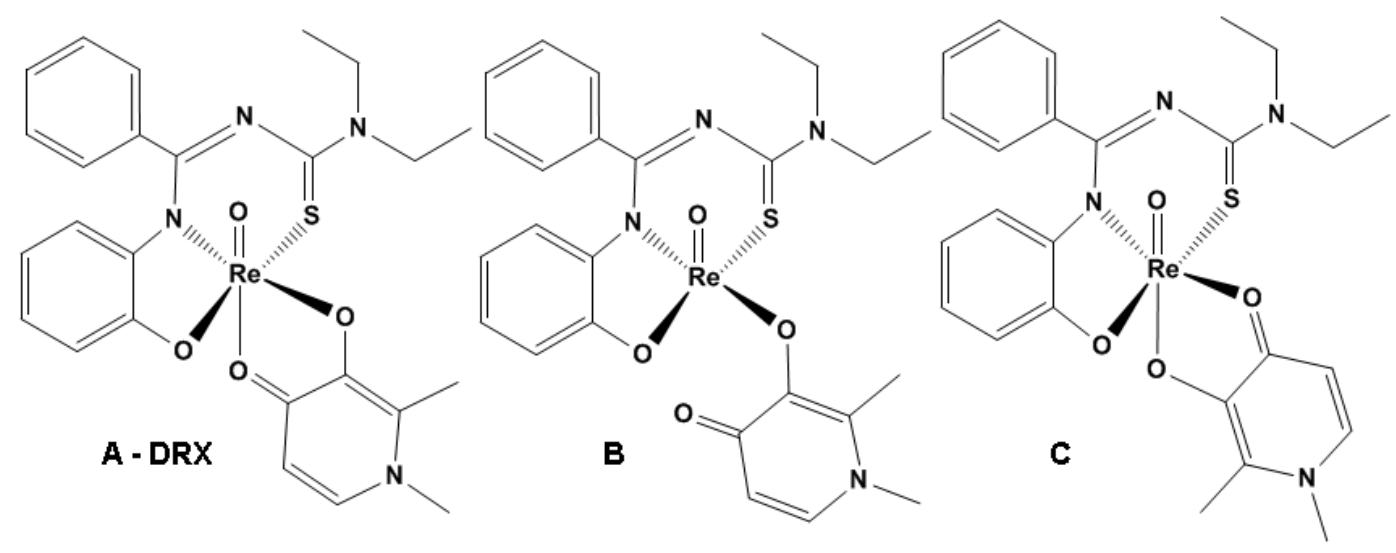

Isômero A: estrutura determinada por meio de difração de raios $\mathrm{X}$ em monocristal. Isômero B: provável intermediário formado, a partir de A, pelo rompimento da ligação alongada $\mathrm{C}=\mathrm{O}$, trans posicionada ao ligante oxo. Deslocamentos químicos observados em $\mathrm{CD}_{2} \mathrm{Cl}_{2}$, somente à $-90 \stackrel{\circ}{\circ}$.

Isômero C: possível isômero de coordenação. Formado pela troca no modo de coordenação do ligante piridinona ao centro metálico, com $\mathrm{C}=\mathrm{O}$ em posição cis ao grupo oxo. 
Tabela 35 - Dados de $\mathrm{RMN}{ }^{13} \mathrm{C}(100,64 \mathrm{MHz})$ para 14 obtidos em $\mathrm{CD}_{2} \mathrm{Cl}_{2}$.

\begin{tabular}{|c|c|c|c|}
\hline & \multicolumn{3}{|c|}{ Deslocamento químico dos isômeros } \\
\hline Temperatura (ㅇ) & A & B & C \\
\hline 20 & 182,38 & 182,38 & 182,52 \\
\hline-70 & 181,08 & $180,10^{\star}$ & $182,05^{\star}$ \\
\hline-90 & 180,78 & 179,45 & 181,67 \\
\hline
\end{tabular}

O sinal $\left({ }^{*}\right)$ descrito na tabela indica que o respectivo pico é pouco intenso e se encontra próximo ao ruído. Desta forma, seu valor possui pouca precisão, conforme pode ser observado na figura 102.

Figura 119 - Espectro de $\mathrm{RMN}{ }^{1} \mathrm{H}$ de [ReO(deba)(bmhp)] (15) $\left(400 \mathrm{MHz}, \mathrm{CD}_{2} \mathrm{Cl}_{2}\right.$ ).

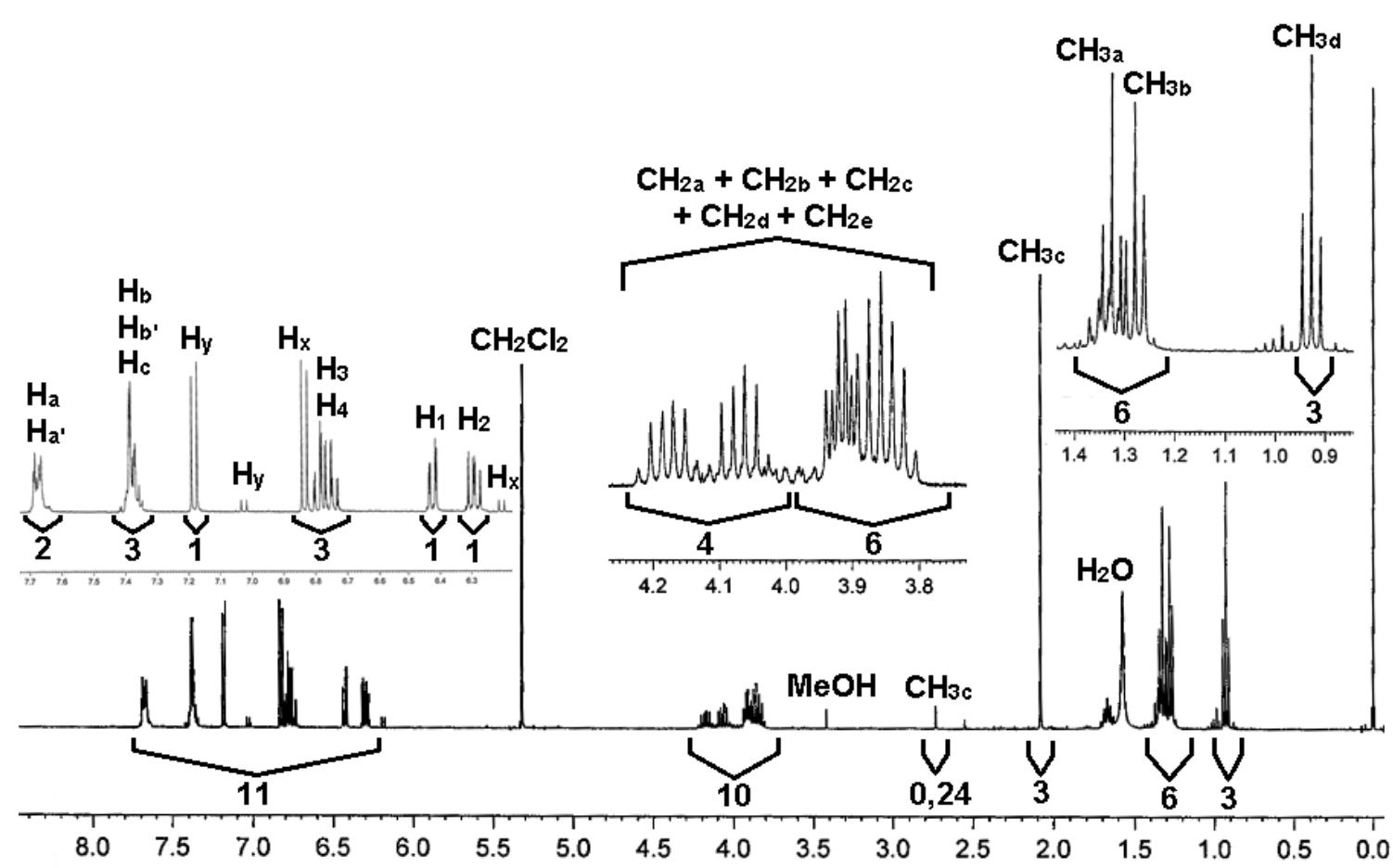


Tabela 36 - Dados de $\mathrm{RMN}{ }^{1} \mathrm{H}(400 \mathrm{MHz})$ para 15 obtidos em $\mathrm{CD}_{2} \mathrm{Cl}_{2}$.

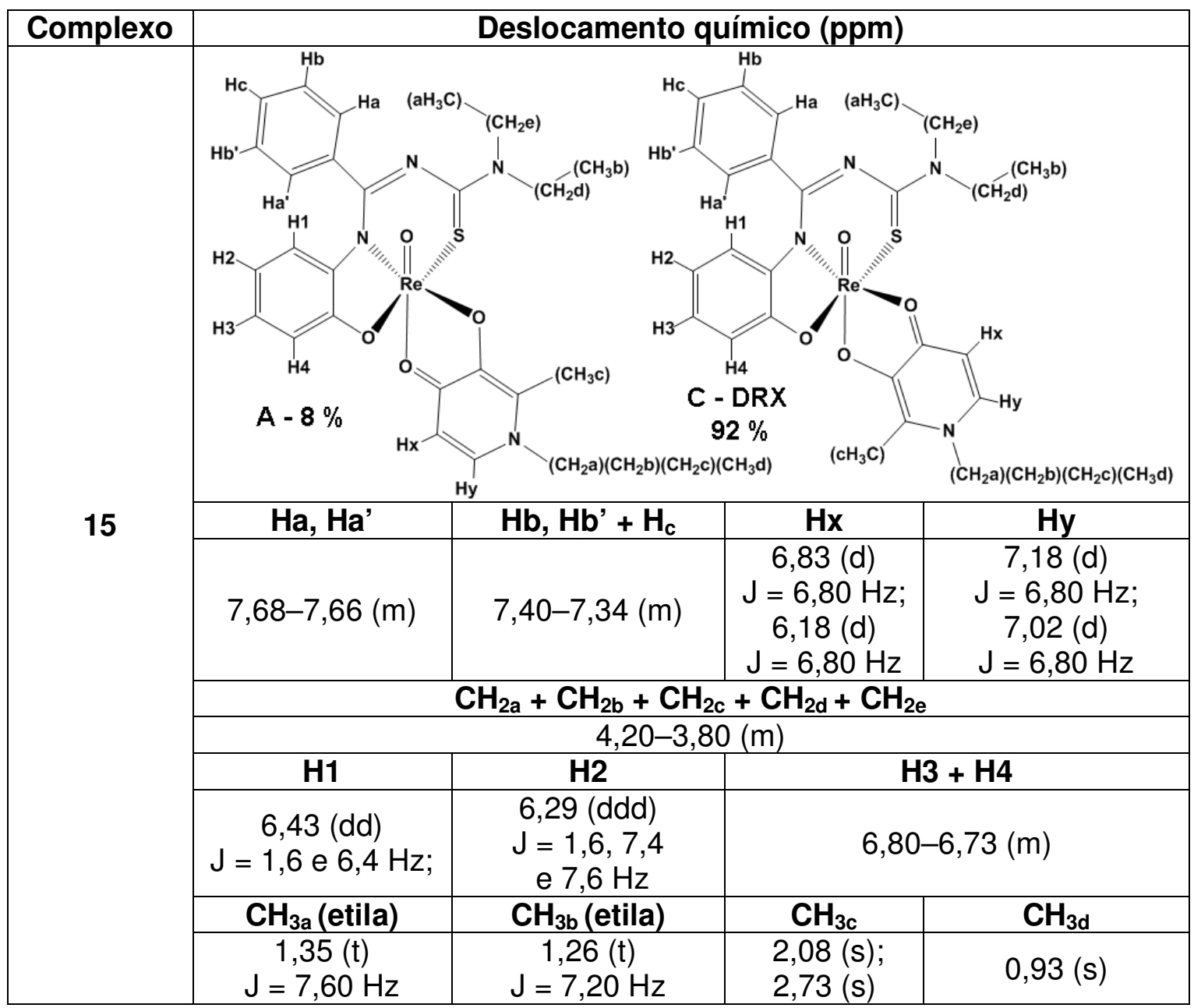


Figura 120 - Comparação entre as regiões aromáticas nos espectros de $\mathrm{RMN}{ }^{1} \mathrm{H}$ dos complexos 14 e 15. (400 MHz, $\left.\mathrm{CD}_{2} \mathrm{Cl}_{2}\right)$.

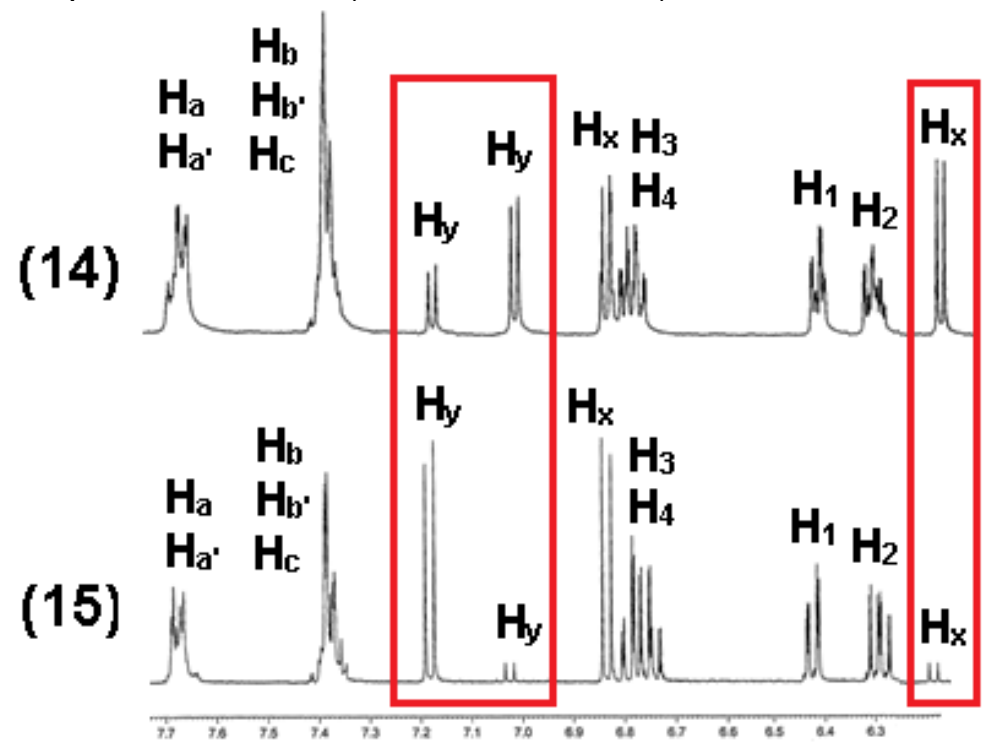

Figura 121 - Conversão do isômero A em C. À esquerda: parte do espectro de 14 obtido a $20 \stackrel{\circ}{\circ}$. À direita: parte do espectro de 14 obtido a $-70 \stackrel{\circ}{\mathrm{C}}$.

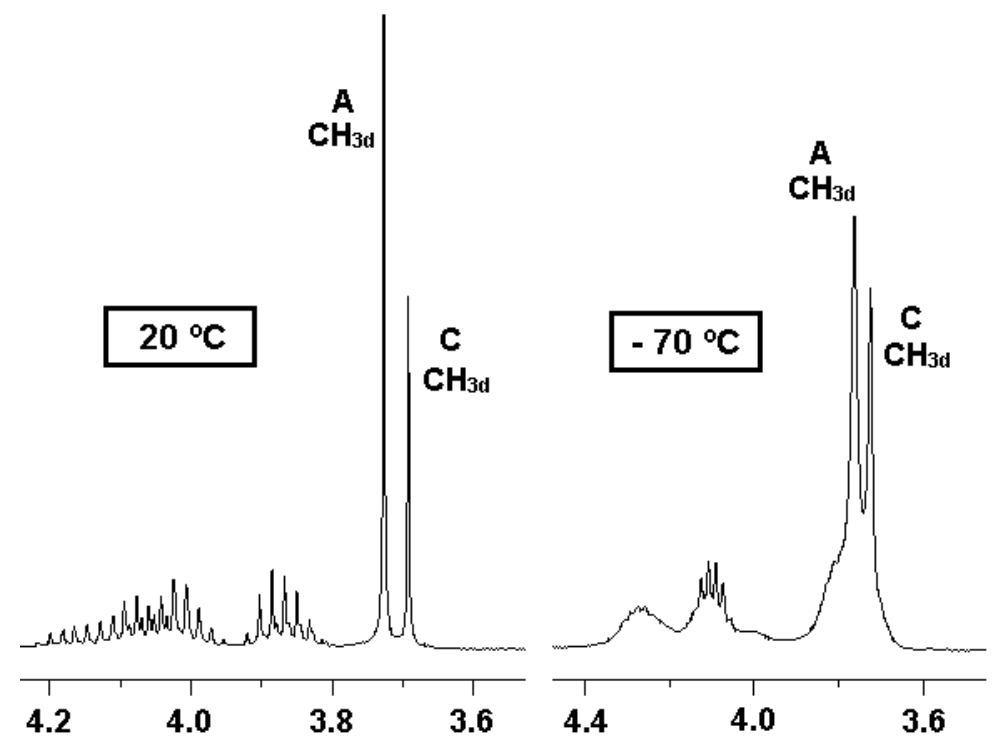




\subsubsection{Difração de Raios X em Monocristal dos Complexos 14 e 15}

\section{Determinação das Estruturas Cristalinas e Moleculares}

Os complexos 14 e 15 cristalizaram-se, respectivamente, sob a forma de prismas e placas verdes escuras, a partir da evaporação lenta de suas respectivas soluções, conforme consta no capítulo de sínteses.

Suas relativas constantes de cela foram calculadas a partir de 9796 e 14990 reflexões, coletadas com uma larga variação do ângulo $2 \theta$.

Os compostos 14 e 15 cristalizaram-se no sistema cristalino triclínico, grupo espacial $P \overline{1}$, indicando que suas relativas celas são primitivas $(P)$ e que possuem o elemento de simetria denominado centro de inversão ( $\overline{1}$ ), com duas moléculas em suas relativas unidades assimétricas.

Foram aplicadas correções de absorção do tipo Integração ${ }^{74}$ à solução de ambas as estruturas aqui apresentadas.

Métodos diretos foram utilizados nas soluções de ambas as estruturas. ${ }^{64}$

Exceto os de hidrogênio, que foram calculados a partir de posições idealizadas, todos os demais átomos foram refinados com deslocamento térmico anisotrópico. ${ }^{65}$

Demais informações pertinentes à determinação das estruturas podem ser visualizadas na tabela 37. Encontram-se disponíveis na tabela 38 os dados referentes aos ângulos e distâncias de ligações selecionadas para estes compostos. 


\section{Discussão das Estruturas Cristalinas e Moleculares}

Todos os átomos de $\operatorname{Re}(\mathrm{V})$ central encontram-se hexacoordenados, com geometrias octaédricas distorcidas (Figuras 122 e 125, respectivamente).

Nos produtos 14 e 15 a benzoamidina $\mathrm{H}_{2}$ deba coordenou-se de modo tridentado, dianiônico, planar e O,N,S-doadora. Por sua vez, as piridinonas (Hdmhp e Hbmhp) coordenaram-se bidentadas, monovalentes e O,O-doadoras.

Em termos de estrutura, 14 e 15 diferenciam-se, em princípio, somente pela troca do grupo metil, no primeiro, por $n$-butil, no segundo, ligado ao átomo de nitrogênio do anel. Entretanto, ainda que os ânions dmhp ${ }^{1-}$ e bmhp ${ }^{1-}$ apresentem o mesmo modo de coordenação, bidentado, monoaniônico e O,O-doador, a posição relativa de seus oxigênios doadores, nos complexos apresentados não são as mesmas. A estrutura molecular do produto 14 revela que o oxigênio carbonílico (O3), do ânion $\mathbf{d m h p}^{1-}$, encontra-se trans-posicionado ao grupo oxo e com um comprimento de ligação Re-O3 de 214,4(11) pm, enquanto em 15, o átomo análogo, do bmhp ${ }^{1-}$, está esta situado em posição trans ao nitrogênio N1 do ligante deba ${ }^{2-} \mathrm{e}$ com um comprimento de ligação de 209,0(5) pm. Os comprimentos das ligações Re-O2 (Tabela 38), onde O2 representa o átomo de oxigênio que foi desprotonado durante a formação dos complexos 14 e 15, são praticamente os mesmos, ainda que $\mathrm{O} 2$ esteja trans posicionado a átomos diferentes.

Com base no comprimento de ligação Re-O3, mais alongado em 14, nota-se que o ânion $\mathbf{d m h p}^{1-}$ está mais fracamente coordenado ao centro metálico do que bmhp $^{1-}$ o fez em 15. Em contrapartida, o deba ${ }^{2-}$ coordenou-se ao rênio por meio de ligações Re-O4 e Re-N1 mais curtas em 14 do que em 15, em concordância com a menor doação de densidade eletrônica por parte do $\mathbf{d m h p}^{1-}$. Estes fatos são condizentes e provavelmente justifiquem a maior formação de isômeros observada no composto 14 , e verificada por meio da técnica de RMN.

Outro fator que contribuiu para o alongamento da ligação Re-O3, em 14, diz respeito à posição do rênio que está deslocado em direção do grupo oxo, situado $31,78(50)$ pm acima do plano equatorial formado pelos átomos O4, N1, S1 e O2, o que dificulta a aproximação de $\mathrm{O} 3$ no eixo axial. No produto 15 , ainda que o metal esteja localizado 27,41(23) pm acima do plano principal, a ligação de O3 ao rênio é favorecida uma vez que este átomo faz parte deste plano. 
Foram encontrados comprimentos de ligação $\mathrm{Re}=\mathrm{O}$ para 0 composto 14 de $168,4(9)$ e de $166,9(5)$ pm para o produto 15, ambos compatíveis com ligações duplas. ${ }^{8,71}$

Nenhum tipo de ligação de hidrogênio foi observada nas redes cristalinas dos compostos apresentados aqui.

Figura 122 - Estrutura molecular do complexo 14. Para facilitar a visualização, os átomos de hidrogênio dos ligantes foram omitidos.

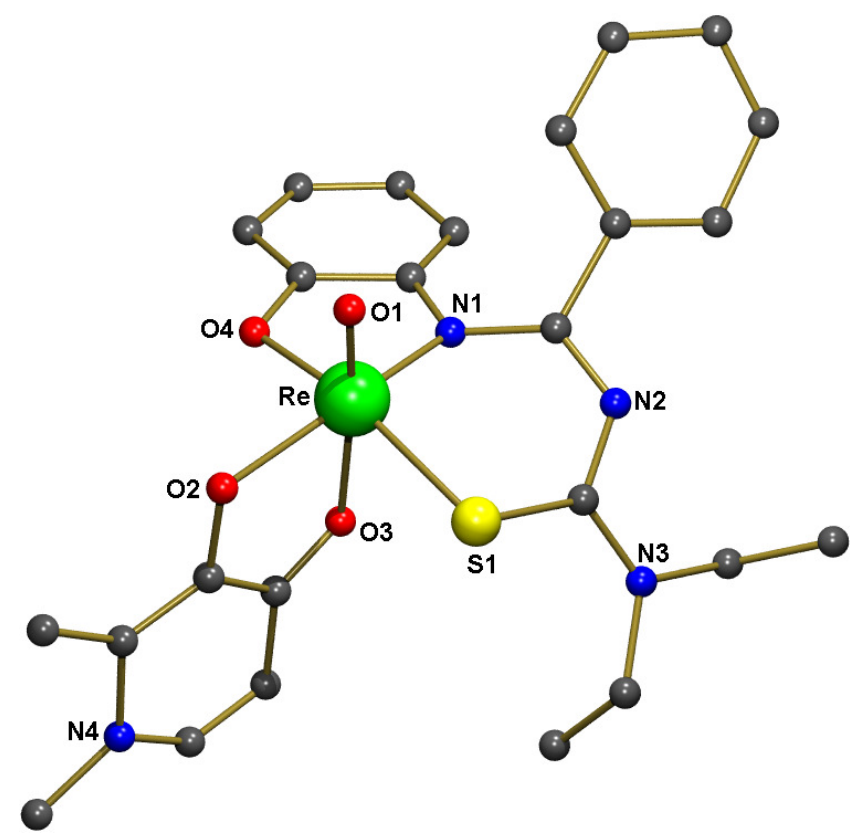

Figura 123 - Cela unitária do complexo 14. Todos os átomos de hidrogênio foram omitidos para facilitar a visualização.

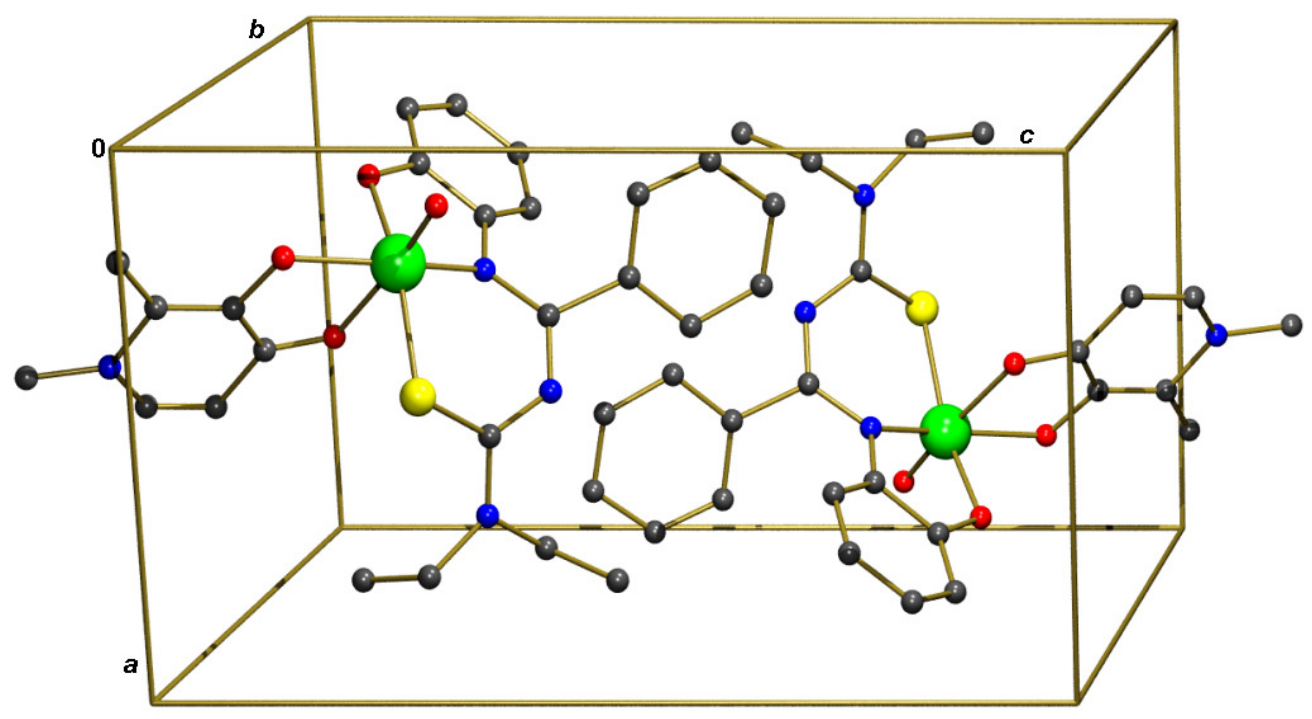


Figura 124 - Visão dos buracos existentes no retículo cristalino de 14. Para facilitar a visualização, os átomos de hidrogênio foram omitidos.

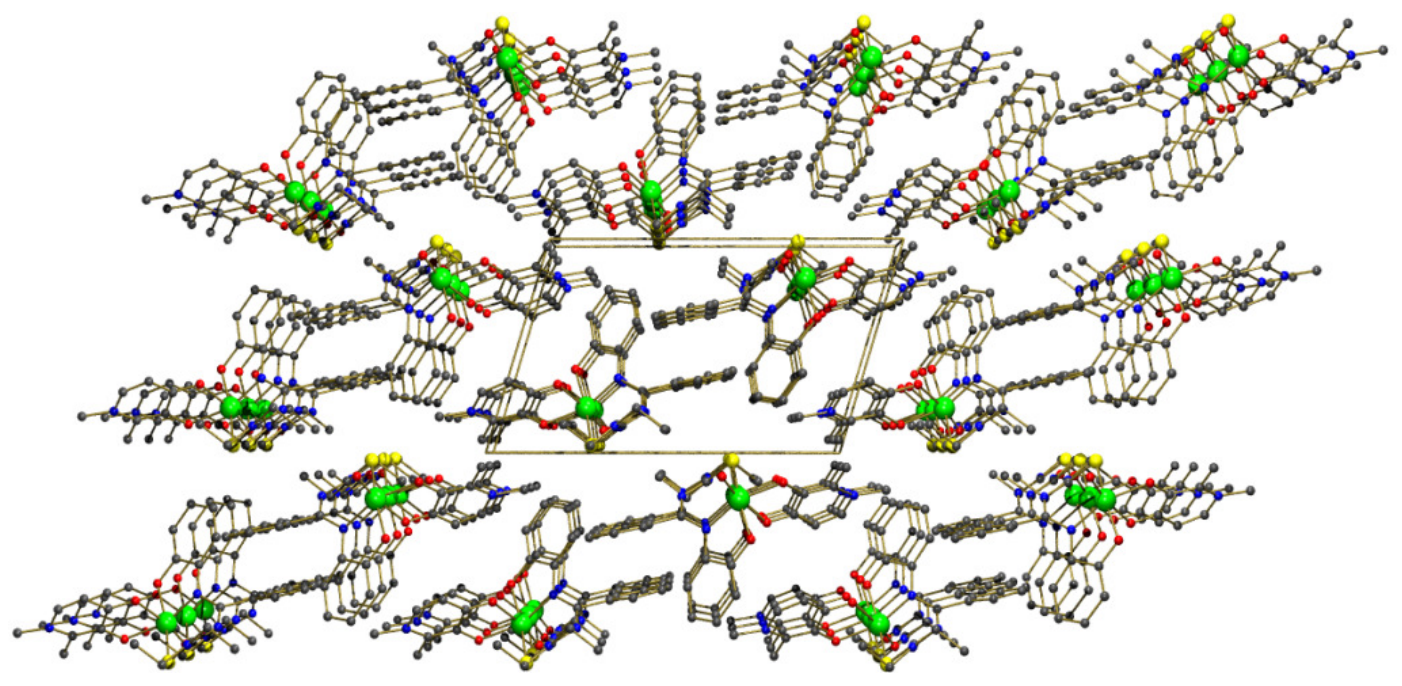

Figura 125 - Estrutura molecular do complexo 15. Para facilitar a visualização, os átomos de hidrogênio dos ligantes foram omitidos.

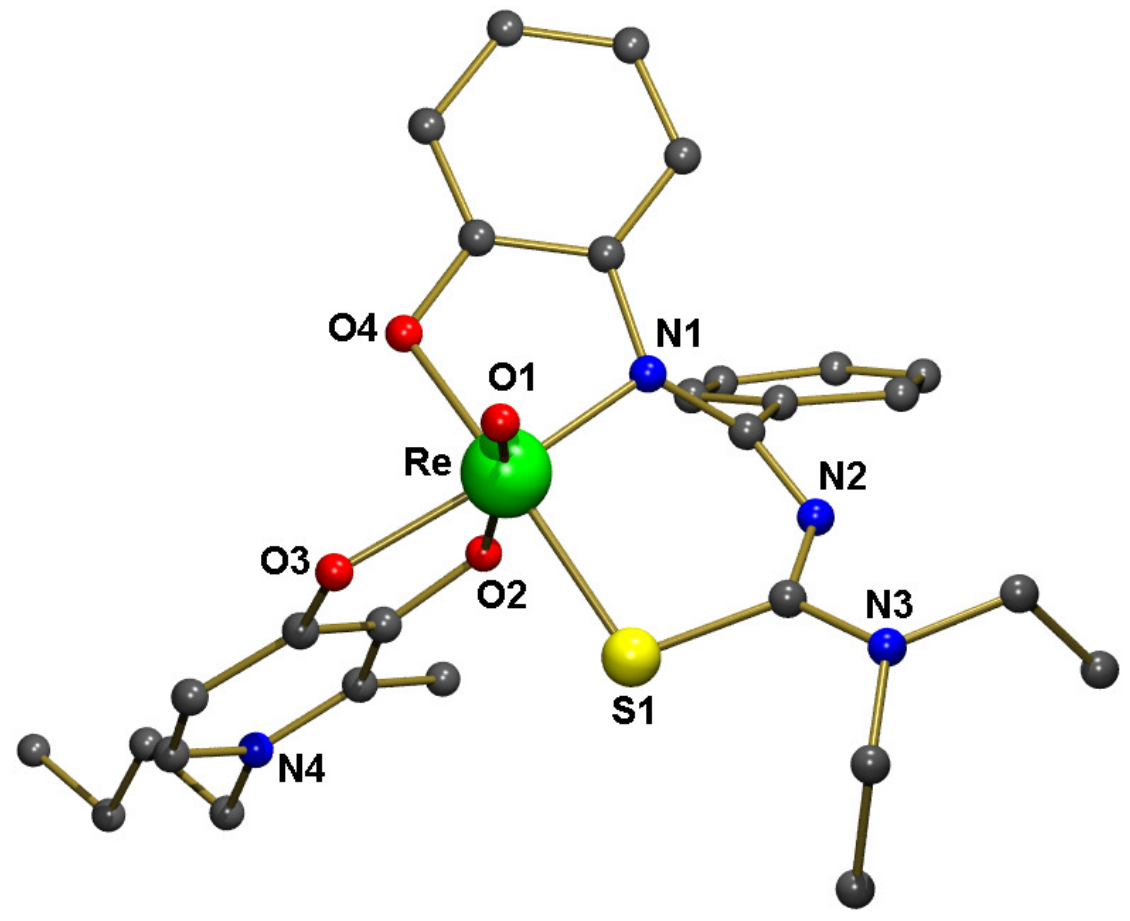


Figura 126 - Cela unitária do composto 15. Os átomos de hidrogênio foram todos removidos para facilitar a visualização da estrutura.

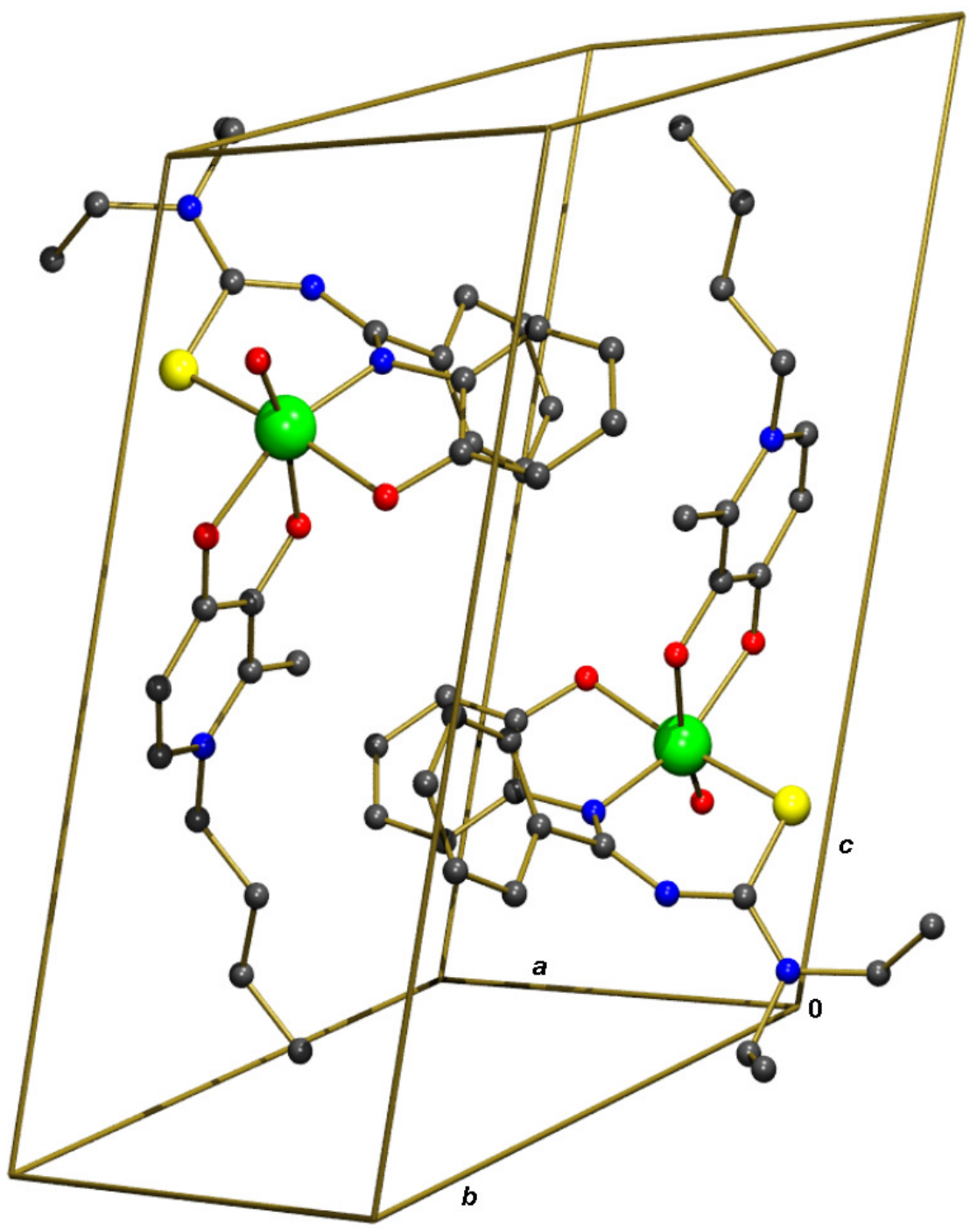


Figura 127 - Visão do retículo cristalino de 15.

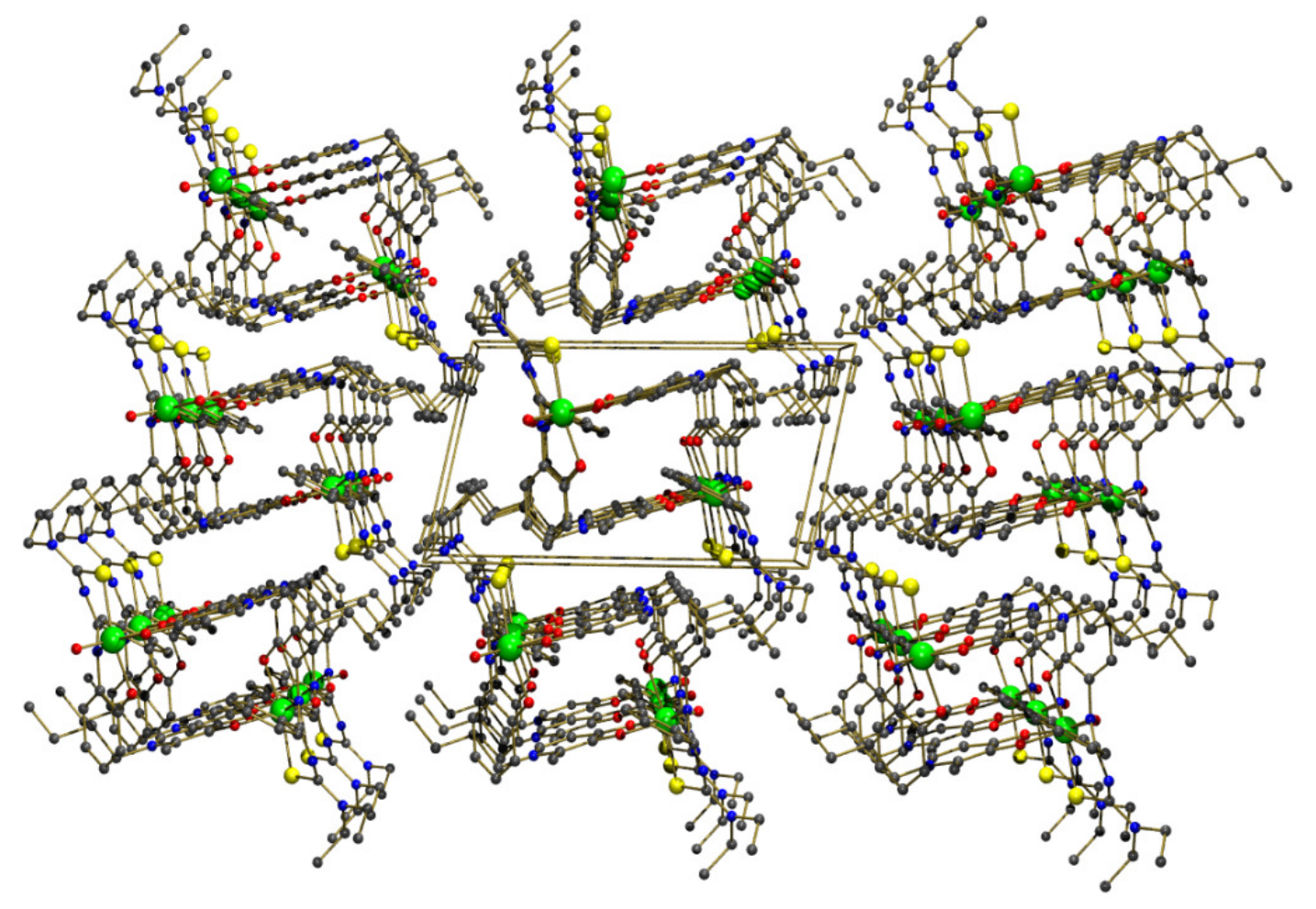


Tabela 37 - Dados cristalográficos de difração de raios $X$ e resultados dos refinamentos das estruturas dos complexos 14 e 15.

\begin{tabular}{|c|c|c|}
\hline Complexo & 14 & 15 \\
\hline Fórmula molecular & $\mathrm{C}_{25} \mathrm{H}_{27} \mathrm{~N}_{4} \mathrm{O}_{4,5} \mathrm{ReS}$ & $\mathrm{C}_{28} \mathrm{H}_{33} \mathrm{~N}_{4} \mathrm{O}_{4} \mathrm{ReS}$ \\
\hline Massa Molar g. $\mathrm{mol}^{-1}$ & 673,77 & 707,84 \\
\hline Temperatura (K) & $200(2)$ & $200(2)$ \\
\hline Comprimento da radiação (pm) & 71,073 & 71,073 \\
\hline Sistema Cristalino & Triclínico & Triclínico \\
\hline Grupo Espacial & $\mathrm{P}_{\overline{1}}^{-}$ & $\mathrm{P}_{\overline{1}}^{-}$ \\
\hline \multicolumn{3}{|l|}{ Parâmetros da cela unitária } \\
\hline$a(\mathrm{pm})$ & $922,3(2)$ & $842,60(7)$ \\
\hline$b(\mathrm{pm})$ & $946,1(2)$ & $1131,5(1)$ \\
\hline$c(\mathrm{pm})$ & $1591,2(3)$ & $1533,5(1)$ \\
\hline$\alpha\left({ }^{\circ}\right)$ & $72,24(2)$ & $103,418(7)$ \\
\hline 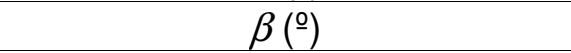 & $86,99(2)$ & $100,330(7)$ \\
\hline$\gamma(\stackrel{0}{)}$ & $88,12(2)$ & $98,242(7)$ \\
\hline Volume $\left(\mathrm{nm}^{3}\right)$ & $1,3203(5)$ & $1,3727(2)$ \\
\hline Z & 2 & 2 \\
\hline Coeficiente de absorção $\left(\mathrm{mm}^{-1}\right)$ & 4,720 & 4,543 \\
\hline Tamanho do cristal $\left(\mathrm{mm}^{3}\right)$ & $0,220 \times 0,200 \times 0,182$ & $0,280 \times 0,143 \times 0,030$ \\
\hline Forma e cor do cristal & Prismas verdes & Placas verdes \\
\hline Método / variação de $\theta\left({ }^{\circ}\right)$ & 2,54 até 25,00 & 1,89 até 29,28 \\
\hline Índices $(\mathrm{h}, \mathrm{k}, \mathrm{l})$ & $\begin{array}{l}-9 \rightarrow \mathrm{h} \rightarrow 10, \\
-11 \rightarrow \mathrm{k} \rightarrow 11, \\
-18 \rightarrow \mid \rightarrow 18\end{array}$ & $\begin{array}{c}-9 \rightarrow h \rightarrow 11, \\
-13 \rightarrow k \rightarrow 15, \\
-20 \rightarrow \mid \rightarrow 20\end{array}$ \\
\hline Reflexões coletadas & 9796 & 14990 \\
\hline Reflexões independentes / $R_{\text {int }}$ & $4566 / 0,1364$ & $7345 / 0,0823$ \\
\hline Correção de Absorção & Integração ${ }^{74}$ & Integração ${ }^{74}$ \\
\hline Transmissão min. / max. & $0,6671 / 0,8851$ & $0,3921 / 0,5974$ \\
\hline Refinamento da estrutura & $\begin{array}{l}\text { Matriz completa dos } \\
\text { mínimos quadrados }\end{array}$ & $\begin{array}{l}\text { Matriz completa dos } \\
\text { mínimos quadrados }\end{array}$ \\
\hline Tratamento dos hidrogênios & Calculados & Calculados \\
\hline Fatores $R$ finais $[I>2 \sigma(I)]$ & $\begin{array}{r}R 1=0,0711 ; \\
w R 2=0,1359\end{array}$ & $\begin{array}{r}\mathrm{R} 1=0,0481 ; \\
\mathrm{wR} 2=0,0978\end{array}$ \\
\hline "Goodness-of-fit" sobre $\mathrm{F}^{2}$ & 0,980 & 1,085 \\
\hline Programas usados & $\begin{array}{l}\text { SHELXS97 } \\
\text { SHELXL }^{65}\end{array}$ & $\begin{array}{l}\text { SHELXS97 } \\
\text { SHELXL }^{65}\end{array}$ \\
\hline
\end{tabular}


Tabela 38 - As principais distâncias (pm) e ângulos $\left(^{\circ}\right)$ de ligação encontrados nos complexos 14 e 15.

\begin{tabular}{|ccc|}
\hline Distâncias & $\mathbf{1 4}$ & $\mathbf{1 5}$ \\
\hline $\operatorname{Re}-\mathrm{O}(1)$ & $168,4(9)$ & $166,9(5)$ \\
\hline $\operatorname{Re}-\mathrm{O}(2)$ & $207,3(10)$ & $207,5(5)$ \\
\hline $\operatorname{Re}-\mathrm{O}(3)$ & $214,4(11)$ & $209,0(5)$ \\
\hline $\operatorname{Re}-\mathrm{O}(4)$ & $198,0(11)$ & $202,0(5)$ \\
\hline $\operatorname{Re}-\mathrm{N}(1)$ & $196,8(12)$ & $200,5(6)$ \\
\hline $\operatorname{Re}-\mathrm{S}(1)$ & $236,8(4)$ & $236,1(2)$ \\
\hline Ângulos & & \\
\hline $\mathrm{O}(1)-\operatorname{Re}-\mathrm{O}(2)$ & $95,1(5)$ & $168,0(2)$ \\
\hline $\mathrm{O}(1)-\operatorname{Re}-\mathrm{O}(3)$ & $170,4(5)$ & $91,9(2)$ \\
\hline $\mathrm{O}(1)-\operatorname{Re}-\mathrm{O}(4)$ & $101,5(5)$ & $98,2(3)$ \\
\hline $\mathrm{O}(1)-\operatorname{Re}-\mathrm{N}(1)$ & $102,7(5)$ & $104,8(2)$ \\
\hline $\mathrm{O}(1)-\operatorname{Re}-\mathrm{S}(1)$ & $96,1(4)$ & $95,2(2)$ \\
\hline $\mathrm{O}(2)-\operatorname{Re}-\mathrm{O}(3)$ & $75,7(5)$ & $76,3(2)$ \\
\hline $\mathrm{O}(2)-\operatorname{Re}-\mathrm{O}(4)$ & $86,8(5)$ & $83,1(2)$ \\
\hline $\mathrm{O}(2)-\operatorname{Re}-\mathrm{N}(1)$ & $159,2(5)$ & $87,3(2)$ \\
\hline $\mathrm{O}(2)-\operatorname{Re}-\mathrm{S}(1)$ & $91,6(3)$ & $83,7(2)$ \\
\hline $\mathrm{O}(3)-\operatorname{Re}-\mathrm{O}(4)$ & $80,9(4)$ & $86,4(2)$ \\
\hline $\mathrm{O}(3)-\operatorname{Re}-\mathrm{N}(1)$ & $86,8(5)$ & $160,7(2)$ \\
\hline $\mathrm{O}(3)-\operatorname{Re}-\mathrm{S}(1)$ & $81,7(3)$ & $92,8(2)$ \\
\hline $\mathrm{O}(4)-\operatorname{Re}-\mathrm{N}(1)$ & $79,3(5)$ & $81,7(2)$ \\
\hline $\mathrm{O}(4)-\operatorname{Re}-\mathrm{S}(1)$ & $162,4(3)$ & $166,5(2)$ \\
\hline $\mathrm{N}(1)-\operatorname{Re}-\mathrm{S}(1)$ & $97,0(4)$ & $95,2(2)$ \\
\hline & & \\
\hline & & \\
\hline & & \\
\hline
\end{tabular}




\subsubsection{Cálculos Computacionais Envolvendo os Complexos 14 e 15}

Os cálculos teóricos foram realizados utilizando o pacote de Programas Gaussian $03 .^{80}$ As geometrias dos complexos, assim como a de seus possíveis isômeros, foram otimizadas em B3LYP ${ }^{84,85} /$ LanL2DZ $^{85}$ e caracterizadas como pontos de menor energia por meio de cálculos de frequências vibracionais. Para os cálculos de otimização das estruturas foram utilizadas, inicialmente, as coordenadas atômicas $x, y$ e $z$ resultantes do refinamento final de suas respectivas estruturas determinadas por DRX.

Os resultados obtidos para os isômeros 14 e 14a demonstram uma pequena diferença de energia de $2,4 \mathrm{KJ} / \mathrm{mol}$ entre suas estruturas otimizadas (Figura 128). Os dados referentes a 15 e seu isômero 15a revelam uma variação de energia cinco vezes maior, 10,8 KJ/mol (Figura 128). Com base nesses valores de energia, a maior formação do isômero $14 a$ (36 \%), constatada no espectro de $\mathrm{RMN}{ }^{1} \mathrm{H}$ do produto 14, é justificada. Pela mesma razão, a pequena formação do isômero 15a ( $8 \%$ ), observada no espectro de $\mathrm{RMN}{ }^{1} \mathrm{H}$ de 15 , também se justifica devido a maior diferença de energia entre as formas isoméricas.

Os cálculos indicam que as estruturas de menor energia e, consequentemente as mais estáveis, são aquelas em que os átomos de oxigênio O3, de suas respectivas piridinonas, estão cis posicionados em relação ao grupo oxo. 
Figura 128 - Formas otimizadas por cálculo DFT, baseadas nas distâncias e ângulos determinados por Difração de Raios $\mathrm{X}$ em monocristal (14 e 15). Os valores de $\Delta$ representam as diferenças de energia, em módulo, entre os compostos 14 ou 15 e seus respectivos isômeros $14 a$ ou $15 a$.

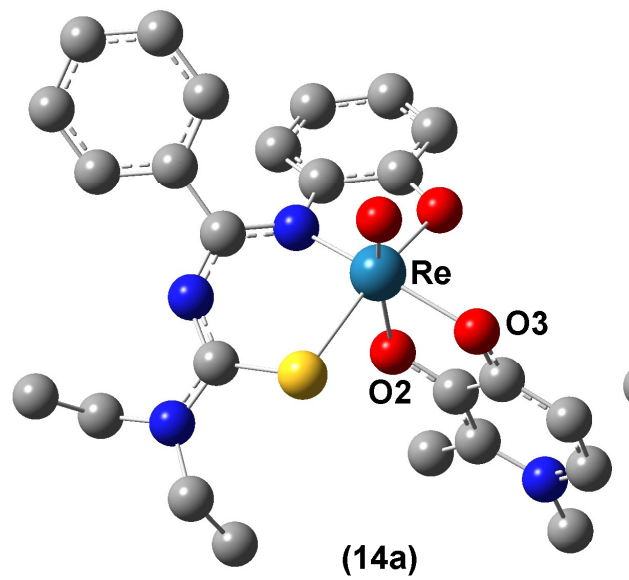

$E_{\mathrm{h}}=-1.577,9608213$

$\triangle=2,40 \mathrm{KJ} / \mathrm{mol}$

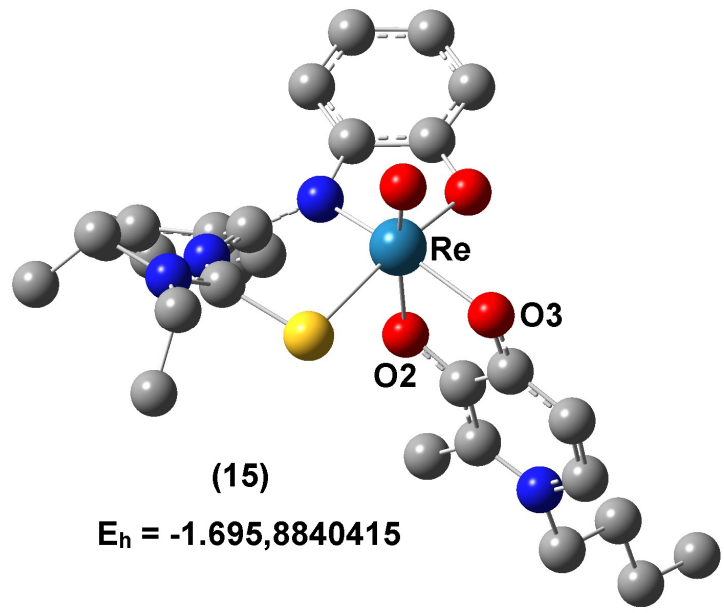

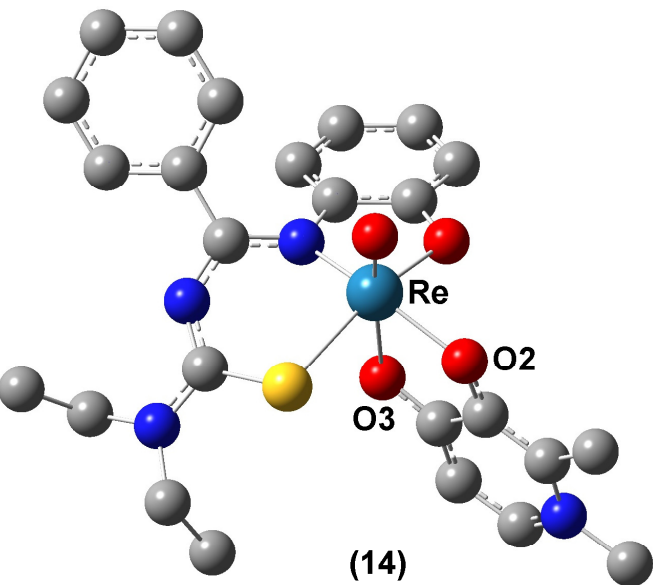

$E_{h}=-1.577,959906$

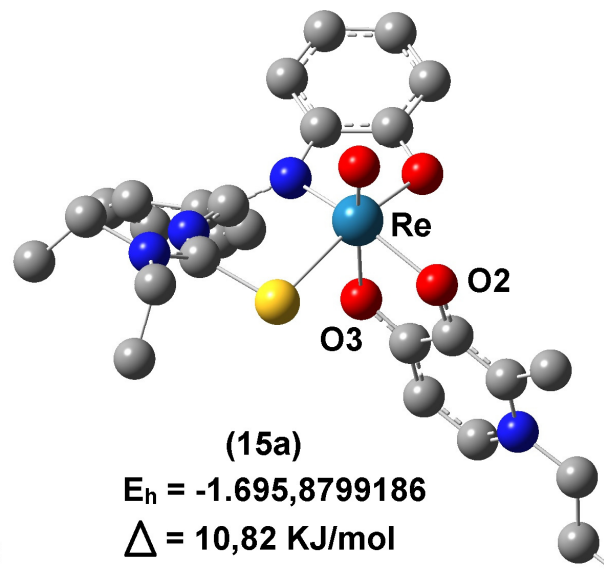




\section{Considerações Finais}

Este trabalho apresentou 15 complexos, todos inéditos e caracterizados por diversas técnicas, confirmando-se as estruturas e o elevado grau de pureza dos mesmos.

Foram usados nas sínteses quatro diferentes classes de ligantes (pironas, piridinonas, ditiocarbazatos e N-(N",N"-dietilaminotiocarbonil)-N'-(2hidroxifenil)benzoamidinas) O,N,S-, N,S- e O,O-doadores, que se coordenaram de formas distintas, quelada de forma monoaniônica e bidentada (pironas, piridinonas e ditiocarbazatos) ou dianiônica e tridentada (ditiocarbazatos e $\mathrm{N}$-(N",N"dialquilaminotiocarbonil)-N'-(2-hidroxifenil)benzoamidinas) para formar anéis quelatos com cinco ou seis membros nos complexos obtidos.

Treze dos quinze complexos caracterizados (12 de $\operatorname{Re}(\mathrm{V})$ e 1 de Tc (V)) tiveram suas estruturas determinadas por difração de raios $X$ em monocristal. Além disso, foram realizadas análises por $\mathrm{RMN}{ }^{1} \mathrm{H},{ }^{31} \mathrm{P}$ e ${ }^{13} \mathrm{C}$, observando-se que as estruturas em solução são as mesmas observadas no estado sólido em todos os complexos, exceto 14 e 15, que possuem isômeros em solução.

Os testes envolvendo $o$ isótopo metaestável ${ }^{99 m} \mathrm{Tc}$ revelaram que os complexos [ $\left.{ }^{99 \mathrm{~m}} \mathrm{TcO}(\mathrm{bdtc}) \mathrm{Cl}\right]$ e $\left[{ }^{99 \mathrm{~m}} \mathrm{TcO}\right.$ (bdtc)(Hbdtc)] foram obtidos por meio de dois métodos marcação, um convencional e outro que utilizou resina com estanho. Outras metodologias de marcação e/ou separação, com intuito de obtenção apenas do [ ${ }^{99 m} \mathrm{TcO}$ (bdtc)(Hbdtc)] estão sob investigação.

As propriedades físico-químicas estudadas para o [ $\left.{ }^{99 m} \mathrm{TcO}(\mathbf{b d t c}) \mathrm{Cl}\right]$ demonstram seu elevado potencial como radiofármaco, justificando os próximos passos desta pesquisa: estudos de biodistribuição utilizando métodos invasivos e de imagem por SPECT e Tomografia Computadorizada.

Certamente, os objetivos propostos para esse trabalho foram atingidos $\mathrm{e}$ acredita-se que os resultados obtidos contribuirão para o melhor entendimento da química de coordenação dos complexos de Re (V) e Tc (V) contendo as classes de ligantes estudadas. 


\section{Referências Bibliográficas}

1 NODDACK, W.; TACKE, I.; Sitzber. Preuss. Akad. Wiss., v. 19, p. 400-405, 1925.

2 WEDEPOHL, K. H.; Met. Their Compd. Environ., p. 3-17, 1991.

3 GREENWOOD, N. N.; EARNSHAW, A.; Chemistry of the elements, $2^{\text {nd }}$ ed, Oxford: London, 2002.

4 COPLEN, T. B.; Pure Appl. Chem., v. 68, p. 2339-2359, 1996.

5 PFENNIG, G.; KLEWE-NEBENIUS, H.; SEELMANN-EGGEBERT, W.; Chart of the nuclides, $6^{\text {th }}$ ed. 1995, revised reprint 1998, Research Centre Karlsruhe, Germany.

6 a) JOHNSON, C. L.; SHIREY, S. B.; BAROVICH, K. M.; Trans. R. Soc.

Edinburgh: Earth Sci., v. 87, p. 339-352, 1996. b) ZHI, X.; Chin. Sci. Bull., v. 45, p. 193-200, 2000.

7 BANERJEE, S.; PILLAI, M. R. A.; RAMAMOORTHY, N.; Seminars in Nuclear Medicine, v. 31, n. 4, p. 260-277, 2001.

8 ABRAM, U.; Rhenium. In Comprehensive Coordination Chemistry II; McCleverty, J. A., Mayer, T. J., Eds.; Elsevier: Amsterdam, The Netherlands, 2003, v. 5, p. 271.

9 NEUHAUS, A.; VELDKAMP, A.; FRENKING, G.; Inorg. Chem., v. 33, p. 52785286, 1994.

10 TISATO, F.; REFOSCO, F.; BANDOLI, G.; Coord. Chem. Rev., 1994, v. 135/136, p. 325-397.

11 FERNANDES, C.; PATRÍCIO, L.; MOREIRA, R.; CANTINHO, G.; PENA, H.; CAMPELLO, P. C.; SANTOS, I.; Nucl. Med. Biol., 2004, v. 31, p. 139-145.

12 JURISSON, S.; LYDON, J. D.; Chem. Rev., v. 99, p. 2205-2218, 1999. 
13 SHUANG, L.; EDWARDS, D. S.; Chem. Rev., v. 99, p. 2235-2268, 1999.

14 MARQUES, F. L. N.; OKAMOTO, M. R. Y.; BUCHPIGUEL, C. A.; Radiol. Bras., v. 34, n. 4, p. 233-239, 2001.

15 Figura retirada do sítio de internet:

<http://www.fcf.usp.br/Ensino/Graduacao/Disciplinas/LinkAula/My-

Files/radiofarmacia.htm>. Acesso em: 02 mar. 2012.

16 VOLKERT, W. A.; HOFFMAN, T. J.; Chem. Rev., v. 99, p. 2269-2292, 1999.

17 SCHUBIGER, P. A.; ALBERTO, R.; SMITH, A.; Bioconjugate Chem., v. 7, n. 2, p. $165-179,1996$.

18 VANDERHEYDEN, J. L.; FRITZBERG, A. R.; RAO, T. N.; KASINA, S.;

SRINIVASAN, A.; RENO, J. M.; MORGAN, A. C.; J. Nucl. Med., v. 28, p. 656, 1987.

19 PAPACHRISTOU, M.; PIRMETTIS, I. C.; TSOUKALAS, C.;

PAPAGIANNOPOULOU, D.; RAPTOPOULOU, C.; TERZIS, A.;

STASSINOPOULOU, C. I.; CHIOTELLIS, E.; PELECANOU, M.; PAPADOPOULOS, M.; Inorg. Chem., v. 42, p. 5778-5784, 2003.

20 HEEG, M. J.; JURISSON, S. S.; Acc. Chem. Res., v. 32, p. 1053-1060, 1999.

21 TASDELEN, B.; J Radioanal. Nucl. Chem., v. 290, p. 283-287, 2011.

22 INSTITUTO DO CORAÇÃO (INCOR), SERVIÇO DE MEDICINA NUCLEAR E IMAGEM MOLECULAR. Principais exames realizados na área cardiovascular. Disponível em: <http://www.incor.usp.br/PET/Medicina_Convencional.html> Acesso em: 20 mar. 2012.

23 BARBARICS, E.; KRONAUGE, J. F.; DAVISON, A.; JONES, A. G.; Nucl. Med. Biol., v. 25, p. 667-673, 1998.

24 ITOH, K.; Ann. Nucl. Med., v. 15, n. 3, p. 179-190, 2001.

25 XIANGJI, C.; LIANG, L.; FEI, L.; BOLI, L.; Bioorg. Med. Chem. Lett., v. 16, p. 5503-5506, 2006. 
26 RADIN, A. Preparo e avaliação de complexos de [ $\left.{ }^{99 \mathrm{~m}} \mathrm{Tc}\right]$ tecnécio aquacarbonil contendo ligantes 1,2-diaminoetano- $\mathrm{N}$-substituídos para detecção de tumores; 2010. 112 f. Dissertação (Mestrado em Ciências) Faculdade de Medicina, Universidade de São Paulo, São Paulo, 2010.

27 INSTITUTO DE PESQUISAS ENERGÉTICAS E NUCLEARES (IPEN). Conjunto de reagente liofilizado para preparar ECD- ${ }^{-99 m} \mathrm{TC}$ Disponível em: <https://www.ipen.br/conteudo/upload/201104250814400.ECD.pdf> Acesso em: 20 mar. 2012.

28 STEFANOYIANNIS, A. P.; GEROGIANNIS, I.; GERONIKOLA-TRAPALI, X.; ARMENIAKOS, I.; PRENTAKIS, A.; SOULTANIS, S.; CHATZIIOANNOU, S. N.; J. Phys.: Conf. Ser., v. 317, p. 1-3, 2011.

29 CATAFAU, A. M.; J. Nucl. Med., v. 42, p. 259-271, 2001.

30 FELICIO, A. C.; GODEIRO-JUNIOR, C.; SHIH, M. C.; BORGES, V.; SILVA, S. M. A.; AGUIAR, P. de C.; HOEXTER, M. Q.; BARSOTTINI, O. G. P.; ANDRADE, L. A. F.; BRESSAN, R. A.; FERRAZ, H. B.; J. Neurol. Sci., v. 291, p. 64-68, 2010.

31 BOLZATI, C.; BENINI, E.; CAVAZZA-CECCATO, M.; CAZZOLA, E.; MALAGO, E.; AGOSTINI, S.; TISATO, F.; REFOSCO, F.; BANDOLI, G.; Bioconjugate Chem., v. 17, p. $419-428,2006$.

32 KUNGA, H. F.; KUNGA, M. P.; WEYC, S. P.; LIND, K. J.; YEN, T. C.; Nucl. Med. Biol., v. 34, p. 787-789, 2007.

33 SHIH, M. C.; AMARO, E. J.; FERRAZ, H. B.; HOEXTER, M. Q.; GOULART, F. O.; WAGNER, J.; FU, L. L.; FU, Y. K.; MARI, J. J.; de LACERDA, A. L. T.; TUFIK, S.; BRESSAN, R. A.; Arq. Neuropsiquiatr., v. 64(3-A), p. 628-634, 2006.

34 BERA, P.; KIM, C.H.; SEOK, S.; Polyhedron, v. 27, p. 3433-3438, 2008.

35 CROUSE, K. A.; CHEW, KAR-BENG; TARAFDER, M. T. H.; KASBOLLAH, A.; ALI, M. A.; YAMIN, B. M.; FUN, H. K.; Polyhedron, v. 23, p. 161-168, 2004.

36 SASMAL, P. K.; PATRA, A. K.; CHAKRAVARTY, A. R.; J. Inorg. Biochem., v. 102, p. 1463-1472, 2008. 
37 PEDRAS, M. S. C.; JHA, M.; Bioorg. Med. Chem., v. 14, p. 4958-4979, 2006.

38 MAIA, P. I. da S.; FERNANDES, A. G. de A.; SILVA, J. J. N.; ANDRICOPULO, A. D.; LEMOS, S. S.; LANG, E. S.; ABRAM, U.; DEFLON, V. M.; J. Inorg. Biochem., v. 104, p. 1276-1282, 2010.

39 DEFLON, V. M.; ANDRICOPULO, A. D.; FERNANDES, A. G. DE A.; MAIA, P. I. DA S.; PESCI, R. B. P.; SILVA, J. J. N. Processos de obtenção de complexos de coordenação de ditiocarbazatos, complexos de coordenação contendo metais de transição, composições farmacêuticas e seus usos. BR n. Pl 1.103.777-6, 19 ago. 2011.

40 LI, M. X.; ZHANG, L. Z.; CHEN, C. L.; NIU, J. Y.; JI, B. S.; J. Inorg. Biochem., v. 106, p. 117-125, 2012.

41 NEELAM, B.; MANNAR, M. R.; FEHMIDA, N.; ALOK, B.; SUDHA, B.; AMIR, A.; Eur. J. Med. Chem., v. 35, p. 481-486, 2000.

42 ALI, M. A.; MIRZA, A. H.; BUTCHER, R. J.; CHOWDHURY, A. K.; Transition Met. Chem., v. 36, p. 471-479, 2011.

43 GERBER, T. I. A.; HOSTEN, E.; MAYER, P.; KNOESEN, O.; J. Coord. Chem., v. 60, n. 16, p. 1763-1769, 2007.

44 MÉVELLEC, F.; ROUCOUX, A.; NOIRET, N.; PATIN, H.; Inorg. Chim. Acta, v. 332, p. 30-36, 2002.

45 KONTOGHIORGHES, G. J.; SHEPPARD, L.; Inorg. Chim. Acta, v. 136, p. L11L12, 1987.

46 SANTOS, M. A.; MARQUES, S. M.; CHAVES, S.; Coord. Chem. Rev., v. 256, p. 240-259, 2012.

47 ASBECK, B. S.; GEORGIOU, N.A.; BRUGGEN, T.; OUDSHOORN, M.; NOTTET, H. S.; MARX, J. J.; J. Clin. Virol., v. 20, p. 141-147, 2001.

48 DRAKESMITH, H.; PRENTICE, A.; Nat. Rev. Microbiol., v. 6, p. 541-552, 2008. 
49 ANDRUS, L.; SZABO, P.; GRADY, R. W.; HANAUSKE, A. R.; HUIMA-BYRON, T.; SLOWINSKA, B.; ZAGULSKA, S.; HANAUSKE-ABEL, H. M.; Biochem.

Pharmacol., v. 55, p. 1807-1818, 1998.

50 FASSIHI, A.; ABEDI, D.; SAGHAIE, L.; SABET, R.; FAZELI, H.; BOSTAKI, G.; DEILAMI, O.; SADINPOUR, H.; Eur. J. Med. Chem., v. 44, p. 2145-2157, 2009.

51 FERNANDES, S. S.; NUNES, A.; GOMES, A. R.; CASTRO, B.; HIDER, R. C.; RANGEL, M.; APPELBERG, R.; GOMES, M. S.; Microbes. Infect., v. 12, p. 287294, 2010.

52 FENG, M. H.; van der DOES, L.; BANTJES, A.; J. Med. Chem., v. 36, p. 28222827, 1993.

53 LUO, H.; RETTIG, S. J.; ORVIG, C.; Inorg. Chem., v. 32, p. 4491-4497, 1993.

54 MONGA, V.; PATRICK, B. O.; ORVIG, C.; Inorg. Chem., v. 44, p. 2666-2677, 2005.

55 SANTOS, M. A.; GRAZINA, R.; NETO, A. Q.; CANTINHO, G.; GANO, L.;

PATRÍCIO, L.; J. Inorg. Biochem., v. 78, p. 303-311, 2000.

56 HUY, N. H.; GREWE, J.; SCHROER, J.; KUHN, B.; ABRAM, U.; Inorg. Chem., v. 47, p. 5136-5144, 2008.

57 JOHNSON, N. P., LOCK, C. J. L., WILKINSON, G.; Inorg. Synth., v. 9, p. 145148, 1967.

58 ALBERTO, R.; SCHIBLI, R.; EGLI, A.; SCHUBIGER, P. A.; HERMANN, W. A.; ARTUS, G.; ABRAM, U.; KADEN, T. A.; J. Organomet. Chem., v. 493, p. 119-127, 1995.

59 ABRAM, U.; HAGENBACH, A.; Radiochemistry practical course for chemists, Freie Universität Berlin, Institute of Chemistry and Biochemistry, p. 49, 2009, Apostila não publicada.

60 Figura retirada do sítio de internet:

<http://sv.wikipedia.org/wiki/Fil:Photomultiplier_schema_de.png>. Acesso em: 02 mar. 2012. 
61 FERNANDES, A. G. de A.; MAIA, P. I. S.; de SOUZA, E. J.; LEMOS, S. S.; BATISTA, A. A.; ABRAM, U.; ELLENA, J.; CASTELLANO, E. E.; DEFLON, V. M.; Polyhedron, v. 27, p. 2983-2989, 2008.

62 de SOUZA, E. J.; DEFLON, V. M.; FERNANDES, A. G. de A.; LEMOS, S. S.; HAGENBACH, A.; ABRAM U.; Inorg. Chim. Acta, v. 359, p. 1513-1518, 2006.

63 de SOUSA, G. F.; GARCIA, E.; GATTO, C. C.; RESCK, I. S.; DEFLON, V. M.; ARDISSON, J. D.; J. Mol. Struct., v. 981, p. 46-53, 2010.

64 SHELDRIK, G. M.; SHELXS-97, University Gottingen, Germany, 1997. Programa de solução de estrutura cristalina.

65 SHELDRIK, G. M.; SHELXL-97, University Gottingen, Germany, 1997. (4.2.4). Programa de refinamento de estrutura cristalina.

66 BLESSING, R. H.; Acta Cryst., v. A51, p. 33-38, 1995.

67 HESSE, M.; MEIER, H.; ZEEH, B.; Spektroskopische methoden in der organischen chemie. 5. Aufl.; Ed. Georg Thieme Verlag: Stuttgard, New York, 1995.

68 de SOUZA, E. J.; FERNANDES, A. G. de A.; DEFLON, V. M.; BESSLER, K. E.; LEMOS, S. S.; BATISTA, A. A.; ELLENA, J.; CASTELLANO, E. E.; ABRAM, U.; HAGENBACH, A.; J. Braz. Chem. Soc., v. 17, n. 8, p. 1578-1583, 2006.

69 a) GRAZIANI, R.; CASELLATO, U.; MARCHI, A.; J. Crystallogr. Spectrosc. Res., v. 15, p. 573-579, 1985. b) SERGIENKO, V. S.; Zh. Neorg Khim., v. 39, p. 1985, 1994. c) GALDECKI, Z.; GALDECKI, E.; KOWALSKI, A.; Pol. J. Chem., v. 73, p. 1391-1403, 1999.

70 LEMOS, S. S.; Estudo do deslocamento químico da trifenilfosfina livre em solução por RMN $\left({ }^{31} \mathrm{P},{ }^{1} \mathrm{H}\right.$ e $\left.{ }^{13} \mathrm{C}\right)$, Trabalho não publicado 2004.

71 FERNANDES, A. G. de A. Síntese e caracterização estrutural de complexos de oxorrênio(V) com ligantes O,O- e N,O-doadores; 2007. 120 f. Dissertação (Mestrado em Química Inorgânica) - Instituto de Química, Universidade de Brasília, Brasília, 2007.

72 PACCHIONI, G.; BAGUS, P. S.; Inorg. Chem., v. 31, p. 4391-4398, 1992. 
73 COPPENS, P.; Crystallographic Computing, F.R. Ahmed, S.R. Hall and C.P. Huber, Copenhagen, Munksgaard, 1970, p. 255.

74 X-RED32. STOE\&Cie GmbH, Darmstadt, Germany.

75 ALBERTO, R.; Technetium. In Comprehensive Coordination Chemistry II. McCleverty, J. A., Mayer, T. J., Eds.; Elsevier: Amsterdam, The Netherlands, 2003; v. 5, p. 140.

76 VIEITES, M.; Otero, L.; SANTOS, D.; TOLOZA, J.; FIGUEROA, R.; NORAMBUENA, E.; AZAR, C. O.; AGUIRRE, G.; CERECETTO, H.; GONZÁLEZ, M.; MORELLO, A.; MAYA, J. D.; GARAT, B.; GAMBINO, D.; J. Inorg. Biochem., v. 102, p. 1033-1043, 2008.

77 OTERO, L.; VIEITES, M.; BOIANI, L.; DENICOLA, A.; RIGOL, C.; OPAZO, L.; AZAR, C. O.; MAYA,J. D.; Morello, A.; SIEGEL, R. L. K.; PIRO, O. E.; CASTELLANO, E.; GONZÁLEZ, M.; GAMBINO, D.; CERECETTO, H.; J. Med. Chem., v. 49, p. 3322-3331, 2006.

78 SINGH, N. K.; KUSHAWAHA, S. K.; BHARTY, M. K.; DULARE, R.; BUTCHER, R. J.; J. Mol. Struct., v. 936, p. 257-263, 2009.

79 de SOUZA, E. J.; FERNANDES, A. G. de A.; MAIA, P. I. S.; LEMOS, S. S.; ELLENA, J.; ABRAM, U.; DEFLON, V. M.; Z. Anorg. Allg. Chem., v. 636, p. 24672470, 2010.

80 FRISCH, M. J.; TRUCKS, G. W.; SCHLEGEL, H. B.; SCUSERIA, G. E.; ROBB, M. A.; CHEESEMAN, J. R.; JR, J. A. M.; VREVEN, T.; KUDIN, K. N.; BURANT, J. C.; MILLAM, J. M.; IYENGAR, S. S.; TOMASI, J.; HONDA, Y.; KITAO, O.; NAKAI, H.; KLENE, M.; LI, X.; KNOX, J.E.; HRATCHIAN, H. P.; CROSS, J. B.; ADAMO, C.; JARAMILLO, J.; GOMPERTS, R.; STRATMANN, R. E.; YAZYEV, O.; AUSTIN, A. J.; CAMMI, R.; POMELLI, C.; OCHTERSKI, J. W.; AYALA, P. Y.; MOROKUMA, K.; VOTH, G. A.; SALVADOR, P.; DANNENBERG, J. J.; ZAKRZEWSKI, V. G.; DAPPRICH, S.; DANIELS, A. D.; STRAIN, M. C.; FARKAS, O.; MALICK, D. K.; RABUCK, A. D.; RAGHAVACHARI, K.; FORESMAN, J. B.; ORTIZ, J. V.; CUI, Q.; BABOUL, A. G.; CLIFFORD, S.; CIOSLOWSKI, J.; STEFANOV, B. B.; G. LIU; LIASHENKO; PISKORZI, P.; KOMAROMI, I.; MARTIN, R. L.; FOX, D. J.; KEITH, T.; AL-LAHAM, M. A.; PENG, C. Y.; NANAYAKKARA, A.; CHALLACOMBE, M.; GILL, P. M. W.; JOHNSON, B.; CHEN, W.; WONG, M. W.; GONZALEZ, C.; POPLE, J. A. Gaussian 03 W: revision 8.02; Gaussian, Inc.: Pittsburgh PA, 2003. Programa de computador. 
81 NYQUIST, R. A.; Interpreting Infrared, Raman, and Nuclear Magnetic

Resonance Spectra, Michigan: Elsevier, 2001, v. 1, p. 1068.

82 KARPLUS, M.; J. Am. Chem. Soc., v. 85, p. 2870-2871, 1963.

83 KIRSCH, S.; JANKOWSKY, R.; LEIBNITZ, P.; SPIES, H.; JOHANNSEN, B.; J. Biol. Inorg. Chem., v. 4, p. 48-55, 1999.

84 LEE, C.; YANG, W.; PARR, R. G.; Phys. Rev. B, v. 37, n. 2, p. 785-789, 1988.

85 LIMA, F. da C. A. Estudo teóricos de propriedades de sistemas heteromacrocíclos que complexam metais de transição divalentes da primeira e segunda filas. 2008. $159 \mathrm{f}$. Tese (Doutorado em Fisico-Química) - Instituto de Química de São Carlos, Universidade de São Paulo, São Carlos, 2008.

86 GAUZE, G. de F. Estudo por espectroscopia de RMN e cálculos teóricos de derivados da norcânfora e de ditianos. 2008. 140 f. Tese (Doutorado em Ciências) - Departamento de Química, Universidade Estadual de Maringá, Maringá, 2008. 


\section{Anexos}

\section{Agentes Complexantes $\mathrm{H}_{2}$ bdtn e $\mathrm{H}_{2}$ bdtm}

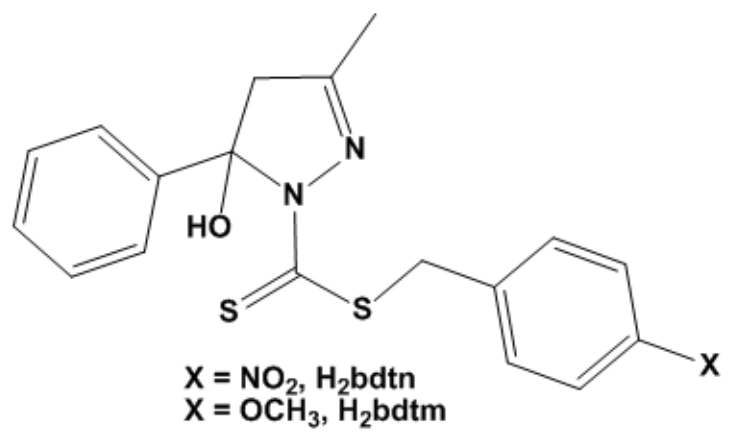

Estrutura dos Ligantes $\mathbf{H}_{\mathbf{2}} \mathbf{b d t n}$ e $\mathbf{H}_{\mathbf{2}} \mathbf{b d t m}$.

Os ditiocarbazatos $\mathbf{H}_{\mathbf{2}} \mathbf{b d t n}$ e $\mathbf{H}_{\mathbf{2}} \mathbf{b d t m}$ podem ser preparados de maneira similar ao método descrito na literatura para síntese do $\mathbf{H}_{\mathbf{2}}$ bdtc. ${ }^{63}$ Entretanto, os reagentes cloreto de $p$-nitro-benzila e cloreto de $p$-metoxi-benzila devem ser utilizados no lugar do cloreto de benzila.

Dois pontos são fundamentais para obtenção dos produtos desejados. O primeiro diz respeito à adição lenta (gota a gota e sob agitação) das soluções de cloreto de $p$-nitro-benzila e cloreto de $p$-metoxi-benzila sobre a solução que contém o sal $\mathrm{H}_{2} \mathrm{NNHCSSK}$, desta maneira, um maior rendimento do produto $\mathrm{H}_{2} \mathrm{NNHCSSCH}$-fenil-X ( $\mathrm{X}=\mathrm{NO}_{2}$ ou $\mathrm{OCH}_{3}$ ) é alcançado. $\mathrm{O}$ segundo trata da tendência à desidratação dos ditiocarbazatos $\mathbf{H}_{2}$ bdtn e $\mathbf{H}_{2} \mathbf{b d t m}$ quando submetidos a refluxo durante as reações de formação da base de Shiff com benzoilacetona. $A$ mistura de benzoilacetona com o ditiocarbazato $\mathrm{H}_{2} \mathrm{NNHCSSCH}_{2}$-fenil-X $\left(X=\mathrm{NO}_{2}\right.$ ou $\mathrm{OCH}_{3}$ ) deve ser mantida sob agitação (jamais refluxo) por 8 horas ou mais para que o produto desejado seja obtido com maior rendimento. Posteriormente, a solução deve ser resfriada, à $-5^{\circ} \mathrm{C}$, para favorecer a precipitação do ditiocarbazato desejado, $\mathbf{H}_{2}$ bdtm ou $\mathbf{H}_{2}$ bdtm. No dia seguinte, o produto poderá ser separado por filtração a vácuo e lavado com alíquotas de metanol e $n$-hexano. O volume da solução deve ser reduzido e o sistema deve ser novamente resfriamento. A repetição deste procedimento por no mínimo três vezes conduz a rendimentos superiores a 82 \% para os dois ligantes. 
A caracterização dos ditiocarbazatos foi feita por espectroscopia de absorção na região do infravermelho, $R M N{ }^{1} \mathrm{H}$, microanálises $(\mathrm{C}, \mathrm{H}, \mathrm{N}$ e $\mathrm{S})$ e no caso do $\mathbf{H}_{2} \mathbf{b d t m}$, por difração de raios $\mathrm{X}$ em monocristal.

Figura 129 - Espectro de absorção na região do infravermelho do agente complexante $\mathbf{H}_{2}$ bdtn.

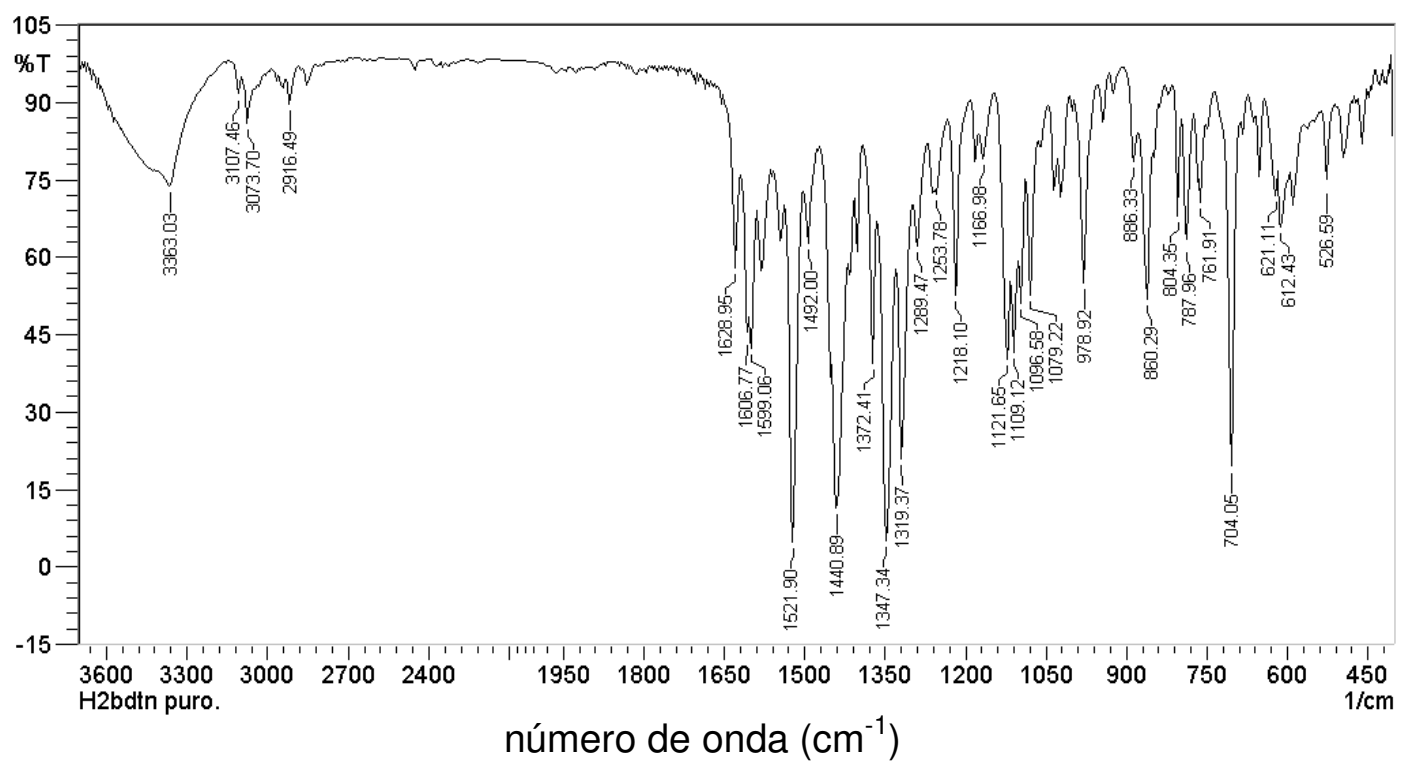

Figura 130 - Espectro de absorção na região do infravermelho do agente complexante $\mathbf{H}_{\mathbf{2}}$ bdtm.

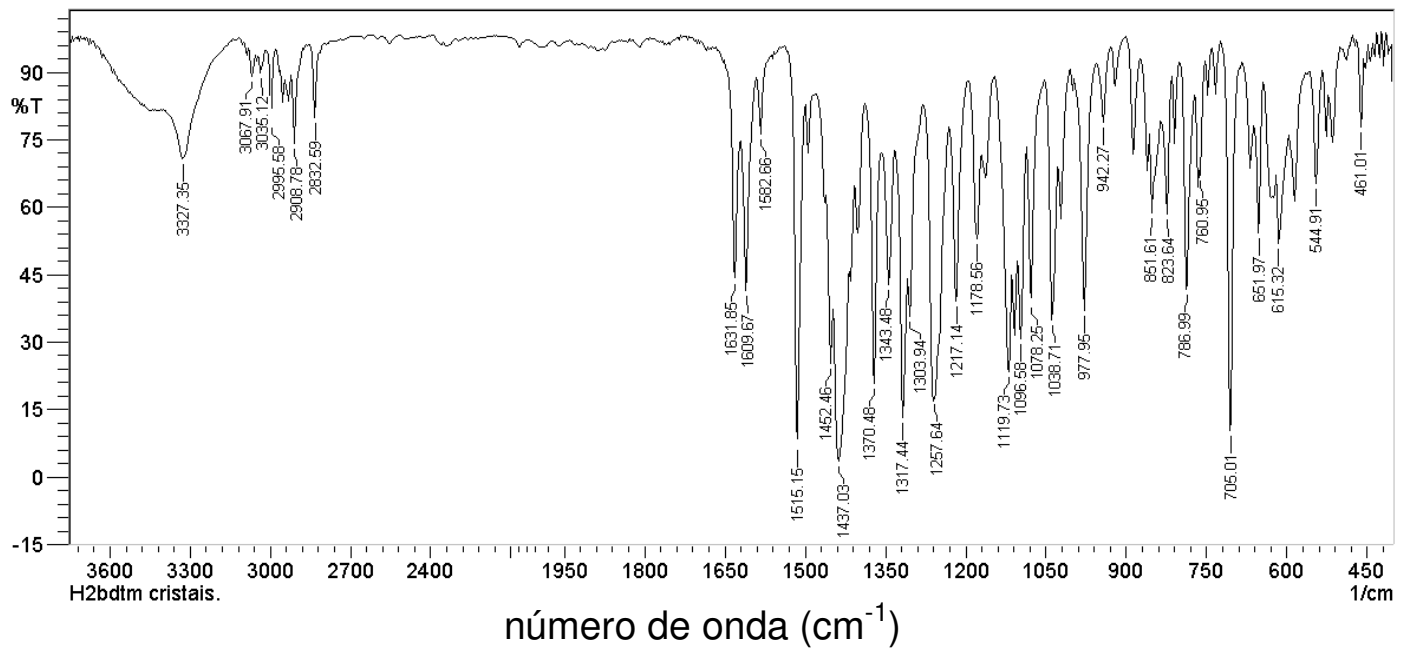


Tabela 39 - Dados de Analise Elementar para os ligantes $\mathbf{H}_{2} \mathbf{b d t n}$ e $\mathbf{H}_{2} \mathbf{b d t m}$ (\% encontrado / \% calculado).

\begin{tabular}{|c|c|c|c|c|}
\hline & \% Carbono & \% Hidrogênio & \% Nitrogênio & \% Enxofre \\
\hline $\mathbf{H}_{2} \mathbf{b d t n}$ & $55,77 / 55,80$ & $4,35 / 4,42$ & $10,81 / 10,84$ & $16,50 / 16,55$ \\
\hline $\mathbf{H}_{2} \mathbf{b d t m}$ & $61,23 / 61,26$ & $5,38 / 5,41$ & $7,50 / 7,52$ & $17,19 / 17,22$ \\
\hline
\end{tabular}


Figura 131 - Espectro de $\mathrm{RMN}{ }^{1} \mathrm{H}$ do $\mathbf{H}_{2}$ bdtn (400 MHz, $\mathrm{CDCl}_{3}$ ).

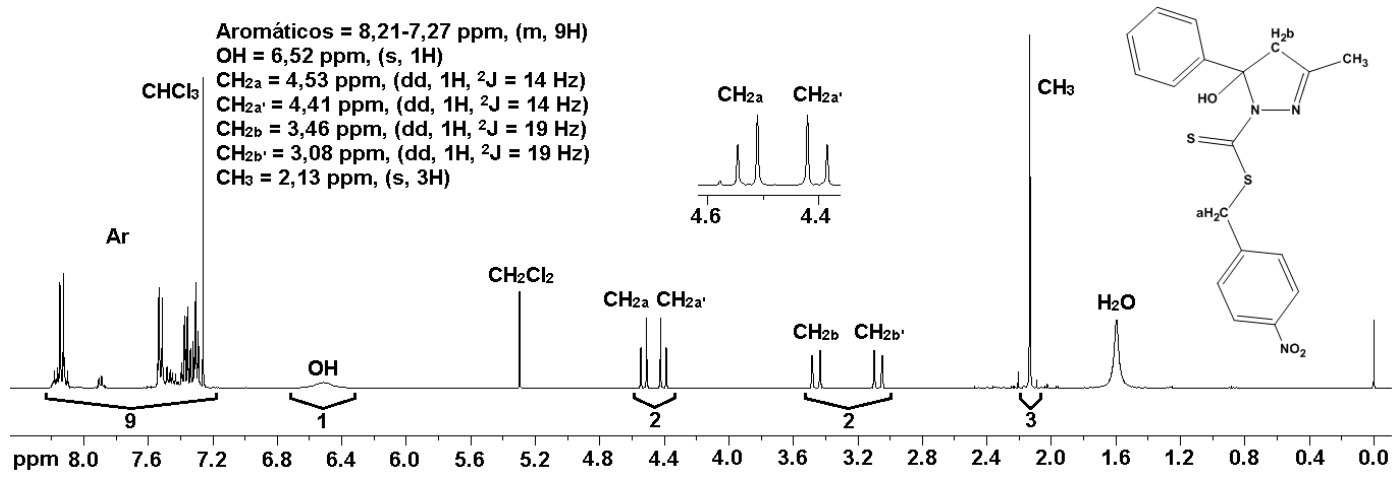

Figura 132 - Espectro de $\mathrm{RMN}{ }^{1} \mathrm{H}$ do $\mathbf{H}_{2}$ bdtm (400 MHz, $\mathrm{CDCl}_{3}$ ).

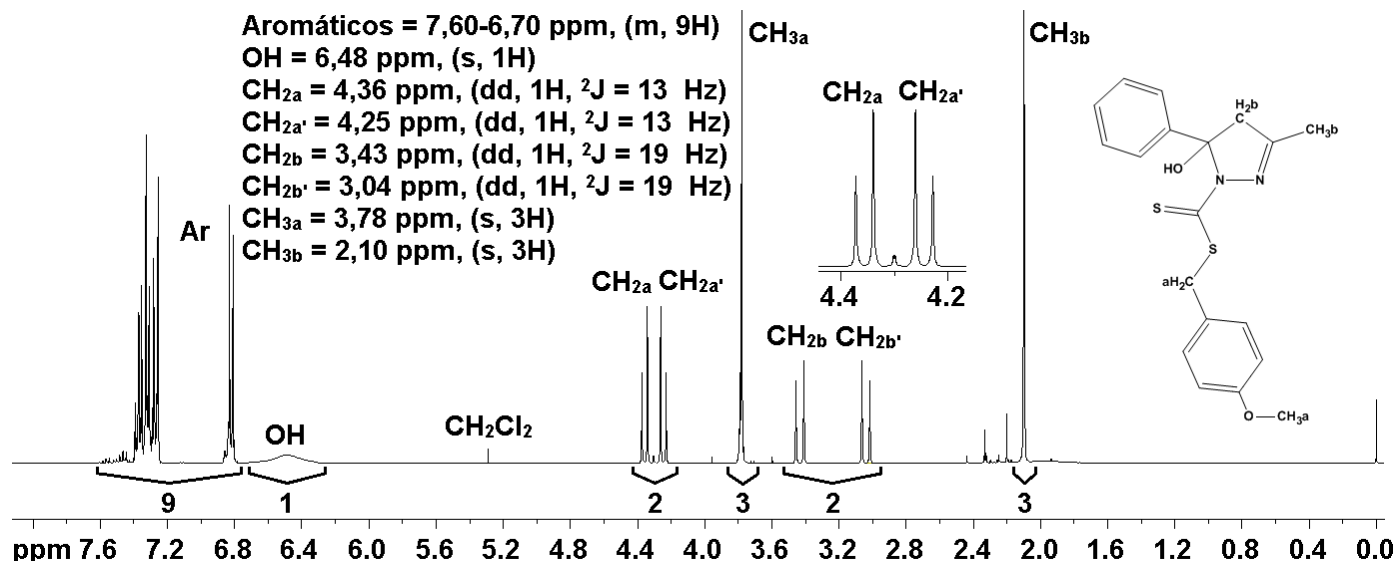

Figura 133 - Estrutura determinada por difração de raios $X$ em monocristal para o agente complexante $\mathbf{H}_{\mathbf{2}} \mathbf{b d t m}$. Todos os hidrogênios foram omitidos para facilitar a visualização.

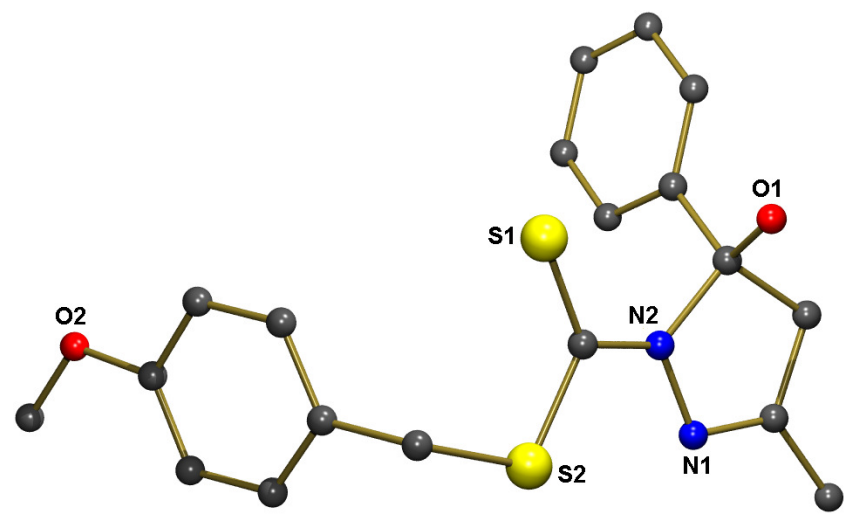

Comprimentos de algumas ligações: $\mathrm{C}=\mathrm{N}(1)=127,9$ pm e C-N(2) $=134,1 \mathrm{pm}$. 


\section{Agente Complexante $\mathrm{H}_{2} \mathrm{Ndta}$}

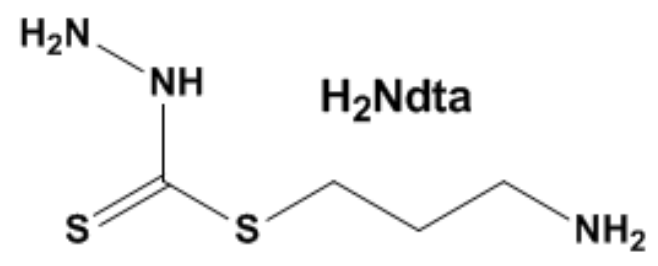

\section{Estrutura proposta para o ligante $\mathbf{H}_{\mathbf{2}} \mathbf{N d t a}$.}

O ditiocarbazato $\mathbf{H}_{2} \mathbf{N d t a}$ foi preparado de maneira análoga ao método descrito na literatura para síntese do $\mathbf{H}_{2}$ bdtc. ${ }^{49} \mathrm{O}$ reagente hidrocloreto de 3cloropropilamina foi utilizado no lugar do cloreto de benzila.

A caracterização deste ditiocarbazato foi feita exclusivamente por $\mathrm{RMN}^{1} \mathrm{H}$.

Figura 134 - Espectro de $\mathrm{RMN}{ }^{1} \mathrm{H}$ do agente complexante $\mathbf{H}_{2} \mathbf{N d t a}(400 \mathrm{MHz}$, DMSO-D 6 ).

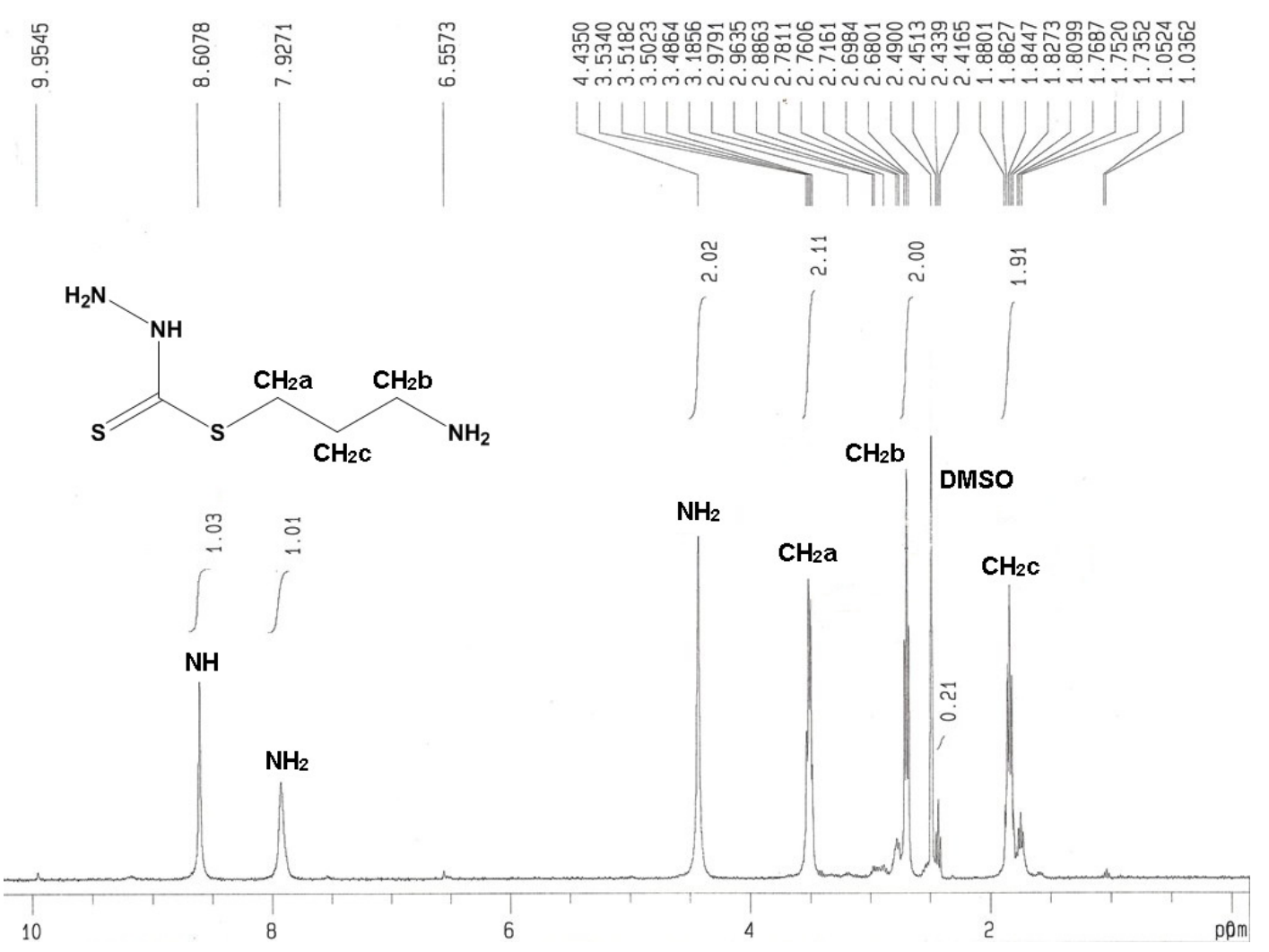




\section{Agente Complexante $\mathrm{H}_{2}$ bdta}

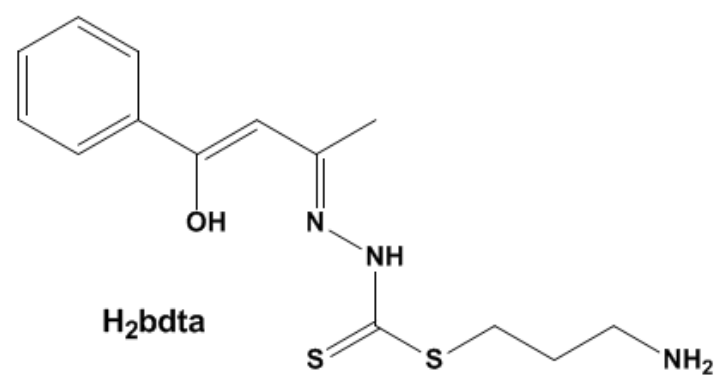

Estrutura proposta para o ligante $\mathbf{H}_{\mathbf{2}}$ bdta.

O ditiocarbazato $\mathbf{H}_{\mathbf{2}}$ bdta foi preparado de maneira análoga ao método descrito na literatura para síntese do $\mathbf{H}_{\mathbf{2}}$ bdtc. ${ }^{49}$ Entretanto, o reagente hidrocloreto de 3cloropropilamina foi utilizado no lugar do cloreto de benzila.

A caracterização deste ditiocarbazato foi feita por espectroscopia de absorção na região do infravermelho, $\mathrm{RMN}{ }^{1} \mathrm{H}$ e microanálises $(\mathrm{C}, \mathrm{H}, \mathrm{N}$ e $\mathrm{S})$.

Figura 135 - Espectro de absorção na região do infravermelho do agente complexante $\mathbf{H}_{\mathbf{2}} \mathbf{b d t a}$.

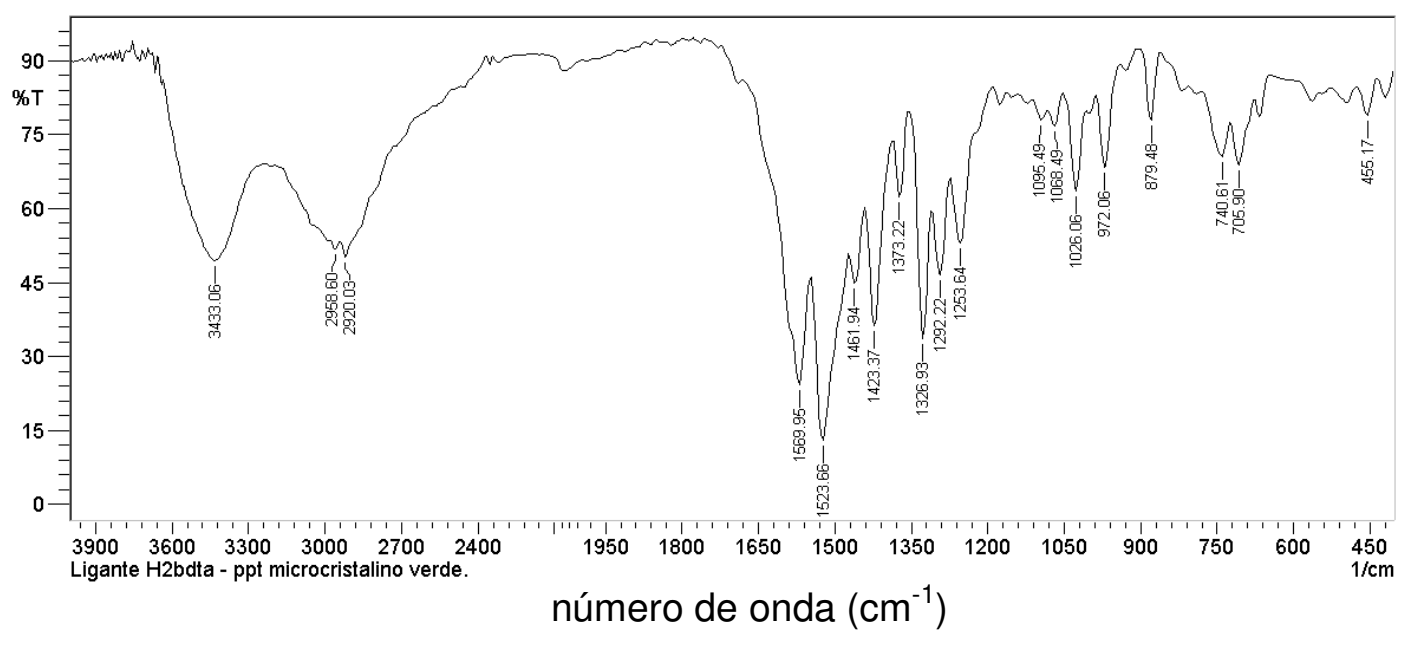


Figura 136 - Espectro de RMN ${ }^{1} \mathrm{H}$ do agente complexante $\mathbf{H}_{2}$ bdta $(400 \mathrm{MHz}$, DMSO- $\left.{ }_{6}\right)$.

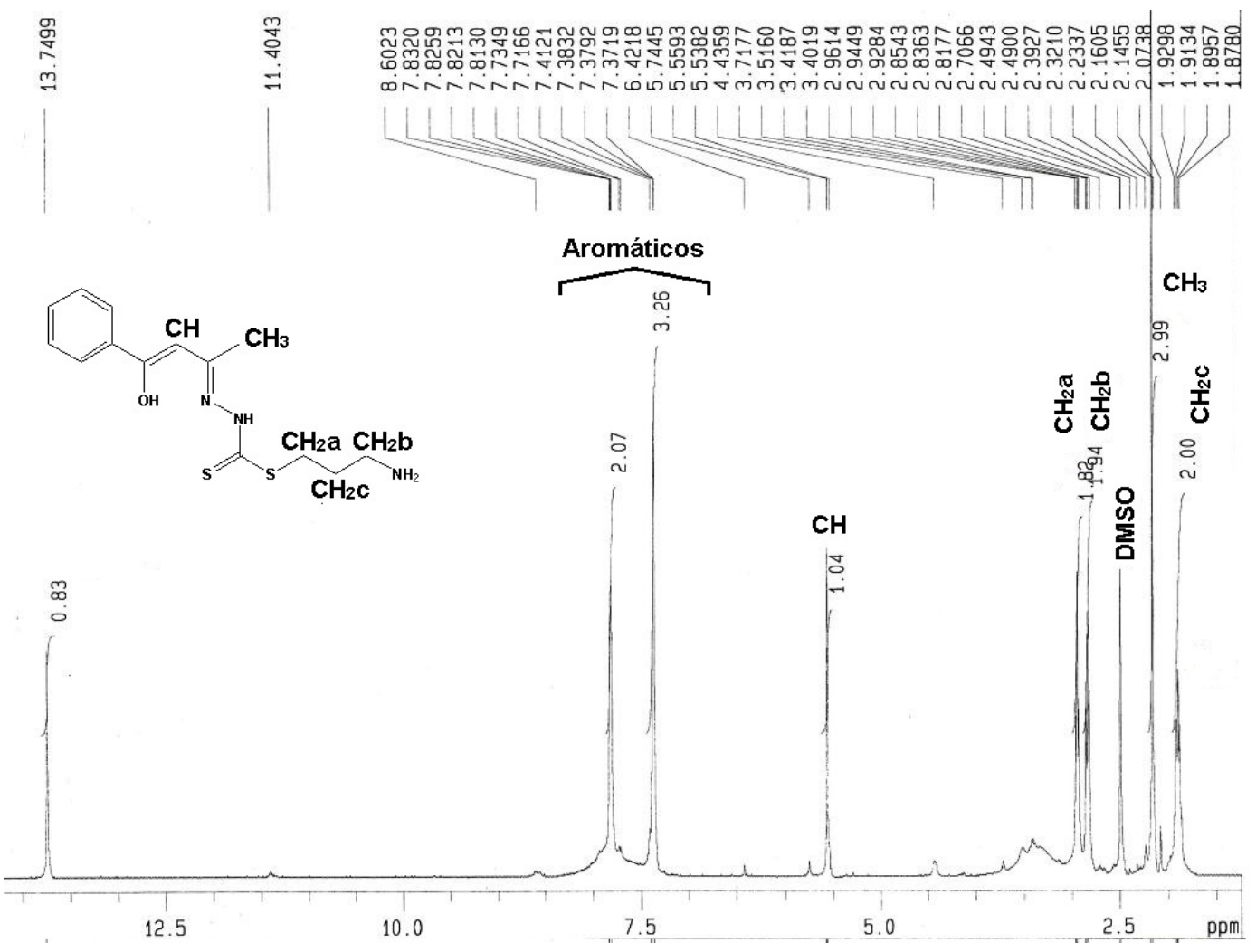

Tabela 40 - Dados de Analise Elementar para o ligante $\mathbf{H}_{2} \mathbf{b d t a}$ (\% encontrado / \% calculado).

\begin{tabular}{|c|c|c|c|c|}
\hline & \% Carbono & \% Hidrogênio & \% Nitrogênio & \% Enxofre \\
\hline $\mathbf{H}_{2}$ bdta & $54,27 / 54,34$ & $6,12 / 6,19$ & $13,51 / 13,58$ & $20,68 / 20,72$ \\
\hline
\end{tabular}




\section{Agente Complexante $\mathrm{H}_{2}$ bdtb}

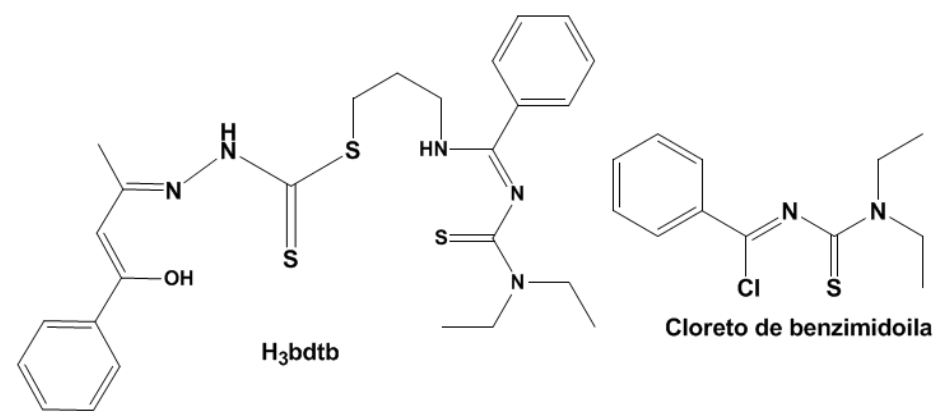

Estrutura proposta para o ligante $\mathbf{H}_{\mathbf{2}} \mathbf{b d t b}$.

O ditiocarbazato $\mathbf{H}_{2}$ bdtb foi obtido através de uma reação entre $\circ \mathbf{H}_{2} \mathbf{b d t a}$ e 0 cloreto de benzimidoila descrito na figura acima.

A caracterização deste ligante foi feita por $\mathrm{RMN}^{1} \mathrm{H}$ e microanálises $(\mathrm{C}, \mathrm{H}, \mathrm{N}$ e S).

Figura 137 - Espectro de $\mathrm{RMN}{ }^{1} \mathrm{H}$ do agente complexante $\mathbf{H}_{\mathbf{2}} \mathbf{b d t b}$.

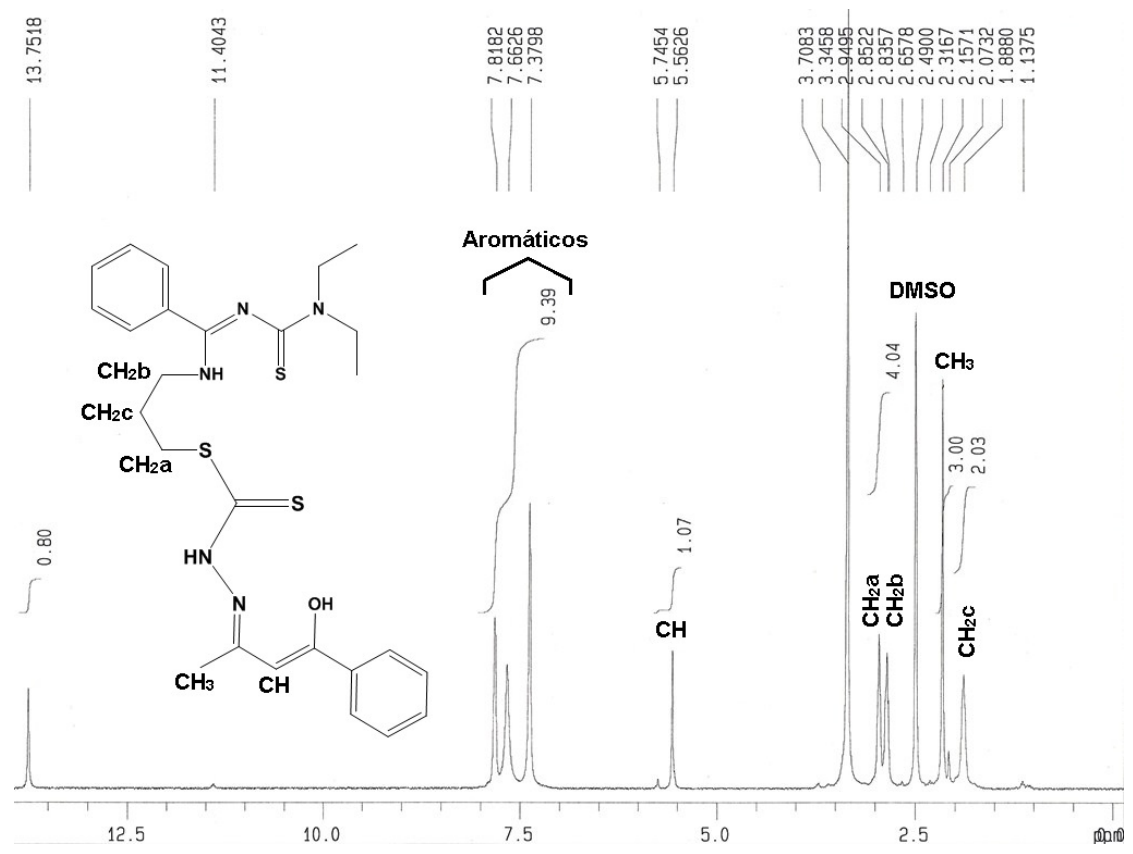

Tabela 41 - Dados de Analise Elementar para o ligante $\mathbf{H}_{\mathbf{2}} \mathbf{b d t b}$ (\% encontrado / \% calculado).

\begin{tabular}{|c|c|c|c|c|}
\hline & \% Carbono & \% Hidrogênio & \% Nitrogênio & \% Enxofre \\
\hline $\mathbf{H}_{\mathbf{2}} \mathbf{b d t b}$ & $59,15 / 59,17$ & $6,09 / 6,30$ & $13,23 / 13,27$ & $18,18 / 18,23$ \\
\hline
\end{tabular}




\section{Agente Complexante $\mathrm{H}_{4}$ Pydtc}

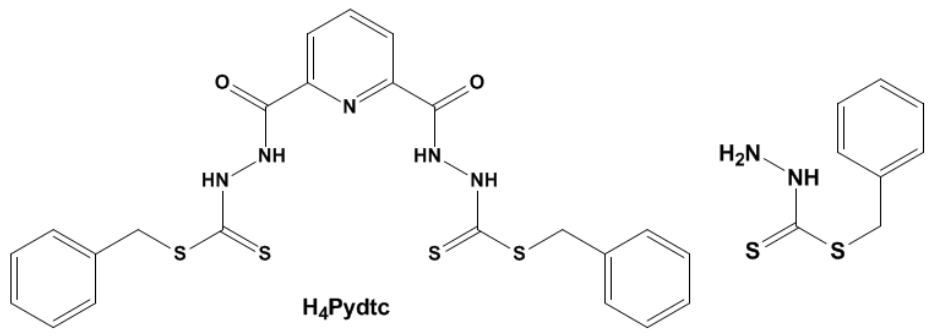

Estrutura do ligante $\mathbf{H}_{\mathbf{4}}$ Pydtc e do seu ditiocarbazato precursor.

O ditiocarbazato $\mathbf{H}_{4}$ Pydtc foi obtido através de uma reação entre o cloreto de 2,6-dicarbonilpiridina e o ditiocarbazato descrito acima.

A caracterização deste ligante foi feita por IV, $R M N{ }^{1} \mathrm{H}$, microanálises $(\mathrm{C}, \mathrm{H}, \mathrm{N}$ e S), espectrometria de massas ( e difração de raios $X$ em monocristal.

Figura 138 - Espectro de absorção na região do infravermelho do agente complexante $\mathbf{H}_{4}$ Pydtc.

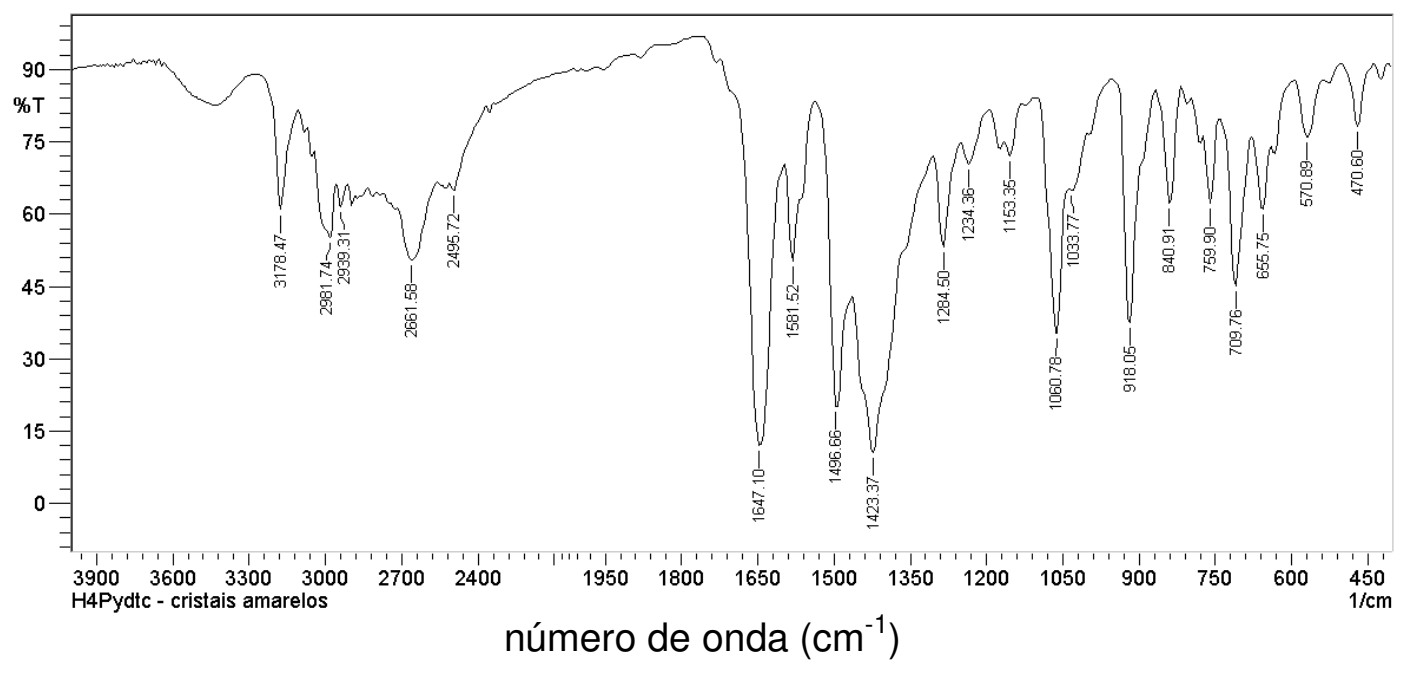


Figura 139 - Espectro de RMN ${ }^{1} \mathrm{H}$ do agente complexante $\mathbf{H}_{4} \mathbf{P y d t c}$.

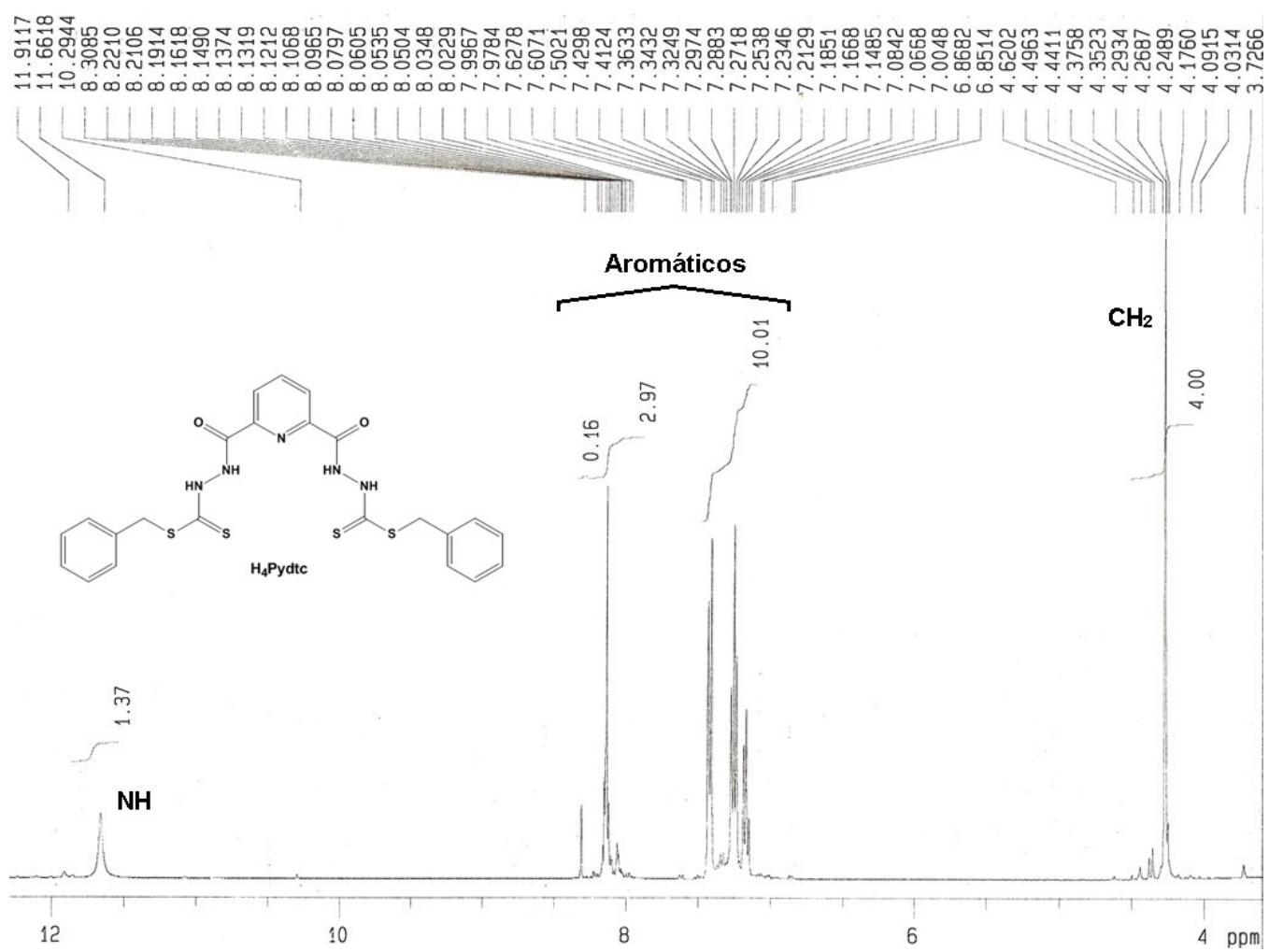

Tabela 42 - Dados de Analise Elementar para o ligante $\mathbf{H}_{4}$ Pydtc (\% encontrado / \% calculado).

\begin{tabular}{|c|c|c|c|c|}
\hline & \% Carbono & \% Hidrogênio & \% Nitrogênio & \% Enxofre \\
\hline $\mathbf{H}_{\mathbf{4}}$ Pydtc & $57,51 / 57,58$ & $6,91 / 7,04$ & $13,31 / 13,43$ & $16,94 / 17,57$ \\
\hline
\end{tabular}

Figura 140 - Estrutura determinada por difração de raios $X$ em monocristal para o agente complexante $\mathbf{H}_{4}$ Pydtc. Todos os hidrogênios foram omitidos para facilitar a visualização.

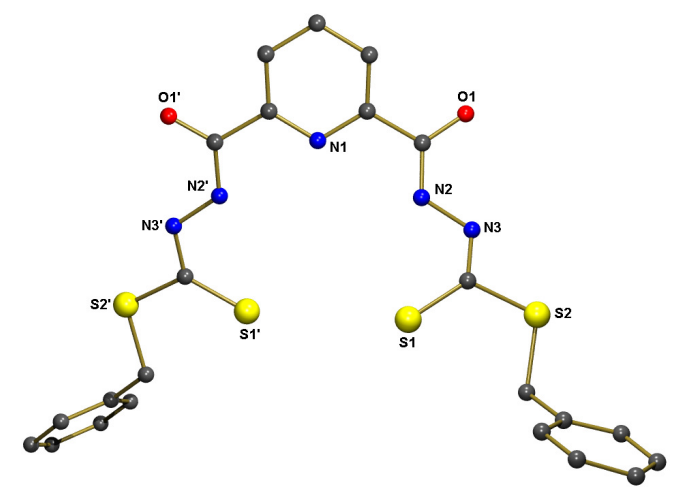

Comprimentos de algumas ligações: $\mathrm{C}=\mathrm{N}(2)=130,4 \mathrm{pm} ; \mathrm{C}-\mathrm{N}(3)=128,2 \mathrm{pm} ; \mathrm{C}=\mathrm{O}(1)$ $=125,3 \mathrm{pm}$. 


\section{Participação em Eventos e Cursos}

1. FERNANDES, A. G. de A.; DEFLON, V. M.; Síntese e Caracterização de Complexos de Rênio: Modelos para a Química Medicinal Nuclear; 16ํㅡㄴ Encontro da SBQ Regional (SP), Franca, Livro de resumos, 2007.

2. FERNANDES, A. G. de A.; DEFLON, V. M.; ABRAM, Ulrich; LEMOS, S. S.; SOUSA, G. F. de; Back, D. F.; LANG, E. S.; BATISTA, A. A.; Síntese e Caracterização de Novos Complexos de Rênio(V) Hexacoordenados com Benzoilacetilacetona-S-benzilditiocarbazato $\left(\mathrm{H}_{2} \mathrm{BDTC}\right)$ como Ligante O,N,S-Doador. In: $31^{\text {a }}$ Reunião Anual da Sociedade Brasileira de Química, 2008, Águas de Lindóia. Programa, p. 129 (QI-135).

3. MAIA, P. I. da S.; FERNANDES, A. G. de A.; Back, D. F.; LANG, E. S.; LEMOS, S. S.; SOUSA, G. F. de; DEFLON, V. M.; Complexes Of Dithiocarbazates Derivatives With The $\left[\mathrm{M}\left(\mathrm{PPh}_{3}\right)\right]^{2+}$ Moiety $(\mathrm{M}=$ Paladium or Platinum). In: XIV BMIC / I LABIC, 2008, Foz do Iguaçu. Livro de resumos, p. 216 (PB124).

4. NEVES, L. M. C.; FeRnandeS, A. G. de A.; MAIA, P. I. da S.; HAGENBACH, A.; ABRAM, U.; DEFLON, V. M.; Uso de Ditiocarbazatos O,N,S-Doadores na Obtenção de Complexos de Rênio(V) Modelos para Química Medicinal Nuclear do Tecnécio. In: $32^{\mathrm{a}}$ Reunião Anual da Sociedade Brasileira de Química, Fortaleza, painel QI-049, 2009.

5. FERNANDES, A. G. de A.; HUY, N. H.; ABRAM, U.; DEFLON, V. M.; Complexos Modelos de Rênio(V) com Ligantes Mistos no Desenvolvimento de Radiofármacos de Tecnécio: Novas Possibilidades de Ajuste Fino na Relação entre Estrutura e Atividade. In: $32^{\mathrm{a}}$ Reunião Anual da Sociedade Brasileira de Química, Fortaleza, painel QI-050, 2009.

6. GRAMINHA, A. E.; CASTELLANO, E. E.; FERnANDES, A. G. de A.; DEFLON, V. M.; BATISTA, A. A.; Complexos Fosfínicos de Pd(II) com Bases de Schiff derivadas de Ditiocarbazatos. In: $32^{a}$ Reunião Anual da Sociedade Brasileira de Química, Fortaleza, painel QI-074, 2009. 
7. FERNANDES, A. G. de A.; Rhenium Complexes with Dithiocarbazates and Related Compounds, and their Biological Activity. In: International Workshop on Coordination Chemistry of Metals with Medical Relevance, 2010, Berlim, Alemanha, apresentação oral.

8. ABRAM, U.; MARQUES, F. L. N.; RADIN, A.; DEFLON, V. M.; PEREIRA, M. C.; ESPINOSA, D.; FERNANDES, A. G. de A.; NAGAI, M. A.; BUCHPIGUEL, C. A.; Preparo e Avaliação da Captação de $\left[{ }^{99 m} \mathrm{Tc}(\mathrm{MeOBzEN})(\mathrm{CO})_{3}\left(\mathrm{H}_{2} \mathrm{O}\right)\right]^{+}$e $\left[{ }^{99 m} \mathrm{Tc}(\mathrm{MIBI})_{6}\right]^{+}$em Células de Tumor de Mama. In: $33^{\mathrm{a}}$ Reunião Anual da Sociedade Brasileira de Química, Águas de Lindóia, painel QM-100, 2010.

9. FERNANDES, A. G. de A.; DEFLON, V. M.; ABRAM, U.; Complexos Mistos de Rênio(V) contendo Ditiocarbazatos, Pironas e Piridinonas: Novas Possibilidades de Ajuste Fino entre a Relação Estrutura e Atividade. In: $33^{a}$ Reunião Anual da Sociedade Brasileira de Química, Águas de Lindóia, painel QI-070, 2010. 


\section{Seminários Proferidos}

1. Título: "Rhenium(V) Complexes with Mixed Ligands as New Models for the Nuclear Medicine".

Evento: XIV Brazilian Meeting on Inorganic Chemistry / I Latin American Meeting on Biological Inorganic Chemistry. Foz do Iguaçu.

Data: 02/09/2008

2. Título: "Metal Complexes with Dithiocarbazates".

Evento: Research Seminar Radiochemistry, Berlim, Alemanha.

Data: 20/10/2009

3. Título: "Rhenium(V) Complexes with Dithiocarbazates and Related Compounds, and Their Biological Activity".

Evento: International Workshop on Coordination Chemistry of Metals with Medical Relevance, Berlim, Alemanha.

Data: 21/07/2009 


\section{Produção Científica}

- $\quad$ FERNANDES, A. G. de A.; MAIA, P. I. da S.; SOUZA, E. J. de; LEMOS, S. S.; BATISTA, A. A.; ABRAM, Ulrich; ELLENA, Javier; CASTELLANO, E. E.; DEFLON, V. M.; Rhenium chelate complexes with maltolate or kojate. Polyhedron, 2008, 27, 2983.

- MAIA, P. I. da S.; FERNANDES, A. G. de A.; SILVA, J. J. N.; ANDRICOPULO, A.; LEMOS, S. S.; LANG, E. S.; ABRAM, Ulrich; DEFLON, V. M.; Dithiocarbazate complexes with the $\left[\mathrm{M}\left(\mathrm{PPh}_{3}\right)\right]^{2+}(\mathrm{M}=\mathrm{Pd}$ or $\mathrm{Pt})$ moiety Synthesis, characterization and anti-Tripanosoma cruzi activity. Journal of Inorganic Biochemistry, 2010, 104, 1276.

- $\quad$ SOUZA, E. J. de; FERNANDES, A. G. de A.; MAIA, P. I. da S.; LEMOS, S. S.; ELLENA, Javier; ABRAM, Ulrich; DEFLON, V. M.; Oxorhenium(V) Complexes with 2,3-Dihydroxynaphthalene. Zeitschrift fur Anorganische und Allgemeine Chemie, 2010, 636, 2467. 


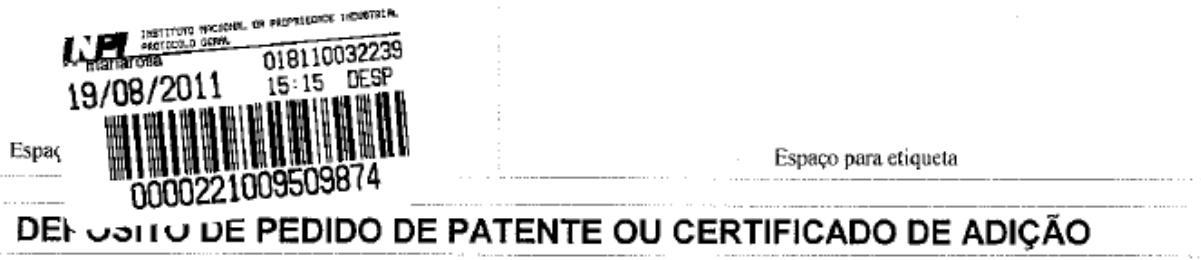

Ao Instituto Nacional da Propriedade Industrial:

O requerente solicita a concessão de uma patente na natureza e nas condiçőes abaixo indiçadas:

1. Depositante (71):

1.1 Nome: UNIVERSIDADE DE SÃO PAULO - USP

1.2 Qualificação: AUTARQUIA ESTADUAL DE REGIME ESPECIAL

1.3 CNPJ/CPF: 63025530000104

1.4 Endereço completo: AV. BRASIL, N 1971 JARDIM PAULISTA São Paulo SP

1.5 CEP: $01431001 \quad 1.6$ Telefone: (11)30911580 1.7 FAX: $\quad$ (11)30310922

1.8 E-mail: PIDIRETO@USP.BR

$\bar{X}$ continua em folha anexa

2. Natureza: $x$ Invençăo $\bigcirc$ Modelo de Utilidade $\bigcirc$ Certificado de Adição

Escreva, obrigatoriamente e por extenso, a Natureza desejada: 2.1 INVENÇÄO

3. Título da Invençăo, do Modelo de Utilidade ou do Certificado de Adição (54):

"PROCESSOS DE OBTENÇÃO DE COMPLEXOS DE COORDENAÇÃO DE DITIOCARBAZATOS, COMPLEXOS DE COORDENAÇÃO CONTENDO METAIS DE TRANSIÇÃO, COMPOSIÇÕES FARMACÊUTICAS E SEUS USOS"

continua em folha anexa

4. Pedido de Divisão: do pedido

Data de Depósito:

5. Prioridade $\bigcirc$ interna $\bigcirc$ unionista $O$ depositante reivindica $a(s)$ seguinte(s) prioridade(s):

\begin{tabular}{|l|l|l|}
\hline Pais ou organização de origem & Número do depósito & Data do depósito \\
\hline & & \\
\hline & & \\
\hline
\end{tabular}

6. Inventor (72):

Assinale aqui se o(s) mesmo(s) requer(em) a năo divulgação de seu(s) nome(s)

6.1 Nome: VICTOR MARCELO DEFLON

6.2 Qualificação: BRASILEIRO SEPARADO PROFESSOR 6.3 CPF: 48812331149

6.4 Endereço completo: RUA NICOLETA STELLA GERMANO NO 51, APTO 803 SÃO CARLOS SP
6.5 CEP: 13561090
6.6 Telefone: (11)30911580
6.7 FAX (11)30310922

$6.8 \quad$ E-mail: PIDIRETO@USP.BR

$X$ continua em folha anexa 
'ANEXO DE INVENTORES

Titulo: "PROCESSOS DE OBTENÇÃO DE COMPLEXOS DE COORDENAÇÃO DE

Página : 2

Nome: ADRIANO DEFINI ANDRICOPULO

Qualificą̧ão BRASILEIRO CASADO PROFESSOR UNIVERSITÁRIO

CNPJ/CPF: 61585556068

Endereço: AVENIDA MIGUEL DAMHA, 100

Bairro;

CEP: $13565814 \quad$ Estado: $S P$ Pais

Cidade: SĀO CARLOS

Telefone: (11)30911580 Fax: (11)30310922

Nome: JEAN JERLEY NOGUEIRA DA SILVA

Qualificação BRASILEIRO CASADO PESQUISADOR

Endereço: ALAMEDA PLATÃO, 369

Bairro: APARECIDA

CEP: 69306371 Estado: RR Pais

Telefone: (11)30911580 Fax: (11)30310922

Nome: PEDRO IVO DA SILVA MAIA

Qualificaçăo BRASILEIRO SOLTEIRO QUÍMICO

Endereço: RUA MIGUEL JOÃO, 173

Bairro:

CNPJ/CPF: 80015433587

CEP:

13562180

Estado: SP Pais

Telefone: (11)30911580 Fax: (11)30310922

Nome: ANDRÉ GUSTAVO DE ARAÚJO FERNANDES

Qualificação BRASILEIRO CASADO QUIMICO

Endereço: RUA LUIS SAIA, N ${ }^{\circ} 51$ APTO 21

Bairro:

CEP:

13564010

Estado: SP Pais

Telefonc:

(11)30911580

Fax: (11)30310922

CNPJ/CPF: 61486175368

Nome: RAFAELA BERNARDO PROVAZI PESCI

Qualificaçẳo BRASILEIRA SOLTEIRA QUIMICA

Endereço: AV. FRANCISCO PEREIRA LOPES NO 2569, BLOCO 2, APTO 43

Bairro: Cidade: SÃO CARLOS

CEP: $13564002 \quad$ Estado: SP Pais

Telefone: (11)30911580 Fax: (11)30310922

CNPJ/CPF: 01350459160 